\title{
Sex-related differences in local and whole-body heat loss responses: Physical or physiological?
}

\author{
DANIEL GAGNON
}

M.Sc., University of Ottawa, 2007

Thesis submitted to the

Faculty of Graduate and Postdoctoral Studies

In partial fulfillment of the requirements

For the degree of Doctor of Philosophy - Human Kinetics

School of Human Kinetics

Faculty of Health Sciences

University of Ottawa

(C) Daniel Gagnon, Ottawa, Canada, 2012. 


\section{THESIS ABSTRACT}

The current thesis examined whether sex-differences in local and whole-body heat loss are evident after accounting for confounding differences in physical characteristics and rate of metabolic heat production. Three experimental studies were performed: the first examined whole-body heat loss in males and females matched for body mass and surface area during exercise at a fixed rate of metabolic heat production; the second examined local and whole-body heat loss responses between sexes during exercise at increasing requirements for heat loss; the third examined sex-differences in local sweating and cutaneous vasodilation to given doses of pharmacological agonists, as well as during passive heating. The first study demonstrates that females exhibit a lower whole-body sudomotor thermosensitivity $\left(553 \pm 77\right.$ vs. $\left.795 \pm 85 \mathrm{~W} \cdot{ }^{\circ} \mathrm{C}^{-1}, \mathrm{p}=0.05\right)$ during exercise performed at a fixed rate of metabolic heat production. The second study shows that whole-body sudomotor thermosensitivity is similar between sexes at a requirement for heat loss of $250 \mathrm{~W} \cdot \mathrm{m}^{-2}\left(496 \pm 139\right.$ vs. $\left.483 \pm 185 \mathrm{~W} \cdot \mathrm{m}^{-2} \cdot{ }^{\circ} \mathrm{C}^{-1}, \mathrm{p}=0.91\right)$ and $300 \mathrm{~W} \cdot \mathrm{m}^{-2}$ $\left(283 \pm 70\right.$ vs. $\left.211 \pm 66 \mathrm{~W} \cdot \mathrm{m}^{-2} \cdot{ }^{\circ} \mathrm{C}^{-1}, \mathrm{p}=0.17\right)$, only becoming greater in males at a requirement for heat loss of $350 \mathrm{~W} \cdot \mathrm{m}^{-2}\left(197 \pm 61 \mathrm{vs} .82 \pm 27 \mathrm{~W} \cdot \mathrm{m}^{-2} \cdot{ }^{\circ} \mathrm{C}^{-1}, \mathrm{p}=0.007\right)$. In the third study, a lower sweat rate to the highest concentration of acetylcholine $(0.27 \pm 0.08$ vs. $\left.0.48 \pm 0.13 \mathrm{mg} \cdot \mathrm{min}^{-1} \cdot \mathrm{cm}^{-2}, \mathrm{p}=0.02\right)$ and methylcholine $(0.41 \pm 0.09$ vs. $0.57 \pm 0.11$ $\left.\mathrm{mg} \cdot \mathrm{min}^{-1} \cdot \mathrm{cm}^{-2}, \mathrm{p}=0.04\right)$ employed was evidenced in females, with no differences in cholinergic sensitivity. Taken together, the results of the current thesis show that sex itself can modulate sudomotor activity, specifically the thermosensitivity of the response, during both exercise and passive heat stress. Furthermore, the results of the third study point towards a peripheral modulation of the sweat gland as a mechanism responsible for the lower sudomotor thermosensitivity in females. 


\section{Table of contents}

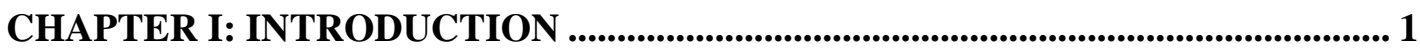

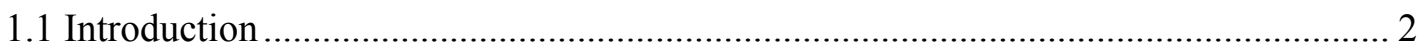

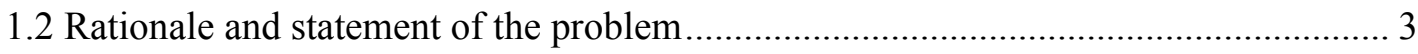

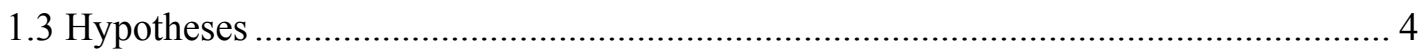

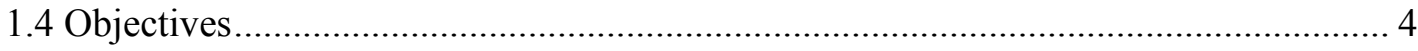

1.5 Relevance

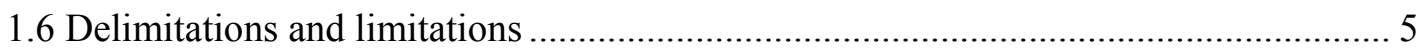

CHAPTER II: REVIEW OF LITERATURE .................................................... 6

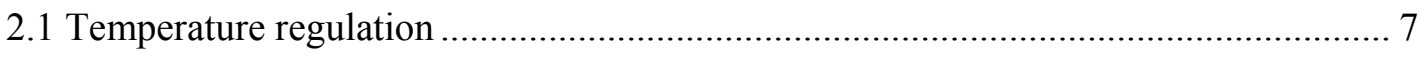

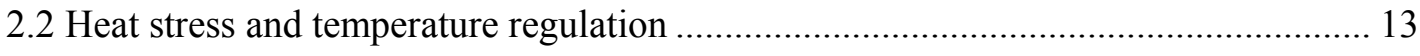

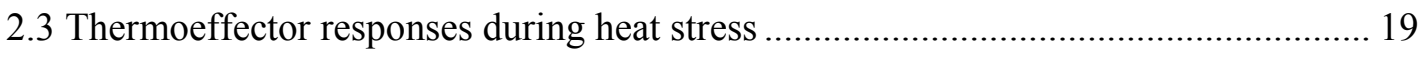

2.4 Differences between sexes in heat loss responses.................................................. 22

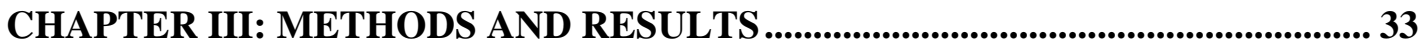

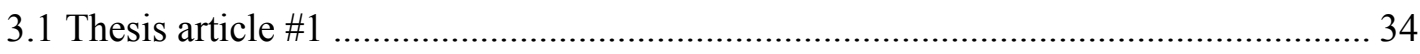

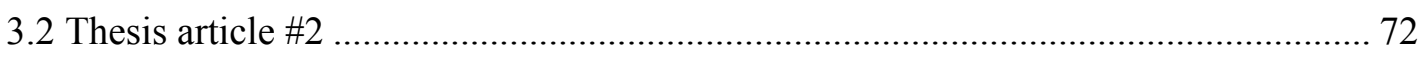

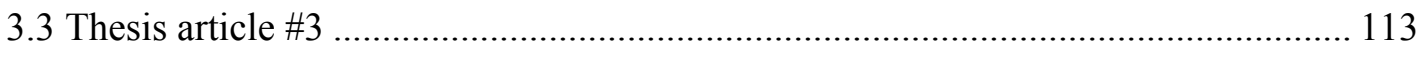

CHAPTER IV: THESIS DISCUSSION....................................................................... 141

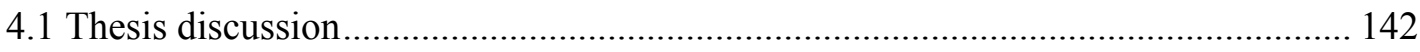

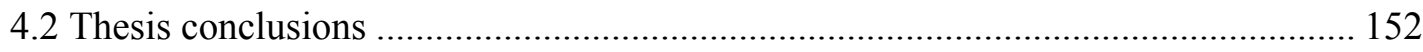

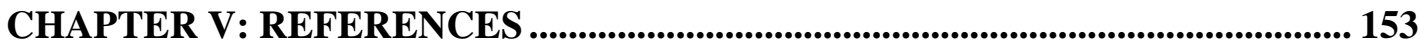

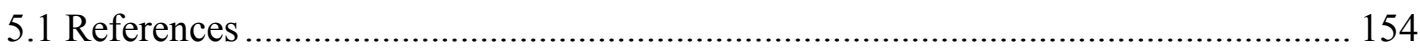

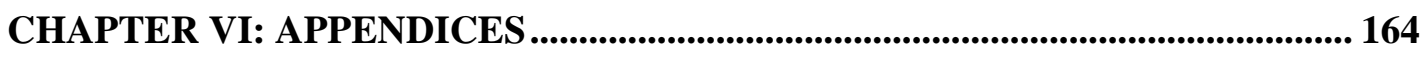

APPENDIX A: Final published version of thesis article \#1 ....................................... 165

APPENDIX B: Final published version of thesis article \#2 …................................... 179

APPENDIX C: Additional results from thesis study \#1 .............................................. 192

APPENDIX D: Published version of article examining the reliability of the modified

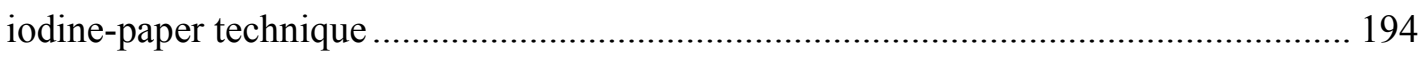

APPENDIX E: Final version of topical review article submitted to the Journal of

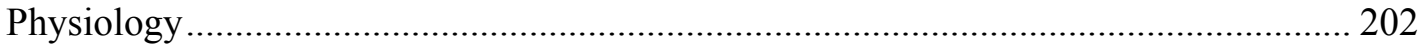

APPENDIX F: Ethics approval notices for thesis research projects........................... 233 


\section{List of figures}

\section{THESIS}

Figure 1. Schematic representation of the thermoeffector output-to-mean body temperature relationship during heat stress ............................................................................... 10

Figure 2. Rates of metabolic heat production and total heat loss during a rest period and a subsequent 90

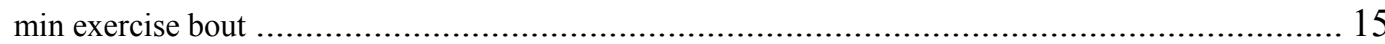

Figure 3. Schematic illustration of the relationship between the required evaporation for heat balance and evaporative heat loss during exercise ............................................................ 16

Figure 4. Rates of heat production and exchange during a rest period at thermoneutral conditions, followed by a $90 \mathrm{~min}$ period of passive heat stress ................................................... 18

Figure 5. Whole-body calorimetry data for rate of heat production and rate of total heat loss for both males and females for $60 \mathrm{~min}$ of rest followed by $60 \mathrm{~min}$ of exercise at $40 \%$ maximum oxygen consumption at $40^{\circ} \mathrm{C}$ and $30 \%$ relative humidity

\section{THESIS ARTICLE \#1}

Figure 1. Sex-related differences in evaporative heat loss during exercise performed at either a fixed percentage of maximum oxygen consumption or a fixed rate of metabolic heat production 67

Figure 2. Relationship between evaporative heat loss and rate of metabolic heat production for males and females during exercise performed at a fixed percentage of maximum oxygen consumption..... 68

Figure 3. Sex-related differences in the cutaneous vascular response during exercise performed at either a fixed percentage of maximum oxygen consumption, or a fixed rate of metabolic heat production..... 69

Figure 4. Sex-related differences in the sensitivity of the evaporative heat loss response to changes in mean body temperature during exercise performed at either a fixed percentage of maximum oxygen consumption, or a fixed rate of metabolic heat production 70

Figure 5. Sex-related differences in the sensitivity of the cutaneous vascular conductance (CVC) response to changes in mean body temperature during exercise performed at either a fixed percentage of maximum oxygen consumption, or a fixed rate of metabolic heat production

\section{THESIS ARTICLE \#2}

Figure 1. Sex-differences in evaporative heat loss relative to the required evaporation for heat balance, as well as in evaporative heat loss as a function of changes in mean body temperature during exercise performed at increasing rates of metabolic heat production 108

Figure 2. Sex-differences in back sweat rate and skin vascular conductance presented as a percentage of maximum during exercise performed at increasing rates of metabolic heat production.....

Figure 3. Sex-differences in chest sweat rate and skin vascular conductance presented as a percentage of maximum during exercise performed at increasing rates of metabolic heat production....

Figure 4. Sex-differences in forearm sweat rate and skin vascular conductance presented as a percentage of maximum during exercise performed at increasing rates of metabolic heat production 111 
Figure 5. Graphical representation of local sweat rate and skin vascular conductance as a function of changes in mean body temperature in males and females during exercise performed at increasing rates of metabolic heat production

\section{THESIS ARTICLE \#3}

Figure 1. Sex-differences in dose-response relationships for sweating to incremental doses of methylcholine and acetylcholine

136

Figure 2. Sex-differences in dose-response relationships for cutaneous vascular conductance to incremental doses of acetylcholine and sodium nitroprusside

Figure 3. Sex-differences in dry heat exchange (heat flux) as a function of progressive increases in mean body temperature elicited by passive heating...

Figure 4. Sex-differences in local sudomotor activity (sweat rate) as a function of progressive increases in mean body temperature elicited by passive heating.

Figure 5. Sex-differences in cutaneous vascular conductance as a function of progressive increases in mean body temperature elicited by passive heating. 


\section{List of tables}

\section{THESIS ARTICLE \#1}

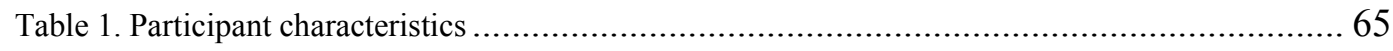

Table 2. Baseline and end-exercise esophageal and rectal temperatures for males and females during exercise at a fixed percentage of $\mathrm{VO}_{2 \max }$ and a fixed rate of absolute heat production...................... 66

\section{THESIS ARTICLE \#2}

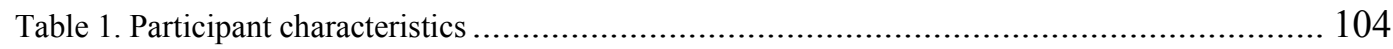

Table 2. Onset threshold of thermoeffector responses .......................................................... 105

Table 3. Thermosensitivity of thermoeffector responses .................................................... 106

Table 4. Sex-differences in the number of active sweat glands and the sweat output per gland during exercise performed at increasing rates of metabolic heat production ........................................ 107

THESIS ARTICLE \#3

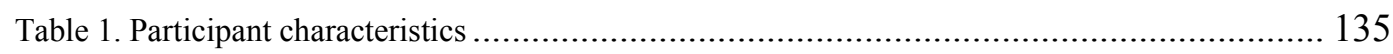




\section{CHAPTER I}

INTRODUCTION 


\subsection{Introduction}

Many investigations have examined if temperature regulation differs between males and females during exercise. However, conclusions remain limited as to whether or not true physiological differences in heat loss responses (i.e. onset threshold and/or thermosensitivity) exist between sexes or if previously observed differences are solely due to confounding differences in physical characteristics and/or rate of metabolic heat production.

It is well recognised that physical characteristics are important for the individual heat stress response (Havenith, 2001b). This is particularly relevant when thermoregulatory responses of males and females are compared during exercise, since males are typically taller, heavier, and consequently have a greater body surface area. Body mass has been shown to influence the core temperature response to a given heat stress, such that larger individuals (e.g. males) will have a lower increase in core temperature compared to smaller (e.g. females) individuals (Havenith et al., 1998; Gagnon et al., 2009). Furthermore, since males are typically heavier than females, they usually have a greater maximum oxygen consumption $\left(\mathrm{VO}_{2} \max \right)$. To account for differences in $\mathrm{VO}_{2}$ max between males and females, experimental protocols are often designed to have both sexes exercise at the same percentage of their $\mathrm{VO}_{2}$ max. However, rate of metabolic heat production is primarily determined by absolute oxygen consumption and to a lesser extent the respiratory exchange ratio. As such, exercise at any given percentage of $\mathrm{VO}_{2}$ max results in a greater metabolic heat production in males which is paralleled by a greater rate of total heat loss (Gagnon et al., 2008); which must result in greater local heat loss responses. Since many studies which report sex-related differences in temperature regulation during exercise are based on data obtained from males and females exercising at the same percentage of $\mathrm{VO}_{2}$ max (Paolone et al., 1978; 
Avellini et al., 1980a; Frye \& Kamon, 1981; Horstman \& Christensen, 1982; Keatisuwan et al., 1996; Ichinose-Kuwahara et al., 2010), it remains unknown if these previously reported differences are due to physiological differences in sweating and/or skin blood flow between sexes or if they are solely related to differences in physical characteristics and/or rate of metabolic heat production.

Although there are known physiological differences between sexes, these generally pertain to the female menstrual cycle. For example, the control of body temperature has consistently been shown to be shifted to higher levels during the luteal phase of the menstrual cycle (Stephenson \& Kolka, 1993). On the other hand, few investigations have reported physiological differences in temperature regulation between males and females which were not related to the menstrual cycle. Yet, there is reason to believe that such differences may exist. For example, Inoue et al. (2005) reported a lower sweat rate, sweating sensitivity, and sweat gland output despite a greater number of heat activated sweat glands in females compared to males during a passive heat stress. It was suggested that this may be due to a sex-difference in the sweat glands themselves (i.e. size and/or cholinergic sensitivity). They also reported a greater skin blood flow sensitivity for females, suggesting a greater sensitivity of the vasculature to cotransmitters and/or substances released from cholinergic nerves (Inoue et al., 2005).

\subsection{Rationale and statement of the problem}

The literature pertaining to differences in thermoregulatory function between males and females during exercise/heat stress is confounded by the fact that many studies either did not take into account differences in body size, or employed an experimental protocol which resulted in different rates of metabolic heat production between sexes. Consequently, conclusions remain limited as to whether or not differences between sexes in the mean body temperature onset threshold and/or thermosensitivity of heat loss 
responses exist. The current experiments aimed to determine if sex-related differences in temperature regulation are apparent during exercise/heat stress after taking into account differences in body mass and surface area, as well as in rate of metabolic heat production.

\subsection{Hypotheses}

General hypothesis of the thesis: It was hypothesised that, after considering differences in body mass and surface area, as well as rate of metabolic heat production between sexes, males and females would differ in their physiological responses to exercise and passive heat stress.

Specific hypotheses of the thesis: Specifically, it was hypothesised that females would have a greater mean body temperature onset threshold for whole-body and local heat loss responses, as well as a lower thermosensitivity of these responses during exercise and passive heating. Furthermore, it was hypothesised that these differences would be paralleled by both a lower pharmacological sensitivity and maximal responsiveness of the sweat gland and cutaneous vasculature in females.

\subsection{Objectives}

The objectives of the current thesis were to: 1) determine if sex-differences in temperature regulation are evident during exercise/heat stress after accounting for differences in physical characteristics and rate of metabolic heat production and; 2) determine possible physiological mechanisms responsible for potential sex-differences in sweat rate and/or skin blood flow. In order to fulfill these objectives, three studies were performed. The first study compared whole-body heat loss responses between males and females matched for body mass and surface area during exercise performed at a fixed rate of metabolic heat production. These responses were compared to a condition during which exercise was performed at a fixed percentage of maximum oxygen consumption. The second study compared whole-body and local heat loss responses during exercise 
performed at fixed requirements for heat loss. The third study examined post-junctional sweating and cutaneous vasodilation to incremental doses of pharmacological agonists in males and females. The sweating and cutaneous vasodilation responses elicited by pharmacological agonists were also compared to those observed in response to increases in mean body temperature elicited by passive heating.

\subsection{Relevance}

As a whole, the results of this thesis provide direct evidence that sex-differences in local and whole-body sudomotor activity go beyond those associated with differences in physical characteristics and rate of metabolic heat production. Additionally, the results of the current thesis provide insight as to whether these differences are mediated peripherally at the level of the thermoeffector organ and/or centrally due to differences in thermal neural activity. These results may lead to future studies examining potential practical implications for the development and advancement of health and safety guidelines as they relate to heat stress and/or injury in the industrial, military and sporting industries.

\subsection{Delimitations and limitations}

The participants recruited for all experiments were physically active and lean individuals aged between 18 and 40 years. Therefore, the thesis results are not applicable to children, the elderly and to a sedentary or obese population. Male and female participants were not subjected to a heat acclimatisation procedure prior to each experiment and all experimental protocols were performed between the months of September and June. It is therefore assumed that both sexes had a similar degree of heat acclimatisation. Female participants were only examined during the follicular phase of the menstrual cycle or low hormone period of oral contraceptive use. 


\section{CHAPTER II}

\section{REVIEW OF LITERATURE}




\subsection{Temperature regulation}

\section{General control}

Temperature regulation is a vital aspect of human survival as relatively small deviations in internal body (i.e. core) temperature can lead to profound disruptions in whole-body homeostasis. The maintenance of core temperature within relatively narrow limits, despite wide variations in environmental conditions and/or levels of physical activity, is dependent upon a fine balance between heat production and loss, as represented by the heat balance equation (Gagge \& Gonzales, 1996):

$$
S=M-( \pm W) \pm(R+C)-E
$$

Where: $\quad S$ is the rate of body heat storage;

$M$ is the rate of metabolic energy expenditure;

$W$ is the rate of external work;

$R$ is the rate of radiant heat exchange;

$C$ is the rate of convective heat exchange and;

$E$ is the rate of evaporative heat exchange. (All values in $\mathrm{W} \cdot \mathrm{m}^{-2}$ )

As evidenced by the heat balance equation, any mismatch between the rates of metabolic heat production $(M \pm W)$ and total heat loss $( \pm R \pm C-E)$ will lead to either a positive or negative rate of body heat storage $(S)$. In any environment, a positive rate of body heat storage $(S)$ will lead to an increase in core temperature over time when rate of metabolic heat production exceeds rate of total heat loss (i.e. $M \pm W> \pm R \pm C-E$ ). Similarly, in a hot environment, the combined rates of metabolic heat production and dry heat gain will result in a positive rate of body heat storage $(S)$ if they exceed rate of evaporative heat loss (i.e. $M \pm W \pm R \pm C>E$ ). On the other hand, if rate of total heat loss exceeds rate of metabolic heat production (i.e. $M \pm W< \pm R \pm C-E$ ), the negative rate of body heat storage $(S)$ will result in a decrease in core temperature over time. If uncompensated, an increasing or decreasing core temperature over time would eventually result in hyperthermia or hypothermia respectively, both of which are known to be 
potentially fatal conditions (Castellani et al., 2006; Armstrong et al., 2007). This highlights the fact that the body is able to sense and integrate changes in its temperature in order to initiate appropriate effector responses to counter and minimise changes in temperature. As a whole, the human thermoregulatory system can be divided into four subsystems: 1) receptors which send afferent thermal information to the; 2) integrating system which transmits efferent thermal information to the; 3) active systems which act to regulate the temperature of the; 4) passive (controlled) system (Werner, 1980, 1981).

\section{Thermosensitivity and thermointegration}

Peripheral thermoreceptors located throughout the body are responsible for detecting changes in skin and core temperatures. The skin contains both warm and cold thermoreceptors which display basal tonic activity in thermoneutral environments and increase their firing rate in response to the magnitude and the rate of increase or decrease in skin temperature respectively (Pierau, 1996). It is also thought that similar thermoreceptors which respond to changes in core and/or muscle temperatures exist throughout the rest of the body (e.g. viscera, muscles, major blood vessels, etc.) (Werner, 1980, 1981; Stitt, 1993). The peripheral thermoreceptors are responsible for transmitting afferent thermal information to the central nervous system (i.e. spinal cord and brain) where it is integrated (Schepers \& Ringkamp, 2009). It is well established that central thermoreceptors are located throughout the central nervous system, particularly in the region of the preoptic anterior hypothalamus (Hammel et al., 1960), where most of thermal integration is thought to occur (Stitt, 1993; Boulant, 1996). Integration of thermal information ultimately results in the central nervous system sending efferent signals, via the autonomic nervous system, to the appropriate effector organs (e.g. skin vasculature, sweat glands). 


\section{The active system}

The active system of temperature regulation comprises the physiological effector mechanisms which control and alter rates of heat exchange within the body and from the body to the environment (Werner, 1980, 1981). The main effector responses the body initiates due to deviations in core and skin temperatures are shivering thermogenesis, vasomotor responses (i.e. vasoconstriction and vasodilation), and sudomotor activity (Hardy, 1961; Hammel, 1968). When rate of total heat loss exceeds rate of metabolic heat production in a cold environment, the decrease in skin and/or core temperatures will stimulate shivering thermogenesis as well as cause a reflex cutaneous vasoconstriction to minimise heat exchange with the environment (Hardy, 1961; Hammel, 1968). The combined actions of these responses will lead to a greater rate of metabolic heat production and a decreased rate of heat loss to the environment allowing the body to attain and/or maintain heat balance. On the other hand, when rate of metabolic heat production exceeds rate of total heat loss (e.g. exercise), or when the heat gained by the body exceeds rate of heat loss from the body (e.g. passive heat exposure), the increase in core and/or skin temperatures will lead to cutaneous vasodilation and an increased sweat production (Hardy, 1961; Hammel, 1968; Benzinger, 1969). Both of these responses serve to increase heat dissipation from the body to the environment allowing the body to attain and/or maintain heat balance. Each effector response is characterised by a core temperature onset threshold (Bligh, 2006) beyond which it increases proportionally to the change in core and/or skin temperature (Figure 1). Since input from both core and skin temperatures are known to affect each response (Fusco et al., 1961; Nadel et al., 1971a,b; Wenger et al., 1985; Jessen, 1996; Wissler, 2008), the change in effector response is typically analysed as a function of the change in mean body temperature, which is calculated using a weighted summation of core and mean skin temperatures (i.e. [X • 
core $]+[\{1-X\} \cdot$ mean skin $]=$ mean body temperature $)($ Gisolfi \& Wenger, 1984). The

rate at which the effector response changes as a function of the change in mean body temperature is known as the sensitivity, or gain, of the response (Hammel, 1968; Gagge

\& Gonzales, 1996).
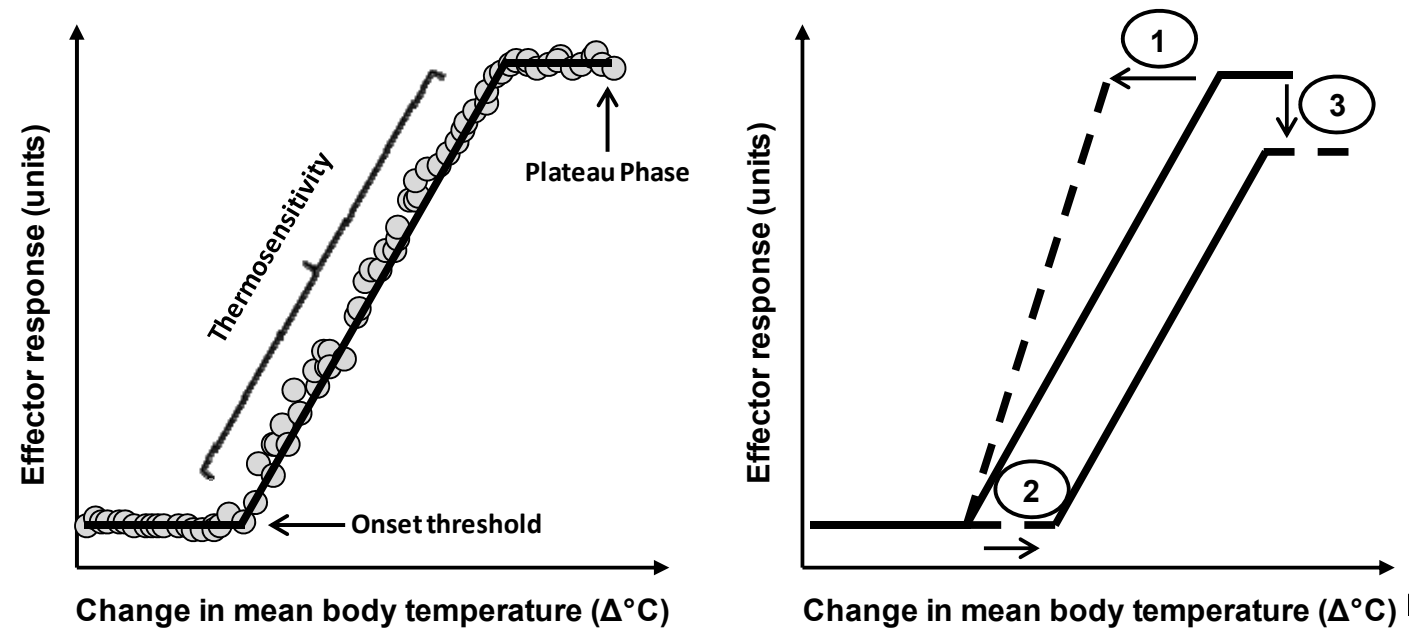

Figure 1. Schematic representation of the thermoeffector output-to-mean body temperature relationship during heat stress. Left panel: An increase in mean body temperature occurs before the effector response is activated at a given onset threshold. The effector output subsequently increases proportionally to the increase in mean body temperature, the linear portion of which represents the thermosensitivity of the response. Once the effector response reaches maximal values, a flattening of the line is observed, whereby no further increase in effector output occurs despite increasing mean body temperature. Right panel: Examples of how the parameters of the thermoeffector output-to-mean body temperature relationship can change: 1) The thermosensitivity of the response is increased, such that a greater change in effector output occurs for a given change in mean body temperature. 2) The onset threshold of the response is shifted to the right, such that a greater change in mean body temperature is required to initiate the activation of effector output. 3) The plateau phase of the effector output is reduced, such that lower maximal values are attained for a given change in mean body temperature.

The onset threshold and the thermosensitivity of thermoeffector responses provide valuable insight into the physiology of temperature regulation (Figure 1). Although both variables can represent a central and/or peripheral modulation of temperature regulation (Hammel, 1968), it has been suggested that changes in the onset threshold of all effector responses must occur to qualify as a central modulation (Gisolfi \& Wenger, 1984). Traditionally, changes in onset threshold have been used as an indicator of central modulation of temperature regulation, while the thermosensitivity has been used to 
describe peripheral adaptations in effector responses (Nadel et al., 1971b; Nadel et al., 1974). As such, changes in the thermosensitivity of an effector response, without parallel changes in the onset threshold likely imply a peripheral modulation.

\section{The passive system}

The passive system represents the physical characteristics of the human body which affect the exchange, distribution and production of heat within the different body compartments (Stitt, 1993). The body is typically partitioned into skin, fat, muscle, and viscera which are grouped to form the shell (i.e. skin and subcutaneous fat) and the core (i.e. muscle and viscera) compartments of the human body (Stolwijk \& Hardy, 1966). The properties of each compartment have been used to determine the rates of heat exchange that can be sustained within the body compartments as well as between the body and the external environment (Fiala et al., 1999), and have also been used to predict human regulatory and thermal responses to various environmental conditions (Fiala et al., 2001). Ultimately, the characteristics of each body compartment determine body mass, body composition, and body surface area, which are the main physical factors influencing core temperature to a given thermal stress (Anderson, 1999; Havenith, 2001b).

Body mass represents the heat storage capacity of the body, such that a greater amount of heat can be lost from, or gained by, the body before core temperature changes to a given thermal challenge (Anderson, 1999; Havenith, 2001b). As such, individuals with a greater body mass typically have smaller increases in core temperature during heat stress (Havenith et al., 1995, 1998), and smaller decreases in core temperature during cold exposures (White et al., 1992). While primarily dictated by body mass, the heat storage capacity of the body is also influenced by body composition. Variations in the relative amounts of fat vs. fat-free mass determine the specific heat capacity of the human body, defined as the amount of heat energy required to increase $1 \mathrm{~kg}$ of body weight by 
$1{ }^{\circ} \mathrm{C}$. Individuals with a greater relative amount of fat mass will have a greater change in core temperature for a given change in body heat content (Anderson, 1999; Cheung et al., 2000). In other words, it takes less heat gain/loss to increase/decrease core temperature in individuals with a greater percentage of body fat (Anderson, 1999). Body composition also influences the amount of heat transfer from the body core to the body shell, as well as from the body shell to the external environment. Fat mass and fat-free mass not only have different specific heat capacity values, but also have different thermal conductivities (Anderson, 1999). During cold stress, high levels of adipose tissue, combined with high amounts of vasoconstricted muscle tissue, contribute to greater total body insulation and reduced core temperature decay (Keatinge, 1960; Veicsteinas et al., 1982; Park et al., 1984). On the other hand, high levels of adipose tissue can potentially act as a barrier to heat loss from the body during periods of heat stress; however, its effect becomes limited as the level of heat stress increases (Havenith et al., 1995, 1998).

Finally, the amount of body surface area exposed to the external environment will determine the rate of heat exchange between the skin and the ambient air, such that a greater body surface area allows for a greater rate of heat exchange (Gagge \& Gonzales, 1996). Body surface area is usually calculated from the measurements of height and weight according to the formula proposed by DuBois \& DuBois (1916). Therefore, bigger and taller individuals have a greater body surface area which allows for a greater rate of evaporative and dry heat exchange. Individuals with a high body surface area, on average, have lower core temperatures during heat stress (Havenith \& van Middendorp, 1990; Havenith et al., 1995, 1998). However, during cold stress, the larger surface area available for heat exchange in bigger individuals if often counterbalanced by their greater mass (Anderson, 1999). Since core temperature is ultimately determined by a balance between the heat produced within the body (a function of mass), and the heat lost from 
the body (a function of body surface area), the relation between body mass and body surface area is often represented by the body surface area to mass ratio (Anderson, 1999). The body surface area to mass ratio has been used to explain differences in core temperature response during both cold (McArdle et al., 1984) and heat (Shapiro et al., 1980a) stress situations. However, the body surface area to mass ratio is considered to be less important a factor than the separate influences of body surface area and body mass (White et al., 1992; Anderson, 1999; Havenith, 2001a). For example, although individuals with a high body surface area and a high body mass usually have a low body surface area to mass ratio, they exhibit lower core temperatures during heat stress due to the large area available for heat exchange (i.e. body surface area) and the high capacity for heat storage (i.e. body mass) (Havenith, 2001a).

\subsection{Heat stress and temperature regulation}

\section{Exercise}

Exercise is characterized by high levels of internal metabolic heat production as a by-product of muscular metabolism. The high levels of metabolic heat production stem for the relative inefficiency of the human body to perform external work. In fact, humans have at most a $30 \%$ mechanical efficiency which will vary depending on the type of exercise performed (Joyner \& Coyle, 2008). Therefore, a minimum of $70 \%$ of the metabolic rate required to perform external work is liberated as heat, which must be dissipated to avoid eventual hyperthermia.

At the onset of dynamic exercise, there is an instant and rapid elevation in the rate of metabolic heat production. If exercise intensity and mechanical efficiency are kept constant, rate of metabolic heat production will attain a steady-state level within $\sim 5$ min (Kenny et al., 2008) and remain elevated for as long as exercise continues. The increased heat production by the active muscles at the onset of exercise is not immediately matched 
by an increased heat loss response (Webb, 1995). In fact, much of the heat produced in the early stages of exercise will be stored in the active musculature and muscle temperature will increase (Gisolfi \& Wenger, 1984; Nadel, 1984). As muscle temperature increases, heat transfer within the body will occur through 1) an increase in muscle blood flow which allows a greater conductive heat exchange between the working muscle and the blood, and 2) heat will be passively transferred from the working muscle to the surrounding tissues and compartments by conduction (Hardy, 1961; Hammel, 1968). With heat being stored in the core tissues of the body, core temperature will rise beyond threshold values thus activating the heat loss responses of cutaneous vasodilation and sweat production (Benzinger, 1969; Werner, 1993; Sawka et al., 1996). Cutaneous vasodilation will lead to an increase in skin blood flow, allowing warm blood returning from the active muscles and core tissues to be redirected towards the skin surface permitting transfer of heat by conduction/convection and/or radiation with the surrounding environment (Hardy, 1961; Hammel, 1968). However, the main avenue for heat loss during exercise is typically via the evaporation of sweat (Sawka et al., 1996), such that warming of the skin by increases in skin blood flow is balanced by the cooling action of increased sweat evaporation (Gisolfi \& Wenger, 1984; Sawka et al., 1996).

Together, increased skin blood flow and sweat production will be responsible for the increase in whole-body heat loss, which increases at a relatively slower rate compared to rate of metabolic heat production (Figure 2), with a time constant of $\sim 10 \mathrm{~min}$ (Webb et al., 1970; Kenny et al., 2008). As rate of total heat loss increases, rate of body heat storage will progressively decrease until rate of total heat loss matches rate of metabolic heat production (i.e. heat balance), at which time rate of body heat storage will be zero and core temperature will attain an elevated steady-state value (Stitt, 1993; Parsons, 2003). Depending on the temperature and humidity of the surrounding environment, as 
well as the intensity of exercise, it may take up to $45 \mathrm{~min}$ for rate of total heat loss to match rate of metabolic heat production (Kenny et al., 2008). It must be noted that heat balance will only be attained if the heat loss capacity of the individual is sufficient to offset the rate of metabolic heat production and/or the environmental conditions (i.e. compensable heat stress). Since rate of metabolic heat production is not initially matched by the rate of total heat loss, the absolute difference between the two rates, as well as the time taken for both rates to match, will dictate the magnitude of positive change in body heat content (Figure 2). The greater the change in body heat content during exercise, the greater the change in core temperature for a given mass.

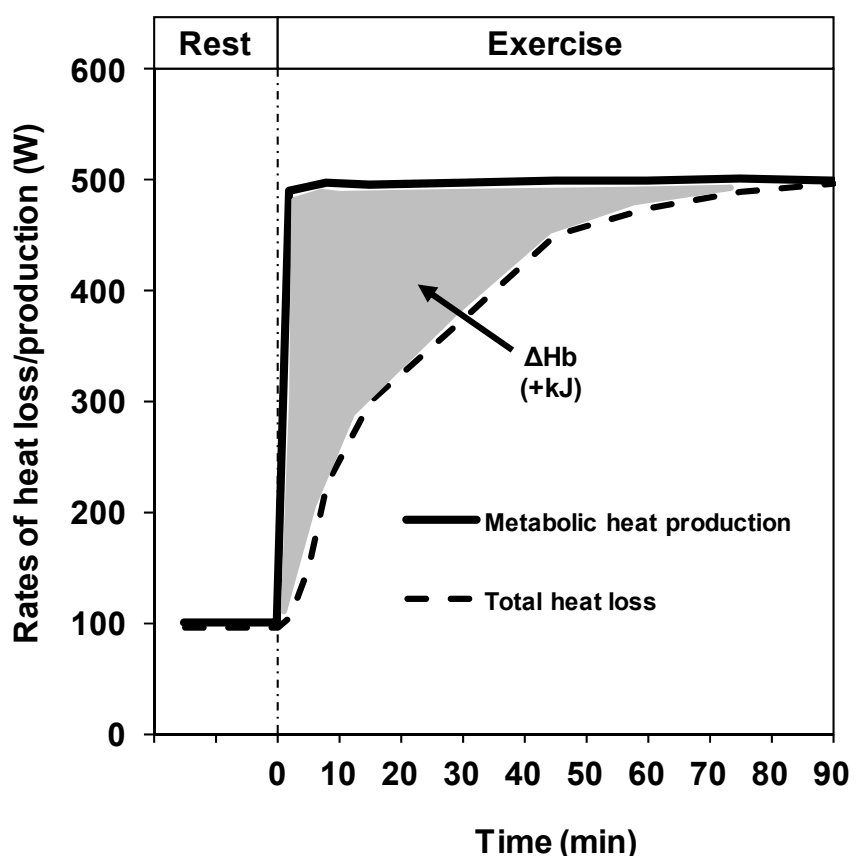

Figure 2. Rates of metabolic heat production (solid line) and total heat loss (dashed line) during a rest period and a subsequent $90 \mathrm{~min}$ exercise bout. The shaded area between the rates of metabolic heat production and total heat loss represents the change in body heat content $(\Delta \mathrm{Hb})$ for the exercise period.

While the onset threshold at which heat loss responses are activated and the rate at which they increase (thermosensitivity) primarily depend upon changes in mean body temperature (Figure 3), the level of whole-body heat loss achieved during exercise in the heat depends upon the required evaporation for heat balance $\left(E_{\text {req }}\right)$, which is the sum of metabolic heat production and dry heat exchange. Since evaporation of sweat represents 
the main component of total heat loss during exercise, particularly in the heat, the level of sudomotor activity achieved is driven by the evaporation needed for heat balance (Figure 3). When the maximal evaporation possible within a given environment $\left(E_{\max }\right)$ does not limit an individual's ability to achieve heat balance (i.e. compensable; $E_{\max } \geq E_{\text {req }}$ ), the level of sudomotor activity achieved during exercise is driven by the required evaporation for heat balance (Jay et al., 2011; Cramer et al., 2012). However, when the combination of environmental conditions and metabolic heat production exceed the individual's maximum evaporative capacity, therefore creating an uncompensable heat stress scenario (i.e. $E_{\mathrm{sk}} \max <E_{\text {req }}$ ), the level of sudomotor activity will be driven by the individual's maximum sweating rate (Figure 3).
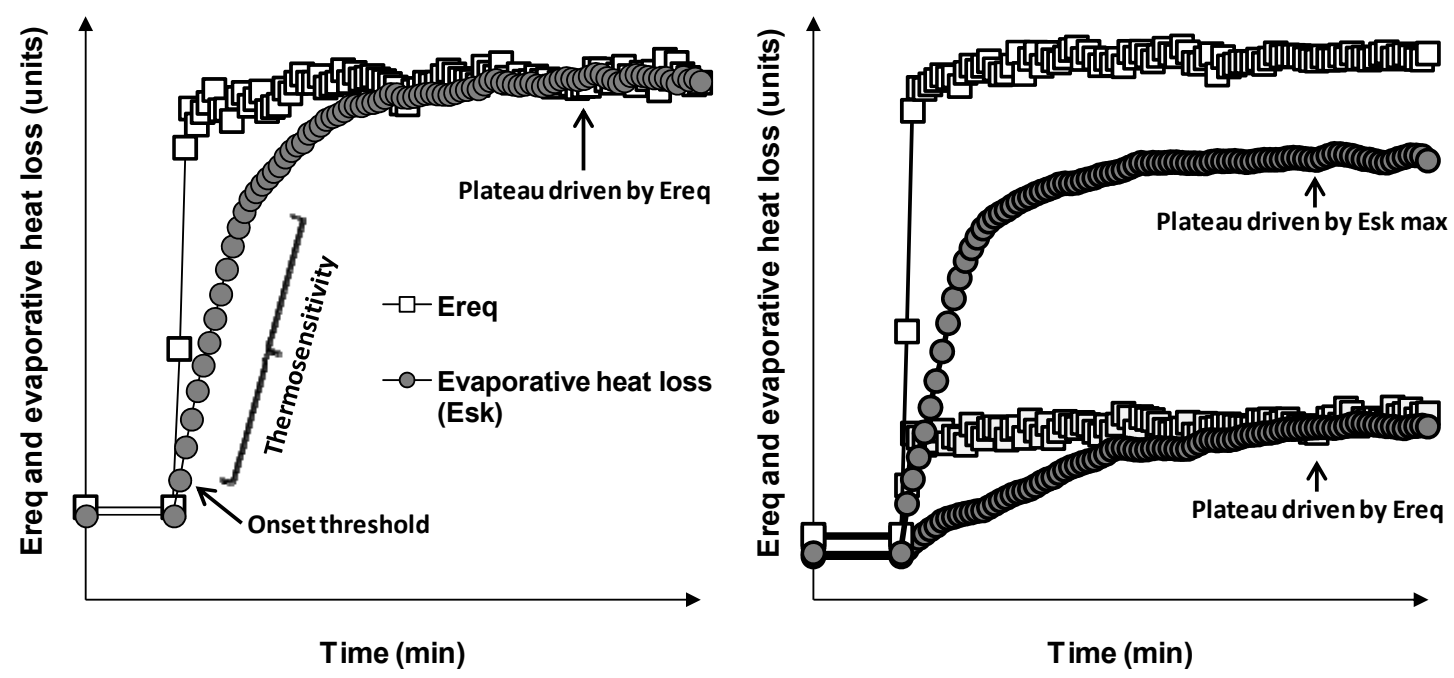

Figure 3. Schematic illustration of the relationship between the required evaporation for heat balance $\left(E_{\text {req }}\right)$ and evaporative heat loss $\left(E_{\mathrm{sk}}\right)$ during exercise. Left panel: The initial increase in evaporative heat loss during exercise is dictated by the onset threshold for sweating, with the subsequent linear increase in evaporative heat loss a function of the change in mean body temperature (thermosensitivity). However, the level of evaporative heat loss attained during exercise is determined by the required evaporation for heat balance $\left(E_{\text {req }}\right)$. Right panel: When the required evaporation for heat balance does not exceed the individual's maximal evaporative (sweating) capacity $\left(E_{\mathrm{sk}} \max \geq E_{\mathrm{req}}\right)$, the level of evaporative heat loss attained during exercise is determined by the required evaporation for heat balance. However, when the required evaporation for heat balance exceeds the individual's maximum evaporative capacity $\left(E_{\mathrm{sk}} \max <\right.$ $E_{\text {req }}$ ), the level of evaporative heat loss attained during exercise is determined by the individual's maximal evaporative $\left(E_{\mathrm{sk}} \max \right)$ capacity.

It should be noted that these scenarios assume that all of the sweat produced by the body is evaporated (i.e. 100\% efficiency). In reality, however, sweating efficiency decreases as the required evaporation for heat balance approaches the maximal 
evaporative capacity of the individual within a given environment (Candas et al., 1979).

Consequently, the level of sudomotor activity achieved at a fixed requirement for heat loss is more precisely dependent upon the relationship between the required evaporation for heat balance and the individual's maximum evaporative capacity in that environment (Shapiro et al., 1982; Bain et al., 2011).

\section{Passive heat stress}

Similarly to exercise, passive heat stress results in an imbalance of the parameters that make up the heat balance equation. However, the imbalance does not stem from high levels of internal heat production, but rather by heat gained from the external environment. As rate of dry heat exchange is driven by temperature gradients, the human body gains heat from the environment when air temperature exceeds that of skin temperature (Gagge \& Gonzales, 1996; Parsons, 2003). Therefore, as environmental temperature increases, rate of dry heat gain increases and is not immediately offset by an increase in evaporative heat loss (Figure 4). The initial imbalance between the rates of dry heat gain and evaporative loss results in a positive rate of heat storage, and an increase in core temperature (Stitt, 1993; Parsons, 2003). Mean body temperature will therefore rise beyond threshold values activating the heat loss responses of cutaneous vasodilation and sweat production (Benzinger, 1969; Werner, 1993; Sawka et al., 1996). Since environmental temperature is greater than skin temperature, increased skin blood flow will not serve to increase dry heat loss, but rather will serve to increase skin temperature and decrease the temperature gradient between the skin and the environment, attenuating the rate of dry heat gain. Consequently, heat loss via evaporation is the only means by which the body can lose heat when environmental temperatures exceed that of skin temperature (Hardy \& DuBois, 1937). Eventually, rate of evaporative heat loss will increase to a level sufficient to match the rate of dry heat gain, thereby restoring heat 
balance. As heat balanced is attained, rate of heat storage will become zero and core temperature will remain at an elevated steady-state value. Since rate of dry heat gain is not initially matched by the rate of evaporative heat loss, the absolute difference between the two rates, as well as the time taken for both rates to match, will dictate the magnitude of positive change in body heat content (Figure 4). The greater the change in body heat content during passive heat stress, the greater the change in core temperature for a given mass.

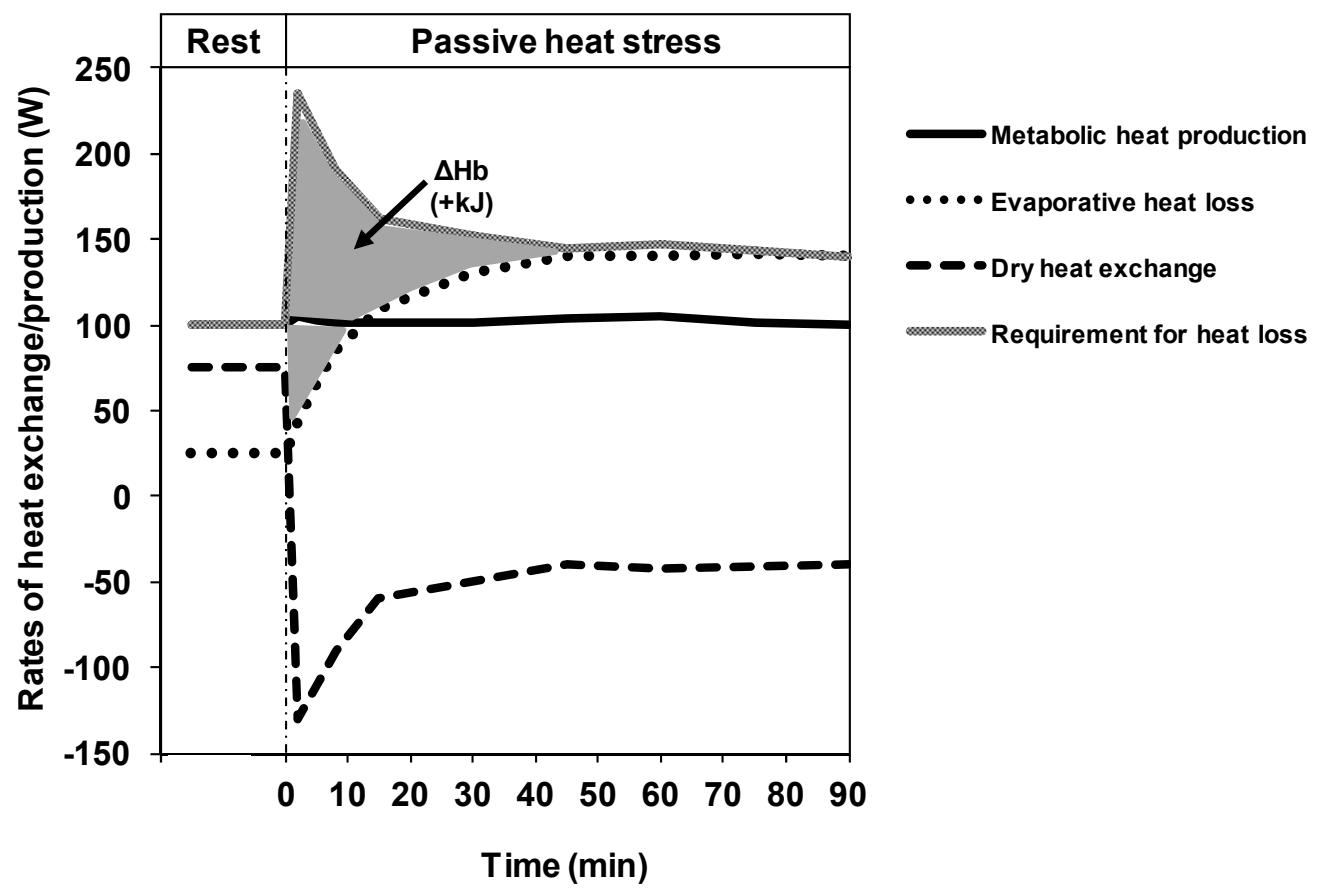

Figure 4. Rates of heat production and exchange during a rest period at thermoneutral conditions (e.g lightly clothed at $24^{\circ} \mathrm{C}$ ), followed by a $90 \mathrm{~min}$ period of passive heat stress (e.g. increasing ambient temperature). The requirement for heat loss represents the sum of the rates of metabolic heat production and dry heat exchange. The shaded area between the requirement for heat loss and evaporative heat loss represents the change in body heat content $(\Delta \mathrm{Hb})$ for the passive heat stress period. 


\subsection{Thermoeffector responses during heat stress}

\section{Eccrine sweat production}

The evaporation of sweat from the skin surface provides the greatest potential for heat loss during heat stress due to its high latent heat of vaporisation $\left(2426 \mathrm{~J} \cdot \mathrm{g} \mathrm{sweat}^{-1}\right.$ at $30^{\circ} \mathrm{C}$, [Wenger, 1972]). The secretion of sweat onto the skin surface is achieved by approximately 2 to 4 million eccrine sweat glands distributed all over the body surface (Sato, 1977, 1993). The regional distribution of these sweat glands varies to a certain extent between individuals, but their density is generally greatest on the forehead, followed by the upper limbs, trunk, and lower limbs (Szabo, 1962; Bar-Or et al., 1968; Sato \& Dobson, 1970). The actions of the sweat glands are primarily determined by cholinergic activity, but also respond to adrenergic agonists (Sato, 1977, 1993; Shibasaki et al., 2006). As core temperature rises, thermoefferent activity from the central nervous system induces the release of acetylcholine at the sudomotor junction which binds to muscarinic receptors on the sweat gland, and is subsequently broken down by the enzyme acetylcholinesterase (Shibasaki et al., 2006). Therefore, both the amount of acetylcholine released from the sudomotor nerves, and the breakdown rate of acetylcholine by acetylcholinesterase modulate local sweat rate (Shibasaki \& Crandall, 2001). Nitric oxide has also been shown to have a role in the control of sweat rate (Welch et al., 2009).

Increases in sweat rate during heat stress are primarily driven by increases in core temperature beyond a given core temperature onset threshold (Nielsen \& Nielsen, 1965; Benzinger, 1969; Wyss et al., 1974). However, changes in mean skin temperature (Hertzman et al., 1952; Nadel et al., 1971a,b) as well as local skin temperature (Ogawa, 1970; Nadel et al., 1971a,b) have been shown to modify the core temperature onset threshold for sweating and its sensitivity to changes in core temperature. The secretion of sweat onto the skin surface occurs almost simultaneously across the whole-body (Cotter 
et al., 1995; Kondo et al., 1998) with noticeable differences in sweat rate between body segments (Weiner, 1945; Cotter et al., 1995; Takano et al., 1996; Kondo et al., 1998) and within each segment (Taylor et al., 2006; Machado-Moreira et al., 2008a,b,c). During heat stress, the initial increases in sweat rate have been shown to be due to an increase in the number of activated sweat glands (Buono \& Connolly, 1992), while further increases are achieved by increases in the sweat output per gland (Kondo et al., 1998, 2001). Therefore, differences between individuals in sweat rate during heat stress could be attributed to differences in either the number of active sweat glands and/or the sweat output per gland. Differences in sweat rate between individuals have been shown to be mostly related to differences in the maximal sweat output a gland can achieve rather than to variations in the number of activated glands (Sato \& Dobson, 1970). Furthermore, the sweat output an individual gland can achieve, as well as its cholinergic sensitivity, has been shown to correlate with the actual size of the gland (Sato \& Sato, 1983).

\section{Cutaneous vasodilation}

Redistribution of regional blood flows to the skin (Rowell, 1974; Johnson \& Proppe, 1996) is the only controllable means by which heat can be transferred from within the body core to the skin surface where it can be exchanged with the environment (Hardy, 1961; Hammel, 1968). Therefore, vasodilation of the cutaneous vasculature, and the subsequent increase in skin blood flow, is an important complement to sweating in order to maintain heat balance during exercise and passive heat stress. The cutaneous vasculature contains both vasoconstrictor and vasodilator nerves (Edholm et al., 1957; Roddie et al., 1957) and is therefore under dual autonomic nervous control (Kellogg et al., 1989; Kellogg, 2006). The vasoconstrictor system acts primarily via an adrenergic system, through the binding of norepinephrine to $\alpha_{1}$ - and $\alpha_{2}$-adrenergic receptors (Kellogg, 2006). The cutaneous vasoconstrictor system is responsible for the 
vasoconstriction properties of the human skin which occur in response to cold stress (Kellogg et al., 1989) as well as for the transient decrease in skin blood flow typically observed at the onset of dynamic exercise (Kenney \& Johnson, 1992; Pawelcyzk, 1993). On the other hand, active vasodilation is primarily achieved via cholinergic activity with many studies demonstrating a co-transmission of nitric oxide for full expression of its response (Kellogg et al., 1998, 1999; Shibasaki et al., 2002; Kellogg, 2006).

Similar to sweating, increases in skin blood flow during heat stress are primarily stimulated by increases in core temperature (Wyss et al., 1974), such that skin blood flow increases linearly with increases in core temperature beyond a core temperature onset threshold (Kenney \& Johnson, 1992; Wissler, 2008). However, cutaneous vasodilation is also influenced by local (Johnson et al., 1976; Wenger et al., 1985, 1986) as well as mean skin (Wyss et al., 1974) temperatures, which primarily modify the onset threshold and the sensitivity of the response (Wissler, 2008). The amount of skin blood flow ultimately represents the balance between the vasoconstrictor and active vasodilator systems such that initial increases in skin blood flow during heat stress are achieved by withdrawal of sympathetic vasoconstrictor tone, while further increases are mainly due to active cutaneous vasodilation (Kamijo et al., 2005). The ultimate purpose of increasing skin blood flow is to induce changes in skin temperature which affect the rate of dry heat exchange with the environment (Gagge \& Gonzales, 1996). When air temperature exceeds mean skin temperature, increasing skin blood flow will serve to increase skin temperature, which decreases the temperature gradient between the skin surface and ambient air, consequently reducing the rate of dry heat gain from the environment. In contrast, when mean skin temperature exceeds ambient air temperature, increasing skin temperature via increased skin blood flow will create a greater skin to air temperature gradient, favouring a greater rate of dry heat loss to the environment. Furthermore, 
increased skin blood flow supplies the heat to the skin surface which is to be evaporated via sweating (Benzinger, 1969; Gisolfi \& Wenger, 1984; Sawka et al., 1996).

\subsection{Differences between sexes in heat loss responses}

James D. Hardy and Eugene F. DuBois were quite possibly the first to systematically investigate differences in the responses to heat and cold exposure between males and females at rest (Hardy \& DuBois, 1940; Hardy et al., 1941). By exposing both sexes to environmental temperatures ranging from 22 to $35^{\circ} \mathrm{C}$, they observed that females did not begin sweating until ambient temperature reached $32^{\circ} \mathrm{C}$, as opposed to $29^{\circ} \mathrm{C}$ for males (DuBois et al., 1952). These observations set the stage for research comparing males and females during heat stress which began in the 1960s (Wyndham et al., 1965; Morimoto et al., 1967; Weinman et al., 1967). These early studies were directed at evaluating differences between sexes in heat tolerance, mainly pre- and post-heat acclimatisation, as females began to enter the workforce in large numbers. Consequently, much of the evidence for differences between sexes in temperature regulation came from experimental protocols based on long duration exercise in the heat at a given external workload. As a whole, these studies suggested that, prior to heat acclimatisation; females regulated body temperature less effectively than males because they displayed higher rectal temperatures and heart rates as well as lower sweat rates (Nunneley, 1978; Burse, 1979; Kenney, 1985). However, following heat acclimatisation, females typically had similar rectal temperatures compared to males despite having lower sweat rates. This led to the idea that females were more efficient in regulating their body temperature following heat acclimatisation (Wyndham et al., 1965; Weinman et al., 1967). However, many of these earlier studies did not take into account possible differences in physical characteristics between males and females. Since, as a population, females are smaller, have a greater body surface area to mass ratio and have a lower maximum oxygen 
consumption, it was suggested that the reported differences between sexes in temperature regulation could have been due to differences in physical characteristics and/or fitness (Nunneley, 1978; Burse, 1979; Kenney, 1985).

\section{Physical differences}

The fact that females exhibited higher rectal temperatures at a given exercise/heat stress highlighted the importance of considering differences in physical characteristics between sexes. The possible impact such differences may have upon temperature regulation was put forward in a review by Burse (1979), who emphasised that females typically have a smaller body mass and a greater body surface area to mass ratio. A smaller body mass implied a lower heat storage capacity, such that less heat would have to be stored to increase body temperature in females. On the other hand, a greater body surface area to mass ratio was thought to provide an advantage to females during heat stress, as more surface area would be available for heat loss in relation to the metabolically active body mass (Burse, 1979). At the time, the body surface area to mass ratio was thought to be the main physical characteristic which could result in differences between sexes during heat stress (Shapiro et al., 1980a, 1981). By comparing endexercise rectal temperatures between subgroups of males and females with similar characteristics (e.g. body weight, body surface area, maximum oxygen consumption, etc.), Shapiro et al. (1980) reported that body surface area to mass ratio was the only physical characteristic which was significantly related to end-exercise rectal temperature. The lower body surface area to mass ratio in females was suggested to provide the advantage of making available more surface area for heat loss in relation to the metabolically active mass (Shapiro et al., 1980a), which was thought to explain their lower end-exercise rectal temperatures. However, the exercise protocol employed by Shapiro et al. (1980) consisted of treadmill walking at a given external workload (i.e. 
$1.34 \mathrm{~m} \cdot \mathrm{sec}^{-1}$ on a level treadmill). Since energy expenditure during weight bearing exercise is proportional to the individual's body mass (Austin \& Lansing, 1986), the heavier males in the study of Shapiro et al. (1980) had a greater rate of metabolic heat production. As such, the differences in metabolic heat production between sexes far outweighed the differences in body surface area to mass ratio, and the lower rectal temperatures observed in females were likely due to their lower rate of metabolic heat production (Havenith, 2001a). Rather than relating the amount of surface area available for heat exchange to the metabolically active body mass, both variables considered separately are now thought to represent the main physical characteristics which influence temperature regulation during exercise and/or heat stress. In fact, it has been shown that bigger individuals (e.g. males) who have both a greater body mass and a higher body surface area, resulting in a lower body surface area to mass ratio relative to smaller individuals (e.g. females), have lower end-exercise rectal temperatures (Havenith \& van Middendorp, 1990; Havenith et al., 1995, 1998).

The impact physical characteristics may have upon conclusions regarding sexdifferences in temperature regulation is perhaps best exemplified by early studies which reported greater core temperatures in females during exercise in the heat, suggesting they may be "less efficient" at regulating body temperature (Wyndham et al., 1965; Weinman et al., 1967; Morimoto et al., 1967). Although sex-differences in core temperature might intuitively suggest differences in the physiology of temperature regulation (e.g. altered sweating response), females can exhibit greater core, skin and active muscle temperatures despite a similar whole-body heat loss response to males (Gagnon et al., 2009). Therefore, core temperature alone cannot be reliably used to gain insight into potential physiological differences in temperature regulation when males and females are not matched for select physical characteristics. 


\section{Physical fitness}

In addition to body mass and surface area, physical fitness is also thought to be an important individual characteristic influencing temperature regulation during exercise and/or heat stress. An individual's fitness level, represented by maximum oxygen consumption, is thought to be strongly associated with the ability to thermoregulate in the heat due to the improvements in heat loss responses associated with the increases in core temperature that accompany physical training (Nadel et al., 1974). Consequently, a fit individual with a relatively higher maximum oxygen consumption is thought to have improved heat loss responses due to regular training compared to an unfit individual who does not train regularly.

In the studies performed in the $1960 \mathrm{~s}$, the higher heart rates observed in females, and the fact that rectal temperatures were similar between sexes following heat acclimatisation, emphasised that females were less fit and thus less heat acclimatised than males owing to their traditionally sedentary lifestyle. This led to the suggestion that physical fitness should be considered when comparing males and females during exercise in the heat (Drinkwater et al., 1976, 1977). To account for potential differences in physical fitness, subsequent studies either compared males and females during treadmill exercise at a fixed external workload (Davies, 1979; Avellini et al., 1980b; Shapiro et al., 1980b; McLellan, 1998; Moran et al., 1999), or during exercise performed at a given percentage of $\mathrm{VO}_{2} \max$ (Paolone et al., 1978; Avellini et al., 1980a; Frye \& Kamon, 1981; Horstman \& Christensen, 1982; Keatisuwan et al., 1996; Ichinose-Kuwahara et al., 2010). In some cases, an attempt was made to compare males and females with similar aerobic capacities expressed relative to body weight (Avellini et al., 1980a; Frye \& Kamon, 1981; Moran et al., 1999; Ichinose-Kuwahara et al., 2010). In general, it was found that physically active females had similar cardiovascular responses and heat 
tolerance times despite lower sweat rates compared to males when treadmill exercise was performed at a given external workload. On the other hand, when both sexes exercised at the same percentage of maximum oxygen consumption, it was generally found that females had lower end-exercise core temperatures despite having lower sweat rates. However, both exercise protocols contain inherent methodological issues due to the fact that males and females were not matched for body mass.

As mentioned previously, metabolic energy expenditure is proportional to body mass during weight bearing exercise such as treadmill walking. Consequently, the smaller females had a lower rate of metabolic heat production resulting in a lower required evaporation for heat balance, resulting in lower changes in body weight due to sweat loss. Similarly, when males and females perform exercise at a given percentage of maximum oxygen consumption, females also have a lower rate of metabolic heat production during exercise. This occurs despite the fact that both sexes may be matched for relative maximum oxygen consumption (expressed either in per $\mathrm{kg}$ of body weight or of fat free mass) because rate of metabolic heat production is determined by absolute oxygen consumption (Nishi, 1981). For example, if a male and a female perform exercise at 50\% of their same relative maximum oxygen consumption of $50 \mathrm{ml} \cdot \mathrm{kg}^{-1} \cdot \mathrm{min}^{-1}$, exercise oxygen consumption would be equal to $25 \mathrm{ml} \cdot \mathrm{kg}^{-1} \cdot \mathrm{min}^{-1}$ in both cases. Assuming the male weighs $70 \mathrm{~kg}$ and the female $60 \mathrm{~kg}$, then absolute oxygen consumption will equal $1750 \mathrm{ml} \cdot \mathrm{min}^{-1}$ and $1500 \mathrm{ml} \cdot \mathrm{min}^{-1}$ for the male and the female respectively. Assuming a respiratory exchange ratio of 0.85 , the $250 \mathrm{ml} \cdot \mathrm{min}^{-1}$ difference between the male and female will result in a rate of metabolic heat production which is $\sim 85 \mathrm{~W}$ greater in the male.

While this problem has been recognised previously (Kenney, 1985; Bar-Or, 1998), this protocol was nonetheless employed in many studies because it was thought 
that exercise at a given rate of metabolic heat production would cause undue physiological strain to females since they would be working at a higher percentage of their maximum oxygen consumption (Bar-Or, 1998). However, when males and females exercise at the same percentage of their maximum oxygen consumption, the lower rate of metabolic heat production in females results in a lower rate of evaporative heat loss (Figure 5), which must influence the heat loss responses of sweating and skin blood flow (Gagnon et al., 2008).

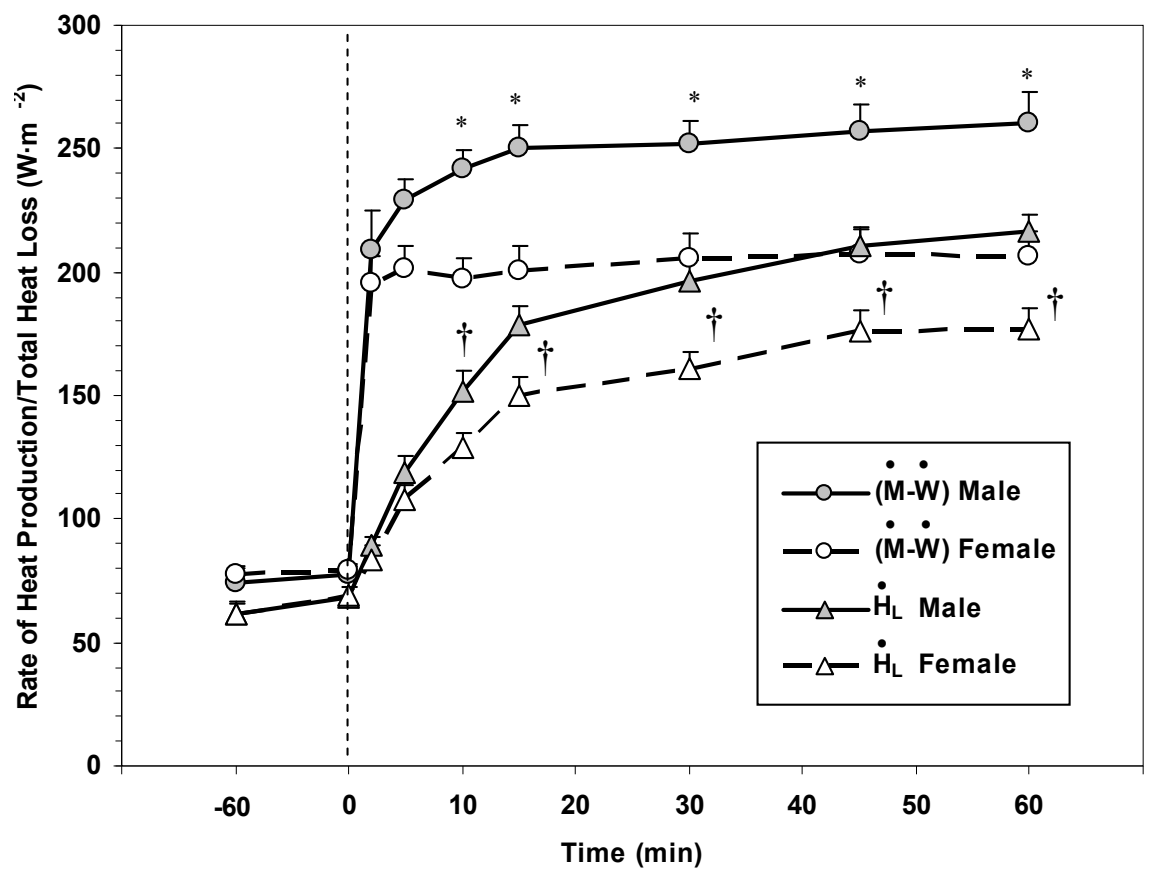

Figure 5. Whole-body calorimetry data for rate of net heat production $(\mathrm{M}-\mathrm{W})$ and rate of total heat loss $\left(\mathrm{H}_{\mathrm{L}}\right)$ for both males and females for $60 \mathrm{~min}$ of rest followed by $60 \mathrm{~min}$ of exercise at $40 \%$ maximum oxygen consumption at $40^{\circ} \mathrm{C}$ and $30 \%$ relative humidity. Vertical dotted line indicates onset of exercise. Significant difference between sex is indicated by asterisk (*) for $\mathrm{M}-\mathrm{W}$ and cross $(\dagger)$ for $\mathrm{H}_{\mathrm{L}}$. Values are mean \pm SE. The differences in $\mathrm{H}_{\mathrm{L}}$ were solely due to differences in the rate of evaporative heat loss between sexes. Note that the differences in $\mathrm{H}_{\mathrm{L}}$ are proportional to the differences in $\mathrm{M}-\mathrm{W}$. Reproduced with kind permission of Springer Science+Business Media from Gagnon et al. Eur J Appl Physiol 104, 821-829, 2008.

As such, protocols based either on treadmill exercise performed at a given external workload, or on exercise performed at a given percentage of maximum oxygen consumption which do not match males and females for body mass result in a lower 
required evaporation to attain heat balance, thereby explaining the lower sweat rates previously reported in many studies.

\section{Physiological differences}

Few experiments have examined possible sex-related differences in the mechanisms of sweating and/or skin blood flow. This is probably due to the general consensus that differences between males and females in temperature regulation can be explained by differences in physical characteristics and aerobic fitness (Sawka et al., 1996; Havenith, 2001b). However, this consensus was mainly derived from experiments which found similar end-exercise core temperatures and changes in body weight without properly accounting for differences in physical characteristics. End-exercise core temperatures and changes in body weight do not provide much information on possible differences between sexes in the control of heat loss responses (onset and/or thermosensitivity). Furthermore, many of these same experiments have employed experimental protocols which result in different rates of metabolic heat production between sexes during exercise, thereby influencing the responses of sweating and/or skin blood flow. It can therefore be argued that conclusions regarding sex-related differences in temperature regulation during exercise and/or heat stress remain limited. Yet, there are reasons to believe that sex-differences in temperature regulation of a physiological nature may exist during exercise and/or heat stress.

Studies examining sex-differences in temperature regulation during passive heat stress may provide some insight as to possible physiological differences because the methodological problems associated with different rates of metabolic heat production are minimised as responses are examined at rest. The initial observation of Hardy \& DuBois (1940) that females began to sweat at a higher ambient temperature compared to males during passive heat exposure suggested a greater onset threshold for sweating in females. 
This finding was later confirmed by Fox et al. (1969) who reported a greater aural canal temperature onset threshold for sweating and a lower total body sweat loss in females. Furthermore, Bittel \& Henane (1975) reported a delay before the onset of sweating that was $\sim 4$ min greater in females compared to males, while Bar-Or et al. (1968) reported that females have both a greater density and total number of heat activated sweat glands compared to males at the end of a 45 min passive heat exposure (dry bulb temperature of $47^{\circ} \mathrm{C}$ ). More recently, Inoue et al. (2005) examined differences in sweating and skin blood flow between males and females at various body sites during a 60 min passive heat stress (lower limb immersion). In general, the mean body temperature onset thresholds for sweating and cutaneous vasodilation were not different between sexes. However the sensitivity of sweating, but not cutaneous vasodilation, was generally lower in females. Furthermore, local sweat rate on the forehead, back, and chest was lower in females and was due to a lower sweat output per gland, as females generally had greater sweat gland activation. These findings led to the suggestion that sex-differences in sweat rate might be associated with differences in the size and/or pharmacological sensitivity of the sweat glands (Inoue et al., 2005).

In terms of physiological control, differences in onset threshold and/or thermosensitivity of sweating could be due to differences in: 1) afferent information from peripheral thermoreceptors; 2) neural integration of thermoafferent activity, 3) thermoefferent activity, 4) the effector response for a given level of thermoefferent activity, or 5) a combination of these possibilities. In theory, if sex modulates sudomotor activity centrally though differences in neural activity and/or integration, sex-differences in sweat rate would be expected to be observed at any combination of ambient conditions and metabolic heat production. In contrast to this possibility, a study by IchinoseKuwahara et al. (2010) suggests that sex-differences in sweat gland function 
improvements elicited by exercise training are intensity-dependent. Although they used an exercise protocol in which fixed percentages of $\mathrm{VO}_{2}$ max were employed, they report a greater thermosensitivity of the local sweating response in trained males compared to trained females. In contrast, no differences were observed between untrained males and untrained females. Despite the discussed limitations associated with the experimental protocol (Gagnon et al., 2008; Schwiening et al., 2011), the fact that differences in local sudomotor thermosensitivity were only observed between the males and females which exercised at the highest external workloads (and therefore rates of metabolic heat production), might suggest that the threshold at which the requirement for heat loss exceeds the capacity of the sweat gland to contribute to temperature regulation is lower in females.

In contrast, a peripheral modulation of the thermoeffector organ could stem from differences in the physical properties of the sweat gland itself (e.g. size), the sensitivity of the sweat gland to a given concentration of neurotransmitters released from sudomotor nerve terminals, and/or in the breakdown of acetylcholine within the sudomotor junction. Many previous studies have shown that, if anything, sweat gland recruitment is greater in females during passive heating (Bar-Or et al., 1968; Knip, 1969; Inoue et al., 2005), as well as during exercise (Morimoto et al., 1967; Frye \& Kamon, 1983; Ichinose-Kuwahara et al., 2010). Since variations in sweat gland output (Sato \& Dobson, 1970) and the maximal capacity of the gland to produce sweat (Sato \& Sato, 1983) have been used to evaluate differences in the physical properties of the sweat gland, these findings hint towards the possibility of sex-differences in the physical properties of the sweat gland itself. Furthermore, studies have shown a lower sweat response in females to locally administered acetylcholine (Kahn \& Rothman, 1942; Gibson \& Shelley, 1948) and 
pilocarpine (Madeira et al., 2010), which points towards a sex-difference in the cholinergic sensitivity of the sweat gland.

\section{Menstrual Cycle}

The cyclic variations in progesterone and estrogen which normally occur during the female menstrual cycle have been found to influence temperature regulation. Specifically, the rise in plasma concentration of progesterone and estrogen during the luteal phase of the menstrual cycle shifts the control of body temperature to higher levels (Stephenson \& Kolka, 1993; Kaciuba-Uscilko \& Grucza, 2001). This is most often exemplified by a resting core temperature which is $\sim 0.3-0.5^{\circ} \mathrm{C}$ higher during the luteal phase relative to the follicular phase. In parallel, the core temperature onset thresholds for cutaneous vasodilation (Stephenson \& Kolka, 1985; Kolka \& Stephenson, 1997) and vasoconstriction (Charkoudian \& Johnson, 1999) as well as sweating (Stephenson \& Kolka, 1985) are similarly shifted to core temperatures which are $\sim 0.3-0.5^{\circ} \mathrm{C}$ greater relative to the follicular phase. This upward shift in the control of body temperature is similarly affected in females taking oral contraceptives by the synthetic progesterone and estrogen contained in combination contraceptives (Charkoudian \& Johnson, 1997). Although the plasma concentrations of both progesterone and estrogen are elevated during the luteal phase of the menstrual cycle (and during the high hormone phase of oral contraceptive use), it is thought that progesterone is the main hormone influencing temperature regulation (Charkoudian \& Johnson, 2000; Charkoudian, 2003). This is supported by the observation that estrogen alone decreases core temperature, as well as the onset thresholds for sweating and cutaneous vasodilation (Stephenson \& Kolka, 1999). While it has been suggested that females are at a greater risk of suffering from heat-related injuries when performing exercise in the luteal phase of their menstrual cycle (Pivarnik et al., 1992), the general consensus is that exercise performance is not 
negatively affected by the menstrual cycle (Marsh \& Jenkins, 2002; Charkoudian \& Joyner, 2004). However, when comparing temperature regulation between males and females, phase of the menstrual cycle should be considered (Stephenson \& Kolka, 1985). 


\section{CHAPTER III}

\section{METHODS AND RESULTS}




\subsection{Thesis article \#1}

\section{Sex modulates whole-body sudomotor thermosensitivity during exercise.}

Final accepted version of article published in the Journal of Physiology, 589 (Pt 24): 6205-6217, 2011 (Appendix A)

Daniel Gagnon and Glen P. Kenny

Human and Environmental Physiology Research Unit, School of Human Kinetics, University of Ottawa, Ottawa, Canada

Running title: Sex differences in temperature regulation.

Key words: Skin blood flow, Sweat, Thermoregulation

Total word count: 5,868

Table of contents category: Integrative 


\section{NON-TECHNICAL SUMMARY}

The human body controls its temperature through coordinated physiological processes. Prior to the current study, it remained unknown if differences between males and females existed in these processes. The results from the current study show that females have a lower whole-body sweat response during exercise in the heat compared to males, which results in a greater increase in body temperature. The physiological process responsible for the lower whole-body sweat rate was a lower thermosensitivity of the response, meaning a lower increase in sweat production for a given increase in body temperature. Knowledge of sex-related differences in the physiology of temperature regulation may lead to better improvements in heat exposure guidelines for industrial, military, and athletic settings.

Word count: 116 


\section{ABSTRACT}

It is unclear whether true physiological differences exist in temperature regulation between males and females during exercise, independently of differences in physical characteristics and metabolic heat production. Therefore, we examined differences in the onset threshold and thermosensitivity of whole-body sudomotor activity and cutaneous vascular conductance between males and females matched for body mass and surface area. Nine males and nine females performed $90 \mathrm{~min}$ of exercise at each of the following intensities in a warm/dry environment: $50 \%$ of maximum oxygen consumption $\left(\dot{\mathrm{VO}}_{2 \max }\right)$ and at a fixed rate of metabolic heat production equal to $500 \mathrm{~W}$. Evaporative heat loss (EHL, direct calorimetry) and cutaneous vascular conductance (CVC, laser-Doppler) were measured continuously. Mean body temperature was calculated from the measurements of esophageal and mean skin temperatures. During exercise at $50 \%$ $\dot{\mathrm{VO}}_{2 \text { max }}$, a lower rate of sudomotor activity was observed in females (385 \pm 12 vs. $512 \pm$ $24 \mathrm{~W}, \mathrm{p}<0.001)$. However, irrespective of sex, individual EHL values were strongly associated with metabolic heat production $\left(\mathrm{R}^{2}=0.82, \mathrm{p}<0.001\right)$. Nonetheless, a lower rate of EHL was observed in females when exercise was performed at $500 \mathrm{~W}$ of metabolic heat production $(419 \pm 7$ vs. $454 \pm 11 \mathrm{~W}, \mathrm{p}=0.032)$. Furthermore, a lower increase in EHL per increase in mean body temperature was observed in females (553 \pm 77 vs. $795 \pm$ $\left.85 \mathrm{~W} \cdot{ }^{\circ} \mathrm{C}^{-1}, \mathrm{p}=0.051\right)$, with no differences in the onset threshold $(36.77 \pm 0.06$ vs. $36.61 \pm$ $0.11^{\circ} \mathrm{C}, \mathrm{p}=0.242$ ). In contrast, no differences were observed in CVC. Collectively, these findings demonstrate that females have a lower thermosensitivity of the whole-body sudomotor response compared to males during exercise in the heat performed at a fixed rate of metabolic heat production. 


\section{INTRODUCTION}

The physiological variables of temperature regulation, consisting of the body temperature at onset of effector responses (onset threshold) and the increase in effector output per unit increase in body temperature (thermosensitivity), dictate the capacity of the human body to regulate its temperature. When comparing these variables between populations however, all other environmental (e.g. air temperature/humidity, heat production) and physical (e.g. body mass/surface area) factors must remain constant. This is particularly relevant when comparing temperature regulation between males and females, since both have unique physical characteristics which make it difficult to discern whether differences in temperature regulation are attributed to either physiological or physical/environmental variables (Nunneley, 1978; Burse, 1979; Kenney, 1985).

Most studies examining differences in temperature regulation between males and females have focused on core temperature responses (Wyndham et al., 1965; Morimoto et al., 1967; Weinman et al., 1967; Shapiro et al., 1980; Shapiro et al., 1981; McLellan, 1998). Although sex differences in core temperature might intuitively suggest differences in the physiology of temperature regulation, core temperature alone does not provide an accurate assessment of thermoregulatory function when differences in physical characteristics between sexes are not taken into account (Gagnon et al., 2009). Furthermore, studies which have examined sex differences in heat loss responses during exercise have exclusively done so during weight bearing exercise (i.e. treadmill) at a fixed external workload (Davies, 1979; Avellini et al., 1980a; Avellini et al., 1980b; Moran et al., 1999), or during exercise at a fixed percentage of maximum oxygen consumption (Paolone et al., 1978; Frye \& Kamon, 1981; Horstman \& Christensen, 1982; Keatisuwan et al., 1996; Ichinose-Kuwahara et al., 2010). Although a consistent finding from these studies is a lower sweat rate in females, this observation is 
proportional to the variations in metabolic heat production elicited by such experimental protocols (Havenith, 2001a; Gagnon et al., 2008). Since previous studies have not fully accounted for differences in physical and/or environmental variables, differential core temperature and/or sweating responses between sexes during exercise may not necessarily indicate a true sex-related difference in temperature regulation, but may rather be attributed to simple differences in physical characteristics and rate of metabolic heat production. As such, conclusions whether sex can modulate the physiology of temperature regulation remain limited, a matter which has recently gained interest within this field of research (Schwiening et al., 2011).

Determining whether sex can modulate the physiology of temperature regulation has important mechanistic and practical implications. Sex has traditionally not been considered an independent modulator of temperature regulation (Sawka et al., 1996). It therefore often remains unknown if and/or how changes in thermoregulatory function differ between males and females, as a function of age, chronic disease and various physiological states. Such findings could lead to sex-specific improvements in public health, particularly in the improvement of heat exposure guidelines for industrial, military and sport settings which currently do not consider sex as a potential factor affecting heat stress and strain during work in the heat (United States Army Center for Health Promotion and Preventive Medicine, 2003; American Conference of Industrial Hygienists, 2007).

Therefore, the purpose of this study was to examine whether sex can modulate the physiological variables of human temperature regulation independently of physical and environmental factors. To achieve this objective, males and females were matched for body mass and surface area, while exercise at a fixed percentage of maximum oxygen consumption was compared to a condition of fixed metabolic heat production. The 
physiological variables of temperature regulation consisted of the onset threshold and thermosensitivity of the evaporative heat loss and cutaneous vascular conductance responses. We hypothesised that no sex-related differences in the onset threshold and thermosensitivity of the evaporative heat loss and cutaneous vascular conductance responses would be observed during exercise at a fixed rate of metabolic heat production. A secondary objective was to contrast the results from this condition with exercise performed at a fixed percentage of maximum oxygen consumption, which we hypothesised would result in a lower evaporative heat loss response in females, proportional to a lower rate of metabolic heat production. 


\section{METHODS}

\section{Ethical approval}

The current experimental protocol was approved by the University of Ottawa Health Sciences and Science Research Ethics Board, in accordance with the Declaration of Helsinki. Written informed consent was obtained from all volunteers prior to their participation in the study.

\section{Participants}

An effect size of $10 \%$ and standard deviation of $5 \%$, estimated from previous publications (Gagnon et al., 2008; Gagnon et al., 2009), resulted in a minimum calculated $(\beta=0.9, \alpha=0.05)$ sample size of 6 participants in each group. Eighteen participants, 9 males and 9 females, were recruited within the University community and volunteered for the study. To eliminate the confounding influence of differences in physical characteristics between sexes, males and females were matched in pairs for body mass. Furthermore, to eliminate the influence of differences in hormonal status across the menstrual cycle, female participants performed each experimental session within the first and tenth day after the onset of their self-reported menses. Female participants taking oral contraceptives $(n=6)$ performed the experimental sessions during the no pill/placebo phase of oral contraceptive use. Hormonal status was confirmed by taking a venous blood sample on the day of each experimental session. None of the experimental sessions for female participants had to be withdrawn or repeated based on blood sample results. Participants were healthy, non-smoking, and free of any known cardiovascular, metabolic and respiratory diseases. Participant characteristics are presented in Table 1. 


\section{Experimental Design}

Participants volunteered for one screening visit and two experimental sessions. During the screening visit, measurements of body height and mass, as well as maximum oxygen uptake were determined. Body height was determined using a stadiometer (Detecto, model 2391, Webb City, MO, USA), while body mass was calculated as the sum of fat tissue mass, lean tissue mass, and bone mass as determined using Dual Energy X-Ray Absorpsiometry. Body surface area was calculated from the measurements of body height and mass (DuBois \& DuBois, 1916). Maximum oxygen uptake was determined by an automated indirect calorimetry system (MOXUS system, Applied Electrochemistry, Pittsburgh, PA, USA) during a progressive incremental cycling protocol performed on an upright seated constant-load cycle ergometer (Corival, Lode B.V., Groningen, Netherlands). The participants were asked to cycle continuously at 80 rpm, at a starting work rate of $80 \mathrm{~W}$ for 2 minutes. The work rate was then increased by $20 \mathrm{~W}$ increments every minute thereafter until the subject could not maintain a pedaling cadence of at least $60 \mathrm{rpm}$ (Canadian Society for Exercise Physiology, 1986).

For each experimental session, participants reported to the laboratory between $7 \mathrm{~h} 00$ and $9 \mathrm{~h} 00$, after eating a small breakfast (i.e. toast and juice), but consuming no tea or coffee that morning. The participants were also asked to drink $500 \mathrm{~mL}$ of water the night prior to, as well as the morning of, each experimental session and to refrain from alcohol and exercise for $24 \mathrm{~h}$ prior to experimentation. Upon arrival at the laboratory, the participants voided their bladder and provided a urine sample before weighing themselves nude. Subsequently, the participants changed into shorts and sandals (as well as a sports bra for female participants), and sat quietly for a $30 \mathrm{~min}$ instrumentation period at an ambient room temperature of $24^{\circ} \mathrm{C}$. Following instrumentation, the participant entered the calorimeter regulated to an ambient air temperature of $35.21 \pm 0.24^{\circ} \mathrm{C}$, a specific 
humidity of $4.27 \pm 1.51 \mathrm{~g} \cdot \mathrm{kg}^{-1}(\sim 12 \%$ relative humidity), and an air mass flow of $5.75 \pm$ $0.28 \mathrm{~kg}$ of air $\cdot \mathrm{min}^{-1}$. The participant, seated in the upright position, rested for a $45 \mathrm{~min}$ habituation period. Subsequently, the participant performed 90 min of continuous cycling exercise at either $50 \%$ of maximum oxygen consumption, or a rate of metabolic heat production equal to $500 \mathrm{~W}$. A fixed percentage of maximum oxygen consumption (50\%) was selected since it is a widely used approach to study sex-related differences in thermoregulation during exercise. In contrast, a fixed rate of absolute heat production $(500 \mathrm{~W})$ was chosen to provide the same requirement for heat loss for males and females. At the end of the exercise period, all instrumentation was removed except for the laserDoppler probe, and participants remained seated for a 45 min local heating period to determine maximum skin blood flow (see details below). At the end of the local heating period, the participants exited the calorimeter and a final nude body mass measurement was obtained.

The two experimental sessions were performed on separate days, separated by a minimum of 48 hours. For all experimentation, clothing was standardized to cotton underwear, running shorts, sandals, and sports bra for female participants. Possible differences in acclimation status between males and females were not taken into account. However, since all experimentation occurred between the months of October and May, it was assumed that all participants were not heat acclimated.

\section{Measurements}

The main thermoeffector responses during exercise in the heat consist of wholebody sudomotor activity and cutaneous vasodilation. Therefore, the current study focused on differences between sexes in evaporative heat loss and local skin blood flow.

Whole-body sudomotor activity was estimated from measurements of evaporative heat loss using the modified Snellen direct air calorimeter (Reardon et al., 2006). In order 
for evaporative heat loss to be a valid measure of whole-body sudomotor activity, we ensured that the environmental conditions provided a high vapour pressure gradient between the skin surface and the surrounding air. Furthermore, we continually maintained this vapour pressure gradient by continuously providing a high air mass flow of dry air through the calorimeter. Calorimeter outflow to inflow differences in absolute humidity were collected at $8 \mathrm{~s}$ intervals throughout the trials. The real time data were displayed and recorded on a personal computer with LabVIEW software (Version 7.0, National Instruments, TX, USA). Evaporative heat loss (in Watts) was subsequently calculated using the following equation:

$$
\left[\left(\text { Massflow } \cdot\left(\text { Humidity }_{\text {out }}-\text { Humidity }_{\text {in }}\right) \cdot 2426\right] / 60\right.
$$

where mass flow is the rate of flow of air mass $\left(\mathrm{kg}_{\left.\text {air } \bullet \mathrm{min}^{-1}\right)}\right)$ ( Humidity ${ }_{\text {out }}-$ Humidity $\left._{\text {in }}\right)$ is the calorimeter outflow-inflow difference in absolute humidity ( $\mathrm{g}$ of water $\bullet \mathrm{kg}$ of air ${ }^{1}$ ); and 2426 is the latent heat of vaporization of sweat $\left(\mathrm{J} \cdot \mathrm{g}\right.$ of sweat $\left.{ }^{-1}\right)$ at $30^{\circ} \mathrm{C}($ Wenger, 1972) .

Cutaneous vasodilation was estimated using laser-Doppler velocimetry (PeriFlux System 5000, Perimed AB, Stockholm, Sweden). Prior to the start of the experimental trial, the laser-Doppler flow probe (PR 401 Angled Probe, Perimed AB, Stockholm, Sweden) was affixed with an adhesive ring to the upper back in a site without superficial veins that demonstrated pulsatile activity. Upper back skin blood flow responses have been shown to be similar to those observed on the forearm and chest (Ichinose et al., 2009). The probe was not moved from its location throughout the experimental trial. To determine maximum skin blood flow, a local heating period to $42^{\circ} \mathrm{C}$ for $30 \mathrm{~min}$ and then to $44^{\circ} \mathrm{C}$ for an additional 15 min was performed at the end of each experimental trial. Cutaneous vascular conductance was subsequently calculated as laser-Doppler 
velocimetry output in arbitrary perfusion units divided by mean arterial pressure and expressed as a percentage of maximum.

Indirect calorimetry was used for the concurrent measurement of metabolic energy expenditure (Nishi, 1981). Expired gas was analyzed for $\mathrm{O}_{2}$ (error of $\pm 0.01 \%$ ) and $\mathrm{CO}_{2}$ (error of $\pm 0.02 \%$ ) concentrations using electrochemical gas analyzers located outside of the calorimeter chamber (AMETEK model S-3A/1 and CD 3A, Applied Electrochemistry, Pittsburgh, PA, USA). Expired air was recycled back into the calorimeter chamber in order to account for respiratory heat exchange. Prior to each session gas mixtures of $4 \% \mathrm{CO}_{2}, 17 \% \mathrm{O}_{2}$, balance nitrogen were used to calibrate the gas analyzers and a $3 \mathrm{~L}$ syringe was used to calibrate the turbine ventilometer (error $\pm 3 \%$, typically $<1 \%$ ).

Mean arterial pressure was measured using a Finometer (Finapres Medical Systems, Amsterdam, Netherlands) from the beat-to-beat recording of the right middle finger arterial pressure waveform with the volume-clamp method (Penaz, 1973) and physiocal criteria (Wesseling et al., 1995). Prior to beginning the measurement period, a level calibration was performed and brachial artery pressure reconstruction (Gizdulich et al., 1996; Gizdulich et al., 1997) was calibrated with an upper arm return-to-flow systolic pressure detection (Bos et al., 1996).

Heart rate was monitored using a Polar coded transmitter, recorded continuously and stored with a Polar Advantage interface and Polar Precision Performance software (Polar Electro, Oy, Finland).

Esophageal and rectal temperatures were measured with general purpose thermocouple temperature probes (Mallinckrodt Medical Inc., St-Louis, MO, USA). The esophageal probe was inserted $40 \mathrm{~cm}$ past the entrance of the nostril while the participants sipped water $(250-500 \mathrm{~mL})$ through a straw. Rectal temperature was inserted 
to a depth of $15 \mathrm{~cm}$ past the anal sphincter. Skin temperature was measured at 10 sites using thermocouples (Concept Engineering, Old Saybrook, CT, USA) attached to the skin with surgical tape. Mean skin temperature was subsequently calculated using a 10 point weighting of the regional proportions determined by Hardy \& DuBois (1938). Temperature data were collected using a HP Agilent data acquisition module (model 3497A) at a rate of one sample every $15 \mathrm{~s}$ and simultaneously displayed and recorded in spreadsheet format on a personal computer with LabVIEW software (Version 7.0, National Instruments, TX, USA).

Whole-body sweat production was calculated as the difference in pre to post measurements of body mass to the nearest $0.01 \mathrm{~kg}$ using a digital high-performance weighing terminal (model CBU150X, Mettler Toledo Inc., Mississauga, ON, CAN). Urine specific gravity was determined in duplicate using a handheld total solids refractometer (model TS400, Reichter Inc., Depew, NY, USA).

On the day of each experimental session, a venous blood sample $(10 \mathrm{~mL})$ was obtained from female participants to confirm that the session occurred in the follicular/low hormone phase of the menstrual cycle. The blood samples were collected with a $\mathrm{SST}^{\mathrm{TM}}$ vacutainer (BD Vacutainer, Franklin lakes, NJ, USA) for the determination of plasma $17 \beta$-estradiol and progesterone. Plasma concentrations of $17 \beta$-estradiol and progesterone were quantified using automated chemiluminescent microparticle immunoassays (ARCHITECT system; Abbott Diagnostics, Abbott Park, IL, USA) by an independent external laboratory (Gamma-Dynacare Medical Laboratories, Ottawa, ON, Canada) using appropriate monoclonal antibody-coated microparticles and acridiumlabeled conjugates. The plasma concentrations representative of the follicular phase of the menstrual cycle for $17 \beta$-estradiol and progesterone are $46-604 \mathrm{pmol} / \mathrm{L}$ and $0.6-4.7$ $\mathrm{nmol} / \mathrm{L}$ respectively. 


\section{Statistical analyses}

For all variables, minute averages were performed to carry out the statistical analyses. To examine sex-related differences in the thermal control of the evaporative heat loss and cutaneous vascular conductance responses, the visually determined linear portion of each response against mean body temperature was analyzed using a simple linear regression. The onset threshold was defined as the intercept of the regression line with the evaporative heat loss and cutaneous vascular conductance values at rest, while the thermosensitivity was defined as the slope of the regression line (Cheuvront et al., 2009). To account for the relative influence of core and skin temperatures on the activation of heat loss responses (Hertzman et al., 1952; Nadel et al., 1971a; Nadel et al., 1971b), mean body temperature was calculated as: $0.9 \times$ esophageal temperature $+0.1 \times$ mean skin temperature (Shibasaki et al., 2006).

All dependent variables were compared between groups (males vs. females) within each experimental condition $(50 \%, 500 \mathrm{~W})$. Independent samples T-tests were used for single comparisons between groups, while a two-way mixed model analysis of variance was used for multiple comparisons using the repeated factor of time and the non-repeated factor of group. When a significant main effect was observed, post-hoc comparisons were carried out with independent samples T-tests. Furthermore, a simple linear correlation was performed to assess the relationship between end-exercise evaporative heat loss and rate of metabolic heat production values during exercise at a fixed percentage of maximum oxygen consumption. The level of significance for all analyses was set at an alpha level of $p \leq 0.05$, corrected for multiple comparisons using the Holm-Bonferonni approach. Analyses were performed using commercially available statistical software (SPSS 18.0 for Windows, SPSS Inc., Chicago, IL, USA). All values 
for sample parameters are reported as mean \pm standard deviation, while those for variables are reported as mean \pm standard error. 


\section{RESULTS}

\section{Participant characteristics}

By design, there were no differences in body mass between groups $(\mathrm{p}=0.873)$. Furthermore, there were no differences in height between groups $(p=0.104)$, such that both sexes had a similar body surface area $(\mathrm{p}=0.504)$. In contrast, males had a lower absolute fat mass $(\mathrm{p}<0.001)$, as well as a greater absolute lean $(\mathrm{p}<0.001)$ and bone $(\mathrm{p}=0.021)$ mass compared to females. Finally, males had a greater maximum oxygen consumption both in absolute values $(p=0.001)$ and relative to body mass $(p=0.002)$. However, there were no sex differences in maximum oxygen consumption expressed as a function of lean body mass $(\mathrm{p}=0.767)$.

\section{Exercise at a fixed percentage (50\%) of maximum oxygen consumption}

On the day of the experimental session, plasma concentrations of $17 \beta$-estradiol and progesterone for the female participants averaged $139 \pm 28 \mathrm{pmol} \cdot \mathrm{L}^{-1}$ and $1.2 \pm 0.2$ $\mathrm{nmol} \cdot \mathrm{L}^{-1}$ respectively. Baseline urine specific gravity did not differ between groups (males: $1.015 \pm 0.002$ vs. females: $1.015 \pm 0.003, \mathrm{p}=0.816$ ). Furthermore, there were no differences between groups in baseline esophageal, $(p=0.786$, Table 2$)$, rectal $(p=0.555$, Table 2), mean skin (males: $34.72 \pm 0.11^{\circ} \mathrm{C}$ vs. females: $34.54 \pm 0.19^{\circ} \mathrm{C}, \mathrm{p}=0.432$ ), and mean body (males: $36.68 \pm 0.08^{\circ} \mathrm{C}$ vs. females: $36.67 \pm 0.10^{\circ} \mathrm{C}, \mathrm{p}=0.936$ ) temperatures. Similarly, heart rate $(\mathrm{p}=0.409)$, metabolic heat production $(\mathrm{p}=0.328)$, whole-body evaporative heat loss $(p=0.110)$ and cutaneous vascular conductance $(p=0.469)$ did not differ between males and females prior to the beginning of exercise.

Based on the participants pre-determined absolute maximum oxygen consumption, the target oxygen consumption during exercise averaged $1917 \pm 239$ $\mathrm{mL} \cdot \mathrm{min}^{-1}$ for males and $1544 \pm 153 \mathrm{~mL} \cdot \mathrm{min}^{-1}$ for females $(\mathrm{p} \leq 0.001)$. Consequently, rate of metabolic heat production was significantly greater in males during exercise $(p<0.001)$, 
which was paralleled by a greater rate of whole-body evaporative heat loss $(\mathrm{p}<0.001$, see Fig. 1A). However, the level of evaporative heat loss achieved during exercise significantly correlated $(\mathrm{p}<0.001)$ with rate of metabolic heat production. In fact, differences in metabolic heat production between sexes explained more than $80 \%$ of the variance in evaporative heat loss (Fig. 2). The differences in whole-body evaporative heat loss were reflected by a greater whole-body sweat production in males $(1.69 \pm 0.06 \mathrm{~kg}$ vs. $1.29 \pm 0.08 \mathrm{~kg}, \mathrm{p}=0.002$ ). In contrast, there were no differences between sexes in cutaneous vascular conductance during exercise $(\mathrm{p}=0.221$, see Fig. $3 \mathrm{~A})$, as well as the maximum cutaneous vascular conductance values reached during the local heating period (males: $1.02 \pm 0.18 \mathrm{PU} \cdot \mathrm{mmHg}^{-1}$ vs. females: $1.23 \pm 0.25 \mathrm{PU} \cdot \mathrm{mmHg}^{-1}, \mathrm{p}=0.500$ ). Overall, the differences in whole-body evaporative heat loss between sexes were proportional to the differences in metabolic heat production such that no differences in both esophageal $(p=0.953)$ and rectal $(p=0.433)$ temperatures were observed at the end of exercise (see Table 2). Furthermore, there were no significant differences in mean skin temperature throughout exercise $(p=0.117)$, which averaged $35.36 \pm 0.08^{\circ} \mathrm{C}$ and $34.96 \pm 0.16^{\circ} \mathrm{C}$ for males and females respectively at the end of exercise.

The mean body temperature onset threshold for evaporative heat loss (males: $36.67 \pm 0.09^{\circ} \mathrm{C}$ vs. females: $36.76 \pm 0.09^{\circ} \mathrm{C}, \mathrm{p}=0.518$ ) and cutaneous vasodilation (males: $36.70 \pm 0.09^{\circ} \mathrm{C}$ vs. females: $36.76 \pm 0.09^{\circ} \mathrm{C}, \mathrm{p}=0.617$ ) did not differ between groups. However, the thermosensitivity of the whole-body evaporative heat loss $\left(762 \pm 56 \mathrm{~W} \cdot{ }^{\circ} \mathrm{C}^{-1}\right.$ vs. $559 \pm 75 \mathrm{~W} \cdot{ }^{\circ} \mathrm{C}^{-1}, \mathrm{p}=0.049$, see Fig. $4 \mathrm{~A}$ ) and cutaneous vascular conductance responses $\left(52 \pm 5 \% \mathrm{CVC} \cdot{ }^{\circ} \mathrm{C}^{-1}\right.$ vs. $30 \pm 4 \% \mathrm{CVC} \cdot{ }^{\circ} \mathrm{C}^{-1}, \mathrm{p}=0.002$, see Fig. $\left.5 \mathrm{~A}\right)$ were significantly greater in males compared to females. 


\section{Exercise at a fixed rate of absolute metabolic heat production (500 W)}

On the day of the experimental session, plasma concentrations of $17 \beta$-estradiol and progesterone for the female participants averaged $233 \pm 66 \mathrm{pmol} \cdot \mathrm{L}^{-1}$ and $1.1 \pm 0.3$ $\mathrm{nmol} \cdot \mathrm{L}^{-1}$ respectively. Baseline urine specific gravity did not differ between groups (males: $1.020 \pm 0.003$ vs. females: $1.014 \pm 0.002, \mathrm{p}=0.249$ ). Furthermore, there were no differences between groups in baseline esophageal $(p=0.261$, Table 2$)$, rectal $(p=0.550$, Table 2), mean skin (males: $34.83 \pm 0.13^{\circ} \mathrm{C}$ vs. females: $34.83 \pm 0.10^{\circ} \mathrm{C}, \mathrm{p}=0.962$ ), and mean body (males: $36.45 \pm 0.12^{\circ} \mathrm{C}$ vs. females: $36.60 \pm 0.08^{\circ} \mathrm{C}, \mathrm{p}=0.353$ ) temperatures. Similarly, heart rate $(\mathrm{p}=0.226)$, metabolic heat production $(\mathrm{p}=0.147)$, whole-body evaporative heat loss $(\mathrm{p}=0.196)$, and cutaneous vascular conductance $(\mathrm{p}=0.919)$ did not differ between males and females prior to the beginning of exercise.

By experimental design, rate of metabolic heat production during exercise did not differ between sexes (males: $508 \pm 5 \mathrm{~W}$ vs. females: $504 \pm 6 \mathrm{~W}, \mathrm{p}=0.573$ ). Nonetheless, a greater rate of whole-body evaporative heat loss was observed in males $(\mathrm{p}=0.028$, see Fig. 1B). The greater rate of whole-body evaporative heat loss was paralleled by a greater whole-body sweat production in males $(1.63 \pm 0.07 \mathrm{~kg}$ vs. $1.38 \pm 0.06 \mathrm{~kg}, \mathrm{p}=0.029) . \mathrm{In}$ contrast, there were no differences in cutaneous vascular conductance during exercise ( $\mathrm{p}=0.899$, see Fig. $3 \mathrm{~B}$ ), as well as the maximum cutaneous vascular conductance values reached during local heating (males: $1.24 \pm 0.34 \mathrm{PU} \cdot \mathrm{mmHg}^{-1}$ vs. females: $0.97 \pm 0.20$ $\left.\mathrm{PU} \cdot \mathrm{mmHg}^{-1}, \mathrm{p}=0.362\right)$. The net consequence of the lower evaporative heat loss in females was a greater end-exercise esophageal $(p=0.019)$ and rectal $(p=0.026)$ temperature (Table 2). In contrast, there were no significant differences between groups in mean skin temperature during exercise $(\mathrm{p}=0.486)$, which averaged $35.38 \pm 0.07^{\circ} \mathrm{C}$ and $35.58 \pm$ $0.21^{\circ} \mathrm{C}$ for males and females respectively at the end of exercise. 
The mean body temperature onset threshold for whole-body evaporative heat loss (males: $36.61 \pm 0.11^{\circ} \mathrm{C}$ vs. females: $36.77 \pm 0.06^{\circ} \mathrm{C}, \mathrm{p}=0.242$ ) and cutaneous vasodilation (males: $36.65 \pm 0.11^{\circ} \mathrm{C}$ vs. females: $36.77 \pm 0.08^{\circ} \mathrm{C}, \mathrm{p}=0.363$ ) did not differ between groups. However, the thermosensitivity of the whole-body evaporative heat loss response was significantly greater in males compared to females $\left(795 \pm 85 \mathrm{~W} \cdot{ }^{\circ} \mathrm{C}^{-1}\right.$ vs. $553 \pm 77$ $\mathrm{W} \cdot{ }^{\circ} \mathrm{C}^{-1}, \mathrm{p}=0.051$, see Fig. $\left.4 \mathrm{~B}\right)$. In contrast, there were no significant differences in the thermosensitivity of the cutaneous vascular conductance response $\left(48 \pm 13 \% \mathrm{CVC} \cdot{ }^{\circ} \mathrm{C}^{-1}\right.$ vs. $38 \pm 5 \%$ CVC $\cdot{ }^{\circ} \mathrm{C}^{-1}, \mathrm{p}=0.447$, see Fig. $\left.5 \mathrm{~B}\right)$. 


\section{DISCUSSION}

This is the first study to examine the independent effect of sex on the thermoeffector responses of whole-body sudomotor activity and cutaneous vasodilation during exercise. The findings confirm previous observations that differences in sudomotor activity between males and females during exercise at a fixed percentage of maximum oxygen consumption are proportional to variations in metabolic heat production. However, contrary to our hypothesis, females demonstrate a lower wholebody sudomotor activity during exercise at a fixed rate of metabolic heat production (500 W). The physiological variable responsible for the lower sudomotor activity is a lower thermosensitivity of the response to changes in mean body temperature. In contrast, no differences in cutaneous vascular conductance were observed during exercise at a fixed rate of metabolic heat production. Collectively, these findings demonstrate that sex modulates the thermosensitivity of whole-body sudomotor activity during exercise, independently of differences in body mass, surface area and metabolic heat production.

Similar to previous studies which have examined sweating responses between males and females during exercise (Paolone et al., 1978; Frye \& Kamon, 1981; Horstman \& Christensen, 1982; Keatisuwan et al., 1996; Ichinose et al., 2009; Ichinose-Kuwahara et al., 2010), a lower rate of whole-body evaporative heat loss was observed in females when exercise was performed at a fixed percentage of maximum oxygen consumption. However, this response was paralleled by a lower rate of metabolic heat production (Fig. 2). These findings confirm previous observations that a lower sudomotor response in females during exercise at a fixed percentage of maximum oxygen consumption is proportional to a lower rate of metabolic heat production, and not necessarily due to physiological differences in temperature regulation (Gagnon et al., 2008). Nonetheless, the lower thermosensitivity of both the evaporative heat loss and cutaneous vascular 
conductance responses in females may suggest a physiological difference in the control of heat loss responses. However, greater exercise intensities (and therefore rates of metabolic heat production) are generally paralleled by a greater thermosensitivity of the sweating response (Montain et al., 1995; Kondo et al., 1998). In contrast, the thermosensitivity of the cutaneous vascular conductance response has generally been found to be unaffected by exercise intensity (Kondo et al., 2010). Yet, no differences between males and females were observed in the onset threshold and thermosensitivity of the cutaneous vascular response when exercise was performed at a fixed rate of metabolic heat production. Together, these observations suggest that that the greater thermosensitivities observed in males during exercise at a fixed percentage of maximum oxygen consumption were due to a greater rate of metabolic heat production.

In order to isolate the physiological variables of temperature regulation, consisting of the onset threshold and themosensitivity of thermoeffector responses, males and females were matched for body mass and surface area to account for the main physical characteristics which determine the individual heat stress response (Havenith et al., 1995; Havenith et al., 1998; del Coso et al., 2011). As such, the use of a fixed absolute heat production in constant environmental conditions provided a similar requirement for heat loss in both groups. Yet, females nonetheless exhibited a lower whole-body evaporative heat loss response compared to males, due to a lower thermosensitivity of the response, with no significant differences in the onset threshold. Consequently, these observations provide conclusive and novel evidence that sex can independently modulate whole-body sudomotor activity during exercise. A lower whole-body evaporative heat loss response for a given increase in mean body temperature suggests either: 1) altered afferent neural activity from peripheral (i.e. skin) and central (i.e. core) thermoreceptors causing a different integration of thermal information; 2) altered efferent neural activity for a given 
level of afferent input, and/or; 3) an altered effector response (i.e. sweat production) for a given level of efferent neural activity.

Ichinose-Kuwahara et al., (2010) recently suggested that sex differences in sweat gland function improvements elicited by exercise training are intensity-dependent. They reported a greater thermosensitivity of the sweating response in trained males compared to trained females. In contrast, no differences in thermosensitivity of the sweating response were observed between untrained males and untrained females. It should be noted, however, that these observations were made during exercise at fixed percentages (i.e. $35 \%, 50 \%$, and $65 \%$ ) of maximum oxygen consumption. Since males and females of various training status were compared, both sexes exercised at different external workloads (and therefore rates of metabolic heat production), which may have confounded their results (Gagnon et al., 2008; Schwiening et al., 2011). Nonetheless, their observations, combined with the results of the current study, may provide important insight into the mechanisms responsible for the lower evaporative heat loss and thermosensitivity of the response observed in females at a fixed rate of metabolic heat production.

The study by Ichinose-Kuwahara et al., (2010) suggests that sex can modulate human temperature regulation in an intensity-dependent manner, such that differences are only observed above a certain requirement for heat loss. If sex modulates the level of thermal afferent and/or efferent neural activity during exercise, it would be expected that the differences in thermosensitivity of the sweating response reported by IchinoseKuwahara et al., (2010) would not only be limited to trained males and females, but would also be evidenced between the untrained males and females. Since they only observed differences in thermosensitivity of the sweating response between the males and females which exercised at the highest external workloads (and therefore metabolic heat 
production), there must be a point at which the requirement for heat loss exceeds the capacity of the sweat gland to contribute to temperature regulation which, as evidenced from the current study, is lower in females compared to males. Consequently, it can be hypothesized that thermal integration and subsequent efferent neural activity is similar between sexes during exercise in the heat, with sex modulating the effector organ (i.e. sweat gland) and its response (i.e. sweat rate). This modulation may not be evidenced at lower rates of metabolic heat production (or external workloads), since the requirement for heat loss would not exceed the ability of the sweat gland to contribute to temperature regulation. This would explain the lack of differences in sweat rate and thermosensitivity of the sweating response between untrained males and females, while a difference was observed between trained males and females in the study by Ichinose-Kuwahara et al., (2010)

In contrast, the rate of metabolic heat production chosen in the current study (500 W) evidently exceeded the capacity of the sweat gland to contribute to temperature regulation in females, since the greater end-exercise esophageal and rectal temperatures could only be ascribed to differences in whole-body evaporative heat loss. Furthermore, a given level of thermal afferent and/or efferent activity would only be expected to result in a lower thermosensitivity of the effector response if a maximal effector output could not offset the overall requirement for heat loss. In this situation, the combination of a lower maximal effector output and a greater increase in body temperature would result in a lower thermosensitivity of the response, as observed for evaporative heat loss in females during the $500 \mathrm{~W}$ condition of the current study. This hypothesis is further supported by previous observations of a lower sweat output per gland, despite a greater number of active sweat glands in females during passive heating (Bar-Or et al., 1968; Inoue et al., 2005), as well as a lower eccrine sweat gland response to given doses of acetylcholine 
(Kahn \& Rothman, 1942; Gibson \& Shelley, 1948) and pilocarpine (Madeira et al., 2010). However, since these observations were made during passive heat stress or in the absence of heat stress, future studies are needed to directly asses the specific mechanism mediating the lower whole-body evaporative heat loss response observed during exercise in the current study. Furthermore, we are unable to determine at which rate of metabolic heat production this modulation occurs since we did not compare responses between males and females at progressively increasing rates of metabolic heat production. Future studies are warranted to address this hypothesis.

While whole-body sudomotor activity represents the main thermoeffector response, particularly during exercise in the heat, increases in skin blood flow also represent an important avenue for heat exchange. In contrast to the observed differences in sudomotor activity, no sex differences in cutaneous vascular conductance were observed. To our knowledge, only Inoue et al., (2005) have specifically examined sexrelated differences in skin blood flow during heat stress. Although their observations were made during passive heating, they observed similar skin blood flow responses between males and females on the forehead, chest, back and forearm. As such, the observations in the current study support these findings and extend them to exercise in the heat. However, Inoue et al., (2005) did note a greater skin blood flow response on the thigh in females. Furthermore, Hodges et al., (2010) have recently reported lower peak blood flow responses in females following a period of forearm occlusion. As such, future studies should consider examining potential sex-differences in regional skin blood flow during exercise at greater combinations of exercise intensity and/or environmental temperatures. 


\section{Perspectives}

The net outcome of the lower whole-body sudomotor thermosensitivity in females was evidenced as a greater esophageal and rectal temperature at the end of exercise performed at a fixed rate of metabolic heat production. Prior to the current study, it was generally thought that sex differences in temperature regulation were associated with differences in physical characteristics and not with physiological differences in heat loss responses (Sawka et al., 1996; Havenith, 2001b). The findings of the current study therefore have important implications. They warrant considering sex as an independent factor in modulating human temperature regulation, particularly when examining the effects of age, chronic disease and various physiological states (e.g. dehydration, orthostatic stress, etc.). Since the majority of human temperature regulation studies focus on male participants only, or do not include enough female participants to analyse potential sex differences, it is often unknown if and/or how changes in temperature regulation differ between males and females as a function of such factors. Considering sex as a modulator of human temperature regulation could lead to improvements in public health, particularly for heat exposure guidelines which do not currently provide sexspecific exposure limits for safe work in the heat (United States Army Center for Health Promotion and Preventive Medicine, 2003; American Conference of Industrial Hygienists, 2007).

\section{Considerations}

The current study employed whole-body direct calorimetry to assess sex-related differences in sudomotor activity, the main thermoeffector during exercise in the heat. The design of the calorimeter (high air mass flow), as well as the environmental conditions employed (low specific humidity) ensure that our measurements of whole- 
body evaporative heat loss reflect local changes in sweat rate. In fact, the lower wholebody evaporative heat loss observed in females was paralleled by a lower whole-body sweat production. It is also interesting to note that the onset thresholds for evaporative heat loss, expressed as a change from baseline rest, were generally lower than those reported for local measurements of sweat rate, which may be due to the sensitivity of whole-body calorimetry. Nonetheless, we acknowledge that measurements of local sweat rate and/or the number of active sweat glands would provide insight into the specific mechanisms (number of glands vs. sweat output per gland) responsible for the lower whole-body evaporative heat loss response observed in females. It is possible that differences in absolute maximum oxygen consumption ("fitness") between males and females may explain the observed results. Several observations argue against this reasoning however. First, the differences in absolute maximum oxygen consumption between sexes in the current study are due to differences in the amount of metabolically active tissue and not necessarily to differences in training status, since no differences were observed when maximum oxygen consumption was expressed as a function of lean body mass. Second, resting heart rates and core temperatures, a strong indication of training status, did not differ between groups. Third, recent evidence suggests that maximum oxygen consumption itself does not modulate absolute levels of sweat production, nor the thermosensitivity of the sweating response (Jay et al., 2011). Finally, female participants performed the experimental trials between the first and tenth day after the onset of menses, or during the no pill/placebo period of oral contraceptive use. These time periods were primarily chosen to ensure low levels of progesterone, which has been associated with an elevated resting core temperature and parallel increases in thermoeffector onset thresholds (Stephenson \& Kolka, 1985). However, it is possible that elevations in oestrogen, which have been shown to decrease resting core temperature and 
onset thresholds of thermoeffector responses (Stephenson \& Kolka, 1999), may have occurred by the tenth day after the onset of menses. It is equally possible that progestin exposure may not have completely subsided during the no pill/placebo period. Nonetheless, baseline esophageal temperature and onset thresholds of thermoeffector responses did not differ between sexes.

\section{CONCLUSION}

The current study examined the effect of sex on whole-body sudomotor activity and cutaneous vascular conductance during exercise in the heat. When exercise was performed at a fixed rate of absolute metabolic heat production, females demonstrated a lower evaporative heat loss, and lower thermosensitivity of the response, despite a similar requirement for heat loss compared to males. Importantly, these results were not due to differences in physical characteristics, as both sexes were matched for body mass and surface area. In contrast, no differences in cutaneous vascular conductance were observed. These results demonstrate that sex modulates whole-body sudomotor activity during exercise in the heat, independently of differences in body mass, surface area, and rate of metabolic heat production. 


\section{REFERENCES}

American Conference of Industrial Hygienists (ACGIH). (2007). Heat Stress and Strain: TLV Physical Agents Documentation, pp. 1-36. ACGIH, Cincinnati, OH.

Avellini BA, Kamon E \& Krajewski JT. (1980a). Physiological responses of physically fit men and women to acclimation to humid heat. $J$ Appl Physiol 49, 254-261.

Avellini BA, Shapiro Y, Pandolf KB, Pimental NA \& Goldman RF. (1980b). Physiological responses of men and women to prolonged dry heat exposure. Aviat Space Environ Med 51, 1081-1085.

Bar-Or O, Lundegren HM, Magnusson LI \& Buskirk ER. (1968). Distribution of HeatActivated Sweat Glands in Obese and Lean Men and Women. Hum Biol 40, 235-248.

Bos WJW, Van Goudoever J, Van Montfrans GA, Van den Meiracker AH \& Wesseling KH. (1996). Reconstruction of brachial artery pressure from noninvasive finger pressure measurement. Circulation 94, 1870-1875.

Burse RL. (1979). Sex differences in human thermoregulatory response to heat and cold stress. Hum Factors 21, 687-699.

Canadian Society for Exercise Physiology. (1986). Chapter II: Determination of Aerobic Power. In Certified Fitness Appraiser Resource Manual pp. 1-32. CSEP, Gloucester, Ontario.

Cheuvront SN, Bearden SE, Kenefick RW, Ely BR, Degroot DW, Sawka MN \& Montain SJ. (2009). A simple and valid method to determine thermoregulatory sweating threshold and sensitivity. J Appl Physiol 107, 69-75.

Davies CT. (1979). Thermoregulation during exercise in relation to sex and age. Eur $J$ Appl Physiol 42, 71-79.

del Coso J, Hamouti N, Ortega JF, Fernandez-Elias VE \& Mora-Rodriguez R. (2011). Relevance of individual characteristics for thermoregulation during exercise in a hot-dry environment. Eur J Appl Physiol 111, 2173-2181.

DuBois D \& DuBois EF. (1916). A formula to estimate the approximate surface area if height and weight be known. Arch Intern Med 17, 863-871.

Frye AJ \& Kamon E. (1981). Responses to dry heat of men and women with similar aerobic capacities. J Appl Physiol 50, 65-70.

Gagnon D, Dorman LE, Jay O, Hardcastle SG \& Kenny GP. (2009). Core temperature differences between sexes during intermittent exercise: physical considerations. Eur $J$ Appl Physiol 105, 453-461.

Gagnon D, Jay O, Lemire B \& Kenny GP. (2008). Sex-related differences in evaporative heat loss: the importance of metabolic heat production. Eur J Appl Physiol 104, 821-829. 
Gibson TE \& Shelley WB. (1948). Sexual and racial differences in the response of sweat glands to acetylcholine and pilocarpine. J Invest Dermatol 11, 137-142.

Gizdulich P, Imholz BPM, van den Meiracker AH, Parati G \& Wesseling KH. (1996). Finapres tracking of systolic pressure and baroreflex sensitivity improved by waveform filtering. J Hypertens 14, 243-250.

Gizdulich P, Prentza A \& Wesseling KH. (1997). Models of brachial to finger pulse wave distortion and pressure decrement. Cardiovasc Res 33, 698-705.

Hardy J \& DuBois E. (1938). The technique of measuring radiation and convection. $J$ Nutr 15, 461-475.

Havenith G. (2001a). Human surface to mass ratio and body core temperature in exercise heat stress - a concept revisited. J Therm Biol 26, 387-393.

Havenith G. (2001b). Individualized model of human thermoregulation for the simulation of heat stress response. J Appl Physiol 90, 1943-1954.

Havenith G, Coenen JM, Kistemaker L \& Kenney WL. (1998). Relevance of individual characteristics for human heat stress response is dependent on exercise intensity and climate type. Eur J Appl Physiol 77, 231-241.

Havenith G, Luttikholt VG \& Vrijkotte TG. (1995). The relative influence of body characteristics on humid heat stress response. Eur J Appl Physiol 70, 270-279.

Hertzman AB, Randall WC, Peiss CN \& Seckendorf R. (1952). Regional rates of evaporation from the skin at various environmental temperatures. J Appl Physiol 5, 153161.

Hodges GJ, Sharp L, Clements RE, Goldspink DF, George KP \& Cable NT. (2010). Influence of age, sex, and aerobic capacity on forearm and skin blood flow and vascular conductance. Eur J Appl Physiol 109, 1009-1015.

Horstman DH \& Christensen E. (1982). Acclimatization to dry heat: active men vs. active women. J Appl Physiol 52, 825-831.

Ichinose-Kuwahara T, Inoue Y, Iseki Y, Hara S, Ogura Y \& Kondo N. (2010). Sex differences in the effects of physical training on sweat gland responses during a graded exercise. Exp Physiol 95, 1026-1032.

Inoue Y, Tanaka Y, Omori K, Kuwahara T, Ogura Y \& Ueda H. (2005). Sex- and menstrual cycle-related differences in sweating and cutaneous blood flow in response to passive heat exposure. Eur J Appl Physiol 94, 323-332.

Jay O, Bain AR, Deren TM, Sacheli M \& Cramer MN. (2011). Large differences in peak oxygen uptake do not independently alter changes in core temperature and sweating during exercise. Am J Physiol Regul Integr Comp Physiol 301, 832-841, 2011 
Kahn D \& Rothman S. (1942). Sweat response to acetylcholine. J Invest Dermatol 5, 431-444.

Keatisuwan W, Ohnaka T \& Tochihara Y. (1996). Physiological responses of men and women during exercise in hot environments with equivalent WBGT. Appl Hum Sci 15, 249-258.

Kenney WL. (1985). A review of comparative responses of men and women to heat stress. Environ Res 37, 1-11.

Kondo N, Nishiyasu T, Inoue Y \& Koga S. (2010). Non-thermal modification of heatloss responses during exercise in humans. Eur J Appl Physiol 110, 447-458.

Kondo N, Takano S, Aoki K, Shibasaki M, Tominaga H \& Inoue Y. (1998). Regional differences in the effect of exercise intensity on thermoregulatory sweating and cutaneous vasodilation. Acta Physiol Scand 164, 71-78.

Madeira LG, da Fonseca MA, Fonseca IA, de Oliveira KP, Passos RL, Machado-Moreira CA \& Rodrigues LO. (2010). Sex-related differences in sweat gland cholinergic sensitivity exist irrespective of differences in aerobic capacity. Eur J Appl Physiol 109, 93-100.

McLellan TM. (1998). Sex-related differences in thermoregulatory responses while wearing protective clothing. Eur J Appl Physiol 78, 28-37.

Montain SJ, Latzka WA \& Sawka MN. (1995). Control of thermoregulatory sweating is altered by hydration level and exercise intensity. J Appl Physiol 79, 1434-1439.

Moran DS, Shapiro Y, Laor A, Izraeli S \& Pandolf KB. (1999). Can gender differences during exercise-heat stress be assessed by the physiological strain index? Am J Physiol 276, $1798-1804$.

Morimoto T, Slabochova Z, Naman RK \& Sargent F. (1967). Sex differences in physiological reactions to thermal stress. J Appl Physiol 22, 526-532.

Nadel ER, Bullard RW \& Stolwijk JA. (1971a). Importance of skin temperature in the regulation of sweating. J Appl Physiol 31, 80-87.

Nadel ER, Mitchell JW, Saltin B \& Stolwijk JA. (1971b). Peripheral modifications to the central drive for sweating. J Appl Physiol 31, 828-833.

Nishi Y. (1981). Measurement of thermal balance in man. In: Bioengineering, thermal physiology and comfort, edited by Cena K and Clark J New York, NY: Elsevier, , pp. 2939.

Nunneley SA. (1978). Physiological responses of women to thermal stress: a review. Med Sci Sports Exerc 10, 250-255.

Paolone AM, Wells CL \& Kelly GT. (1978). Sexual variations in thermoregulation during heat stress. Aviat Space Environ Med 49, 715-719. 
Penaz J. (1973). Photoelectric measurement of blood pressure, volume and flow in the finger. . Digest 10th Int Conf Med Biol Engng, 104.

Reardon FD, Leppik KE, Wegmann R, Webb P, Ducharme MB \& Kenny GP. (2006). The Snellen human calorimeter revisited, re-engineered and upgraded: design and performance characteristics. Med Biol Eng Comput 44, 721-728.

Sawka MN, Wenger CB \& Pandolf KB. (1996). Thermoregulatory responses to acute exercise-heat stress and heat acclimation. In Handbook of physiology Section 4: Environmental physiology, ed. Fregly MJ \& Blatteis CM, pp. 157-186. Oxford University press, New York, NY.

Schwiening CJ, Mason MJ \& Thompson M. (2011). Absolute power, not sex, promotes perspiration. Exp Physiol 96, 556-558.

Shapiro Y, Pandolf KB, Avellini BA, Pimental NA \& Goldman RF. (1981). Heat balance and transfer in men and women exercising in hot-dry and hot-wet conditions. Ergonomics 24, 375-386.

Shapiro Y, Pandolf KB \& Goldman RF. (1980). Sex differences in acclimation to a hotdry environment. Ergonomics 23, 635.

Shibasaki M, Wilson TE \& Crandall CG. (2006). Neural control and mechanisms of eccrine sweating during heat stress and exercise. J Appl Physiol 100, 1692-1701.

Stephenson LA \& Kolka MA. (1985). Menstrual cycle phase and time of day alter reference signal controlling arm blood flow and sweating. Am J Physiol 249, R186-191.

Stephenson LA \& Kolka MA. (1999). Esophageal temperature threshold for sweating decreases before ovulation in premenopausal women. J Appl Physiol 86, 22-28.

United States Army Center for Health Promotion and Preventive Medicine. (2003). Heat stress control and heat casualty management, technical bulletin, medical 507, pp. 1-72. Headquarters, Department of the Army and Airforce, Washington, DC.

Weinman KP, Slabochova Z, Bernauer EM, Morimoto T \& Sargent F. (1967). Reactions of men and women to repeated exposure to humid heat. J Appl Physiol 22, 533-538.

Wenger CB. (1972). Heat of evaporation of sweat: thermodynamic considerations. J Appl Physiol 32, 456-459.

Wesseling KH, de Wit B, van der Hoeven GMA, van Goudoever J \& Settels JJ. (1995). Physiocal, calibrating finger vascular physiology for Finapres. Homeostasis 36, 67-82.

Wyndham CH, Morrison JF \& Williams CG. (1965). Heat reactions of male and female Caucasians. J Appl Pysiol 20, 357-364. 


\section{AUTHOR CONTRIBUTIONS}

All authors contributed to the conception and design of the experiments, to the collection, analysis and interpretation of data, as well as to the drafting and critical revising of the manuscript. All authors have approved the final version of the manuscript. All experiments were performed at the University of Ottawa.

\section{ACKNOWLEDGEMENTS}

The current study was performed by D.G., in partial fulfillment for the degree of Doctor of Philosophy from the University of Ottawa. D.G. is supported by an Alexander Graham Bell Canadian Graduate Scholarship from the Natural Sciences and Engineering Research Council. The current work was supported by the Natural Sciences and Engineering Research Council (RGPIN-298159-2004 and RGPIN-298159-2009) and Leaders Opportunity Fund from the Canada Foundation for Innovation (22529). G.P.K. is supported by a University of Ottawa Research Chair in Environmental Physiology. The authors wish to thank Dr. Ollie Jay and Dr. Craig Crandall for providing critical input into the development of this work, as well as all the participants who volunteered for the present study. 
Table 1. Participant characteristics.

\begin{tabular}{|c|c|c|c|c|c|c|c|c|c|c|}
\hline Sex & $\begin{array}{l}\text { Age } \\
\text { (yrs) }\end{array}$ & $\begin{array}{l}\text { Body mass } \\
\quad(\mathrm{kg})\end{array}$ & $\begin{array}{l}\text { Height } \\
(\mathrm{cm})\end{array}$ & $\begin{array}{c}A_{D} \\
\left(\mathrm{~m}^{2}\right)\end{array}$ & $\begin{array}{l}\text { Fat } \\
(\mathrm{kg})\end{array}$ & $\begin{array}{l}\text { Lean mass } \\
(\mathrm{kg})\end{array}$ & $\begin{array}{c}\text { Bone } \\
(\mathrm{kg})\end{array}$ & $\begin{array}{l}\mathrm{VO}_{2 \max } \\
\left(\mathrm{L} \cdot \mathrm{min}^{-1}\right)\end{array}$ & $\begin{array}{c}\dot{\mathrm{VO}}_{2 \max } \\
\left(\mathrm{mL} \cdot \mathrm{kg}^{-1} \cdot \mathrm{min}^{-1}\right)\end{array}$ & $\begin{array}{c}\dot{\mathrm{VO}}_{2 \max } \\
\left(\mathrm{mL} \cdot \mathrm{kg}_{\mathrm{LBM}}{ }^{-1} \cdot \min ^{-1}\right)\end{array}$ \\
\hline Males & $\begin{array}{l}24 \\
\pm 4\end{array}$ & $\begin{array}{l}66.4 \\
\pm 4.6\end{array}$ & $\begin{array}{l}173 \\
\pm 6\end{array}$ & $\begin{array}{c}1.79 \\
\pm 0.08\end{array}$ & $\begin{array}{c}6.1 \\
\pm 2.2 *\end{array}$ & $\begin{array}{c}57.2 \\
\pm 4.6^{*}\end{array}$ & $\begin{array}{c}3.1 \\
\pm 0.3^{*}\end{array}$ & $\begin{array}{c}3.83 \\
\pm 0.48^{*}\end{array}$ & $\begin{array}{c}57.8 \\
\pm 6.3^{*}\end{array}$ & $\begin{array}{l}66.9 \\
\pm 6.1\end{array}$ \\
\hline Females & $\begin{array}{l}27 \\
\pm 4\end{array}$ & $\begin{array}{l}66.8 \\
\pm 5.0\end{array}$ & $\begin{array}{l}168 \\
\pm 5\end{array}$ & $\begin{array}{c}1.76 \\
\pm 0.08\end{array}$ & $\begin{array}{l}17.1 \\
\pm 6.5\end{array}$ & $\begin{array}{l}46.9 \\
\pm 4.8\end{array}$ & $\begin{array}{c}2.7 \\
\pm 0.3\end{array}$ & $\begin{array}{c}3.09 \\
\pm 0.31\end{array}$ & $\begin{array}{l}46.7 \\
\pm 6.4\end{array}$ & $\begin{array}{l}66.0 \\
\pm 6.5\end{array}$ \\
\hline
\end{tabular}

$A_{D}$, body surface area; $\dot{\mathrm{V}} \mathrm{O}_{2 \max }$, maximum oxygen consumption; $\mathrm{LBM}$, lean body mass. ${ }^{*}$ Significantly different from females $(P \leq 0.05)$. Values are mean \pm standard deviation. 
Table 2. Baseline and end-exercise esophageal and rectal temperatures for males and females during exercise at a fixed percentage of $\dot{\mathrm{VO}}_{2 \max }(50 \%)$ and a fixed rate of absolute heat production $(500 \mathrm{~W})$.

\begin{tabular}{cccccc}
\hline Condition & Sex & $\begin{array}{c}\text { Baseline } \mathrm{T}_{\mathrm{es}} \\
\left({ }^{\circ} \mathrm{C}\right)\end{array}$ & $\begin{array}{c}\text { End-Ex } \\
\left({ }^{\circ} \mathrm{C}\right)\end{array}$ & $\begin{array}{c}\text { Baseline } \mathrm{T}_{\mathrm{re}} \\
\left({ }^{\circ} \mathrm{C}\right)\end{array}$ & $\begin{array}{c}\text { End-Ex T } \\
\left({ }^{\circ} \mathrm{C}\right)\end{array}$ \\
\hline \multirow{2}{*}{$50 \%$} & Males & $36.90 \pm 0.07$ & $37.81 \pm 0.08$ & $36.90 \pm 0.07$ & $38.10 \pm 0.09$ \\
& Females & $36.93 \pm 0.09$ & $37.80 \pm 0.11$ & $36.97 \pm 0.08$ & $38.19 \pm 0.07$ \\
& & & & & \\
$500 \mathrm{~W}$ & Males & $36.65 \pm 0.11$ & $37.54 \pm 0.08^{*}$ & $36.78 \pm 0.10$ & $37.89 \pm 0.07^{*}$ \\
& Females & $36.83 \pm 0.09$ & $38.13 \pm 0.19$ & $36.86 \pm 0.08$ & $38.35 \pm 0.17$
\end{tabular}

End-Ex, end-exercise, $\mathrm{T}_{\mathrm{es}}$, esophageal temperature; $\mathrm{T}_{\mathrm{re}}$, rectal temperature. ${ }^{*}$ Significantly different from females $(P \leq 0.05)$. Values are mean \pm standard error. 

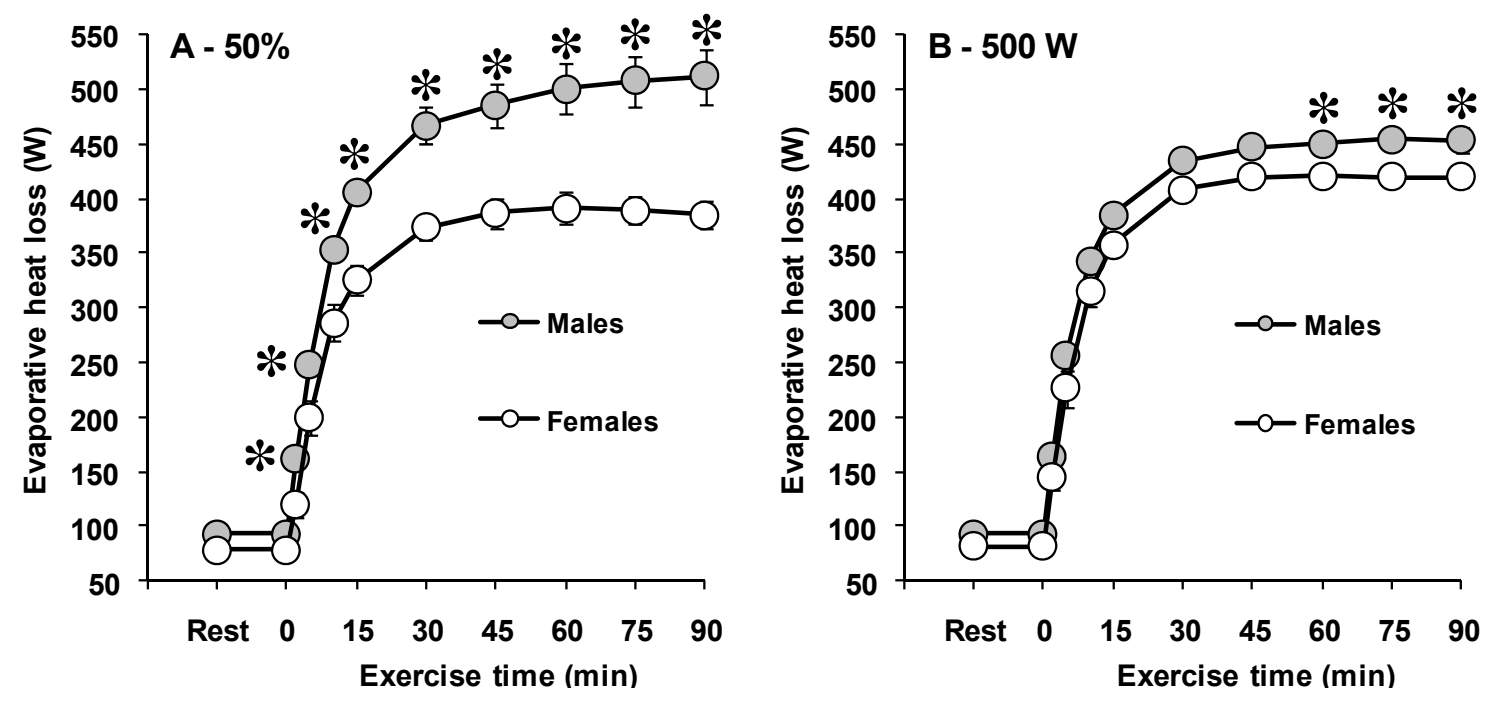

Figure 1. Sex-related differences in evaporative heat loss during exercise performed at either a fixed percentage of maximum oxygen consumption $(50 \%$, panel $\mathrm{A})$, or a fixed rate of metabolic heat production $(500 \mathrm{~W}$, panel $\mathrm{B})$. Values are mean \pm standard error. *Significantly different from females $(P \leq 0.05)$. 


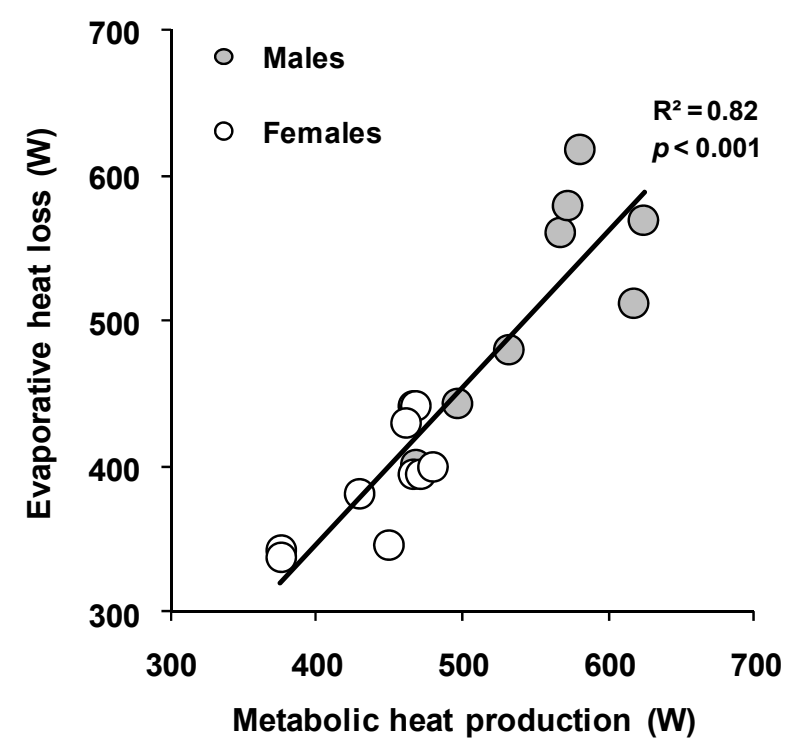

Figure 2. Relationship between evaporative heat loss and rate of metabolic heat production for males and females during exercise performed at a fixed percentage of maximum oxygen consumption. 

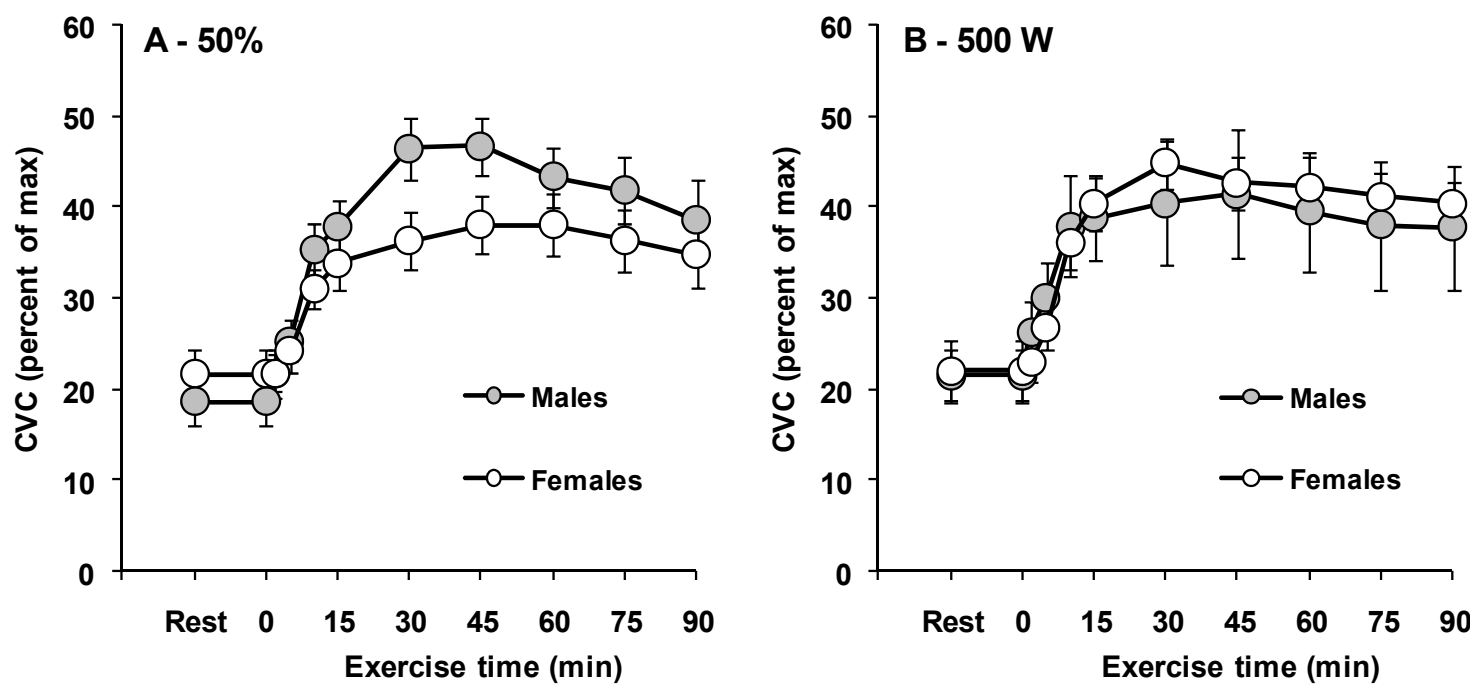

Figure 3. Sex-related differences in the cutaneous vascular response (CVC) during exercise performed at either a fixed percentage of maximum oxygen consumption $(50 \%$, panel A), or a fixed rate of metabolic heat production $(500 \mathrm{~W}$, panel B). Values are mean \pm standard error. 

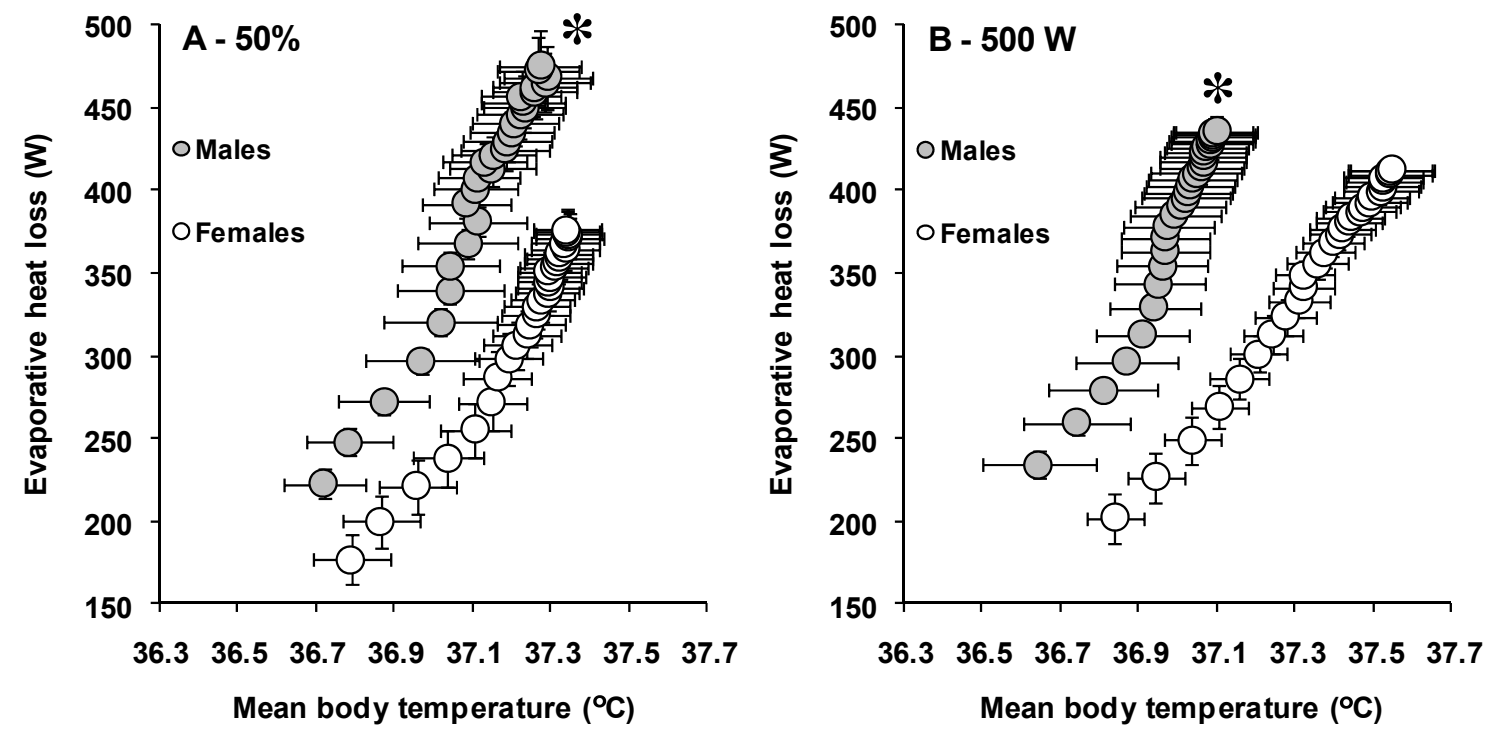

Figure 4. Sex-related differences in the sensitivity of the evaporative heat loss response to changes in mean body temperature during exercise performed at either a fixed percentage of maximum oxygen consumption $(50 \%$, panel $\mathrm{A})$, or a fixed rate of metabolic heat production $(500 \mathrm{~W}$, panel B). The data represent the average slopes of the linear portion of the response. Values are mean \pm standard error. *Significantly different slope from females $(P \leq 0.05)$. 

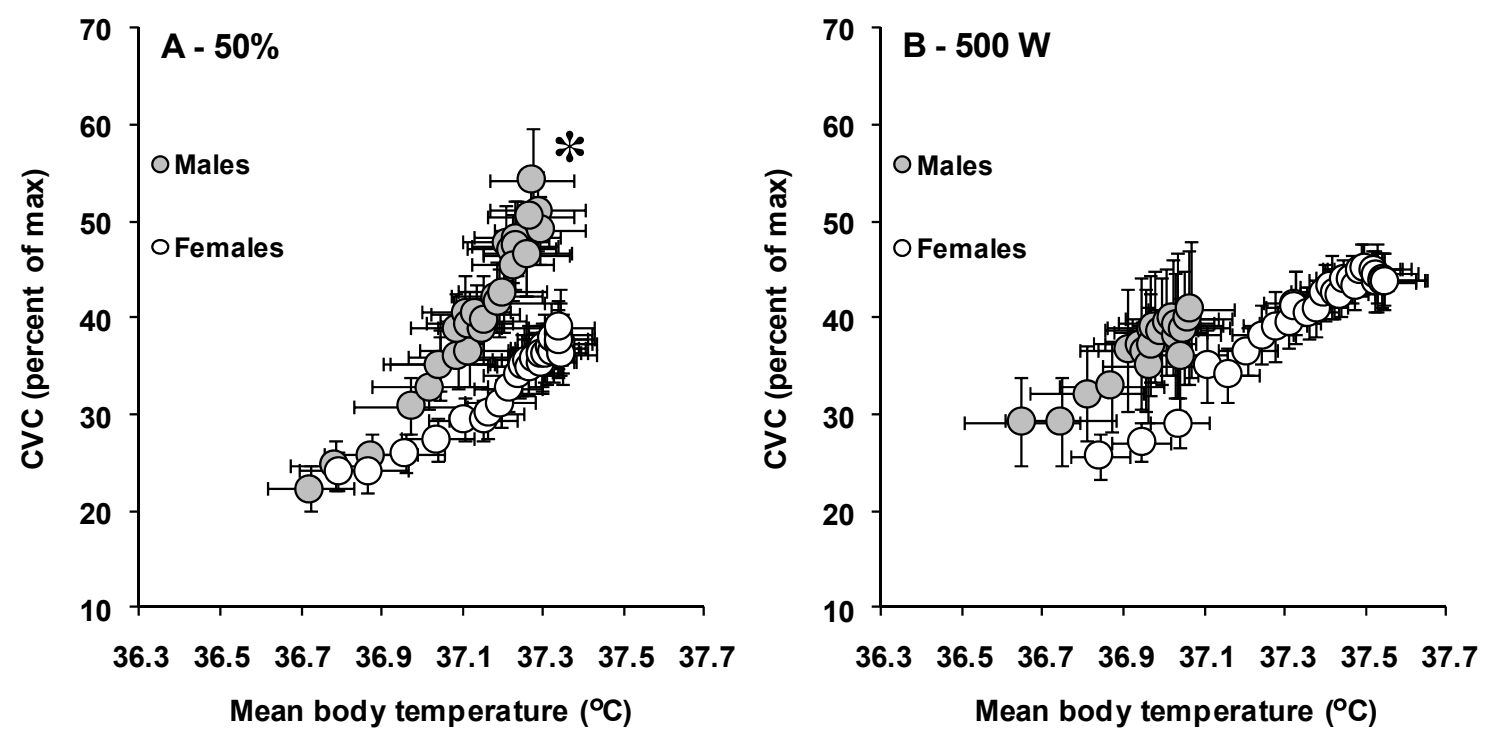

Figure 5. Sex-related differences in the sensitivity of the cutaneous vascular conductance (CVC) response to changes in mean body temperature during exercise performed at either a fixed percentage of maximum oxygen consumption $(50 \%$, panel $\mathrm{A})$, or a fixed rate of metabolic heat production $(500 \mathrm{~W}$, panel B). The data represent the average slopes of the linear portion of the response. Values are mean \pm standard error. *Significantly different slope from females $(P \leq 0.05)$. 


\title{
3.2 Thesis article \#2
}

\section{Sex-differences in thermoeffector responses during exercise at fixed requirements for heat loss.}

\author{
Final version of article published in the Journal of Applied Physiology, 113(5): 746-757, 2012 \\ (Appendix B) \\ Daniel Gagnon and Glen P. Kenny \\ Human and Environmental Physiology Research Unit, School of Human Kinetics, \\ University of Ottawa, Ottawa, Canada
}

Author contributions: The current study was performed by D.G., in partial fulfillment for the degree of Doctor of Philosophy from the University of Ottawa. All authors contributed to the conception and design of the experiments, to the collection, analysis and interpretation of data, as well as to the drafting and critical revising of the manuscript. All authors have approved the final version of the manuscript. All experiments were performed at the University of Ottawa.

Running head: Sex-differences in heat loss during exercise. 


\section{ABSTRACT}

To assess potential mechanisms responsible for the lower sudomotor thermosensitivity in females during exercise, we examined sex-differences in sudomotor function and skin blood flow during exercise performed at progressive increases in the requirement for heat loss. Eight males and eight females cycled at rates of metabolic heat production of 200 , 250 , and $300 \mathrm{~W} \cdot \mathrm{m}^{-2}$ of body surface area, each rate being performed sequentially for 30 min. The protocol was performed in a direct calorimeter to measure evaporative heat loss (EHL) and in a thermal chamber to measure local sweat rate (ventilated capsule, LSR), skin blood flow (laser-Doppler, SkBF), sweat gland activation (modified iodine-paper technique) and sweat gland output (SGO) on the back, chest, and forearm. Despite a similar requirement for heat loss between sexes, significantly lower increases in EHL and LSR were observed in females $(\mathrm{p} \leq 0.001)$. Sex-differences in EHL and LSR were not consistently observed during the first and second exercise periods, while EHL (348 \pm 13 vs. $\left.307 \pm 9 \mathrm{~W} \cdot \mathrm{m}^{-2}\right)$, and LSR on the back $\left(1.61 \pm 0.07\right.$ vs. $\left.1.20 \pm 0.09 \mathrm{mg} \cdot \mathrm{min}^{-1} \cdot \mathrm{cm}^{-2}\right)$, chest $\left(1.33 \pm 0.06\right.$ vs. $\left.1.08 \pm 0.09 \mathrm{mg} \cdot \mathrm{min}^{-1} \cdot \mathrm{cm}^{-2}\right)$ and forearm $(1.53 \pm 0.07$ vs. $1.20 \pm$ $0.06 \mathrm{mg} \cdot \mathrm{min}^{-1} \cdot \mathrm{cm}^{-2}$ ) became significantly greater in males during the last exercise period $(p<0.05)$. At each site, differences in LSR were solely due to a greater SGO in males, as opposed to differences in sweat gland activation. In contrast, no sex-differences in SkBF were observed throughout the exercise period. The current study demonstrates that sexdifferences in sudomotor function are only evidenced beyond a certain requirement for heat loss, solely through differences in sweat gland output. In contrast, the lower EHL and LSR in females are not paralleled by a lower skin blood flow response.

Keywords: Skin blood flow, Sweat, Temperature regulation, Thermoregulation. 


\section{INTRODUCTION}

During exercise, increases in core and mean skin temperatures provide afferent neural information initiating (i.e. onset threshold) sweat production and increases in skin blood flow, their output increasing proportionally (i.e. thermosensitivity) to the rise in core and mean skin temperatures $(20,51)$. Together, the onset threshold and thermosensitivity represent the physiological mechanisms of temperature regulation. Recently, we observed a lower thermosensitivity of whole-body evaporative heat loss in females during exercise, with no differences in the onset threshold (16). In contrast, no sex-differences were observed in skin vascular conductance (16). Importantly, the lower sudomotor thermosensitivity in females was independent of differences in physical characteristics and rate of metabolic heat production, suggesting that true physiological differences exist between sexes.

A lower thermosensitivity of whole-body evaporative heat loss could be related to either a central (neural activity) and/or peripheral (effector response) modulation of temperature regulation. The onset threshold of thermoeffector responses has typically been used to represent central modifications of temperature regulation, while the thermosensitivity is thought to represent a peripheral modulation (36). Additionally, it is generally accepted that any factor which exhibits a central modulation of temperature regulation must shift the onset threshold of both local sweat production and skin blood flow (18). For example, factors such as sex hormones (47), hyperosmolality (41), and heat acclimation (1) consistently shift the onset threshold of both heat loss responses, with inconsistent (acclimation) or no changes (sex hormones, osmolality) in thermosensitivity. Finally, if sex modulates the level of thermal afferent and/or efferent neural activity, sex-differences in thermoeffector responses should be evident at any 
combination of exercise intensity and environmental conditions (i.e. requirement for heat loss).

In contrast, a peripheral modulation of sudomotor function would be expected to result in sex-differences in the thermosensitivity of the response, without any differences in the onset threshold for sweating and skin blood flow. Furthermore, the lower sweat rate in females would be associated with a lower sweat gland output (39), and differences in local sweat rate and/or evaporative heat loss would only be evidenced above a certain requirement for heat loss. Although a number of studies have examined sex-differences in sweat rate during exercise, insight into potential physiological differences between males and females are limited due to employed experimental protocols $(15,42)$ and a lack of considering confounding physical differences (13). Nonetheless, recent observations suggest that sex-related differences in local sweat rate may only be observed above a certain exercise intensity (25), suggesting that sex-differences in sudomotor function are not evidenced at all requirements for heat loss. To our knowledge, however, no study has specifically examined whether sex-differences in sudomotor function and/or skin blood flow are only evidenced above a certain requirement for heat loss during exercise. Such information would provide valuable physiological insight to determine whether the lower sudomotor thermosensitivity observed in females during exercise is associated with a central and/or peripheral modulation of temperature regulation.

The current study therefore examined sex-differences in the onset threshold and thermosensitivity of sudomotor function (local and whole-body) and skin blood flow during exercise performed at increasing requirements for heat loss. To determine if sexdifferences in sudomotor function are only evidenced above a certain requirement for heat loss, the experimental paradigm included one continuous exercise bout divided into three consecutive periods performed at increasing levels of metabolic heat production. 
We hypothesised that sex-differences in sudomotor function would only be evidenced at the highest requirement for heat loss. Furthermore, we hypothesised that these differences would be paralleled by a lower thermosensitivity of the response, without any differences in the onset threshold. In contrast, we hypothesised that no sex-differences in skin blood flow would be observed, both in terms of the onset threshold and thermosensitivity. 


\section{METHODS}

\section{Ethical approval}

The current experimental protocol was approved by the University of Ottawa Health Sciences and Science Research Ethics Board. Written informed consent was obtained from all volunteers prior to their participation in the study.

\section{Participants}

Expected sex-differences in end-exercise whole-body evaporative heat loss (16) and local sweat rate $(25)$ were used to calculate $(\beta=0.8, \alpha=0.05)$ a minimum sample size of 6 participants in each group, assuming an effect of $20 \%$ and standard deviation of $12 \%$. Sixteen participants, 8 males and 8 females, were recruited within the University community and volunteered for the study. To minimise the influence of differences in hormonal status across the menstrual cycle, female participants performed each experimental session within the first and tenth day after the onset of their self-reported menses. Three female participants were taking oral contraceptives, one used Aviane ${ }^{\mathrm{TM}}$ (pill 1: $0.1 \mathrm{mg}$ levonorgestrel/0.020 mg ethinyl estradiol, pill 2: placebo), another used Tri-Cyclen $^{\mathrm{TM}}$ (pill 1: $0.180 \mathrm{mg}$ norgestimate/0.025 mg ethinyl estradiol, pill 2: $0.215 \mathrm{mg}$ norgestimate $/ 0.025 \mathrm{mg}$ ethinyl estradiol, pill 3: $0.250 \mathrm{mg}$ norgestimate $/ 0.025 \mathrm{mg}$ ethinyl estradiol, pill 4: placebo) and the other used Triquilar ${ }^{\circledR}$ (pill 1: $50 \mu \mathrm{g}$ levonorgestrel/30 $\mu \mathrm{g}$ ethinyl estradiol, pill 2: $75 \mu \mathrm{g}$ levonorgestrel/40 $\mu \mathrm{g}$ ethinyl estradiol, pill 3: $125 \mu \mathrm{g}$ levonorgestrel/30 $\mu \mathrm{g}$ ethinyl estradiol, pill 4: placebo). These three female participants performed the experimental sessions during the no pill/placebo phase of oral contraceptive use. Hormonal status was confirmed by taking a venous blood sample on the day of each experimental session. None of the experimental sessions for female participants had to be withdrawn or repeated based on blood sample results. Participants 
were healthy, non-smoking, and free of any known cardiovascular, metabolic and respiratory diseases. Participant characteristics are presented in Table 1.

\section{Experimental Design}

All participants volunteered for one preliminary and two experimental sessions. During the preliminary session, training history, body height, mass, and density, as well as maximum oxygen uptake were determined. Training history was assessed by having the participants quantify their physical activity levels using the quantitative (3 month) and seven day physical activity recall questionnaires proposed by Kohl et al. (30). Body height was determined using a stadiometer (Detecto, model 2391, Webb City, MO, USA), while body mass was measured using a digital high-performance weighing terminal (model CBU150X, Mettler Toledo Inc., Mississauga, ON, CAN). Body surface area was subsequently calculated from the measurements of body height and mass (9). Body density was measured using the hydrostatic weighing technique, and used to calculate body fat percentage (46). Maximum oxygen uptake was determined by indirect calorimetry (MOXUS system, Applied Electrochemistry, Pittsburgh, PA, USA) during a progressive incremental exercise protocol (5) performed on an upright seated constantload cycle ergometer (Corival, Lode B.V., Groningen, Netherlands).

For each experimental session, participants reported to the laboratory between $7 \mathrm{~h} 00$ and $9 \mathrm{~h} 00$. The participants were asked to drink $500 \mathrm{~mL}$ of water the night prior to, as well as the morning of, each experimental session and to refrain from alcohol, caffeine, and exercise $24 \mathrm{~h}$ prior to experimentation. Upon arrival at the laboratory, the participants provided a urine sample, weighed themselves nude, and changed into shorts, sandals, as well as a sports bra for female participants. They subsequently sat upright for a $60 \mathrm{~min}$

instrumentation period at an ambient room temperature of $24^{\circ} \mathrm{C}$. Following instrumentation, participants entered a thermal chamber for one of the experimental 
sessions, while they entered a whole-body calorimeter for the other session. The order in which the sessions were performed was balanced both within and between sexes. The thermal chamber was regulated to an ambient air temperature of $40.1 \pm 0.2^{\circ} \mathrm{C}$, a relative humidity of $24 \pm 2 \%\left(\sim 11.31 \mathrm{~g} \cdot \mathrm{kg}^{-1}\right.$ specific humidity), and a fan placed in front of the participant provided an airflow of $1.04 \pm 0.20 \mathrm{~m} \cdot \mathrm{s}^{-1}$. The calorimeter was regulated to an ambient air temperature of $40.08 \pm 0.15^{\circ} \mathrm{C}$, a specific humidity of $5.47 \pm 2.82 \mathrm{~g} \cdot \mathrm{kg}^{-1}$ $\left(\sim 12 \%\right.$ relative humidity), and an air mass flow of $7.74 \pm 0.25 \mathrm{~kg}$ of air $\cdot \mathrm{min}^{-1}$. In both cases, participants rested for a $30 \mathrm{~min}$ baseline period in the upright seated posture. Subsequently, they performed 90 min of continuous upright seated cycling exercise. The exercise period was performed at fixed rates of metabolic heat production equal to 200, 250, and $300 \mathrm{~W} \cdot \mathrm{m}^{-2}$, each level being $30 \mathrm{~min}$ in duration. The participants did not stop exercising between each exercise period. At the end of exercise during the experimental session performed in the thermal chamber, all instrumentation was removed except for the laser-Doppler flow probes, and the participants remained seated for a 45 min local heating period to determine maximum skin blood flow (see details below). A final nude body weight measurement was obtained at the end of the experimental session.

Body mass, by influencing rate of metabolic heat production, and body surface area, by affecting heat exchange, are the main physical characteristics that can influence local and whole-body sweat rate during exercise (22). As such, we employed fixed rates of metabolic heat production during non-weight bearing exercise (i.e. cycling) to negate any influence of differences in body mass, while we adjusted the rate of metabolic heat production per unit of surface area to negate any differences in the surface area available for heat exchange. Previous studies have shown that the level of local and whole-body sweat rate achieved during exercise is determined by the ratio of the required evaporation for heat balance $\left(\mathrm{E}_{\mathrm{req}}\right)$ and the maximum evaporation possible $\left(\mathrm{E}_{\max }\right)$ in a given 
environment $(2,43)$. Since males and females performed the exercise bout in the same environmental conditions (producing the same $\mathrm{E}_{\max }$ ), the use of fixed rates of metabolic heat production expressed per unit of body surface area (producing the same $\mathrm{E}_{\text {req }}$ ) ensured that the $E_{\text {req }}$ to $E_{\max }$ ratio, and therefore the requirement for heat loss (12), was similar between sexes. As such, any observed differences in either local sweat rate or wholebody evaporative heat loss could be ascribed to physiological (rather than physical) differences between sexes.

In addition to the two experimental sessions, 10 of the participants ( 5 males and 5 females) returned to the laboratory for a third experimental visit to address possible sexdifferences in changes in plasma volume and osmolality. For this experimental visit, the participants first rested for a minimum of $30 \mathrm{~min}$ in the upright seated posture, after which baseline blood samples were drawn. The participants were then transferred to the thermal chamber where they exercised at the same external workloads and environmental conditions as during the experimental session performed in the chamber, while blood samples were taken at the end of each exercise period.

Experimental sessions were performed on separate days, separated by a minimum of 48 hours. For all experimentation, clothing was standardised to cotton underwear, running shorts, and sandals (as well as a sports bra for female participants). Possible differences in acclimatisation status between males and females were not taken into account. However, since all experimentation occurred between the months of February and June, it was assumed that all participants were not heat acclimatised.

\section{Measurements}

Local sweat rate on the left upper back, chest and forearm was measured from 3.8

$\mathrm{cm}^{2}$ plastic capsules attached to the skin with adhesive rings and topical skin glue (Collodion HV, Mavidon Medical products, Lake Worth, FL, USA). Anhydrous 
compressed air was passed through each capsule at a rate of $1 \mathrm{~L} \cdot \mathrm{min}^{-1}$. Water content of the effluent air was measured using high precision dew point mirrors (model 473, RH systems, Albuquerque, NM, USA). Local sweat rate was calculated using the difference in water content between effluent and influent air multiplied by the flow rate and normalised for the skin surface area under the capsule.

The number of active sweat glands was measured in an area adjacent to each local sweat rate site (to avoid removing the sweat capsule) at 30, 60, and 90 min of exercise using the modified iodine-paper technique with computer-assisted analysis (14). The number of glands determined by computer analysis was divided by the surface area of the paper to give a value of active sweat glands per square centimetre. The sweat output per gland was calculated by dividing the sweat rate at the corresponding measurement period by the number of active sweat glands.

Local skin blood flow was estimated using laser-Doppler velocimetry (PeriFlux System 5000, Perimed AB, Stockholm, Sweden). Prior to the start of the experimental trial, laser-Doppler flow probes (integrating probe 413, Perimed AB, Stockholm, Sweden) were affixed with an adhesive ring to the left upper back, chest and forearm in a site adjacent to the sweat capsules that demonstrated pulsatile activity. The probes were not moved from their location throughout the experimental trial. To determine maximum skin blood flow, a local heating period to $42^{\circ} \mathrm{C}$ for $30 \mathrm{~min}$ and then to $44^{\circ} \mathrm{C}$ for an additional 15 min was performed at the end of the experimental trial.

Blood flow to the right forearm was measured using venous occlusion plethysmography (model AI6, D.E. Hokanson Inc., Bellevue, WA, USA). Cuffs were placed around the wrist and upper arm, and a mercury-in-rubber strain gauge was placed around the widest part of the forearm. Measurements were performed for 2 min periods at the $10^{\text {th }}$ and $20^{\text {th }}$ min of each exercise period. The right forearm was supported at heart 
level by placing custom supports at the elbow and hand such that the forearm did not touch anything. Prior $(5 \mathrm{sec})$ and throughout the measurement periods, the wrist cuff was inflated to a pressure of $250 \mathrm{mmHg}$ to occlude the circulation of blood to the hand, while the cuff around the upper arm inflated $(50 \mathrm{mmHg})$ and deflated in cycles of 15 seconds. This procedure yielded eight measurements per time period, which were averaged to give one forearm blood flow value per time point (in $\mathrm{ml} \cdot 100 \mathrm{~mL}$ of tissue $\mathrm{e}^{-1} \cdot \mathrm{min}^{-1}$ ).

Systolic and diastolic blood pressures were determined by manual auscultation of the brachial artery at the $5^{\text {th }}, 15^{\text {th }}$ and $25^{\text {th }}$ minute of each exercise period, as well as during the local heating period to determine maximum skin vascular conductance. All auscultations were performed by the same experienced investigator. Mean arterial pressure was subsequently calculated as diastolic blood pressure $+1 / 3$ of pulse pressure. Skin vascular conductance was calculated as laser-Doppler velocimetry output in arbitrary perfusion units divided by mean arterial pressure and expressed as a percentage of maximum. Forearm vascular conductance (in $\mathrm{ml} \cdot 100 \mathrm{~mL}$ of tissue ${ }^{-1} \cdot \mathrm{min}^{-1} \cdot \mathrm{mmHg}^{-1}$ ) was calculated by dividing forearm blood flow by mean arterial pressure.

Esophageal temperature was measured with a general purpose thermocouple temperature probe (Mallinckrodt Medical Inc., St-Louis, MO, USA). The probe was inserted $40 \mathrm{~cm}$ past the entrance of the nostril while the participants sipped water (100$300 \mathrm{~mL}$ ) through a straw. Skin temperature was measured at 10 sites using thermocouples (Concept Engineering, Old Saybrook, CT, USA) attached to the skin with surgical tape. Mean skin temperature was subsequently calculated using a 10 point weighting of the regional proportions determined by Hardy and Dubois (21). Temperature data were collected using a HP Agilent data acquisition module (model 3497A) at a rate of one sample every $15 \mathrm{~s}$ and simultaneously displayed and recorded in spreadsheet format on a 
personal computer with LabVIEW software (Version 7.0, National Instruments, TX, USA).

The modified Snellen direct air calorimeter (38) was employed to measure wholebody evaporative heat loss. In order for evaporative heat loss to be a valid measure of whole-body sweat production, we ensured that the environmental conditions provided a high vapour pressure gradient between the skin surface and the surrounding air. Furthermore, we continually maintained this vapour pressure gradient by providing a high mass flow of dry air through the calorimeter. Inflow and outflow values of absolute humidity were collected at $8 \mathrm{~s}$ intervals throughout the trials. The real time data were displayed and recorded on a personal computer with LabVIEW software (Version 7.0, National Instruments, TX, USA). Evaporative heat loss was subsequently calculated using the calorimeter outflow-inflow difference in absolute humidity, multiplied by the air mass flow and latent heat vaporization of sweat at $30^{\circ} \mathrm{C}(50)$.

Indirect calorimetry was used for the measurement of metabolic energy expenditure (37). Expired gas was analysed for oxygen (error of $\pm 0.01 \%$ ) and carbon dioxide (error of $\pm 0.02 \%$ ) concentrations using electrochemical gas analysers (AMETEK model S-3A/1 and CD 3A, Applied Electrochemistry, Pittsburgh, PA, USA). For the calorimeter session, the gas analysers were located outside of the calorimeter and expired air was recycled back into the calorimeter to account for respiratory heat exchange. Prior to each session, gas mixtures of known concentrations were used to calibrate the gas analysers and a $3 \mathrm{~L}$ syringe was used to calibrate the turbine ventilometer.

Urine specific gravity was determined in duplicate using a handheld total solids refractometer (model TS400, Reichter Inc., Depew, NY, USA).

On the day of each experimental session, a venous blood sample $(10 \mathrm{~mL})$ was obtained from female participants to confirm that the session occurred in the 
follicular/low hormone phase of the menstrual cycle. The blood samples were collected with a $\mathrm{SST}^{\mathrm{TM}}$ vacutainer (BD Vacutainer, Franklin lakes, NJ, USA) for the determination of plasma $17 \beta$-estradiol and progesterone. Plasma concentrations of $17 \beta$-estradiol and progesterone were quantified by an independent external laboratory (Gamma-Dynacare Medical Laboratories, Ottawa, ON, Canada), with plasma concentrations representative of the follicular phase of the menstrual cycle of $46-604 \mathrm{pmol} / \mathrm{L}$ and $0.6-4.7 \mathrm{nmol} / \mathrm{L}$ respectively.

For the additional experimental visit, blood samples were drawn without stasis after a minimum of $30 \mathrm{~min}$ baseline rest in the upright seated posture, as well as at 30,60 and 90 min of exercise through an indwelling plastic catheter in a superficial vein. At each time point, one sample $(\sim 5 \mathrm{~mL})$ was drawn and transferred into a K2 EDTA vacutainer (BD Vacutainer, Franklin lakes, NJ, USA) to determine hematocrit and hemoglobin, while two additional samples $(\sim 10 \mathrm{~mL})$ were drawn and transferred into $\mathrm{SST}^{\mathrm{TM}}$ vacutainers (BD Vacutainer, Franklin lakes, NJ, USA) for the measurement of plasma osmolality. Hematocrit and hemoglobin concentrations were determined using the Coulter method (Coulter ${ }^{\circledR} \mathrm{A}^{\mathrm{c}} \cdot \mathrm{T}$ diff $2^{\mathrm{TM}}$ analyzer, Beckman Coulter, Miami, Florida, USA), and used to estimate changes in plasma volume (8). To determine plasma osmolality, both samples were immediately centrifuged at normal room temperature and osmolality was determined in duplicate by freezing point depression (Osmometer, Advanced Instruments Inc., MA, USA).

\section{Data analysis}

For all variables, minute averages were performed to carry out the statistical analyses. To account for the relative influence of core and mean skin temperatures on the activation of sweat production $(24,35,36)$ and increases in skin blood flow $(53,54)$, mean body temperature was calculated as: $0.9 \times$ esophageal temperature $+0.1 \times$ mean 
skin temperature (45). The onset threshold and thermosensitivity of local sweat rate and whole-body evaporative heat loss during each exercise period were determined using the linear portion of each response plotted against mean body temperature and analysed using segmented regression analysis (6). Since skin blood flow did not increase with each exercise period (see results section), the onset threshold was determined during the first exercise period only, by plotting skin blood flow (as a percentage of maximum) over time and determining visually the point at which it increased over three consecutive measurements. The corresponding mean body temperature at that time point was taken as the onset threshold $(32,49)$. The thermosensitivity was determined as the slope of the relationship between skin vascular conductance and mean body temperature, plotted using the values at baseline, as well as at the end of each exercise period.

\section{Statistical analysis}

All dependent variables were compared between groups (males vs. females) within each experimental condition (chamber and calorimeter). Independent samples Ttests were used for single comparisons between groups, while a two-way mixed model analysis of variance was used for multiple comparisons using the repeated factor of time and the non-repeated factor of group. When a significant main effect was observed, posthoc comparisons were carried out with the Holm-Bonferonni approach. The level of significance for all analyses was set at an alpha level of $p \leq 0.05$. Statistical analyses were performed using commercially available statistical software (SPSS 19.0 for Windows,

SPSS Inc., Chicago, IL, USA). Segmented regression analysis was performed using GraphPad Prism 5.0 (GraphPad Software, La Jolla, CA, USA). Participant characteristics, training history, and exercise intensities are presented as mean \pm standard deviation, while all other variables are reported as mean $\pm 95 \%$ confidence intervals. 


\section{RESULTS}

\section{Participant characteristics}

There were no differences in age between groups $(p=0.607)$. However, males had a significantly greater height $(p=0.040)$ and body mass $(p=0.018)$. The differences in body mass were due to differences in fat free mass $(\mathrm{p} \leq 0.001)$, as fat mass did not significantly differ between groups $(\mathrm{p}=0.363)$. Furthermore, males had a greater maximum oxygen consumption, both in absolute values $(\mathrm{p}=0.001)$ and relative to body mass $(p=0.025)$. However, there were no significant differences between groups in maximum oxygen consumption when expressed as a function of fat free mass $(p=0.204)$.

\section{Training history}

During the 3 months prior to their participation in the study, males and females reported engaging in physical activities long enough to work up a sweat on average $6 \pm 3$ (range: $3-10)$ and $7 \pm 2$ (range: $5-12)$ times per week respectively $(\mathrm{p}=0.433)$. On average, males exercised $11 \pm 8$ (range: 2-25) hours per week, while females exercised $11 \pm 6$ (range: 2-22) hours per week $(\mathrm{p}=0.972)$. During the 7 days prior to their participation in the study, males and females reported performing vigorous physical activity for $4 \pm 3$ (range: $0-8$ ) and $5 \pm 2$ (range: $1-8$ ) hours respectively ( $\mathrm{p}=0.744)$. Males and females also reported performing moderate physical activity for $4 \pm 3$ (range: $0-9$ ) and $4 \pm 4$ (range: 0 13) hours respectively $(\mathrm{p}=0.933)$.

\section{Experimental session 1: Whole-body evaporative heat loss}

On the day of the experimental session, plasma concentrations of $17 \beta$-estradiol and progesterone for the female participants averaged $406 \pm 139 \mathrm{pmol} \cdot \mathrm{L}^{-1}$ and $1.6 \pm 0.1$ $\mathrm{nmol} \cdot \mathrm{L}^{-1}$ respectively. Urine specific gravity did not differ between groups (males: 1.016 \pm 0.009 vs. females: $1.011 \pm 0.008, \mathrm{p}=0.244)$. By design, rate of metabolic heat 
production did not differ between groups during the first (males: $200 \pm 3$ vs. females: 200 $\left.\pm 7 \mathrm{~W} \cdot \mathrm{m}^{-2}, \mathrm{p}=0.856\right)$, second $\left(247 \pm 2\right.$ vs. $\left.248 \pm 5 \mathrm{~W} \cdot \mathrm{m}^{-2}, \mathrm{p}=0.646\right)$, and third (302 $\pm 3 \mathrm{vs}$. $300 \pm 4 \mathrm{~W} \cdot \mathrm{m}^{-2}, \mathrm{p}=0.412$ ) exercise periods. The external workloads associated with these rates of metabolic heat production did not differ between groups (males: $71 \pm 9 \mathrm{~W}, 96 \pm$ $13 \mathrm{~W}, 116 \pm 15 \mathrm{~W}$ vs. females: $67 \pm 6 \mathrm{~W}, 92 \pm 9 \mathrm{~W}, 109 \pm 11 \mathrm{~W}, \mathrm{p}=0.321)$, but represented a lower percentage of maximum oxygen consumption in males $(36 \pm 5 \%, 45$ $\pm 6 \%, 55 \pm 7 \%$ vs. $45 \pm 6 \%, 57 \pm 5 \%, 68 \pm 5 \%, \mathrm{p} \leq 0.001)$

Despite exercising at similar requirements for heat loss, changes over time in whole-body evaporative heat loss significantly differed between groups $(\mathrm{p}=0.002$, Fig. 1A). Although evaporative heat loss was similar at the end of the first $(p=0.418)$ and second $(p=0.394)$ exercise periods, it became greater in males at the end of the third exercise period $\left(348 \pm 26\right.$ vs. $\left.305 \pm 17 \mathrm{~W} \cdot \mathrm{m}^{-2}, \mathrm{p}=0.015\right)$. When examined in relation to the requirement for heat loss (Fig. 1A), evaporative heat loss reached a similar percentage of the required evaporation needed for heat balance in males and females during the first $(\mathrm{p}=0.480)$ and second $(\mathrm{p}=0.402)$ exercise periods. However, during the third exercise period, evaporative heat loss reached $84 \pm 5 \%$ of the required evaporation needed for heat balance in females, whereas it represented $94 \pm 5 \%$ in males $(\mathrm{p}=0.024)$. These differences were primarily due to a "levelling off" of evaporative heat loss in females, such that it did not significantly change over time during the last $10 \mathrm{~min}$ of the exercise period $(\mathrm{p}>0.1)$, whereas evaporative heat loss significantly increased with time until the $26^{\text {th }} \mathrm{min}$ of exercise in males $(\mathrm{p}<0.05)$. The onset threshold for evaporative heat loss did not differ between males and females at the start of each exercise period (all $p>0.1$, Table 2 ). The thermosensitivity of evaporative heat loss did not differ between sexes during the first two exercise periods (both $\mathrm{p}>0.1$ ), but was greater in males during the last exercise period $(p=0.007$, Table 3 and Fig. 1B). 
At the end of the 30 min baseline period, esophageal temperature averaged 36.69 $\pm 0.12^{\circ} \mathrm{C}$ in males and $37.03 \pm 0.18^{\circ} \mathrm{C}$ in females $(\mathrm{p} \leq 0.01)$. During the exercise period, changes over time in esophageal temperature significantly differed between sexes (time $\times$ sex interaction, $\mathrm{p}=0.010$ ). Although the change in esophageal temperature during the first $\left(0.36 \pm 0.09^{\circ} \mathrm{C}\right.$ vs. $\left.0.52 \pm 0.18^{\circ} \mathrm{C}, \mathrm{p}=0.145\right)$ and second $\left(0.24 \pm 0.04^{\circ} \mathrm{C}\right.$ vs. $0.33 \pm 0.13^{\circ} \mathrm{C}$, $\mathrm{p}=0.215$ ) exercise periods did not significantly differ between sexes, it was significantly greater in females $\left(0.61 \pm 0.16^{\circ} \mathrm{C}\right)$ compared to males $\left(0.37 \pm 0.07^{\circ} \mathrm{C}, \mathrm{p}=0.018\right)$ during the last exercise period. In contrast, no sex-differences in mean skin temperature were observed throughout the exercise period $(\mathrm{p}=0.490)$, averaging $35.52 \pm 0.26^{\circ} \mathrm{C}, 35.60 \pm$ $0.26^{\circ} \mathrm{C}, 35.82 \pm 0.29^{\circ} \mathrm{C}$ for males and $35.83 \pm 0.26^{\circ} \mathrm{C}, 35.94 \pm 0.39^{\circ} \mathrm{C}, 36.24 \pm 0.58^{\circ} \mathrm{C}$ for females at the end of the first, second, and third exercise period respectively. Furthermore, no sex-differences in heart rate were observed at the end of the first $(108 \pm$ 7 vs. $113 \pm 7$ beats $\left.\cdot \min ^{-1}, p=0.351\right)$, second $\left(125 \pm 11\right.$ vs. $135 \pm 10$ beats $\left.\cdot \mathrm{min}^{-1}, p=0.212\right)$, and third $\left(143 \pm 12\right.$ vs. $153 \pm 10$ beats $\left.\cdot \mathrm{min}^{-1}, \mathrm{p}=0.251\right)$ exercise period. Overall, the change in body weight was significantly greater in males during the exercise period (1.70 \pm 0.12 vs. $1.45 \pm 0.10 \mathrm{~kg}, \mathrm{p}=0.008)$. However, it represented a similar percent change in both groups $(-2.32 \pm 0.20$ vs. $-2.38 \pm 0.14 \%, \mathrm{p}=0.596)$.

\section{Experimental session 2: Local heat loss responses}

On the day of the experimental session, plasma concentrations of $17 \beta$-estradiol and progesterone for the female participants averaged $225 \pm 138 \mathrm{pmol} \cdot \mathrm{L}^{-1}$ ( $\mathrm{p}=0.205 \mathrm{vs}$. calorimeter session) and $1.7 \pm 0.5 \mathrm{nmol} \cdot \mathrm{L}^{-1} \quad(\mathrm{p}=0.520$ vs. calorimeter session $)$ respectively. Urine specific gravity did not differ between groups (males: $1.018 \pm 0.010$ vs. females: $1.009 \pm 0.008, \mathrm{p}=0.061)$. By design, rate of metabolic heat production did not differ between groups during the first (males: $197 \pm 16 \mathrm{vs}$. females: $204 \pm 3 \mathrm{~W} \cdot \mathrm{m}^{-2}$, $\mathrm{p}=0.246)$, second $\left(252 \pm 2\right.$ vs. $\left.250 \pm 3 \mathrm{~W} \cdot \mathrm{m}^{-2}, \mathrm{p}=0.076\right)$, and third $(303 \pm 2$ vs. $305 \pm 6$ 
$\mathrm{W} \cdot \mathrm{m}^{-2}, \mathrm{p}=0.412$ ) exercise periods. The external workloads associated with these rates of metabolic heat production did not differ between groups (males: $68 \pm 7 \mathrm{~W}, 86 \pm 10 \mathrm{~W}$, $105 \pm 16 \mathrm{~W}$ vs. females: $60 \pm 9 \mathrm{~W}, 81 \pm 12 \mathrm{~W}, 93 \pm 13 \mathrm{~W}, \mathrm{p}=0.140)$, but represented a lower percentage of maximum oxygen consumption in males $(37 \pm 5 \%, 46 \pm 7 \%, 55 \pm$ $7 \%$ vs. $46 \pm 4 \%, 58 \pm 4 \%, 69 \pm 5 \%, \mathrm{p} \leq 0.001)$

Local sweat rate. Despite exercise being performed at fixed requirements for heat loss, changes in local sweat rate on the back $(p<0.001)$, chest $(p \leq 0.001)$, and forearm $(\mathrm{p}<0.001)$ significantly differed over time between sexes. Upper back sweat rate (Fig. 2A) was similar at the end of the first exercise period $(\mathrm{p}=0.483)$, but became greater in males at the end of the second $(p=0.012)$, and third $(p=0.004)$ exercise periods. Similarly, chest sweat rate (Fig. 3A) did not differ between groups at the end of the first $(p=0.802)$ and second $(\mathrm{p}=0.382)$ exercise periods, but was greater in males at the end of the last $(\mathrm{p}=0.044)$ exercise period. In contrast, forearm sweat rate (Fig. 4A) was significantly greater in males at the end of each exercise period $(\mathrm{p} \leq 0.05)$. The onset threshold for local sweat rate at all sites (Table 2), as well as at the onset of each exercise period, did not differ between males and females $(p>0.1)$. There were no sex-differences in the thermosensitivity of local sweat rate at all sites during the first exercise period $(\mathrm{p}>0.1$, Table 3). During the second exercise period, no differences in thermosensitivity were observed between sexes on the chest and forearm $(p>0.1)$, while it was greater in males on the upper back $(\mathrm{p}=0.014)$. In contrast, the thermosensitivity at all sites was significantly greater in males during the last exercise period $(p \leq 0.01$, Table 3$)$. The mean of all three local sweat rate measurements against the change in mean body temperature is presented in Figure 5A. The change in body weight was significantly greater in males during the exercise period $(2.02 \pm 0.15$ vs. $1.59 \pm 0.09 \mathrm{~kg}, \mathrm{p} \leq 0.001)$. However, it 
represented a similar percent change in both groups $(-2.78 \pm 0.25$ vs. $-2.62 \pm 0.13 \%$, $\mathrm{p}=0.323)$.

Sweat gland activation. The number of active sweat glands (Table 4) on the upper back was significantly greater in females compared to males at the end of each exercise period $(\mathrm{p}<0.001)$. As such, the greater upper back sweat rate in males was entirely due to a greater sweat gland output $(\mathrm{p}<0.001)$. Similarly, changes over time in the number of active sweat glands on the chest significantly differed between males and females $(\mathrm{p}=0.018)$. Although, the number of active sweat glands did not differ at the end of the first $(\mathrm{p}=0.871)$ and second $(\mathrm{p}=0.770)$ exercise periods, it became greater in females at the end of the third exercise period $(\mathrm{p}=0.021)$. A similar pattern was observed for sweat gland output on the chest $(\mathrm{p}<0.001)$, such that it did not differ between sexes at the end of the first $(\mathrm{p}=0.480)$ and second $(\mathrm{p}=0.153)$ exercise periods, but became greater in males at the end of the third exercise period $(\mathrm{p} \leq 0.001)$. In contrast, the number of active sweat glands on the forearm did not differ between sexes throughout exercise $(p=0.456)$. Consequently, the greater forearm sweat rate observed in males was entirely due to a greater sweat output per gland $(\mathrm{p} \leq 0.001$, Table 4$)$.

Local skin blood flow. Skin blood flow at each site increased significantly from baseline rest during exercise $(\mathrm{p}<0.001)$. Although skin blood flow values at the upper back significantly increased from the first to third exercise period $(p \leq 0.05)$, those at the chest and forearm did not $(\mathrm{p}>0.05)$. No significant differences were observed between sexes in skin blood blow at the back $(p=0.195)$, chest $(p=0.705)$, and forearm $(p=0.212)$. Similarly, no differences were observed in the onset threshold for increases in skin blood flow at each site $(\mathrm{p}>0.1$, Table 2$)$. 
Local skin vascular conductance. Mean arterial pressure significantly increased form baseline values during exercise $(p<0.001)$, with no significant changes from the first to the third exercise period $(\mathrm{p}=0.363)$. Mean arterial pressure was significantly lower in females at baseline rest ( $80 \pm 2$ vs. $86 \pm 3 \mathrm{mmHg}, \mathrm{p}=0.006$ ), and remained lower at the end of the first ( $83 \pm 2$ vs. $90 \pm 5 \mathrm{mmHg}, \mathrm{p}=0.014)$, second ( $83 \pm 2$ vs. $91 \pm 5 \mathrm{mmHg}$, p=0.026), and third ( $84 \pm 3$ vs. $91 \pm 5 \mathrm{mmHg}, \mathrm{p}=0.038)$ exercise periods. Nonetheless, skin vascular conductance at the back ( $p=0.199$, Fig. $2 B)$, chest $(p=0.643$, Fig. 3B), and forearm ( $\mathrm{p}=0.221$, Fig. 4B) did not differ between sexes. There were also no sexdifferences in the thermosensitivity of skin vascular conductance $(p>0.1$, Table 3$)$. The mean of all three local skin vascular conductance measurements against the change in mean body temperature is presented in Figure 5B.

Whole-limb forearm blood flow and vascular conductance. Forearm blood flow and vascular conductance increased from baseline values during exercise $(p<0.001)$, with no significant changes from the first to the third exercise period $(\mathrm{p}>0.1)$. Forearm blood flow $(\mathrm{p}=0.721)$ and vascular conductance $(\mathrm{p}=0.278)$ did not differ between sexes throughout exercise. Forearm vascular conductance averaged $0.05 \pm 0.01,0.09 \pm 0.03,0.09 \pm 0.02$ and $0.09 \pm 0.01 \mathrm{ml} \cdot 100 \mathrm{~mL}$ of tissue $\mathrm{e}^{-1} \cdot \mathrm{min}^{-1} \cdot \mathrm{mmHg}^{-1}$ in males vs. $0.06 \pm 0.01,0.10 \pm$ $0.01,0.10 \pm 0.01$, and $0.10 \pm 0.02 \mathrm{ml} \cdot 100 \mathrm{~mL}$ of tissue ${ }^{-1} \cdot \mathrm{min}^{-1} \cdot \mathrm{mmHg}^{-1}$ in females during baseline rest, the first, second and third exercise period respectively. Furthermore, the thermosensitivity of forearm vascular conductance $(p=0.651$, Table 3$)$ did not differ between groups.

Esophageal and mean skin temperatures, heart rate. At the end of the $30 \mathrm{~min}$ baseline period, esophageal temperature averaged $36.97 \pm 0.17^{\circ} \mathrm{C}$ in males and $37.42 \pm 0.07^{\circ} \mathrm{C}$ in females $(\mathrm{p} \leq 0.01)$. The change in esophageal temperature during the first $\left(0.28 \pm 0.15^{\circ} \mathrm{C}\right.$ 
vs. $\left.0.43 \pm 0.13^{\circ} \mathrm{C}, \mathrm{p}=0.184\right)$ and second $\left(0.32 \pm 0.07^{\circ} \mathrm{C}\right.$ vs. $\left.0.37 \pm 0.13^{\circ} \mathrm{C}, \mathrm{p}=0.500\right)$ exercise periods did not significantly differ between sexes. However, it was significantly greater in females $\left(0.72 \pm 0.16^{\circ} \mathrm{C}\right)$ compared to males $\left(0.53 \pm 0.09^{\circ} \mathrm{C}, \mathrm{p}=0.052\right)$ during the last exercise period. Mean skin temperature was statistically greater in females at the end of the first $\left(36.80 \pm 0.15\right.$ vs. $\left.36.33 \pm 0.12^{\circ} \mathrm{C}, \mathrm{p} \leq 0.001\right)$, second $(36.97 \pm 0.27$ vs. $\left.36.46 \pm 0.18^{\circ} \mathrm{C}, \mathrm{p}=0.008\right)$, and third $\left(37.30 \pm 0.24\right.$ vs. $\left.36.83 \pm 0.23^{\circ} \mathrm{C}, \mathrm{p}=0.015\right)$ exercise period. In contrast, no sex-differences in heart rate were observed at the end of the first $\left(103 \pm 6\right.$ vs. $114 \pm 9$ beats $\left.\cdot \min ^{-1}, p=0.063\right)$, second $\left(123 \pm 9\right.$ vs. $134 \pm 12$ beats $\cdot \mathrm{min}^{-1}$, $\mathrm{p}=0.136)$, and third $\left(146 \pm 8\right.$ vs. $151 \pm 13$ beats $\left.\cdot \min ^{-1}, \mathrm{p}=0.546\right)$ exercise periods.

\section{Changes in plasma volume and osmolality}

Decreases in plasma volume became greater with each exercise period $(\mathrm{p} \leq 0.001)$, with no significant differences between sexes $(p=0.767)$. Changes from baseline in plasma volume averaged $-2.5 \pm 4.3,-5.7 \pm 3.9$ and $-10.4 \pm 4.2 \%$ for males and $0.1 \pm 3.7$, $7.0 \pm 4.0$ and $-9.2 \pm 2.6 \%$ for females at the end of the first, second and third exercise period respectively. Baseline values of plasma osmolality did not significantly differ between sexes (males: $295 \pm 1 \mathrm{mosmol} \cdot \mathrm{kgH}_{2} \mathrm{O}^{-1}$ vs. females: $296 \pm 3 \mathrm{mosmol} \cdot \mathrm{kgH}_{2} \mathrm{O}^{-1}$, $\mathrm{p}=0.659$ ). Plasma osmolality levels significantly increased with each exercise period $(\mathrm{p} \leq 0.001)$. However, there were no significant differences in plasma osmolality between sexes at the end of each exercise period ( $\mathrm{p}=0.805)$, averaging $297 \pm 2,300 \pm 2$, and $302 \pm$

$2 \mathrm{mosmol} \cdot \mathrm{kgH}_{2} \mathrm{O}^{-1}$ for males and $297 \pm 3,300 \pm 2$, and $303 \pm 3 \mathrm{mosmol} \cdot \mathrm{kgH}_{2} \mathrm{O}^{-1}$ for females at the end of the first, second, and third exercise period respectively. 


\section{DISCUSSION}

The current study examined sex-differences in sudomotor function (local and whole-body) and skin blood flow during exercise performed at increasing requirements for heat loss. The main findings demonstrate that females exhibit a lower whole-body evaporative heat loss and local sweat rate that is only evidenced beyond a certain requirement for heat loss. These differences are paralleled by a lower thermosensitivity of both responses, without any differences in the onset threshold. The lower local sweat rate in females is attributed to a lower sweat output per gland, as opposed to differences in the number of active sweat glands. In contrast, no sex-differences in skin blood flow, as well as in the onset threshold and thermosensitivity of the skin blood flow response, were observed at all requirements for heat loss.

Although a number of studies have examined differences in sweat rate between males and females during exercise, the majority employed experimental protocols which resulted in males exercising at greater rates of metabolic heat production compared to females, making it difficult to determine if sex-differences in sweat rate were truly due to physiological differences in temperature regulation, or simply associated with differences in metabolic heat production (15). An important consideration of the current study is the use of fixed rates of metabolic heat production expressed per unit of body surface area which, combined with fixed environmental conditions, resulted in the same required evaporation for both sexes during exercise. This experimental approach is essential to ascribe the observed differences in local sweat rate and whole-body evaporative heat loss to physiological sex-differences (rather than physical), as previous studies have shown that the level of local and whole-body sweat rate achieved during exercise is determined by the ratio of the required evaporation for heat balance and the maximum evaporation possible in a given environment $(2,43)$. 
To differentiate between a central and peripheral modulation of sudomotor function, the current study examined the onset threshold and thermosensitivity of local sweat rate and whole-body evaporative heat loss during progressive increases in the requirement for heat loss. In theory, differences in neural activity between males and females would expect to yield differences in sweat production, as well as in the onset threshold of the response, at all requirements for heat loss. For example, central adaptations associated with acclimation, sex hormones, and hyperosmolality consistently result in a shift in the onset threshold of both sweating and skin blood flow with little to no change in thermosensitivity $(1,47)$. Furthermore, these shifts are apparent whether the requirement for heat loss is high, such as during exercise, or whether it is relatively low such as during passive heat stress $(4,10,48)$. In the current study, the onset threshold of both local sweat rate and whole-body evaporative heat loss, as well as for increases in skin blood flow did not differ between sexes. Furthermore, sex-differences in sudomotor thermosensitivity were not observed at lower exercise intensities, only becoming evident at the greatest requirement for heat loss employed. It should be noted that the greater local sweat rate on the back and forearm observed in males during the first and second exercise bouts is likely the result of regional differences in sweat rate between sexes (23), as whole-body evaporative heat loss did not differ at these two requirements for heat loss.

Measurements of sweat gland activation have also been used to determine whether differences in sweat rate between conditions and/or populations are mediated centrally or peripherally. While sweat gland activation must result from thermoefferent neural activity, the sweat output per gland reflects the peripheral properties of the sweat gland itself (39). As such, differences in central sudomotor function between sexes would be expected to result in varying levels of sweat gland activation. In the current study, sweat gland activation was greater in females compared to males. These results are 
consistent with previous observations during passive heat stress $(3,26,29)$ and exercise $(11,25,34)$. Consequently, the observed sex-differences in local sweat rate were solely the result of a lower sweat gland output in females. The sweat gland's maximal capacity to produce sweat has been used as an indicator of peripheral modulation (40). Interestingly, we observed a clear levelling off in females of whole-body evaporative heat loss at the highest requirement for heat loss, whereas it continued to increase in males. This observation is particularly evident when examining evaporative heat loss in relation to the required evaporation for heat balance (see Fig. 1A). During the first two exercise periods, evaporative heat loss accounted for a similar proportion of the evaporation needed for heat balance in males and females. However, the lack of increase in evaporative heat loss during the last $10 \mathrm{~min}$ of the third exercise period in females resulted in evaporative heat loss values that accounted for a significantly lower proportion of the required evaporation needed for heat balance. In contrast, the greater and continued increase in whole-body evaporative heat loss in males maintained evaporative heat loss values that accounted for more than $90 \%$ of the required value for heat balance. Although a true test of concept would require an additional rise in the requirement for heat loss combined with a total absence of increases in evaporative heat loss, these observations provide evidence of a lower maximal evaporative capacity, and therefore maximal sweat production, in females.

In contrast to sudomotor function, sex-related differences in skin blood flow during heat stress have been less examined. Inoue et al. (26) did not observe any sexdifferences in back, chest, and forearm skin blood flow during passive heating of the lower limbs, while Kolka et al. (31) reported a similar onset threshold and thermosensitivity of forearm skin blood flow between sexes during exercise in a warm $\left(30^{\circ} \mathrm{C}\right)$ environment. It should be noted, however, that Inoue et al. (26) did report a 
greater thermosensitivity of skin blood flow on the thigh in females which led them to speculate that females may rely to a greater extent on increases in skin blood flow compared to males for effective heat dissipation. In contrast, our results do not support a greater reliance on skin blood flow in females for heat loss during exercise in the heat as we did not observe any differences in both local and whole-limb skin blood flow at all requirements for heat loss. Furthermore, recent evidence suggests that skin blood flow can independently modulate the thermosensitivity of local sweat rate, without affecting the onset threshold of the response (52). As such, the similar local and whole-limb skin blood flow between males and females in the current study rule out the possibility that the lower thermosensitivity of local sweat rate in females is associated with differences in skin blood flow.

\section{Perspectives}

The observed sex-differences in sudomotor thermosensitivity, which only occurred at the highest requirement for heat loss, combined with the lack of sexdifferences in the onset threshold of the response as well as in skin blood flow as a whole, are consistent with a peripheral modulation of sudomotor function in females. This is particularly evident when considering that parallel shifts in the onset threshold of both thermoeffector responses are typical of a central modulation of temperature regulation (18). A peripheral modulation of sudomotor function during exercise in females could be mediated through sex-differences in either the cholinergic sensitivity of the sweat gland $(17,28,33)$, the physical properties (e.g. size) of the sweat gland (40), the concentration of cholinergic agonists released in the sudomotor junction, and/or the concentration of acetylcholinesterase present within the sudomotor junction (44). Further research is therefore needed to determine which of these factors are specifically responsible in mediating the lower sudomotor thermosensitivity in females during exercise. 


\section{Considerations}

It may be argued that the observed differences in sudomotor function are related to differences in the percentage of maximum oxygen consumption elicited by fixed rates of metabolic heat production. However, this would disregard recent findings which demonstrate that differences in relative exercise intensity and maximum oxygen consumption between independent groups do not modulate local sweat production when exercise is performed at a fixed requirement for heat loss $(7,27)$. It is also noteworthy that relative exercise intensity differed between males and females during each exercise period, yet consistent differences in local sweat rate and whole-body evaporative heat loss were only observed during the last exercise period. Moreover, both sexes in the current study had a similar training history, suggesting that the lower absolute maximum oxygen consumption in females is likely attributed to a lower fat free mass, as opposed to differences in training status. In contrast to local sweat rate $(7,27)$, increases in skin blood flow during exercise are not only determined by the requirement for heat loss, but also by the competition created by the metabolic requirement of the active musculature (19). In the current study, the similar skin blood flow response in females occurred despite a relatively greater demand for blood flow to the active musculature, particularly at the highest requirement for heat loss. It is unknown whether similar results would have been observed if exercise had been performed at fixed percentages of maximum oxygen consumption. Future studies are required to determine the impact of using fixed requirements for heat loss compared with fixed percentages of maximum oxygen consumption on the skin blood flow response. Finally, it should also be considered that we did not observe any sex-differences in changes in plasma volume and osmolality throughout the experimental protocol in a subset of participants. It is therefore unlikely that the current results can be attributed to possible differences in either of these 
variables. However, it is possible that although changes in plasma volume were similar between males and females, absolute plasma volume would have started at a lower level in females, thus reducing to lower absolute values. Future studies are needed to examine this possibility.

\section{CONCLUSION}

The current study examined sex-differences in sudomotor function (local and whole-body) and skin blood flow during exercise in the heat performed at increasing requirements for heat loss. Consistent sex-differences in local sweat rate and whole-body evaporative heat loss were only evidenced at the highest requirement for heat loss employed. A lower local sweat rate and whole-body evaporative heat loss was observed in females, which was paralleled by a lower thermosensitivity of each response without any differences in the onset threshold. Furthermore, the lower local sweat rate in females was solely the result of a lower sweat gland output, as opposed to differences in sweat gland activation. We also observed a levelling off of whole-body evaporative heat loss at the highest requirement for heat loss in females, which suggests a lower maximal evaporative capacity. In contrast, no sex-differences in both the onset threshold and thermosensitivity of skin blood flow were observed throughout the experimental protocol. Taken together, these results provide evidence that sex-differences in sudomotor function during exercise are mediated peripherally. 


\section{REFERENCES}

1. Armstrong CG, and Kenney WL. Effects of age and acclimation on responses to passive heat exposure. J Appl Physiol 75 2162-2167, 1993.

2. Bain AR, Deren TM, and Jay O. Describing individual variation in local sweating during exercise in a temperate environment. Eur J Appl Physiol 111: 15991607, 2011.

3. Bar-Or O, Lundegren HM, Magnusson LI, and Buskirk ER. Distribution of Heat-Activated Sweat Glands in Obese and Lean Men and Women. Hum Biol 40: 235248, 1968.

4. Bittel J, and Henane R. Comparison of thermal exchanges in men and women under neutral and hot conditions. J Physiol 250: 475-489, 1975.

5. Canadian Society for Exercise Physiology. Chapter II: Determination of Aerobic Power. In: Certified Fitness Appraiser Resource Manual Gloucester, Ontario: CSEP, 1986, p. 1-32.

6. Cheuvront SN, Bearden SE, Kenefick RW, Ely BR, Degroot DW, Sawka MN, and Montain SJ. A simple and valid method to determine thermoregulatory sweating threshold and sensitivity. J Appl Physiol 107: 69-75, 2009.

7. Cramer MN, Bain AR, and Jay O. Local sweating on the forehead, but not forearm, is influenced by aerobic fitness independently of heat balance requirements during exercise. Exp Physiol 97: 572-582, 2012.

8. Dill DB, and Costill DL. Calculation of percentage changes in volumes of blood, plasma, and red cells in dehydration. J Appl Physiol 37: 247-248, 1974.

9. DuBois D, and DuBois EF. A formula to estimate the approximate surface area if height and weight be known. Arch Intern Med 17: 863-871, 1916.

10. Fox RH, Goldsmith R, Kidd DJ, and Lewis HE. Blood flow and other thermoregulatory changes with acclimatization to heat. J Physiol 166: 548-562, 1963.

11. Frye AJ, and Kamon E. Sweating efficiency in acclimated men and women exercising in humid and dry heat. J Appl Physiol 54: 972-977, 1983.

12. Gagge AP, and Gonzales RR. Mechanisms of heat exchange In: Handbook of Physiology Section 4: Environmental Physiology, edited by Fregley MJ, and Blatteis CM. New York, NY: Oxford University press, 1996, p. 45-84.

13. Gagnon D, Dorman LE, Jay O, Hardcastle SG, and Kenny GP. Core temperature differences between sexes during intermittent exercise: physical considerations. Eur J Appl Physiol 105: 453-461, 2009.

14. Gagnon D, Ganio MS, Lucas RA, Pearson J, Crandall CG, and Kenny GP. Modified iodine-paper technique for the standardized determination of sweat gland activation. J Appl Physiol 112: 1419-1425, 2012. 
15. Gagnon D, Jay O, Lemire B, and Kenny GP. Sex-related differences in evaporative heat loss: the importance of metabolic heat production. Eur J Appl Physiol 104: 821-829, 2008.

16. Gagnon D, and Kenny GP. Sex modulates whole-body sudomotor thermosensitivity during exercise. J Physiol 589: 6205-6217, 2011.

17. Gibson TE, and Shelley WB. Sexual and racial differences in the response of sweat glands to acetylcholine and pilocarpine. J Invest Dermatol 11: 137-142, 1948.

18. Gisolfi $\mathbf{C V}$, and Wenger $\mathbf{C B}$. Temperature regulation during exercise: old concepts, new ideas. Exerc Sport Sci Rev 12: 339-372, 1984.

19. González-Alonso J, Crandall CG, and Johnson JM. The cardiovascular challenge of exercising in the heat. J Physiol 586: 45-53, 2008.

20. Hammel HT. Regulation of internal body temperature. Ann Rev Physiol 30: 641$710,1968$.

21. Hardy $\mathbf{J}$, and DuBois $\mathbf{E}$. The technique of measuring radiation and convection. $J$ Nutr 15: 461-475, 1938.

22. Havenith G, Coenen JM, Kistemaker L, and Kenney WL. Relevance of individual characteristics for human heat stress response is dependent on exercise intensity and climate type. Eur J Appl Physiol 77: 231-241, 1998.

23. Havenith G, Fogarty A, Bartlett R, Smith CJ, and Ventenat V. Male and female upper body sweat distribution during running measured with technical absorbents. Eur J Appl Physiol 104: 245-255, 2008.

24. Hertzman AB, Randall WC, Peiss CN, and Seckendorf R. Regional rates of evaporation from the skin at various environmental temperatures. J Appl Physiol 5: 153$161,1952$.

25. Ichinose-Kuwahara T, Inoue Y, Iseki Y, Hara S, Ogura Y, and Kondo N. Sex differences in the effects of physical training on sweat gland responses during a graded exercise. Exp Physiol 95: 1026-1032, 2010.

26. Inoue Y, Tanaka Y, Omori K, Kuwahara T, Ogura Y, and Ueda H. Sex- and menstrual cycle-related differences in sweating and cutaneous blood flow in response to passive heat exposure. Eur J Appl Physiol 94: 323-332, 2005.

27. Jay O, Bain AR, Deren TM, Sacheli M, and Cramer MN. Large differences in peak oxygen uptake do not independently alter changes in core temperature and sweating during exercise. Am J Physiol Regul Integr Comp Physiol 301: 832-841, 2011.

28. Kahn D, and Rothman S. Sweat response to acetylcholine. J Invest Dermatol 5: 431-444, 1942.

29. Knip AS. Measurement and regional distribution of functioning eccrine sweat glands in male and female Caucasians. Hum Biol 41: 380-387, 1969. 
30. Kohl HW, Blair SN, Paffenbarger RS, Macera CA, and Kronenfeld JJ. A mail survey of physical activity habits as related to measured physical fitness. Am $J$ Epidemiol 127: 1228-1239, 1988.

31. Kolka MA, Stephenson LA, Rock PB, and Gonzalez RR. Local sweating and cutaneous blood flow during exercise in hypobaric environments. J Appl Physiol 62: 2224-2229, 1987.

32. Mack GW, Cordero D, and Peters J. Baroreceptor modulation of active cutaneous vasodilation during dynamic exercise in humans. J Appl Physiol 90: 14641473, 2001.

33. Madeira LG, da Fonseca MA, Fonseca IA, de Oliveira KP, Passos RL, Machado-Moreira CA, and Rodrigues LO. Sex-related differences in sweat gland cholinergic sensitivity exist irrespective of differences in aerobic capacity. Eur J Appl Physiol 109: 93-100, 2010.

34. Morimoto T, Slabochova Z, Naman RK, and Sargent F. Sex differences in physiological reactions to thermal stress. J Appl Physiol 22: 526-532, 1967.

35. Nadel ER, Bullard RW, and Stolwijk JA. Importance of skin temperature in the regulation of sweating. J Appl Physiol 31: 80-87, 1971.

36. Nadel ER, Mitchell JW, Saltin B, and Stolwijk JA. Peripheral modifications to the central drive for sweating. J Appl Physiol 31: 828-833, 1971.

37. Nishi Y. Measurement of thermal balance in man. In: Bioengineering, thermal physiology and comfort, edited by Cena K and Clark J New York, NY: Elsevier, pp. 2939, 1981.

38. Reardon FD, Leppik KE, Wegmann R, Webb P, Ducharme MB, and Kenny GP. The Snellen human calorimeter revisited, re-engineered and upgraded: design and performance characteristics. Med Biol Eng Comput 44: 721-728, 2006.

39. Sato K, and Dobson RL. Regional and individual variations in the function of the human eccrine sweat gland. J Invest Dermatol 54: 443-449, 1970.

40. Sato K, and Sato $\mathbf{F}$. Individual variations in structure and function of human eccrine sweat gland. Am J Physiol 245: 203-208, 1983.

41. Sawka MN. Physiological consequences of hypohydration: exercise performance and thermoregulation. Med Sci Sports Exerc 24: 657-670, 1992.

42. Schwiening CJ, Mason MJ, and Thompson M. Absolute power, not sex, promotes perspiration. Exp Physiol 96: 556-558, 2011.

43. Shapiro Y, Pandolf KB, and Goldman RF. Predicting sweat loss response to exercise, environment and clothing. Eur J Appl Physiol Occup Physiol 48: 83-96, 1982.

44. Shibasaki M, and Crandall CG. Effect of local acetylcholinesterase inhibition on sweat rate in humans. J Appl Physiol 90: 757-762, 2001. 
45. Shibasaki M, Wilson TE, and Crandall CG. Neural control and mechanisms of eccrine sweating during heat stress and exercise. J Appl Physiol 100: 1692-1701, 2006.

46. Siri WE. Gross composition of the body. In: Advances in Biological and Medical Physics, edited by Lawrence JH, and Tobias CA. New York: Academic, 1956, p. 239280.

47. Stephenson LA, and Kolka MA. Thermoregulation in women. Exerc Sport Sci Rev 21: 231-262, 1993.

48. Takamata A, Mack GW, Gillen CM, Jozsi AC, and Nadel ER. Osmoregulatory modulation of thermal sweating in humans: reflex effects of drinking. Am J Physiol 268: 414-422, 1995.

49. Takamata A, Nagashima $\mathbf{K}$, Nose $\mathbf{H}$, and Morimoto $\mathbf{T}$. Role of plasma osmolality in the delayed onset of thermal cutaneous vasodilation during exercise in humans. Am J Physiol 275: R286-290, 1998.

50. Wenger CB. Heat of evaporation of sweat: thermodynamic considerations. J Appl Physiol 32: 456-459, 1972.

51. Werner J. Control aspects of human temperature regulation. Automatica 17: 351$362,1981$.

52. Wingo JE, Low DA, Keller DM, Brothers RM, Shibasaki M, and Crandall CG. Skin blood flow and local temperature independently modify sweat rate during passive heat stress in humans. J Appl Physiol 109: 1301-1306, 2010.

53. Wissler EH. A quantitative assesment of skin blood flow in humans. Eur J Appl Physiol 104: 145-157, 2008.

54. Wyss CR, Brengelmann GL, Johnson JM, Rowell LB, and Niederberger $M$. Control of skin blood flow, sweating, and heart rate: role of skin vs. core temperature. $J$ Appl Physiol 36: 726-733, 1974. 


\section{ACKNOWLEDGEMENTS}

D.G. is supported by an Alexander Graham Bell Canadian Graduate Scholarship from the Natural Sciences and Engineering Research Council. The current work was supported by the Natural Sciences and Engineering Research Council (RGPIN-298159-2009) and Leaders Opportunity Fund from the Canada Foundation for Innovation (22529). G.P.K. is supported by a University of Ottawa Research Chair in Environmental Physiology. The authors acknowledge the contributions of Dr. Ollie Jay and Dr. Craig Crandall who provided critical input into the development of this work. The authors thank all the members of the Human and Environmental Physiology Research Unit who assisted with data collection, as well as all the participants who volunteered for the present study. 
Table 1. Participant characteristics.

\begin{tabular}{|c|c|c|c|c|c|c|c|c|c|}
\hline Sex & $\begin{array}{l}\text { Age } \\
\text { (yrs) }\end{array}$ & $\begin{array}{l}\text { Body mass } \\
\quad(\mathrm{kg})\end{array}$ & $\begin{array}{l}\text { Height } \\
(\mathrm{cm})\end{array}$ & $\begin{array}{l}A_{D} \\
\left(\mathrm{~m}^{2}\right)\end{array}$ & $\begin{array}{l}\text { Fat mass } \\
(\mathrm{kg})\end{array}$ & $\begin{array}{c}\text { Fat free mass } \\
\qquad(\mathrm{kg})\end{array}$ & $\begin{array}{l}\dot{\mathrm{VO}}_{2 \max } \\
\left(\mathrm{L} \cdot \mathrm{min}^{-1}\right)\end{array}$ & $\begin{array}{c}\dot{\mathrm{VO}}_{2 \max } \\
\left(\mathrm{mL} \cdot \mathrm{kg}^{-1} \cdot \mathrm{min}^{-1}\right)\end{array}$ & $\begin{array}{c}\dot{\mathrm{VO}}_{2 \max } \\
\left(\mathrm{mL} \cdot \mathrm{kg}_{\mathrm{FFM}}^{-1} \cdot \min ^{-1}\right)\end{array}$ \\
\hline Males & $\begin{array}{l}27 \\
\pm 6\end{array}$ & $\begin{array}{c}73.9 \\
\pm 13.5^{*}\end{array}$ & $\begin{array}{c}174 \\
\pm 10^{*}\end{array}$ & $\begin{array}{c}1.88 \\
\pm 0.22 *\end{array}$ & $\begin{array}{l}11.0 \\
\pm 5.4\end{array}$ & $\begin{array}{c}62.9 \\
\pm 10.4^{*}\end{array}$ & $\begin{array}{c}3.78 \\
\pm 0.70^{*}\end{array}$ & $\begin{array}{c}51.4 \\
\pm 6.8^{*}\end{array}$ & $\begin{array}{l}60.2 \\
\pm 7.8\end{array}$ \\
\hline Females & $\begin{array}{l}28 \\
\pm 5\end{array}$ & $\begin{array}{l}60.7 \\
\pm 3.7\end{array}$ & $\begin{array}{l}166 \\
\pm 5\end{array}$ & $\begin{array}{c}1.67 \\
\pm 0.07\end{array}$ & $\begin{array}{l}13.0 \\
\pm 2.7\end{array}$ & $\begin{array}{l}47.6 \\
\pm 3.3\end{array}$ & $\begin{array}{c}2.68 \\
\pm 0.36\end{array}$ & $\begin{array}{l}44.1 \\
\pm 4.5\end{array}$ & $\begin{array}{l}56.1 \\
\pm 3.9\end{array}$ \\
\hline
\end{tabular}

$A_{D}$, body surface area; $\dot{\mathrm{V} O}$, maximum oxygen consumption; FFM, fat free mass. *Significantly different from females $(P \leq 0.05)$. Values are mean \pm standard deviation. 
Table 2. Onset threshold of thermoeffector responses.

\begin{tabular}{|c|c|c|c|c|c|c|}
\hline & \multicolumn{2}{|c|}{$200 \mathrm{~W} \cdot \mathrm{m}^{-2}$} & \multicolumn{2}{|c|}{$250 \mathrm{~W} \cdot \mathrm{m}^{-2}$} & \multicolumn{2}{|c|}{$300 \mathrm{~W} \cdot \mathrm{m}^{-2}$} \\
\hline & Males & Females & Males & Females & Males & Females \\
\hline & \multicolumn{6}{|c|}{ Sudomotor activity $\left(\Delta^{\circ} \mathrm{C}\right)$} \\
\hline Whole-body & $\begin{array}{c}0.01 \\
\pm 0.01\end{array}$ & $\begin{array}{c}0.01 \\
\pm 0.01\end{array}$ & $\begin{array}{c}0.02 \\
\pm 0.02\end{array}$ & $\begin{array}{c}0.02 \\
\pm 0.02\end{array}$ & $\begin{array}{c}0.04 \\
\pm 0.02\end{array}$ & $\begin{array}{c}0.02 \\
\pm 0.02\end{array}$ \\
\hline Back & $\begin{array}{c}0.02 \\
\pm 0.02\end{array}$ & $\begin{array}{c}0.02 \\
\pm 0.01\end{array}$ & $\begin{array}{c}0.02 \\
\pm 0.01\end{array}$ & $\begin{array}{c}0.01 \\
\pm 0.01\end{array}$ & $\begin{array}{c}0.06 \\
\pm 0.06\end{array}$ & $\begin{array}{c}0.02 \\
\pm 0.01\end{array}$ \\
\hline Chest & $\begin{array}{c}0.02 \\
\pm 0.02\end{array}$ & $\begin{array}{c}0.01 \\
\pm 0.00\end{array}$ & $\begin{array}{c}0.02 \\
\pm 0.01\end{array}$ & $\begin{array}{c}0.01 \\
\pm 0.01\end{array}$ & $\begin{array}{c}0.02 \\
\pm 0.01\end{array}$ & $\begin{array}{c}0.01 \\
\pm 0.01\end{array}$ \\
\hline \multirow[t]{2}{*}{ Forearm } & $\begin{array}{c}0.03 \\
\pm 0.02\end{array}$ & $\begin{array}{c}0.02 \\
\pm 0.02\end{array}$ & $\begin{array}{c}0.02 \\
\pm 0.01\end{array}$ & $\begin{array}{c}0.01 \\
\pm 0.01\end{array}$ & $\begin{array}{c}0.02 \\
\pm 0.01\end{array}$ & $\begin{array}{c}0.03 \\
\pm 0.02\end{array}$ \\
\hline & \multicolumn{6}{|c|}{ Skin blood flow $\left(\Delta^{\circ} \mathrm{C}\right)$} \\
\hline Back & $\begin{array}{c}0.06 \\
\pm 0.02\end{array}$ & $\begin{array}{c}0.07 \\
\pm 0.02\end{array}$ & & $\mathrm{n} / \mathrm{a}$ & & $\mathrm{n} / \mathrm{a}$ \\
\hline Chest & $\begin{array}{c}0.04 \\
\pm 0.02\end{array}$ & $\begin{array}{c}0.07 \\
\pm 0.02\end{array}$ & & $\mathrm{n} / \mathrm{a}$ & & $\mathrm{n} / \mathrm{a}$ \\
\hline Forearm & $\begin{array}{c}0.06 \\
\pm 0.01\end{array}$ & $\begin{array}{c}0.08 \\
\pm 0.02\end{array}$ & & $\mathrm{n} / \mathrm{a}$ & & $\mathrm{n} / \mathrm{a}$ \\
\hline
\end{tabular}

Whole-body sudomotor activity was measured by direct calorimetry. Values are mean $\pm 95 \%$ confidence intervals. n/a, not applicable as the onset threshold for increases in skin blood flow response was only measured at the beginning of the first exercise period. 
Table 3. Thermosensitivity of thermoeffector responses.

\begin{tabular}{|c|c|c|c|c|c|c|}
\hline & \multicolumn{2}{|c|}{$200 \mathrm{~W} \cdot \mathrm{m}^{-2}$} & \multicolumn{2}{|c|}{$250 \mathrm{~W} \cdot \mathrm{m}^{-2}$} & \multicolumn{2}{|c|}{$300 \mathrm{~W} \cdot \mathrm{m}^{-2}$} \\
\hline & Males & Females & Males & Females & Males & Females \\
\hline & \multicolumn{6}{|c|}{ Sudomotor activity } \\
\hline $\begin{array}{l}\text { Whole-body } \\
\left(\mathrm{W} \cdot \mathrm{m}^{-2} \cdot{ }^{\circ} \mathrm{C}^{-1}\right)\end{array}$ & $\begin{array}{c}496 \\
\pm 139\end{array}$ & $\begin{array}{l}483 \\
\pm 185\end{array}$ & $\begin{array}{l}283 \\
\pm 70\end{array}$ & $\begin{array}{l}211 \\
\pm 66\end{array}$ & $\begin{array}{l}197 \\
\pm 61\end{array}$ & $\begin{array}{c}82 \\
\pm 27^{*}\end{array}$ \\
\hline$\underset{\left(\mathrm{mg} \cdot \mathrm{min}^{-1} \cdot \mathrm{cm}^{-2} \cdot{ }^{\circ} \mathrm{C}^{-1}\right)}{\operatorname{Back}}$ & $\begin{array}{c}1.79 \\
\pm 0.61\end{array}$ & $\begin{array}{c}1.38 \\
\pm 0.22\end{array}$ & $\begin{array}{c}1.51 \\
\pm 0.17\end{array}$ & $\begin{array}{c}0.91 \\
\pm 0.35^{*}\end{array}$ & $\begin{array}{c}0.90 \\
\pm 0.19\end{array}$ & $\begin{array}{c}0.34 \\
\pm 0.08 *\end{array}$ \\
\hline $\begin{array}{c}\text { Chest } \\
\left(\mathrm{mg} \cdot \mathrm{min}^{-1} \cdot \mathrm{cm}^{-2} \cdot{ }^{\circ} \mathrm{C}^{-1}\right)\end{array}$ & $\begin{array}{c}1.35 \\
\pm 0.54\end{array}$ & $\begin{array}{c}1.14 \\
\pm 0.23\end{array}$ & $\begin{array}{c}1.21 \\
\pm 0.26\end{array}$ & $\begin{array}{c}0.92 \\
\pm 0.36\end{array}$ & $\begin{array}{c}0.67 \\
\pm 0.14\end{array}$ & $\begin{array}{c}0.30 \\
\pm 0.10 *\end{array}$ \\
\hline \multirow[t]{2}{*}{$\begin{array}{c}\text { Forearm } \\
\left(\mathrm{mg} \cdot \mathrm{min}^{-1} \cdot \mathrm{cm}^{-2} \cdot{ }^{\circ} \mathrm{C}^{-1}\right)\end{array}$} & $\begin{array}{c}1.86 \\
\pm 0.58\end{array}$ & $\begin{array}{c}1.53 \\
\pm 0.29\end{array}$ & $\begin{array}{c}1.30 \\
\pm 0.23\end{array}$ & $\begin{array}{c}1.02 \\
\pm 0.49\end{array}$ & $\begin{array}{c}0.60 \\
\pm 0.19\end{array}$ & $\begin{array}{c}0.29 \\
\pm 0.09 *\end{array}$ \\
\hline & \multicolumn{6}{|c|}{ Skin vascular conductance } \\
\hline $\begin{array}{c}\text { Back } \\
\left(\% \max \cdot{ }^{\circ} \mathrm{C}^{-1}\right)\end{array}$ & $\begin{array}{l}21 \\
\pm 5\end{array}$ & $\begin{array}{l}19 \\
\pm 5\end{array}$ & \multicolumn{2}{|c|}{$\mathrm{n} / \mathrm{a}$} & \multicolumn{2}{|c|}{$\mathrm{n} / \mathrm{a}$} \\
\hline $\begin{array}{l}\text { Chest } \\
\left(\% \max \cdot{ }^{\circ} \mathrm{C}^{-1}\right)\end{array}$ & $\begin{array}{l}21 \\
\pm 6\end{array}$ & $\begin{array}{l}18 \\
\pm 5\end{array}$ & \multicolumn{2}{|c|}{$\mathrm{n} / \mathrm{a}$} & \multicolumn{2}{|c|}{$\mathrm{n} / \mathrm{a}$} \\
\hline $\begin{array}{l}\text { Forearm } \\
\left(\% \max \cdot{ }^{\circ} \mathrm{C}^{-1}\right)\end{array}$ & $\begin{array}{l}18 \\
\pm 5\end{array}$ & $\begin{array}{l}18 \\
\pm 5\end{array}$ & \multicolumn{2}{|c|}{$\mathrm{n} / \mathrm{a}$} & \multicolumn{2}{|c|}{$\mathrm{n} / \mathrm{a}$} \\
\hline $\begin{array}{c}\text { Whole-limb } \\
\left(\mathrm{mL} \cdot 100 \mathrm{~mL}^{-1} \cdot \mathrm{min}^{-1} \cdot \mathrm{mmHg}^{-1} \cdot{ }^{\circ} \mathrm{C}^{-1}\right)\end{array}$ & $\begin{array}{c}3.92 \\
\pm 0.58\end{array}$ & $\begin{array}{c}3.32 \\
\pm 1.25\end{array}$ & \multicolumn{2}{|c|}{$\mathrm{n} / \mathrm{a}$} & \multicolumn{2}{|r|}{$\mathrm{n} / \mathrm{a}$} \\
\hline
\end{tabular}

Whole-body sudomotor activity was measured by direct calorimetry. n/a, not applicable as the thermosensitivity of skin vascular conductance was not measured at each exercise period. *Significantly different from males $(P \leq 0.05)$. Values are mean $\pm 95 \%$ confidence intervals. 
Table 4. Sex-differences in the number of active sweat glands and the sweat output per gland during exercise performed at increasing rates of metabolic heat production.

\begin{tabular}{|c|c|c|c|c|c|c|c|}
\hline \multirow[b]{2}{*}{$\begin{array}{c}\text { Heat } \\
\text { production }\end{array}$} & \multirow[b]{2}{*}{ Sex } & \multicolumn{2}{|c|}{ Back } & \multicolumn{2}{|c|}{ Chest } & \multicolumn{2}{|c|}{ Forearm } \\
\hline & & $\begin{array}{l}\text { Active glands } \\
\quad\left(\text { per } \mathrm{cm}^{2}\right)\end{array}$ & $\begin{array}{c}\text { SGO } \\
\left(\mu \mathrm{g} \cdot \text { gland }^{-1}\right)\end{array}$ & $\begin{array}{l}\text { Active glands } \\
\left(\text { per } \mathrm{cm}^{2}\right)\end{array}$ & $\begin{array}{c}\text { SGO } \\
\left(\mu \mathrm{g} \cdot \text { gland }^{-1}\right)\end{array}$ & $\begin{array}{l}\text { Active glands } \\
\left(\text { per } \mathrm{cm}^{2}\right)\end{array}$ & $\begin{array}{c}\text { SGO } \\
\left(\mu \mathrm{g} \cdot \text { gland }^{-1}\right)\end{array}$ \\
\hline $200 \mathrm{~W} \cdot \mathrm{m}^{-2}$ & $\begin{array}{c}\text { Males } \\
\text { Females }\end{array}$ & $\begin{array}{c}56 \pm 8 \\
82 \pm 13^{*}\end{array}$ & $\begin{array}{l}15.97 \pm 1.79 \\
9.95 \pm 1.06^{*}\end{array}$ & $\begin{array}{l}57 \pm 6 \\
56 \pm 8\end{array}$ & $\begin{array}{l}13.56 \pm 2.76 \\
12.22 \pm 2.20\end{array}$ & $\begin{array}{c}92 \pm 12 \\
106 \pm 27\end{array}$ & $\begin{array}{l}10.09 \pm 1.53 \\
7.46 \pm 1.54^{*}\end{array}$ \\
\hline $250 \mathrm{~W} \cdot \mathrm{m}^{-2}$ & $\begin{array}{c}\text { Males } \\
\text { Females }\end{array}$ & $\begin{array}{c}58 \pm 6 \\
92 \pm 9^{*}\end{array}$ & $\begin{array}{c}22.30 \pm 1.83 \\
11.23 \pm 1.38^{*}\end{array}$ & $\begin{array}{l}64 \pm 9 \\
66 \pm 7\end{array}$ & $\begin{array}{l}16.87 \pm 3.34 \\
13.60 \pm 2.38\end{array}$ & $\begin{array}{l}112 \pm 12 \\
119 \pm 18\end{array}$ & $\begin{array}{l}11.89 \pm 1.64 \\
8.61 \pm 1.06^{*}\end{array}$ \\
\hline $300 \mathrm{~W} \cdot \mathrm{m}^{-2}$ & $\begin{array}{c}\text { Males } \\
\text { Females }\end{array}$ & $\begin{array}{c}58 \pm 8 \\
93 \pm 6^{*}\end{array}$ & $\begin{array}{c}28.01 \pm 3.28 \\
13.04 \pm 1.91^{*}\end{array}$ & $\begin{array}{c}59 \pm 7 \\
73 \pm 8^{*}\end{array}$ & $\begin{array}{c}22.71 \pm 3.28 \\
13.82 \pm 1.69^{*}\end{array}$ & $\begin{array}{c}101 \pm 7 \\
123 \pm 23\end{array}$ & $\begin{array}{l}15.30 \pm 2.00 \\
9.83 \pm 1.65^{*}\end{array}$ \\
\hline
\end{tabular}

SGO, sweat gland output. *Significantly different from males $(P \leq 0.05)$. Values are mean $\pm 95 \%$ confidence intervals. 
A

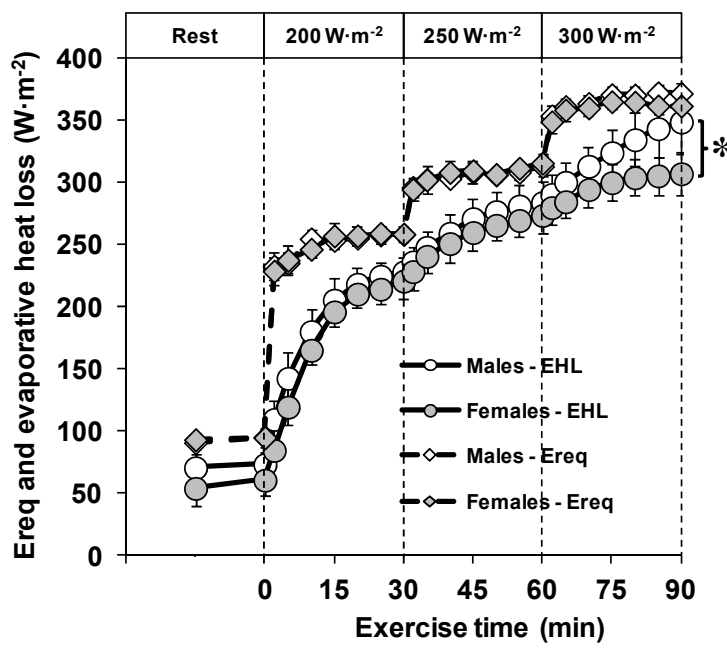

B

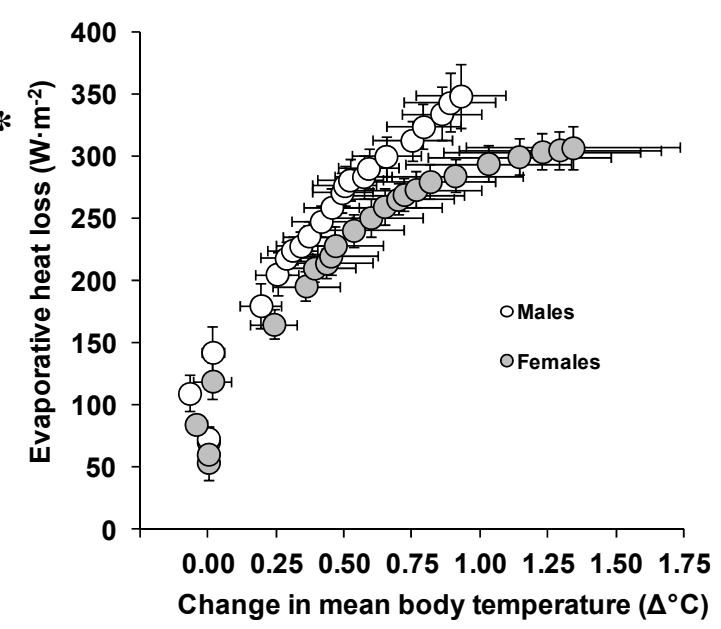

Figure 1. Sex-differences in evaporative heat loss (EHL) relative to the required evaporation for heat balance (Ereq, panel A), as well as in evaporative heat loss as a function of changes in mean body temperature (panel B) during exercise performed at increasing rates of metabolic heat production $\left(200,250,300 \mathrm{~W} \cdot \mathrm{m}^{-2}\right)$. ${ }^{*}$, Significantly different evaporative heat loss between males and females $(p<0.05)$. Dashed lines represent the beginning of each exercise period. Values are mean $\pm 95 \%$ confidence intervals. 
A

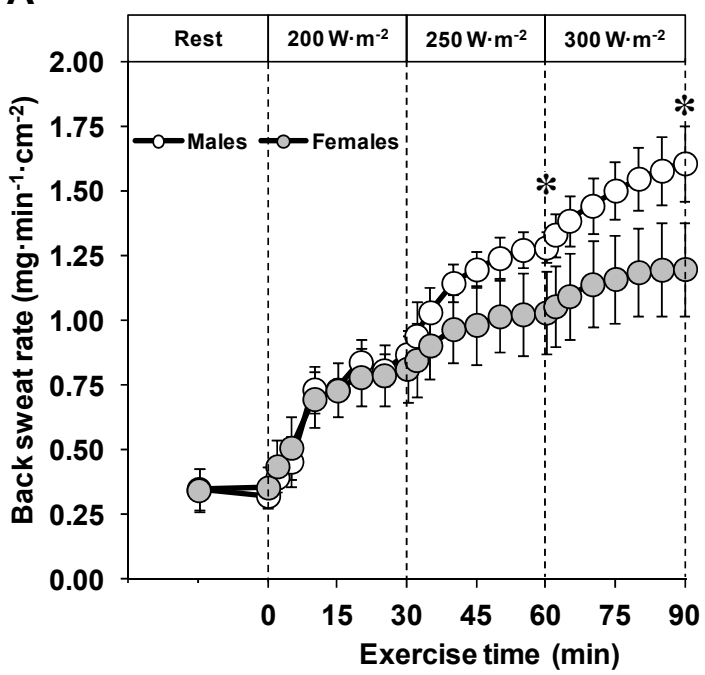

B

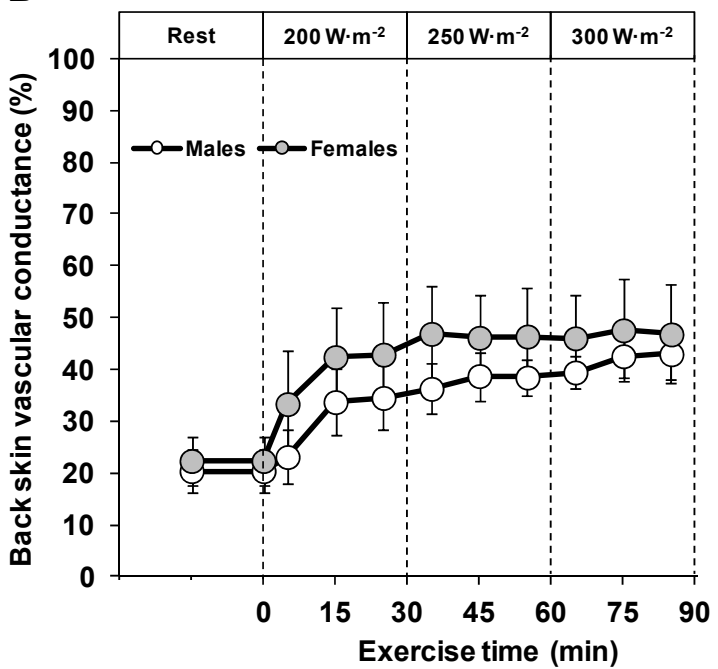

Figure 2. Sex-differences in upper back sweat rate (panel A) and skin vascular conductance presented as a percentage of maximum (panel B) during exercise performed at increasing rates of metabolic heat production $\left(200,250,300 \mathrm{~W} \cdot \mathrm{m}^{-2}\right)$. ${ }^{*}$, Significantly different sweat rate between males and females $(p<0.05)$. Dashed lines represent the beginning of each exercise period. Values are mean $\pm 95 \%$ confidence intervals. 
A

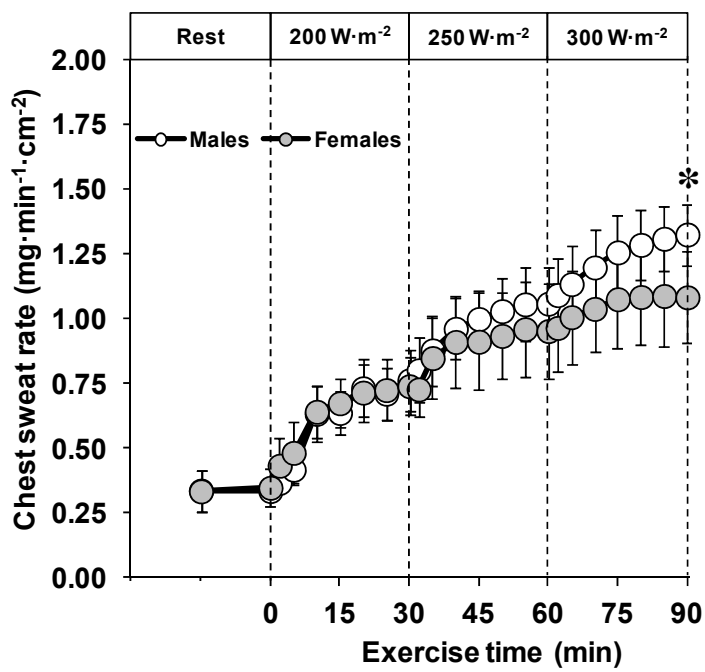

B

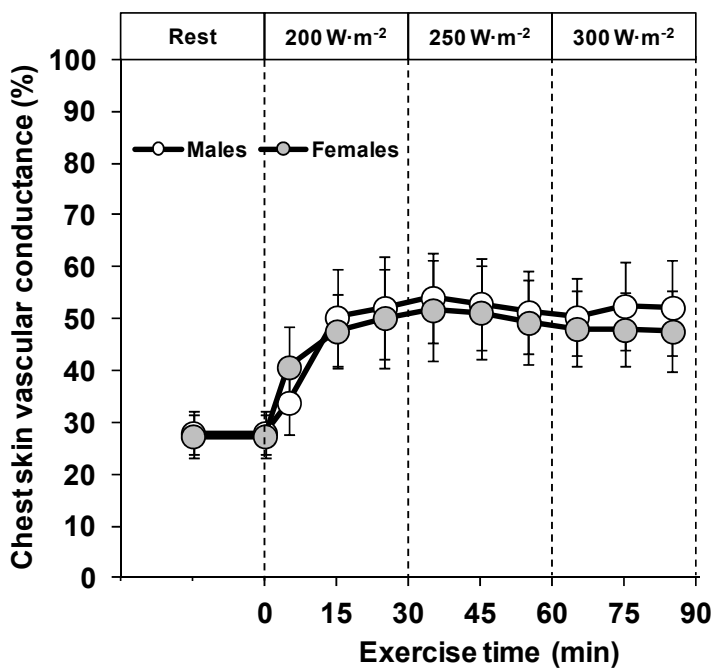

Figure 3. Sex-differences in chest sweat rate (panel A) and skin vascular conductance presented as a percentage of maximum (panel B) during exercise performed at increasing rates of metabolic heat production $\left(200,250,300 \mathrm{~W} \cdot \mathrm{m}^{-2}\right) .{ }^{*}$, Significantly different sweat rate between males and females $(\mathrm{p}<0.05)$. Dashed lines represent the beginning of each exercise period. Values are mean $\pm 95 \%$ confidence intervals. 
A

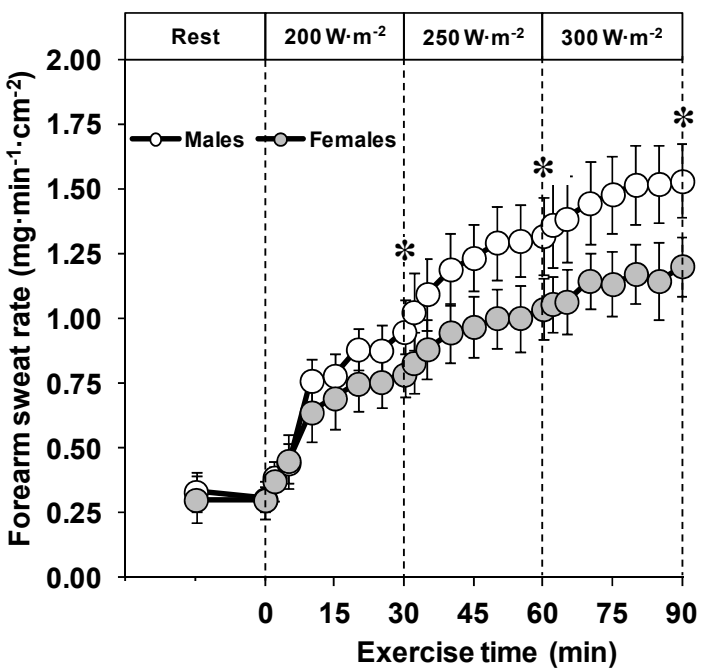

B

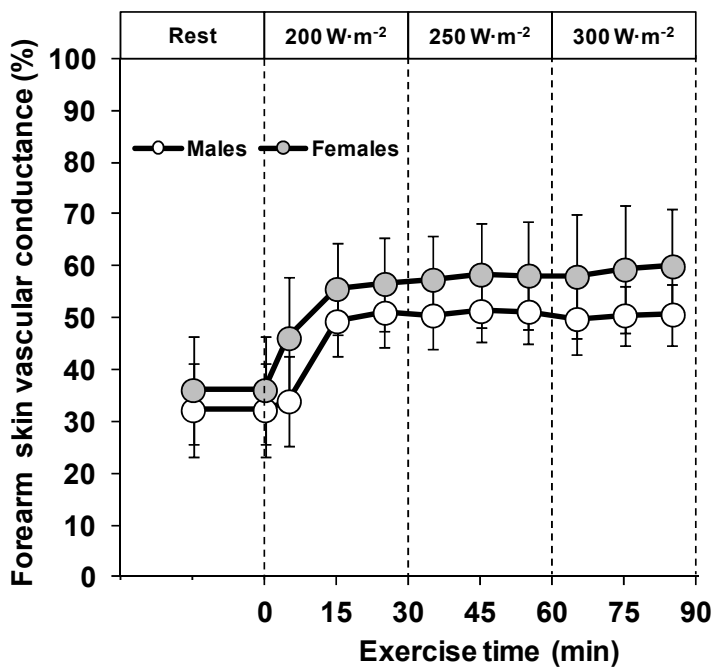

Figure 4. Sex-differences in forearm sweat rate (panel A) and skin vascular conductance presented as a percentage of maximum (panel B) during exercise performed at increasing rates of metabolic heat production $\left(200,250,300 \mathrm{~W} \cdot \mathrm{m}^{-2}\right) .{ }^{*}$, Significantly different sweat rate between males and females $(\mathrm{p}<0.05)$. Dashed lines represent the beginning of each exercise period. Values are mean $\pm 95 \%$ confidence intervals. 

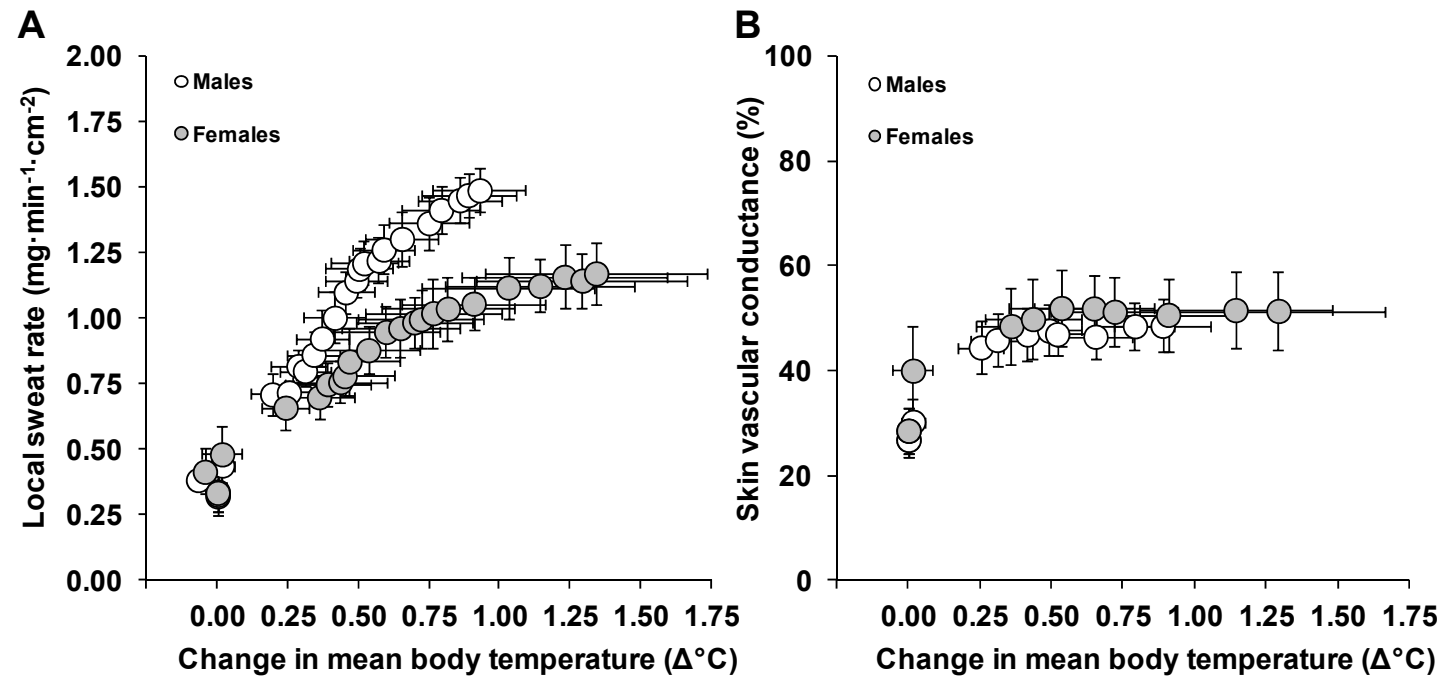

Figure 5. Graphical representation of local sweat rate (panel A) and skin vascular conductance (panel B) as a function of changes in mean body temperature in males and females during exercise performed at increasing rates of metabolic heat production. The values represent the mean of three measurement sites (back, chest, forearm). Values are mean $\pm 95 \%$ confidence intervals. 


\title{
3.3 Thesis article \#3
}

\section{Sex-differences in post-synaptic sweating and cutaneous vasodilation.}

Final version of article submitted to the Journal of Applied Physiology (JAPPL-00877-2012)

\author{
${ }^{1}$ Daniel Gagnon, ${ }^{2}$ Craig G. Crandall, ${ }^{1}$ Glen P. Kenny
}

\begin{abstract}
${ }^{1}$ Human and Environmental Physiology Research Unit, School of Human Kinetics, University of Ottawa, Ottawa, Canada; ${ }^{2}$ Institute for Exercise and Environmental Medicine, Texas Health Presbyterian Hospital Dallas and University of Texas Southwestern Medical Center
\end{abstract}

Author contributions: All authors contributed to the conception and design of the experiments, to the collection, analysis and interpretation of data, as well as to the drafting and critical revising of the manuscript. All authors have approved the final version of the manuscript. Experiments were performed at the University of Ottawa and the Institute for Exercise and Environmental Medicine.

Running head: Sex-differences in heat loss. 


\section{ABSTRACT}

Recent findings show that females exhibit a lower sudomotor thermosensitivity during exercise. To assess if sex modulates sudomotor activity peripherally, we examined doseresponse relationships on 12 males and 12 females to incremental doses of acetylcholine (ACh) and methylcholine (MCh) for sweating (ventilated capsule), as well as to ACh and sodium nitroprusside (SNP) for cutaneous vasodilation (laser-Doppler). On a separate day, we examined if expected sex-differences in the aforementioned dose-response relationships would be paralleled by a different onset threshold and/or thermosensitivity of heat loss responses during progressive increases in mean body temperature $(0.8 \times$ esophageal temperature $+0.2 \times$ mean skin temperature) elicited by passive heating. Sweating increased similarly between sexes across all doses of ACh $(\mathrm{p}=0.507)$ and MCh $(\mathrm{p}=0.817)$, resulting in a similar concentration eliciting $50 \%$ of the maximal response for both agonists $(\mathrm{p}>0.1)$. However, maximal sweat rate was lower in females during prolonged infusion of the greatest concentration employed for ACh $(0.27 \pm 0.08$ vs. 0.48 $\left.\pm 0.13 \mathrm{mg} \cdot \mathrm{min}^{-1} \cdot \mathrm{cm}^{-2}, \mathrm{p}=0.02\right)$ and $\mathrm{MCh}\left(0.41 \pm 0.09\right.$ vs. $0.57 \pm 0.11 \mathrm{mg} \cdot \mathrm{min}^{-1} \cdot \mathrm{cm}^{-2}$, $\mathrm{p}=0.04$ ). This observation was paralleled by a lower thermosensitivity of sudomotor activity in females during passive heating $\left(1.29 \pm 0.34\right.$ vs. $1.83 \pm 0.33 \mathrm{mg} \cdot \mathrm{min}^{-1} \cdot \mathrm{cm}^{-2} \cdot{ }^{\circ} \mathrm{C}^{-1}$, $\mathrm{p}=0.03)$, with no significant differences in the onset threshold $(0.85 \pm 0.19$ vs. $0.67 \pm$ $0.13^{\circ} \mathrm{C}, \mathrm{p}=0.10$ ). No sex-differences in cutaneous vasodilation were observed in response to incremental doses of ACh and SNP, as well as during passive heating (all $\mathrm{p}>0.1$ ). These findings provide direct evidence for a peripheral modulation of sudomotor activity in females. In contrast, sex does not modulate cutaneous vasodilation.

Key words: Sweat gland, Skin blood flow, Temperature regulation, Thermoregulation. 


\section{INTRODUCTION}

Sex-differences in temperature regulation during exercise exist irrespective of confounding differences in metabolic heat production and physical characteristics. Specifically, females exhibit a lower increase in both local (10) and whole-body $(10,11)$ sudomotor activity as a function of increases in body temperature (i.e. thermosensitivity), with no differences in the onset threshold of these responses. Furthermore, these sexdifferences only become evident above a certain requirement for heat loss and are solely attributed to a lower sweat gland output in females (10). Although these findings provide strong evidence for physiological differences between sexes, it remains unclear whether they are related to a central (e.g. neural activity/integration) and/or peripheral (e.g. effector organ/output) modulation of temperature regulation.

The peripheral properties of the sweat glands and cutaneous vasculature can be assessed by examining changes in sweat production and cutaneous vasodilation to various doses of pharmacological agonists. Early studies report a qualitatively lower sweat response (i.e. visual determination of sweat imprints) in females for a given dose of cholinergic agonists $(12,17)$. In contrast, Buono \& Sjoholm (2) observed a similar sweat rate to a given dose of pilocarpine between sexes with similar training status, albeit it was achieved through a greater sweat output in males, relative to greater sweat gland recruitment in females. Most recently, Madeira et al. (20) reported that the extrapolated maximal sweat response to pilocarpine does not differ between males and females matched for fitness, even though females demonstrate a lower cholinergic sensitivity of the sweat gland. Although these studies generally support a peripheral modulation of the sweat gland in females, the mechanisms by which sex-differences in sudomotor activity to a given dose of cholinergic agonist have not been evaluated. For example, the observation that females demonstrate a lower sweat rate to a given dose of acetylcholine 
(17), but not pilocarpine (2), might be explained by sex-differences in acetylcholinesterase activity $(18,25)$. This possibility can be addressed by the simultaneous use of a cholinergic agonist that is hydrolysed by acetylcholinesterase (i.e. acetylcholine) and one that is resistant (i.e. methylcholine) to its activity. Furthermore, previous studies have not examined whether sex-differences in cholinergic sensitivity and/or the capacity of the sweat glands to respond to a cholinergic stimulus are paralleled by different sudomotor responses elicited by increases in body temperature. In fact, it has been suggested that sex-differences in sweating to a given dose of acetylcholine are not associated with differences in sweat rate during heat stress (17). Finally, no studies have evaluated possible sex-related differences in the pharmacological sensitivity of the cutaneous vasculature.

Therefore, the current study examined sex-differences in dose-response relationships of sweating to incremental doses of acetylcholine and methylcholine. We also examined whether potential sex-differences in dose-response relationships were paralleled by different sudomotor responses during whole-body passive heating. A secondary objective of this study was to assess potential sex-differences in cutaneous vascular conductance to incremental doses of acetylcholine and sodium nitroprusside. We hypothesised that males and females would demonstrate a similar cholinergic sensitivity and maximal response to incremental doses of methylcholine, while females would demonstrate a lower cholinergic sensitivity to acetylcholine. We also hypothesised that females would exhibit a lower thermosensitivity of sudomotor activity during wholebody passive heating, with no differences in onset threshold. In contrast, we hypothesised that no sex-differences in cutaneous vascular conductance would be observed, both in response to incremental doses of pharmacological agonists and to increases in mean body temperature. 


\section{METHODS}

\section{Ethical approval}

The current experimental protocol was approved by the University of Ottawa Health Sciences and Science Research Ethics Board, as well as the Institutional Review Boards of the University of Texas Southwestern Medical Center and Texas Health Presbyterian Hospital Dallas. Written informed consent was obtained from all volunteers prior to their participation in the study.

\section{Participants}

Reported sex-differences in sweating during pharmacological stimulation (20) were used to calculate $(\beta=0.8, \alpha=0.05)$ a minimum sample size of 11 participants in each group, assuming an effect of $30 \%$ and standard deviation of $25 \%$. Twenty-four participants, 12 males and 12 females, volunteered for the study. Fourteen of the participants ( 7 males, 7 females) performed the experiments at the Institute for Exercise and Environmental Medicine (IEEM) at Texas Health Presbyterian Hospital Dallas and University of Texas Southwestern Medical Center, while the remaining 10 participants (5 males, 5 females) performed the experiments at the Human and Environmental Physiology Research Unit (HEPRU) at the University of Ottawa. To minimise the influence of differences in hormonal status across the menstrual cycle, female participants performed each experimental session within the first and tenth day after the onset of their self-reported menses. Female participants taking oral contraceptives $(n=4)$ performed the experimental sessions during the no pill/placebo phase of oral contraceptive use. Hormonal status was confirmed by taking a venous blood sample on the day of each experimental session. None of the experimental sessions for female participants were withdrawn or repeated based on blood sample results. Participants were 
healthy, non-smoking, and free of any known cardiovascular, metabolic and respiratory diseases. Participant characteristics are presented in Table 1.

\section{Experimental Design}

Participants volunteered for one preliminary and two experimental sessions. During the preliminary session, training history, body height, mass, and density, as well as maximum oxygen uptake were determined. Since the cholinergic sensitivity of the sweat gland has been associated with an individual's training status (2), we recruited males and females with a similar training history which was assessed by having the participants quantify their physical activity levels using the quantitative ( 3 month) and seven day physical activity recall questionnaires proposed by Kohl et al. (19). Body height was determined using a stadiometer, while body mass was measured using a scale. Body surface area was subsequently calculated from the measurements of body height and mass (8). Body density was measured using the hydrostatic weighing technique, and used to calculate body fat percentage (26). Maximum oxygen uptake was determined by indirect calorimetry (HEPRU: Moxus system, Applied Electrochemistry, Pittsburgh, PA, USA; IEEM: Parvo medics system, Parvo Medics, Sandy, UT, USA) during a progressive incremental exercise protocol (4) performed on a treadmill (HEPRU) or cycle ergometer (IEEM).

For the first experimental session, participants were placed in a semi-recumbent position on a bed, following which three microdialysis membranes were inserted by advancing a 25 -gauge needle 15 to $20 \mathrm{~mm}$ through the dermal layer of dorsal forearm skin. The microdialysis probe was subsequently threaded through the lumen of the needle which was subsequently withdrawn, leaving in place a $1 \mathrm{~cm}$ dialysis membrane within the dermal layer (Bioanalytical Systems Inc., West Lafayette, IN, USA). All microdialysis probes were first perfused with lactated Ringer solution (Baxter, Deerfield, 
IL, USA) at a rate of $4 \mu \mathrm{L} \cdot \mathrm{min}^{-1}$ via a perfusion pump (HEPRU: model 400, CMA Microdialysis, Solna, Sweden; IEEM: Harvard Apparatus, Holliston, MA, USA) for 120 min while hyperemia associated with insertion trauma subsided. During this time, the area directly over one microdialysis membrane was instrumented for the measurement of local sweat rate (site \#1), a second was instrumented for the dual measurement of sweat rate and cutaneous vasodilation (site \#2), while the third was instrumented for the measurement of cutaneous vasodilation (site \#3). Dose-response curves for sweating were subsequently assessed at sites \#1 and \#2 to incremental doses of methylcholine (MCh) and acetylcholine (ACh) respectively (Sigma-Aldrich Co., St-Louis, MO, USA). Both MCh and ACh were infused in 10-fold increments, from $1 \times 10^{-6} \mathrm{M}$ to $1 \mathrm{M}$. Doseresponse curves for cutaneous vasodilation were assessed at sites \#2 and \#3 to incremental doses of ACh and sodium nitroprusside (SNP) respectively (Hospira Inc., Lake Forest, IL, USA). Sodium nitroprusside was infused in 10-fold increments, from $5 \mathrm{x}$ $10^{-8} \mathrm{M}$ to $5 \times 10^{-2} \mathrm{M}$. Each dose was initially primed through the microdialysis membrane at an infusion rate of $102 \mu \mathrm{L} \cdot \mathrm{min}^{-1}$ for $1 \mathrm{~min}$, following which each dose was infused for $10 \mathrm{~min}$ at a rate of $4 \mu \mathrm{L} \cdot \mathrm{min}^{-1}$. The highest dose (i.e. $1 \mathrm{M}$ of $\mathrm{ACh}$ and $\mathrm{MCh}$ and $5 \times 10^{-2} \mathrm{M}$ of SNP) was infused for an additional $15 \mathrm{~min}$ (total of $25 \mathrm{~min}$ ) to ensure a steady-state maximal response to the highest concentration employed. At the end of the experimental protocol, maximum skin blood flow at the site receiving ACh (site \#2) was determined by infusing SNP $\left(5 \times 10^{-2} \mathrm{M}\right)$, while the local heater at the site receiving SNP was set to $44^{\circ} \mathrm{C}$ with continuous infusion of SNP for an additional $20 \mathrm{~min}$.

For the second experimental session, the participants donned a liquid-perfusion garment (Allen-Vanguard Corp., Ottawa, ON, Canada) which covered the entire body except for the feet, hands, and the forearm from which local sweat rate and cutaneous vasodilation were assessed. Participants were then placed in a semi-recumbent position 
on a bed while water at $34^{\circ} \mathrm{C}$ was perfused through the suit for a 30 min instrumentation period. Following instrumentation, a 20 min baseline period was performed with water at $34^{\circ} \mathrm{C}$ circulating through the suit, following which the temperature of the water was increased to $48^{\circ} \mathrm{C}$, and heating continued until an increase in esophageal temperature of $\sim 1.4^{\circ} \mathrm{C}$. At the end of heating, the temperature of the water was decreased to cool the participant while maximum skin blood flow was determined by increasing the temperature of the heater housing the laser-Doppler probes to $44^{\circ} \mathrm{C}$ for $30 \mathrm{~min}$.

For both experimental sessions, participants reported to the laboratory between $7 \mathrm{~h} 00$ and $10 \mathrm{~h} 00$ and provided a urine sample for the measurement of urine specific gravity. The participants were asked to drink $500 \mathrm{~mL}$ of water the night prior to, as well as the morning of, each experimental session and to refrain from alcohol, caffeine, and exercise $24 \mathrm{~h}$ prior to experimentation. The two experimental sessions were performed on separate days, separated by a minimum of $24 \mathrm{~h}$. Possible differences in acclimatisation status between sexes were not taken into account and all experimentation occurred between the months of September and April. Both experimental sessions were performed at an ambient room temperature of $22-24^{\circ} \mathrm{C}$ and clothing was standardised to shorts and a sports bra for female participants during the second experimental session.

\section{Measurements}

Local sudomotor activity was measured on the dorsal forearm using plastic capsules attached to the skin with adhesive rings and topical skin glue (Collodion HV, Mavidon Medical products, Lake Worth, FL, USA). The sweat capsule at site \#2 also housed the laser-Doppler flow probe (see details below), allowing for the simultaneous measurement of local sweat rate and skin blood flow. Anhydrous compressed nitrogen was passed through each capsule at a known flow rate (HEPRU: $1 \mathrm{~L} \cdot \mathrm{min}^{-1}$; IEEM: 0.3 $\left.\mathrm{L} \cdot \mathrm{min}^{-1}\right)$. Water content of the effluent air was measured using high precision dew point 
mirrors (HEPRU: RH systems, Albuquerque, NM, USA) or capacitance hygrometers (IEEM: Vaisala, Woburn, WA, USA). Local sweat rate was calculated using the difference in water content between effluent and influent air multiplied by the flow rate and normalised for the skin surface area under the capsule.

The number of active sweat glands was measured following the $25 \mathrm{~min}$ period of continuous infusion at the highest dose employed during experimental session 1 , as well as at the end of passive heating during experimental session 2 using the modified iodinepaper technique with computer-assisted analysis $(7,9)$. The sweat output per gland was calculated by dividing the sweat rate at the corresponding measurement period by the number of active sweat glands.

Local cutaneous blood flow was estimated using laser-Doppler velocimetry (PeriFlux System 5000, Perimed AB, Stockholm, Sweden). Prior to the start of the experimental trial, laser-Doppler flow probes (integrating probe 413, Perimed AB, Stockholm, Sweden) were affixed with an adhesive ring to the forearm in a site that demonstrated cardio-synchronous pulsatile activity. Cutaneous vascular conductance was subsequently calculated as the ratio of cutaneous blood flow perfusion units to mean arterial pressure and expressed as a percentage of maximum.

Esophageal temperature was measured with a general purpose thermocouple temperature probe (Mallinckrodt Medical Inc., St-Louis, MO, USA). The probe was inserted $40 \mathrm{~cm}$ past the entrance of the nostril while the participants sipped water (100$300 \mathrm{~mL}$ ) through a straw. Skin temperature was measured at 10 (HEPRU) or 6 (IEEM) sites using thermocouples attached to the skin with surgical tape. Mean skin temperature was subsequently calculated using a 10 or 6 point weighting of the regional proportions determined by Hardy and DuBois (14). In 10 participants (5 males and 5 females), the thermocouples were integrated into heat flow sensors (HEPRU: Concept Engineering, 
Old Saybrook, CT, USA) to estimate rate of dry heat exchange. Data were either collected with a data-acquisition system at $50 \mathrm{~Hz}$ (IEEM: Biopac System, Santa Barbara, CA, USA), or with a HP Agilent data acquisition module (HEPRU: model 3497A) at a rate of one sample every $15 \mathrm{~s}$ and simultaneously displayed and recorded in spreadsheet format on a personal computer with LabVIEW software (HEPRU: Version 7.0, National Instruments, TX, USA).

Systolic and diastolic blood pressures were measured using an automated blood pressure monitor (Tango+, SunTech Medical Inc., Morrisville, NC, USA) and used to calculate mean arterial pressure (diastolic blood pressure $+1 / 3 \times$ pulse pressure).

Urine specific gravity was determined in duplicate using a handheld refractometer (HEPRU: TS400, Reichter Inc., Depew, NY, USA, IEEM: PAL-10S, Atago, Japan).

On the day of each experimental session, a venous blood sample $(10 \mathrm{~mL})$ was obtained from female participants to confirm that the session occurred in the follicular/low hormone phase of the menstrual cycle. The blood samples were collected with a $\mathrm{SST}^{\mathrm{TM}}$ vacutainer (BD Vacutainer, Franklin lakes, NJ, USA) for the determination of plasma $17 \beta$-estradiol and progesterone. Plasma concentrations of $17 \beta$-estradiol and progesterone were quantified by independent external laboratories (HEPRU: GammaDynacare Medical Laboratories, Ottawa, ON, Canada; IEEM: ARUP Laboratories, Salt lake City, UT, USA). The plasma concentrations representative of the follicular phase of the menstrual cycle for $17 \beta$-estradiol and progesterone are $46-604 \mathrm{pmol} / \mathrm{L}$ and $0.6-4.7$ $\mathrm{nmol} / \mathrm{L}$ respectively.

\section{Data analysis}

To determine the concentration of the agonist causing $50 \%$ of the maximal response $\left(\mathrm{EC}_{50}\right)$, dose-response curves were constructed by plotting sweat rate/cutaneous vascular conductance over the log concentration of the agonist and fitted using a non- 
linear regression analysis using a standardised slope of $1(6,18)$. During the passive heating session, local sudomotor activity and skin blood flow were measured at two sites, the average of both being used for the statistical analyses. For all variables, minute averages were performed for the statistical analyses. To account for the relative influence of core and skin temperatures on the activation of heat loss responses $(15,21,22,29)$, mean body temperature was calculated as: $0.8 \times$ esophageal temperature $+0.2 \times$ mean skin temperature (28). The onset threshold and thermosensitivity of local sudomotor activity and cutaneous vascular conductance were determined using the linear portion of each response plotted against mean body temperature and analyzed using segmented regression analysis (5).

\section{Statistical analysis}

All dependent variables were compared between groups (males vs. females) within each experimental session. Independent samples T-tests were used for single comparisons between groups, while a two-way mixed model analysis of variance was used for multiple comparisons between groups using the repeated factor of agonist concentration (experimental session 1) or change in mean body temperature (experimental session 2) and the non-repeated factor of sex. When a significant main effect was observed, post-hoc comparisons were carried out with the Holm-Bonferonni approach. The level of significance for all analyses was set at an alpha level of $\mathrm{p} \leq 0.05$. Statistical analyses were performed using commercially available statistical software (SPSS 19.0 for Windows, SPSS Inc., Chicago, IL, USA). Dose-response curves and segmented regression analysis were performed using GraphPad Prism 5.0 (GraphPad Software, La Jolla, CA, USA). Participant characteristics are presented as mean \pm standard deviation, while all variables are reported as mean $\pm 95 \%$ confidence intervals. Confidence intervals were calculated as $1.96 \times$ standard error of the mean. 


\section{RESULTS}

\section{Participant characteristics}

Males had a significantly greater height $(\mathrm{p}=0.01)$, weight $(\mathrm{p}=0.003)$, body surface area $(p=0.002)$, and maximum oxygen consumption both in absolute values $(p \leq 0.001)$ as well as relative to body mass $(\mathrm{p}=0.02)$. However, there were no significant differences between groups in maximum oxygen consumption expressed relative to lean body mass $(\mathrm{p}=0.11)$.

\section{Training history}

During the 3 months prior to their participation in the study, males reported engaging in physical activities long enough to work up a sweat on average $5 \pm 2$ (range: 1-10) times per week, compared with $5 \pm 1$ (range: $2-7)$ for females $(\mathrm{p}=0.81)$. On average, males exercised $7 \pm 3$ (range: 3 -14) hours per week, while females exercised $6 \pm$ 3 (range: $2-11$ ) hours per week $(\mathrm{p}=0.60)$. During the 7 days prior to their participation in the study, males and females reported performing vigorous physical activity for $4 \pm 3$ (range: $0-8$ ) and $4 \pm 3$ (range: $1-10$ ) hours respectively ( $\mathrm{p}=0.93$ ). Males and females also reported performing moderate physical activity for $2 \pm 2$ (range: $0-5$ ) and $4 \pm 3$ (range: 0 10) hours respectively $(\mathrm{p}=0.10)$.

\section{Post-junctional sweating and cutaneous vasodilation}

On the day of the experimental session, plasma concentrations of $17 \beta$-estradiol and progesterone for the female participants averaged $154 \pm 102 \mathrm{pmol} \cdot \mathrm{L}^{-1}$ and $1.1 \pm 0.4$

$\mathrm{nmol} \cdot \mathrm{L}^{-1}$ respectively. Urine specific gravity averaged $1.019 \pm 0.006$ in males and 1.012 \pm 0.007 in females $(\mathrm{p}=0.01)$.

There were no significant differences in baseline sweat rate between males and females at both the MCh and $\mathrm{ACh}$ sites $(\mathrm{p}>0.1)$. Sweating increased as a function of 
increasing concentrations of both $\mathrm{MCh}$ and $\mathrm{ACh}(\mathrm{p} \leq 0.001$, Fig. 1), to a similar extent between males and females (both sites $\mathrm{p}>0.1$, Fig. 1). The similar increases between sexes were paralleled by a similar $\mathrm{EC}_{50}$ of the sweating response at the $\mathrm{MCh}(\mathrm{p}=0.38$, Fig 1A) and ACh ( $\mathrm{p}=0.91$, Fig. 1B) sites. However, the maximal sweating rate after $25 \mathrm{~min}$ of continuous infusion at the highest concentration was significantly lower in females at the MCh ( $\mathrm{p}=0.038$, Fig. 1A) and ACh ( $\mathrm{p}=0.015$, Fig. 1B) sites. The number of active sweat glands at the highest concentration employed was significantly greater in females $\left(56 \pm 7\right.$ glands $\left.\cdot \mathrm{cm}^{-2}\right)$ compared to males $\left(47 \pm 5\right.$ glands $\left.\cdot \mathrm{cm}^{-2}, \mathrm{p}=0.03\right)$. As such, the lower maximal sweat rate in females was associated with a lower sweat gland output $(7.75 \pm$ $\left.1.68 \mu \mathrm{L} \cdot \mathrm{min}^{-1}\right)$ relative to males $\left(12.24 \pm 2.30 \mu \mathrm{L} \cdot \mathrm{min}^{-1}, \mathrm{p} \leq 0.001\right)$.

Baseline cutaneous vascular conductance was lower in females at the ACh $(\mathrm{p} \leq 0.001)$ and SNP $(\mathrm{p}=0.06)$ sites. Cutaneous vascular conductance increased with incremental concentrations of both $\mathrm{ACh}$ and SNP $(\mathrm{p} \leq 0.001)$. These increases were similar between sexes at both sites ( $\mathrm{p}>0.1$, Fig. 2), which was paralleled by similar $\mathrm{EC}_{50}$ of the dose-response curves at the ACh ( $\mathrm{p}=0.26$, Fig. 2A) and SNP ( $\mathrm{p}=0.72$, Fig. 2B) sites. Furthermore, maximal cutaneous vascular conductance after 25 min of continuous infusion at the highest drug concentration did not differ between males and females at both sites ( $\mathrm{p}>0.1$, Fig. 2).

\section{Sweating and cutaneous vasodilation during passive heating}

On the passive heat stress day, plasma concentrations of $17 \beta$-estradiol and progesterone for the female participants averaged $153 \pm 90 \mathrm{pmol} \cdot \mathrm{L}^{-1}$ and $1.4 \pm 1.3$ $\mathrm{nmol} \cdot \mathrm{L}^{-1}$ respectively. Urine specific gravity did not significantly differ between groups (males: $1.013 \pm 0.007$ vs. females: $1.016 \pm 0.008, \mathrm{p}=0.52$ ). The heating period increased mean skin temperature by $4.24 \pm 0.39^{\circ} \mathrm{C}$ and $4.34 \pm 0.38^{\circ} \mathrm{C}$ in males and females respectively $(p=0.91)$, which resulted in a similar dry heat gain between sexes $(p=0.39$, 
Fig. 3). Passive heating increased esophageal temperature by $1.39 \pm 0.10^{\circ} \mathrm{C}$ over $71 \pm 8$ min in males and $1.46 \pm 0.13^{\circ} \mathrm{C}(\mathrm{p}=0.71)$ over $61 \pm 12 \min (\mathrm{p}=0.18)$ in females. The increases in mean skin and esophageal temperatures were associated with an increase of at least $1.75^{\circ} \mathrm{C}$ in mean body temperature for all participants.

Sweat rate increased as a function of increases in mean body temperature $(p \leq 0.001)$ and was significantly different between males and females ( $p=0.013$, Fig. 4). Although sweat rate did not initially differ between males and females, it became significantly greater in males at an increase in mean body temperature of $1.25^{\circ} \mathrm{C}$ $(p<0.01)$. The number of active sweat glands at the end of the heating period did not differ between males $\left(75 \pm 8\right.$ glands $\left.\cdot \mathrm{cm}^{-2}\right)$ and females $\left(83 \pm 12\right.$ glands $\left.\cdot \mathrm{cm}^{-2}, \mathrm{p}=0.22\right)$. As such, the lower sweat rate in females was associated with a lower sweat gland output $\left(9.93 \pm 2.73 \mu \mathrm{L} \cdot \mathrm{min}^{-1}\right)$ relative to males $\left(14.63 \pm 3.22 \mu \mathrm{L} \cdot \mathrm{min}^{-1}, \mathrm{p}=0.03\right)$. The lower sweat rate in females was paralleled by a lower thermosensitivity of the response (females: $1.29 \pm 0.34 \mathrm{mg} \cdot \mathrm{min}^{-1} \cdot \mathrm{cm}^{-2} \cdot{ }^{\circ} \mathrm{C}^{-1}$ vs. males: $1.83 \pm 0.33 \mathrm{mg} \cdot \mathrm{min}^{-1} \cdot \mathrm{cm}^{-2} \cdot{ }^{\circ} \mathrm{C}^{-1}$, $\mathrm{p}=0.03$ ) without any differences in the mean body temperature onset threshold (females: $0.85 \pm 0.19^{\circ} \mathrm{C}$ vs. males: $\left.0.67 \pm 0.13^{\circ} \mathrm{C}, \mathrm{p}=0.10\right)$.

Cutaneous vascular conductance increased as a function of increases in mean body temperature $(p \leq 0.001)$, with no differences between males and females $(p=0.41$, Fig. 5). The similar cutaneous vascular response between males and females was paralleled by a similar onset threshold (males: $0.56 \pm 0.14^{\circ} \mathrm{C}$ vs. females: $0.73 \pm 0.14^{\circ} \mathrm{C}$, $\mathrm{p}=0.07$ ) and thermosensitivity (males: $65 \pm 17 \% \cdot{ }^{\circ} \mathrm{C}^{-1}$ vs. females: $76 \pm 14 \% \cdot{ }^{\circ} \mathrm{C}^{-1}$, $\mathrm{p}=0.31)$ of the response. 


\section{DISCUSSION}

The current study examined sex-differences in post-synaptic sweating and cutaneous vasodilation in response to incremental doses of pharmacological agonists. The main findings show that males and females, matched for training status, demonstrate a similar dose-response relationship for sweating to incremental doses of both acetylcholine and methylcholine. However, females exhibit a lower maximal sweat rate in response to continuous infusion of the highest concentration of cholinergic agonists employed. Furthermore, the lower maximal sweat rate in females to pharmacological stimulation is paralleled by a lower sweat rate and thermosensitivity of the response during progressive increases in mean body temperature, with no differences in the onset threshold. Finally, we did not observe sex-differences in cutaneous vasodilation, either in response to pharmacological stimulation or during passive heat stress.

The primary aim of this study was to assess the possibility that a peripheral modulation of sudomotor activity is responsible for the lower local and whole-body sudomotor thermosensitivity observed in females during exercise $(10,11)$. The significantly lower maximal sweat rate in females during continuous infusion of the highest concentration employed of acetylcholine and methylcholine provides direct evidence of a peripheral modulation of sudomotor activity in females. In contrast, no differences in the $\mathrm{EC}_{50}$ of the sweating response were observed for both agonists. The lack of differences in the $\mathrm{EC}_{50}$ of the response argues against potential sex-differences in the cholinergic sensitivity of the sweat gland (20). Furthermore, the similar dose-response relationships between sexes for both methylcholine and acetylcholine do not support a role for sex-differences in acetylcholinesterase activity in mediating the lower sudomotor thermosensitivity observed during exercise $(10,11)$ and passive heating $(16)$, as well as to intradermal injections of acetylcholine (17). Rather, the lower maximal sweat response at 
the highest concentrations employed in females suggests a lower maximal sweating capacity of the sweat gland, which could be associated with differences in sweat gland size (23). Further studies are therefore needed to assess the morphological properties of the sweat glands in males and females to verify this hypothesis.

Very few studies have examined sweating responses in males and females to various doses of cholinergic agonists, with some only reporting qualitative (e.g. visual assessment of sweat imprints) differences between sexes $(12,17)$. To our knowledge, only two studies have provided a quantitative assessment between males and females, albeit with mixed results. Buono \& Sjoholm (2) first reported similar sweat rates in males and females to a single dose $(0.5 \%)$ of pilocarpine, although this was achieved through greater sweat gland activation in females. It should be noted, however, that the use of a single, relatively low dose of pilocarpine did not allow for a dose-response assessment. It is therefore possible that differences in sweat rate may have been observed at greater concentrations. In fact, Madeira et al. (20) using five incremental doses $(0.125,0.250$, $0.5,1.0$, and $2.0 \%$ ) of pilocarpine reported that the concentration required to elicit $50 \%$ of the maximal sweat response (cholinergic sensitivity, $\mathrm{EC}_{50}$ ) was lower in males compared to females of similar training status. In contrast, maximal sweat rate calculated based on extrapolation of obtained data did not differ between sexes (20). In the current study, we did not observe any differences in the $\mathrm{EC}_{50}$ of the sweating response to both incremental doses of acetylcholine and methylcholine. Furthermore, we observed a lower sweat rate in females at the highest concentration of acetylcholine and methylcholine employed. The differences between the current findings and those of Madeira et al. (20) are not readily apparent. The use of iontophoresis (as opposed to microdialysis), as well as evaluating each dose on separate days (as opposed to performing a dose-response relationship with successive doses) may in part explain the differences between the findings of Madeira et 
al. (20) and those of the current study. Further studies are needed to examine these possibilities.

It is important to note that we observed both a lower maximal sweat rate in females to the highest concentration of cholinergic agonists employed, as well as a lower thermosensitivity of sudomotor activity during whole-body passive heating. Assuming similar levels of thermoefferent activity for a given change in mean body temperature, a lower sweat rate for a given change in mean body temperature (as observed during passive heat stress) can be explained by a peripheral modulation of the sweat gland. These findings are therefore consistent with the lower maximal sweat rate observed with microdialysis. In contrast, factors which are thought to exert a central modulation of temperature regulation, such as hyperosmolality, sex hormones and acclimatisation consistently shift the onset threshold of the sweating response $(1,24,27)$. It is also generally accepted that a central modulation of temperature regulation must shift the onset threshold of both sweating and cutaneous vasodilation (13). Therefore, the lack of sex-differences in the onset threshold of both sweating and cutaneous vasodilation during passive heating in the current study, combined with the observed differences in postjunctional sweating, supports the hypothesis that sex modulates sudomotor activity peripherally during heat stress. These findings are consistent with previous observations during passive heating (16), as well more recently during exercise $(10,11)$. In contrast, the cutaneous vascular response was similar between sexes both in response to pharmacological stimulation, as well as during passive heating. These findings do not support previous suggestions of a greater reliance on cutaneous vasodilation in females for dissipating heat during heat stress (16), and rule out the possibility that observed sexdifferences in sudomotor activity might be related to differences in cutaneous vasodilation (28). 


\section{Considerations}

It may be argued that the observed sex-differences in sudomotor activity are related to the differences in maximum oxygen consumption between groups. Although some studies report a greater sweating response to cholinergic stimulation in individuals with greater maximum oxygen consumption $(2,3,20)$, it is most likely that such observations are associated with the beneficial adaptations that come with regular exercise training, as opposed to a direct effect of maximum oxygen consumption per se. In fact, Buono \& Sjoholm (2) reported a similar sweat rate response to cholinergic stimulation between males and females of similar training status, despite females having lower maximum oxygen consumption values. Furthermore, it has also been shown that the cholinergic sensitivity (i.e., $\mathrm{EC}_{50}$ ) of the sweat gland is improved with exercise training (3), yet we did not observe any differences in the $\mathrm{EC}_{50}$ of the sweating response between males and females. In the current study, males and females were therefore matched for training status, as opposed to maximum oxygen consumption values. The similar training status between sexes, combined with the similar maximum oxygen consumption values expressed as a function of lean body mass, suggest that the lower absolute maximum oxygen consumption values in females were simply due to differences in the amount of metabolically active tissue, as opposed to differences in the benefits of regular exercise training which may confer adaptations for temperature regulation.

\section{CONCLUSION}

The current study examined sex-related differences in post-junctional sweating and cutaneous vasodilation. A similar dose-response relationship was observed for both sweating and cutaneous vascular conductance to incremental doses of pharmacological agonists. However, maximal sweat rate was lower in females compared to males in response to continuous infusion of the highest concentrations of acetylcholine and 
methylcholine employed. We also observed a lower thermosensitivity of sudomotor activity in females during passive heat stress, with no sex-differences in the onset threshold. In contrast, there were no sex-differences in both the onset threshold and thermosensitivity of cutaneous vascular conductance during passive heat stress. Taken together, these findings provide direct evidence of a peripheral modulation of sudomotor activity in females during heat stress. 


\section{REFERENCES}

1. Armstrong CG, and Kenney WL. Effects of age and acclimation on responses to passive heat exposure. J Appl Physiol 75 2162-2167, 1993.

2. Buono MJ, and Sjoholm NT. Effect of physical training on peripheral sweat production. J Appl Physiol 65: 811-814, 1988.

3. Buono MJ, White CS, and Connolly KP. Cholinergic sensitivity of the eccrine sweat gland in trained and untrained men. J Dermatol Sci 4: 33-37, 1992.

4. Canadian Society for Exercise Physiology. Chapter II: Determination of Aerobic Power. In: Certified Fitness Appraiser Resource Manual Gloucester, Ontario: CSEP, 1986, p. 1-32.

5. Cheuvront SN, Bearden SE, Kenefick RW, Ely BR, Degroot DW, Sawka MN, and Montain SJ. A simple and valid method to determine thermoregulatory sweating threshold and sensitivity. J Appl Physiol 107: 69-75, 2009.

6. Davis SL, Shibasaki M, Low DA, Cui J, Keller DM, Purdue GF, Hunt JL, Arnoldo BD, Kowalske KJ, and Crandall CG. Skin grafting impairs postsynaptic cutaneous vasodilator and sweating responses. J Burn Care Res 28: 435-441, 2007.

7. Davis SL, Wilson TE, Vener JM, Crandall CG, Petajan JH, and White AT. Pilocarpine-induced sweat gland function in individuals with multiple sclerosis. J Appl Physiol 98: 1740-1744, 2005.

8. DuBois D, and DuBois EF. A formula to estimate the approximate surface area if height and weight be known. Arch Intern Med 17: 863-871, 1916.

9. Gagnon D, Ganio MS, Lucas RA, Pearson J, Crandall CG, and Kenny GP. Modified iodine-paper technique for the standardized determination of sweat gland activation. J Appl Physiol 112: 1419-1425, 2012.

10. Gagnon D, and Kenny GP. Sex-differences in thermoeffector responses during exercise at fixed requirements for heat loss. J Appl Physiol 113: 746-757, 2012.

11. Gagnon D, and Kenny GP. Sex modulates whole-body sudomotor thermosensitivity during exercise. J Physiol 589: 6205-6217, 2011.

12. Gibson TE, and Shelley WB. Sexual and racial differences in the response of sweat glands to acetylcholine and pilocarpine. J Invest Dermatol 11: 137-142, 1948.

13. Gisolfi CV, and Wenger CB. Temperature regulation during exercise: old concepts, new ideas. Exerc Sport Sci Rev 12: 339-372, 1984.

14. Hardy $\mathbf{J}$, and DuBois $\mathbf{E}$. The technique of measuring radiation and convection. $J$ Nutr 15: 461-475, 1938.

15. Hertzman AB, Randall WC, Peiss CN, and Seckendorf R. Regional rates of evaporation from the skin at various environmental temperatures. J Appl Physiol 5: 153$161,1952$. 
16. Inoue Y, Tanaka Y, Omori K, Kuwahara T, Ogura Y, and Ueda H. Sex- and menstrual cycle-related differences in sweating and cutaneous blood flow in response to passive heat exposure. Eur J Appl Physiol 94: 323-332, 2005.

17. Kahn D, and Rothman S. Sweat response to acetylcholine. J Invest Dermatol 5: 431-444, 1942.

18. Kimura K, Low DA, Keller DM, Davis SL, and Crandall CG. Cutaneous blood flow and sweat rate responses to exogenous administration of acetylcholine and methacholine. J Appl Physiol 102: 1856-1861, 2007.

19. Kohl HW, Blair SN, Paffenbarger RS, Macera CA, and Kronenfeld JJ. A mail survey of physical activity habits as related to measured physical fitness. Am $J$ Epidemiol 127: 1228-1239, 1988.

20. Madeira LG, da Fonseca MA, Fonseca IA, de Oliveira KP, Passos RL, Machado-Moreira CA, and Rodrigues LO. Sex-related differences in sweat gland cholinergic sensitivity exist irrespective of differences in aerobic capacity. Eur J Appl Physiol 109: 93-100, 2010.

21. Nadel ER, Bullard RW, and Stolwijk JA. Importance of skin temperature in the regulation of sweating. J Appl Physiol 31: 80-87, 1971.

22. Nadel ER, Mitchell JW, Saltin B, and Stolwijk JA. Peripheral modifications to the central drive for sweating. J Appl Physiol 31: 828-833, 1971.

23. Sato K, and Sato F. Individual variations in structure and function of human eccrine sweat gland. Am J Physiol 245: 203-208, 1983.

24. Sawka MN. Physiological consequences of hypohydration: exercise performance and thermoregulation. Med Sci Sports Exerc 24: 657-670, 1992.

25. Shibasaki M, and Crandall CG. Effect of local acetylcholinesterase inhibition on sweat rate in humans. J Appl Physiol 90: 757-762, 2001.

26. Siri WE. Gross composition of the body. In: Advances in Biological and Medical Physics, edited by Lawrence JH, and Tobias CA. New York: Academic, 1956, p. 239280.

27. Stephenson LA, and Kolka MA. Thermoregulation in women. Exerc Sport Sci Rev 21: 231-262, 1993.

28. Wingo JE, Low DA, Keller DM, Brothers RM, Shibasaki M, and Crandall CG. Skin blood flow and local temperature independently modify sweat rate during passive heat stress in humans. J Appl Physiol 109: 1301-1306, 2010.

29. Wyss CR, Brengelmann GL, Johnson JM, Rowell LB, and Niederberger M. Control of skin blood flow, sweating, and heart rate: role of skin vs. core temperature. $J$ Appl Physiol 36: 726-733, 1974. 


\section{ACKNOWLEDGEMENTS}

The current study was performed by D.G., in partial fulfillment for the degree of Doctor of Philosophy from the University of Ottawa. D.G. is supported by an Alexander Graham Bell Canadian Graduate Scholarship and a Michael Smith Foreign Study Supplement from the Natural Sciences and Engineering Research Council. The current work was supported by the Natural Sciences and Engineering Research Council (RGPIN-2981592009, G.P.K.), Leaders Opportunity Fund from the Canada Foundation for Innovation (22529, G.P.K.), and Institutes of Health HL61388 and HL64072 (C.G.C). G.P.K. is supported by a University of Ottawa Research Chair in Environmental Physiology. The authors acknowledge the contribution of Dr. Ollie Jay who provided critical input into the

development of this work, as well as James Pearson, Rebekah Lucas, and Zachary Schlader who assisted with data collection. The authors thank all the participants who volunteered for the present study. 
Table 1. Participant characteristics.

\begin{tabular}{|c|c|c|c|c|c|c|c|c|c|}
\hline Sex & $\begin{array}{l}\text { Age } \\
\text { (yrs) }\end{array}$ & $\begin{array}{l}\text { Body mass } \\
\quad(\mathrm{kg})\end{array}$ & $\begin{array}{l}\text { Height } \\
(\mathrm{cm})\end{array}$ & $\begin{array}{l}A_{D} \\
\left(\mathrm{~m}^{2}\right)\end{array}$ & $\begin{array}{l}\text { Fat mass } \\
(\mathrm{kg})\end{array}$ & $\begin{array}{l}\text { Fat free mass } \\
(\mathrm{kg})\end{array}$ & $\begin{array}{l}\dot{\mathrm{VO}}_{2 \max } \\
\left(\mathrm{L} \cdot \mathrm{min}^{-1}\right)\end{array}$ & $\begin{array}{c}\mathrm{VO}_{2 \max } \\
\left(\mathrm{mL} \cdot \mathrm{kg}^{-1} \cdot \mathrm{min}^{-1}\right)\end{array}$ & $\begin{array}{c}\dot{\mathrm{VO}}_{2 \max } \\
\left(\mathrm{mL} \cdot \mathrm{kg}_{\mathrm{FFM}}^{-1} \cdot \min ^{-1}\right)\end{array}$ \\
\hline Males & $\begin{array}{l}27 \\
\pm 6\end{array}$ & $\begin{array}{c}74.9 \\
\pm 9.1 *\end{array}$ & $\begin{array}{l}174 \\
\pm 7^{*}\end{array}$ & $\begin{array}{c}1.89 \\
\pm 0.13^{*}\end{array}$ & $\begin{array}{l}12.3 \\
\pm 5.3\end{array}$ & $\begin{array}{c}61.5 \\
\pm 5.9^{*}\end{array}$ & $\begin{array}{c}4.08 \\
\pm 0.66^{*}\end{array}$ & $\begin{array}{c}55.7 \\
\pm 9.6^{*}\end{array}$ & $\begin{array}{l}66.5 \\
\pm 9.9\end{array}$ \\
\hline Females & $\begin{array}{l}27 \\
\pm 5\end{array}$ & $\begin{array}{l}63.5 \\
\pm 8.0\end{array}$ & $\begin{array}{l}168 \\
\pm 5\end{array}$ & $\begin{array}{c}1.72 \\
\pm 0.12\end{array}$ & $\begin{array}{l}14.9 \\
\pm 4.3\end{array}$ & $\begin{array}{l}48.6 \\
\pm 5.0\end{array}$ & $\begin{array}{c}2.95 \\
\pm 0.62\end{array}$ & $\begin{array}{l}46.3 \\
\pm 7.1\end{array}$ & $\begin{array}{l}60.2 \\
\pm 7.7\end{array}$ \\
\hline
\end{tabular}

$A_{D}$, body surface area; $\dot{\mathrm{VO}}_{2 \max }$, maximum oxygen consumption; FFM, fat free mass. $*$ Significantly different from females $(P \leq 0.05)$. Values are mean \pm standard deviation. 
A

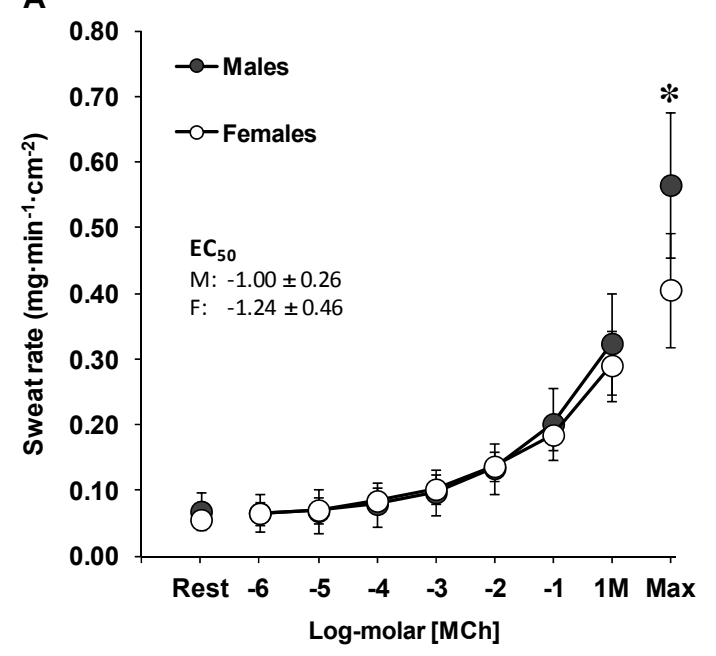

B

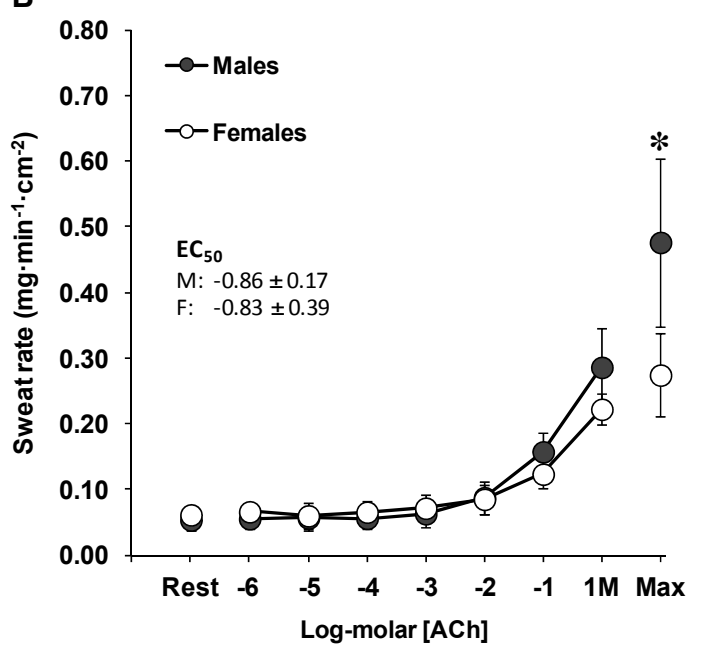

Figure 1. Sex-differences in dose-response relationships for sweating to incremental doses of methylcholine ( $\mathrm{MCh}$, panel A) and acetylcholine (ACh, panel B). Max, the maximal response elicited by continuous infusion of the highest concentration employed. $\mathrm{EC}_{50}$, the concentration required to elicit $50 \%$ of the maximal response. ${ }^{*}$, significant difference between males and females $(\mathrm{p} \leq 0.05)$. Values are mean $\pm 95 \%$ confidence intervals. 

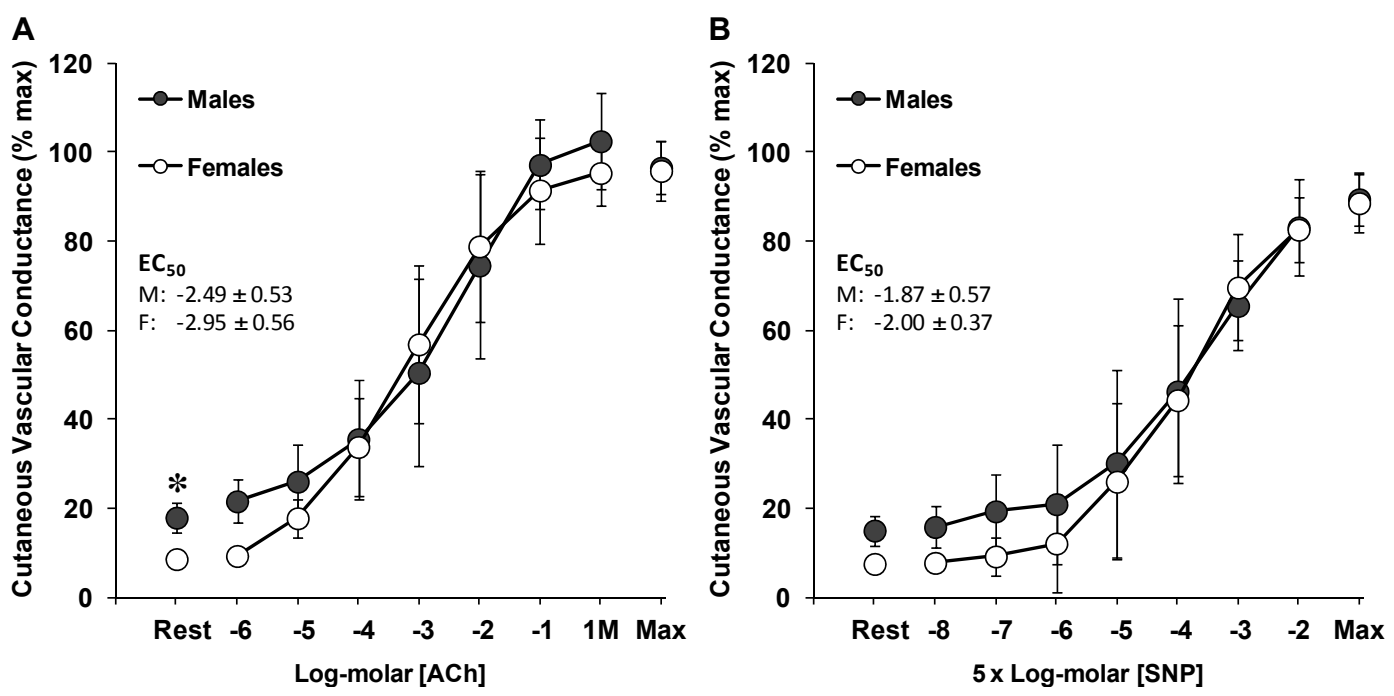

Figure 2. Sex-differences in dose-response relationships for cutaneous vascular conductance to incremental doses of acetylcholine (ACh, panel A) and sodium nitroprusside (SNP, panel B). Max, the maximal response elicited by continuous infusion of the highest concentration employed. $\mathrm{EC}_{50}$, the concentration required to elicit $50 \%$ of the maximal response. ${ }^{*}$, significant difference between males and females $(\mathrm{p} \leq 0.05)$. Values are mean $\pm 95 \%$ confidence intervals. 


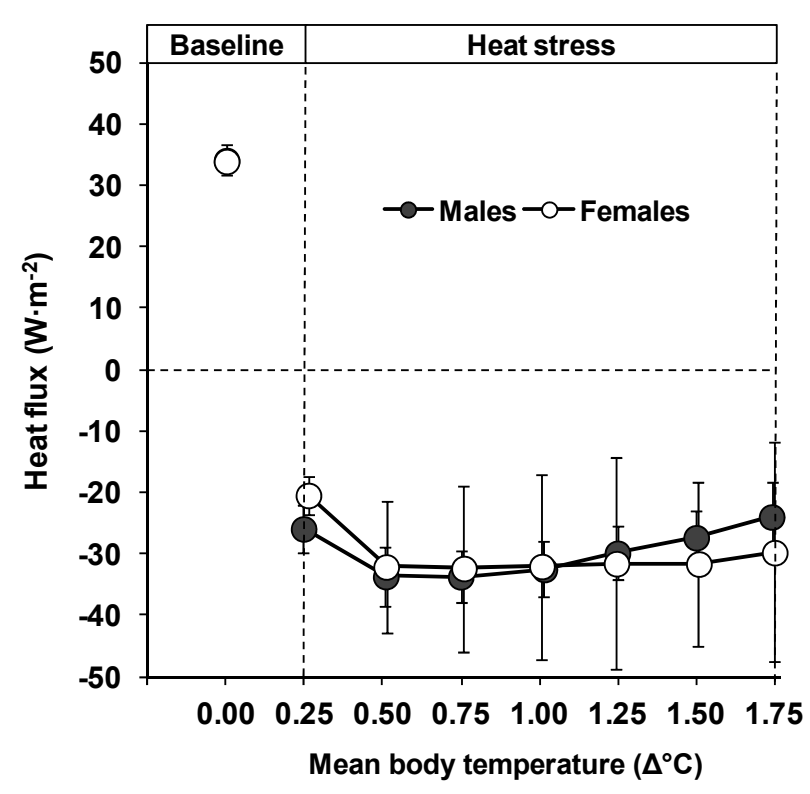

Figure 3. Sex-differences in dry heat exchange (heat flux) as a function of progressive increases in mean body temperature elicited by passive heating. Horizontal dashed line separates dry heat loss (positive values) from dry heat gain (negative values). Values are mean $\pm 95 \%$ confidence intervals. 


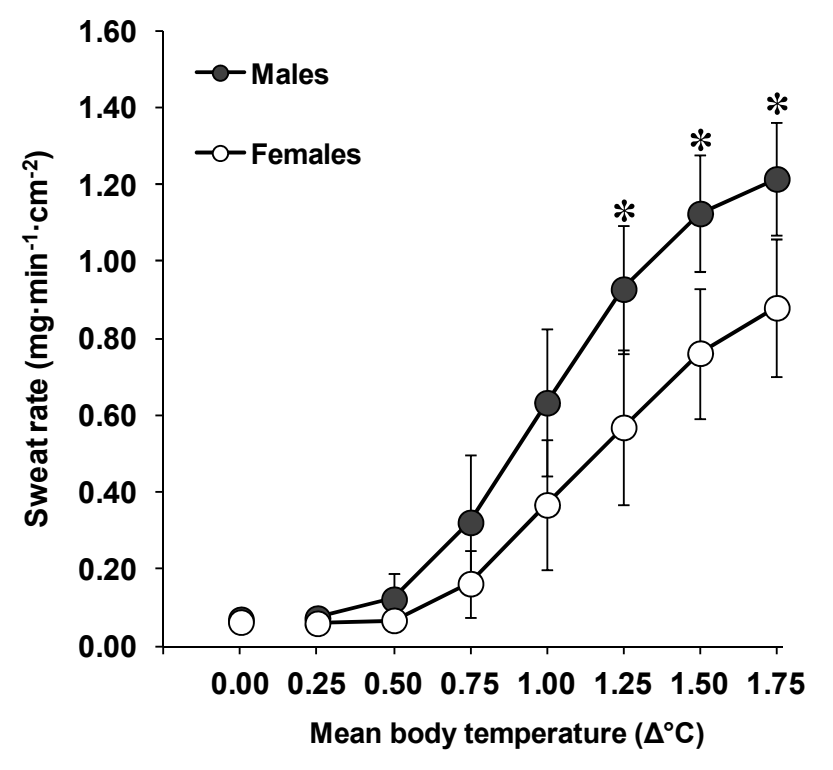

Figure 4. Sex-differences in local sudomotor activity (sweat rate) as a function of progressive increases in mean body temperature elicited by passive heating. *, significant difference between males and females $(\mathrm{p} \leq 0.05)$. Values are mean $\pm 95 \%$ confidence intervals. 


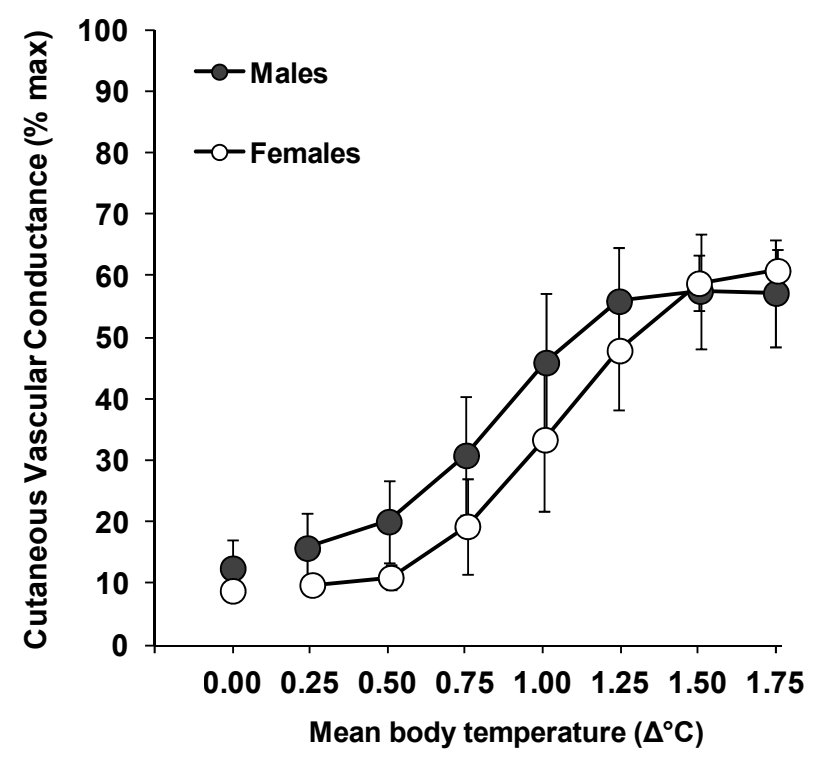

Figure 5. Sex-differences in cutaneous vascular conductance as a function of progressive increases in mean body temperature elicited by passive heating. Values are mean $\pm 95 \%$ confidence intervals. 


\section{CHAPTER IV}

\section{THESIS DISCUSSION}




\subsection{Thesis discussion}

The primary purpose of the current thesis was to determine if sex-differences in local and whole-body heat loss responses are evident when accounting for confounding differences in physical characteristics and rate of metabolic heat production. The results of the first and second studies clearly establish that such differences exist, albeit only as it relates to sudomotor activity as no differences in skin blood flow were observed during each study. Specifically, females exhibit a lower thermosensitivity of both local and whole-body sudomotor activity during exercise, with no differences in the onset threshold. However, the results of the second study reveal that these differences are not evidenced at all combinations of exercise intensity and environmental conditions, but rather only become apparent above a certain requirement for heat loss. Finally, the results of the second and third studies provide insight as to whether the lower sudomotor thermosensitivity in females is associated with a central and/or peripheral modulation of temperature regulation. In particular, the lower sweat rate to the highest concentration of cholinergic agonists employed during the third study provides support for a peripheral modulation of sudomotor activity in females.

The first study was specifically designed to examine the influence of sex per se on whole-body heat loss during exercise. It is important to re-emphasise that although previous studies had examined core temperature and/or heat loss responses in males and females during exercise, none of them had properly accounted for confounding differences in both physical characteristics and rate of metabolic heat production. Furthermore, many previous studies relied upon core temperature measurements which do not provide an accurate insight into potential sex-differences in heat loss (Gagnon et al., 2009), or on single local measures of heat loss responses. Therefore, whole-body heat loss as measured through direct calorimetry was examined in males and females matched 
for body mass and surface area, the main physical characteristics influencing heat exchange during exercise in the heat (Havenith et al., 1995; Havenith et al., 1998). Furthermore, the exercise period was performed at a fixed rate of metabolic heat production to negate any differences in metabolic heat production associated with exercise at a fixed percentage of maximum oxygen consumption (Gagnon et al., 2008). The main findings of the first study show that females exhibit a lower whole-body sudomotor activity during exercise at a fixed rate of metabolic heat production, which is not associated with differences in body mass and surface area. The lower whole-body sudomotor activity in females was also paralleled by a lower thermosensitivity of the response, without any differences in the mean body temperature onset threshold. These findings led us to believe that sex-differences in sudomotor activity go beyond those associated with differences in physical characteristics and rate of metabolic heat production.

It should be noted that although the results obtained during exercise at a fixed (absolute) rate of metabolic heat production (i.e. $500 \mathrm{~W}$ ) were compared to exercise performed at a fixed percentage of maximum oxygen consumption (i.e. 50\%), the participants also performed a third experimental trial during which exercise was performed at a fixed rate of metabolic heat production expressed relative to body surface area (i.e. $250 \mathrm{~W} \cdot \mathrm{m}^{-2}$ ). This additional trial was not included in the accepted manuscript of the first study (Appendix A), the results of which are included in Appendix C and discussed here as they formed the rationale for the design of the second thesis study. Despite males and females being matched for body mass according to our experimental design, the possibility of differences in body surface area between sexes remained if both groups differed in height. We therefore included a condition during which exercise was performed at a fixed rate of metabolic heat production relative to body surface area of 
$250 \mathrm{~W} \cdot \mathrm{m}^{-2}$. However, since matching males and females for body mass resulted in very similar body surface areas between groups, the net result was an exercise trial performed at a similar rate of absolute metabolic heat production of $\sim 450 \mathrm{~W}$. From the figure presented in Appendix C, it can be seen that males and females had a similar rate of whole-body heat loss at this rate of metabolic heat production. Importantly, the absolute rate of metabolic heat production $(\sim 450 \mathrm{~W})$ at which both groups exercised in this condition was lower than when exercise was performed at $500 \mathrm{~W}$. Although it may seem contradictory that a similar whole-body sudomotor activity was observed between males and females during exercise performed at a rate of metabolic heat production of $450 \mathrm{~W}$, yet a lower whole-body sudomotor activity is observed in females when exercise is performed at a rate of metabolic heat production of $500 \mathrm{~W}$, these findings suggested that sex-differences in sudomotor activity may not be evidenced at all levels of metabolic heat production.

Consistent with this hypothesis, recent findings suggest that sex-differences in sweat gland function improvements elicited by exercise training are intensity-dependent (Ichinose-Kuwahara et al., 2010). Specifically, a greater thermosensitivity of the sweating response was reported in trained males compared to trained females, whereas no differences were observed between untrained males and females during exercise performed at $35 \%, 50 \%$, and $65 \%$ of maximum oxygen consumption. Although both sexes exercised at different external workloads (and therefore rates of metabolic heat production), which confounded the results (Gagnon et al., 2008; Schwiening et al., 2011), these findings combined with those of the first thesis study led us to hypothesise that sexdifferences in sudomotor activity may only be evidenced beyond a certain requirement for heat loss, since differences were only observed between the males and females which exercised at the highest external workloads (Ichinose-Kuwahara et al., 2010). To test this 
hypothesis, we therefore examined sex-differences in local and whole-body sudomotor activity during exercise performed at progressive increments in the requirement for heat loss. The main observation of the second study is that sex-differences in whole-body sudomotor activity only occurred at the highest requirement for heat loss employed. Furthermore, the lack of differences in sudomotor activity at the lower requirements for heat loss were paralleled by a similar thermosensitivity of the response, while the lower sudomotor activity in females at the highest requirement for heat loss was paralleled by a lower thermosensitivity of the response. In contrast, no differences were observed in the onset thresholds for both local and whole-body sudomotor activity. These observations confirmed the hypothesis that sex-differences in sudomotor activity are only evidenced above a certain combination of environmental conditions and rate of metabolic heat production.

Since it became clear that sex itself can modulate sudomotor activity during exercise, we sought to examine the possible physiological mechanisms for these differences. In theory, the lower thermosensitivity in females of whole-body sudomotor activity could be due to differences in: 1) thermoafferent activity from peripheraland/central thermoreceptors; 2) neural integration of thermoafferent activity, 3) thermoefferent activity, 4) the thermoffector response for a given level of thermoefferent activity, or 5) a combination of these possibilities. If sex modulates sudomotor activity centrally though differences in the integration and/or level of thermo-afferent/efferent activity, sex-differences in sweat rate would be expected to be observed at any combination of ambient conditions and metabolic heat production. It might also be expected that a central modulation would result in a different onset threshold of sudomotor activity in females (Nadel et al., 1971b). A central modulation of temperature regulation in females might also result in a shift of the onset threshold of not only 
sudomotor activity, but also of cutaneous vasodilation (Gisolfi \& Wenger, 1984). For example, central adaptations associated with factors such as heat acclimatisation (Armstrong \& Kenney, 1993), sex hormones (Stephenson \& Kolka, 1993) and plasma hyperosmolality (Sawka, 1992) consistently shift the onset threshold of both thermoeffector responses with little to no change in thermosensitivity. These shifts are also evidenced whether the requirement for heat loss is high such as during exercise in the heat, or relatively low such as during passive heat stress (Fox et al., 1963; Bittel \& Henane, 1975; Takamata et al., 1995). Finally, a lower sudomotor thermosensitivity in females which is centrally mediated might also be thought to result from reduced sweat gland activation. In contrast to each of these possibilities, no differences in the onset threshold for both sweating and cutaneous vasodilation were observed at all requirements for heat loss, while a lower sudomotor thermosensitivity in females was only evident at the highest requirement for heat loss employed (rather than during each exercise period). Furthermore, the observed differences in local sudomotor activity were solely the result of differences in sweat gland output, as sweat gland recruitment was generally greater in females.

Alternatively, a peripheral modulation might be expected to result in a different sweat gland output (Sato \& Dobson, 1970) and maximal capacity of the gland to produce sweat (Sato \& Sato, 1983) between males and females. Consistent with these possibilities, the lower local sweat rates observed in females during the second thesis study were solely due to differences in sweat gland output. Furthermore, we observed a clear leveling off of sudomotor activity in females at the highest requirement for heat loss, which might provide evidence for a lower maximal sweating capacity. A peripheral modulation of sudomotor activity could stem from differences in the physical properties of the sweat gland itself (e.g. size), the sensitivity of the sweat gland to a given 
concentration of neurotransmitters released from sudomotor nerve terminals, and/or in the breakdown of acetylcholine within the sudomotor junction. Previous studies have provided evidence for a lower sweat response in females to locally administered acetylcholine (Kahn \& Rothman, 1942; Gibson \& Shelley, 1948) and pilocarpine (Madeira et al., 2010), pointing towards a sex-difference in the cholinergic sensitivity of the sweat gland. The results of the second thesis study, combined with previous work, led us to the hypothesis that sex-differences in sudomotor activity are mediated peripherally through differences in the thermoeffector organ, which was evaluated through the third and final thesis study.

The third thesis study evaluated sex-differences in sweat rate and cutaneous vasodilation to incremental doses of pharmacological agonists. The responses elicited during pharmacological stimulation were also compared to the sweating and cutaneous vasodilation responses observed during progressive increases in mean body temperature elicited by passive heating. Although a few previous studies evaluated sex-differences in cholinergic responsiveness of the sweat gland, some only reported qualitative differences (visual examination of sweat imprints) between males and females (Kahn \& Rothman, 1942; Gibson \& Shelley, 1948), while those with quantitative data reported mixed findings (Buono \& Sjoholm, 1988; Madeira et al., 2010). Furthermore, no previous study had examined whether observed differences in sweat rate between males and females to pharmacological stimulation were paralleled by differences in sudomotor activity during heat stress. Finally, no study had evaluated the pharmacological sensitivity of the cutaneous vasculature between males and females. The main finding of the third thesis study was the lower sweat rate in females at the greatest concentration of acetylcholine and methylcholine employed. In contrast, no sex-differences a similar concentration required to elicit $50 \%$ of the maximal response (i.e., $\mathrm{EC}_{50}$ ) was observed for both 
agonists. The lack of sex-differences in $\mathrm{EC}_{50}$ suggests that the cholinergic sensitivity of the sweat gland does not differ between sexes. Furthermore, the fact that females exhibited a lower sweat response to the greatest concentration employed of acetylcholine and methylcholine argues against a role for acetylcholinesterase activity in mediating the lower sudomotor activity during heat stress. Rather, the lower maximal sweat rate during pharmacological stimulation in females points towards sex-differences in the physical characteristics (e.g., size) of the sweat gland (Sato \& Sato, 1983). It is also interesting to note that the observed sex-differences in sweat rate to cholinergic stimulation were paralleled by a lower thermosensitivity of the response during passive heat stress, with no differences observed in the mean body temperature at which sweating occurred. Alone, the results obtained during pharmacological stimulation establish a clear peripheral modulation of the sweat gland in females. Together with the results obtained during passive heating, these findings are consistent with a peripheral modulation of sudomotor activity in females as a mechanism responsible for the lower sudomotor thermosensitivity observed compared to males during exercise and passive heat stress. In contrast, the lack of differences in cutaneous vasodilation during both pharmacological stimulation and passive heat stress suggests that sex does not modulate skin blood flow.

\section{Implications}

The primary implication of the current thesis is the observation that sex itself can modulate local and whole-body sudomotor activity during exercise in the heat. Prior to the current thesis, sex was generally not believed to be an independent modulator of human temperature regulation and most temperature regulation studies are often limited to male participants only. It is therefore unknown if and/or how sex modulates changes in temperature regulation as a function of age, disease and various physiological conditions (e.g., dehydration, acclimatisation, cold stress, etc.). The results of the current thesis 
provide the rationale for considering potential sex-differences in temperature regulation within these various conditions.

An important avenue of future research that is warranted from the results of the current thesis is to examine whether they may have important practical implications. Heat exposure guidelines in occupational and military settings recommend exercise-rest ratios based on a combination of environmental conditions and rates of metabolic heat production in an attempt to minimise core temperature increases (United States Army Center for Health Promotion and Preventive Medicine, 2003; American Conference of Industrial hygienists (ACGIH), 2007). The findings of the second thesis study, particularly those of a lower evaporative heat loss in females relative to the requirement for heat loss, suggest that maximal sudomotor activity is lower in females. This implies that an uncompensable heat stress situation would occur at a relatively lower requirement for heat loss in females compared to males. Since current heat exposure guidelines assume that males and females have a similar capacity for heat loss, they provide similar work-rest ratios regardless of sex to avoid potentially dangerous increases in core temperature. However, these recommendations might underestimate the level of heat stress in females, particularly at high requirements for heat loss which would exceed the maximal evaporative capacity of females, but not that of males. This would not only result in greater increases in core temperature for females during exercise/work performed above a certain requirement for heat loss, but also in a continuous rise in core temperature.

It is important to note, however, that the findings of the current thesis can only be extended to environments which permit full evaporation of the sweat produced. In contrast, many occupational and military settings are characterised by environments which do not permit full evaporation of the sweat produced, such as hot humid 
environments. A greater sweat rate in males at high requirements for heat loss may not be evidenced in hot and humid environments, as the skin surface would become saturated at sweat rates which do not approach maximum due to the relatively low vapour pressure gradient. In these scenarios, it is therefore possible that males and females may exhibit a similar sweat rate, as it would be limited in males by the low vapor pressure gradient between the skin surface and the environment, as opposed to being limited in females by potential peripheral differences in sweating. A few studies have investigated sex-related differences as a function of environmental conditions, generally reporting lower sweat rates in females whether the environment was considered dry or humid (Morimoto et al., 1967; Shapiro et al., 1980b; Keatisuwan et al., 1996). However, the conclusions from these studies are confounded by the differences in rate of metabolic heat production elicited by the experimental protocol employed. Examining sex-differences in sweat rate at a given requirement for heat loss in relation to whether the environment is dry or humid is therefore an important avenue of future research.

The comparisons between males and females in the current thesis are also limited to the follicular phase of the female menstrual cycle or the low hormone period of oral contraceptive use. Nonetheless, the observed sex-differences in sudomotor activity would not be expected to differ across the female menstrual cycle. The main change in thermoregulatory function that occurs over the course of the female menstrual cycle is a shift in resting body temperature, with a parallel shift in the onset threshold for sweating and cutaneous vasodilation (Stephenson \& Kolka, 1985; Kolka \& Stephenson, 1997). In contrast, however, the thermosensitivity of each response is generally not affected. Since we consistently did not observe any sex-differences in the onset threshold for sweating (local and whole-body), but observed a lower thermosensitivity of the response in females during the follicular phase of the menstrual cycle/low hormone period of oral 
contraceptive use, we would expect similar observations if females in the luteal phase of the menstrual cycle/high hormone phase of oral contraceptive use were compared to males. It is important to note that the absolute mean body temperature onset threshold would be expected to be greater in females during the luteal phase of the menstrual cycle/high hormone phase of oral contraceptive use, but this would simply result from a higher resting core temperature. If the change in mean body temperature were examined as the onset threshold, there is no evidence to suggest that it would significantly differ from males. 


\subsection{Thesis conclusions}

The current thesis examined if differences between males and females in local and whole-body heat loss are evident after accounting for confounding differences in physical characteristics and rate of metabolic heat production. Overall, the results show that females exhibit a lower local and whole-body sudomotor thermosensitivity during exercise and passive heat stress, with no differences in the onset threshold of both responses. Furthermore, the lower thermosensitivity of sudomotor activity in females is only evidenced above a certain requirement for heat loss and is solely due to differences in the sweat output per gland, as opposed to lower sweat gland recruitment. Females also demonstrate a lower sweating response to both acetylcholine and methylcholine. In contrast, no sex-differences were observed in cutaneous vasodilation during exercise, passive heat stress, and pharmacological stimulation. Overall, the findings suggest that sex modulates sudomotor activity, the likely mechanism being a peripheral modulation of the thermoeffector organ. 


\section{CHAPTER V}

\section{REFERENCES}




\subsection{References}

American Conference of Industrial hygienists (ACGIH). (2007). Heat Stress and Strain: TLV Physical Agents Documentation, pp. 1-36. ACGIH, Cincinnati, OH.

Anderson GS. (1999). Human morphology and temperature regulation. Int J Biometeorol 43, 99-109.

Armstrong CG \& Kenney WL. (1993). Effects of age and acclimation on responses to passive heat exposure. J Appl Physiol 75, 2162-2167.

Armstrong LE, Casa DJ, Millard-Stafford M, Moran DS, Pyne SW \& Roberts WO. (2007). American College of Sports Medicine position stand. Exertional heat illness during training and competition. Med Sci Sports Exerc 39, 556-572.

Austin DM \& Lansing MW. (1986). Body size and heat tolerance: a computer simulation. Hum Biol 58, 153-169.

Avellini BA, Kamon E \& Krajewski JT. (1980a). Physiological responses of physically fit men and women to acclimation to humid heat. J Appl Physiol 49, 254-261.

Avellini BA, Shapiro Y, Pandolf KB, Pimental NA \& Goldman RF. (1980b). Physiological responses of men and women to prolonged dry heat exposure. Aviat Space Environ Med 51, 1081-1085.

Bain AR, Deren TM \& Jay O. (2011). Describing individual variation in local sweating during exercise in a temperate environment. Eur J Appl Physiol 111, 1599-1607.

Bar-Or O, Lundegren HM, Magnusson LI \& Buskirk ER. (1968). Distribution of HeatActivated Sweat Glands in Obese and Lean Men and Women. Hum Biol 40, 235-248.

Bar-Or O. (1998). Effects of age and gender on sweating pattern during exercise. Int $J$ Sports Med 19 Suppl 2, S106-107.

Benzinger TH. (1969). Heat regulation: homeostasis of central temperature in man. Physiol Rev 49, 671-759.

Bittel J \& Henane R. (1975). Comparison of thermal exchanges in men and women under neutral and hot conditions. $J$ Physiol 250, 475-489.

Bligh J. (2006). A theoretical consideration of the means whereby the mammalian core temperature is defended at a null zone. J Appl Physiol 100, 1332-1337.

Boulant JA. (1996). Hypothalamic neurons regulating body temperature. In Handbook of physiology Section 4: Environmental physiology, ed. Fregly M \& Blatteis C, pp. 105-126. Oxford University press, New York, NY.

Buono MJ \& Sjoholm NT. (1988). Effect of physical training on peripheral sweat production. J Appl Physiol 65, 811-814. 
Buono MJ \& Connolly KP. (1992). Increases in sweat rate during exercise: Gland recruitment versus output per gland. J Therm Biol 17, 267-270.

Burse RL. (1979). Sex differences in human thermoregulatory response to heat and cold stress. Hum Factors 21, 687-699.

Candas V, Libert JP \& Vogt JJ. (1979). Human skin wettedness and evaporative efficiency of sweating. J Appl Physiol 46, 522-528.

Castellani JW, Young AJ, Ducharme MB, Giesbrecht GG, Glickman E \& Sallis RE. (2006). Prevention of Cold Injuries during Exercise. Med Sci Sports Exerc 38, 20122029.

Charkoudian N \& Johnson JM. (1997). Modification of active cutaneous vasodilation by oral contraceptive hormones. J Appl Physiol 83, 2012-2018.

Charkoudian N \& Johnson JM. (1999). Reflex control of cutaneaous vasoconstriction system is reset by exogenous female reproductive hormones. J Appl Physiol 87, 381-385.

Charkoudian N \& Johnson JM. (2000). Female reproductive hormones and thermoregulatory control of skin blood flow. Exerc Sport Sci Rev 28, 108-112.

Charkoudian N. (2003). Skin blood flow in adult human thermoregulation: How it works when it does not and why. Mayo Clinic Proceedings 78, 603-612.

Charkoudian N \& Joyner MJ. (2004). Physiologic considerations for exercise performance in women. Clin Chest Med 25, 247-255.

Cheung SS, McLellan TM \& Tenaglia S. (2000). The thermophysiology of uncompensable heat stress. Physiological manipulations and individual characteristics. Sports Med 29, 329-359.

Cotter JD, Patterson MJ \& Taylor NA. (1995). The topography of eccrine sweating in humans during exercise. Eur J Appl Physiol 71, 549-554.

Cramer MN, Bain AR \& Jay O. (2012). Local sweating on the forehead, but not forearm, is influenced by aerobic fitness independently of heat balance requirements during exercise. Exp Physiol 97, 572-582.

Davies CT. (1979). Thermoregulation during exercise in relation to sex and age. Eur $J$ Appl Physiol 42, 71-79.

Drinkwater BL, Denton JE, Kupprat IC, Talag TS \& Horvath SM. (1976). Aerobic power as a factor in women's response to work in hot environments. $J$ Appl Physiol 41, 815-821.

Drinkwater BL, Kupprat IC, Denton JE \& Horvath SM. (1977). Heat tolerance of female distance runners. Ann NY Acad Sci 301, 777-792.

DuBois D \& DuBois EF. (1916). A formula to estimate the approximate surface area if height and weight be known. Arch Intern Med 17, 863-871. 
DuBois EF, Ebaugh FG, Hardy JD, Soderstrom GF \& Stevens EI. (1952). Basal Heat Production and Elimination of Thirteen Normal Women at Temperatures from $22^{\circ} \mathrm{C}$ to $35^{\circ} \mathrm{C} . \mathrm{J}$ Nutr $48,257-293$.

Edholm OG, Fox RH \& Macpherson RK. (1957). Vasomotor control of cutaneous blood vessels in the human forearm. $J$ Physiol 139, 455-465.

Fiala D, Lomas KJ \& Stohrer M. (1999). A computer model of human thermoregulation for a wide range of environmental conditions: the passive system. J Appl Physiol 87, 1957-1972.

Fiala D, Lomas KJ \& Stohrer M. (2001). Computer prediction of human thermoregulatory and temperature responses to a wide range of environmental conditions. Int J Biometeorol 45, 143-159.

Fox RH, Goldsmith R, Kidd DJ \& Lewis HE. (1963). Blood flow and other thermoregulatory changes with acclimatization to heat. J Physiol 166, 548-562.

Fox RH, Lofstedt BE, Woodward PM, Eriksson E \& Werkstrom B. (1969). Comparison of thermoregulatory function in men and women. $J$ Appl Physiol 26, 444-453.

Frye AJ \& Kamon E. (1981). Responses to dry heat of men and women with similar aerobic capacities. J Appl Physiol 50, 65-70.

Frye AJ \& Kamon E. (1983). Sweating efficiency in acclimated men and women exercising in humid and dry heat. J Appl Physiol 54, 972-977.

Fusco MM, Hardy JD \& Hammel HT. (1961). Interaction of central and peripheral factors in physiological temperature regulation. Am J Physiol 200, 572-580.

Gagge AP \& Gonzales RR. (1996). Mechanisms of heat exchange. In Handbook of Physiology Section 4: Environmental Physiology, ed. Fregley MJ \& Blatteis CM, pp. 4584. Oxford University press, New York, NY.

Gagnon D, Jay O, Lemire B \& Kenny GP. (2008). Sex-related differences in evaporative heat loss: the importance of metabolic heat production. Eur J Appl Physiol 104, 821-829.

Gagnon D, Dorman LE, Jay O, Hardcastle SG \& Kenny GP. (2009). Core temperature differences between sexes during intermittent exercise: physical considerations. Eur $J$ Appl Physiol 105, 453-461.

Gibson TE \& Shelley WB. (1948). Sexual and racial differences in the response of sweat glands to acetylcholine and pilocarpine. J Invest Dermatol 11, 137-142.

Gisolfi CV \& Wenger CB. (1984). Temperature regulation during exercise: old concepts, new ideas. Exerc Sport Sci Rev 12, 339-372.

Hammel HT. (1968). Regulation of internal body temperature. Ann Rev Physiol 30, 641710 . 
Hammel HT, Hardy JD \& Fusco MM. (1960). Thermoregulatory responses to hypothalamic cooling in unanesthetized dogs. Am J Physiol 198, 481-486.

Hardy JD \& DuBois EF. (1937). Regulation of heat loss from the human body. Proc Natl Acad Sci 26, 624-631.

Hardy JD \& DuBois EF. (1940). Differences between Men and Women in Their Response to Heat and Cold. Proc Nat Acad Sci 26, 389-398.

Hardy JD, Milhorat AT \& DuBois EF. (1941). Basal metabolism and heat loss of young women at temperatures from $22^{\circ} \mathrm{C}$ to $35^{\circ} \mathrm{C}$. $J$ Nutr $21,383-404$.

Hardy JD. (1961). Physiology of temperature regulation. Physiol Rev 41, 521-606.

Havenith G \& van Middendorp H. (1990). The relative influence of physical fitness, acclimatization state, anthropometric measures and gender on individual reactions to heat stress. Eur J Appl Physiol 61, 419-427.

Havenith G, Luttikholt VG \& Vrijkotte TG. (1995). The relative influence of body characteristics on humid heat stress response. Eur J Appl Physiol 70, 270-279.

Havenith G, Coenen JM, Kistemaker L \& Kenney WL. (1998). Relevance of individual characteristics for human heat stress response is dependent on exercise intensity and climate type. Eur J Appl Physiol 77, 231-241.

Havenith G. (2001a). Human surface to mass ratio and body core temperature in exercise heat stress - a concept revisited. J Therm Biol 26, 387-393.

Havenith G. (2001b). Individualized model of human thermoregulation for the simulation of heat stress response. J Appl Physiol 90, 1943-1954.

Hertzman AB, Randall WC, Peiss CN \& Seckendorf R. (1952). Regional rates of evaporation from the skin at various environmental temperatures. J Appl Physiol 5, 153161.

Horstman DH \& Christensen E. (1982). Acclimatization to dry heat: active men vs. active women. J Appl Physiol 52, 825-831.

Ichinose-Kuwahara T, Inoue Y, Iseki Y, Hara S, Ogura Y \& Kondo N. (2010). Sex differences in the effects of physical training on sweat gland responses during a graded exercise. Exp Physiol 95, 1026-1032.

Inoue Y, Tanaka Y, Omori K, Kuwahara T, Ogura Y \& Ueda H. (2005). Sex- and menstrual cycle-related differences in sweating and cutaneous blood flow in response to passive heat exposure. Eur J Appl Physiol 94, 323-332.

Jay O, Bain AR, Deren TM, Sacheli M \& Cramer MN. (2011). Large differences in peak oxygen uptake do not independently alter changes in core temperature and sweating during exercise. Am J Physiol Regul Integr Comp Physiol 301, 832-841. 
Jessen C. (1996). Interaction of body temperatures in control of thermoregulatory effector mechanisms. In Handbook of physiology Section 4: Environmental physiology, ed. Fregly MJ \& Blatteis CM, pp. 127-138. Oxford University press, New York, NY.

Johnson JM, Brengelmann GL \& Rowell LB. (1976). Interactions between local and reflex influences on human forearm skin blood flow. J Appl Physiol 41, 826-831.

Johnson JM \& Proppe DW. (1996). Cardiovascular adjustments to heat stress. In Handbook of physiology Section 4: Environmental physiology, ed. Fregly MJ \& Blatteis CM, pp. 215-243. Oxford University press, New York, NY.

Joyner MJ \& Coyle EF. (2008). Endurance exercise performance: the physiology of champions. J Physiol 586, 35-44.

Kaciuba-Uscilko H \& Grucza R. (2001). Gender differences in thermoregulation. Curr Opin Clin Nutr Metab Care 4, 533-536.

Kahn D \& Rothman S. (1942). Sweat response to acetylcholine. J Invest Dermatol 5, 431-444.

Kamijo Y, Lee K \& Mack GW. (2005). Active cutaneous vasodilation in resting humans during mild heat stress. J Appl Physiol 98, 829-837.

Keatinge W. (1960). The effects of subcutaneous fat and of previous cold exposure on the body temperature, peripheral blood flow and metabolic rate of men in cold water. $J$ Physiol 353, 166-178.

Keatisuwan W, Ohnaka T \& Tochihara Y. (1996). Physiological responses of men and women during exercise in hot environments with equivalent WBGT. Appl Hum Sci 15, 249-258.

Kellogg DL Jr., Johnson JM \& Kosiba WA. (1989). Selective abolition of adrenergic vasoconstrictor responses in skin by local iontophoresis of bretylium. Am J Physiol Heart Circ Physiol 257, H1599-1606.

Kellogg DL Jr., Crandall CG, Liu Y, Charkoudian N \& Johnson JM. (1998). Nitric oxide and cutaneous active vasodilation during heat stress in humans. J Appl Physiol 85, 824829.

Kellogg DL Jr., Liu Y, Kosiba IF \& O'Donnell D. (1999). Role of nitric oxide in the vascular effects of local warming of the skin in humans. J Appl Physiol 86, 1185-1190.

Kellogg DL Jr. (2006). In vivo mechanisms of cutaneous vasodilation and vasoconstriction in humans during thermoregulatory challenges. J Appl Physiol 100, 1709-1718.

Kenney WL. (1985). A review of comparative responses of men and women to heat stress. Environ Res 37, 1-11. 
Kenney WL \& Johnson JM. (1992). Control of skin blood flow during exercise. Med Sci Sports Exerc 24, 303-312.

Kenny GP, Webb P, Ducharme MB, Reardon FD \& Jay O. (2008). Calorimetric measurement of postexercise net heat loss and residual body heat storage. Med Sci Sports Exerc 40, 1629-1636.

Knip AS. (1969). Measurement and regional distribution of functioning eccrine sweat glands in male and female Caucasians. Hum Biol 41, 380-387.

Kolka MA \& Stephenson LA. (1997). Effect of luteal phase elevation in core temperature on forearm blood flow during exercise. J Appl Physiol 82, 1079-1083.

Kondo N, Takano S, Aoki K, Shibasaki M, Tominaga H \& Inoue Y. (1998). Regional differences in the effect of exercise intensity on thermoregulatory sweating and cutaneous vasodilation. Acta Physiol Scand 164, 71-78.

Kondo N, Shibasaki M, Aoki K, Koga S, Inoue Y \& Crandall CG. (2001). Function of human eccrine sweat glands during dynamic exercise and passive heat stress. J Appl Physiol 95, 1877-1881.

Machado-Moreira CA, Caldwell JN, Mekjavic IB \& Taylor NA. (2008a). Sweat secretion from palmar and dorsal surfaces of the hands during passive and active heating. Aviat Space Environ Med 79, 1034-1040.

Machado-Moreira CA, Smith FM, van den Heuvel AM, Mekjavic IB \& Taylor NA. (2008b). Sweat secretion from the torso during passively-induced and exercise-related hyperthermia. Eur J Appl Physiol 104, 257-264.

Machado-Moreira CA, Wilmink F, Meijer A, Mekjavic IB \& Taylor NA. (2008c). Local differences in sweat secretion from the head during rest and exercise in the heat. Eur $J$ Appl Physiol 104, 257-264.

Madeira LG, da Fonseca MA, Fonseca IA, de Oliveira KP, Passos RL, Machado-Moreira CA \& Rodrigues LO. (2010). Sex-related differences in sweat gland cholinergic sensitivity exist irrespective of differences in aerobic capacity. Eur J Appl Physiol 109, 93-100.

Marsh SA \& Jenkins DG. (2002). Physiological responses to the menstrual cycle: implications for the development of heat illness in female athletes. Sports Med 32, 601614.

McArdle WD, Magel JR, Gergley TJ, Spina RJ \& Toner MM. (1984). Thermal adjustment to cold-water exposure in resting men and women. J Appl Physiol 56, 15651571 .

McLellan TM. (1998). Sex-related differences in thermoregulatory responses while wearing protective clothing. Eur J Appl Physiol 78, 28-37. 
Moran DS, Shapiro Y, Laor A, Izraeli S \& Pandolf KB. (1999). Can gender differences during exercise-heat stress be assessed by the physiological strain index? Am J Physiol 276, 1798-1804.

Morimoto T, Slabochova Z, Naman RK \& Sargent F. (1967). Sex differences in physiological reactions to thermal stress. J Appl Physiol 22, 526-532.

Nadel ER, Bullard RW \& Stolwijk JA. (1971a). Importance of skin temperature in the regulation of sweating. J Appl Physiol 31, 80-87.

Nadel ER, Mitchell JW, Saltin B \& Stolwijk JA. (1971b). Peripheral modifications to the central drive for sweating. J Appl Physiol 31, 828-833.

Nadel ER, Pandolf KB, Roberts MF \& Stolwijk JA. (1974). Mechanisms of thermal acclimation to exercise and heat. J Appl Physiol 37, 515-520.

Nadel ER. (1984). Temperature regulation and hyperthermia during exercise. Clin Chest Med 5, 13-20.

Nielsen B \& Nielsen M. (1965). On the regulation of sweat secretion in exercise. Acta Physiol Scand 64, 314-322.

Nishi Y. (1981). Measurement of thermal balance in man. In: Bioengineering, thermal physiology and comfort, edited by Cena K and Clark J New York, NY: Elsevier, pp. 2939.

Nunneley SA. (1978). Physiological responses of women to thermal stress: a review. Med Sci Sports Exerc 10, 250-255.

Ogawa T. (1970). Local effect of skin temperature on threshold concentration of sudorific agents. J Appl Physiol 28, 18-22.

Paolone AM, Wells CL \& Kelly GT. (1978). Sexual variations in thermoregulation during heat stress. Aviat Space Environ Med 49, 715-719.

Park YS, Pendergast DR \& Rennie DW. (1984). Decrease in body insulation with exercise in cool water. Undersea Biomed Res 11, 159-168.

Parsons KC. (2003). Human Thermal Environments. Taylor \& Francis, London.

Pawelcyzk JA. (1993). Neural control of skin and muscle blood flow during exercise and thermal stress. In Perspectives in exercise science and sports medicine Volume 6: Exercise, heat, and thermoregulation, ed. Gisolfi CV, Lamb DR \& Nadel ER, pp. 119177. WCB Brown and Benchmark, Dubuque, IA.

Pierau F. (1996). Peripheral thermosensors. In Handbook of physiology Section 4: Environmental physiology, ed. Fregly M \& Blatteis C, pp. 85-104. Oxford University press, New York, NY. 
Pivarnik JM, Marichal CJ, Spillman T \& Morrow JRJr. (1992). Menstrual cycle phase affects temperature regulation during endurance exercise. J Appl Physiol 72, 543-548.

Roddie IC, Shepherd JT \& Whelan RF. (1957). The contribution of constrictor and dilator nerves to the skin vasodilation during body heating. $J$ Physiol 136, 489-497.

Rowell LB. (1974). Human cardiovascular adjustments to exercise and thermal stress. Physiol Rev 54, 75-159.

Sato K \& Dobson RL. (1970). Regional and individual variations in the function of the human eccrine sweat gland. J Invest Dermatol 54, 443-449.

Sato K. (1977). The physiology, phramacology and biochemistry of the eccrine sweat gland. Rev Physiol Biochem Phramacol 79, 52-131.

Sato K \& Sato F. (1983). Individual variations in structure and function of human eccrine sweat gland. Am J Physiol 245, 203-208.

Sato K. (1993). The mechanisms of eccrine sweat production. In Perspectives in exercise science and sports medicine Volume 6: Exercise, heat, and thermoregulation, ed. Gisofi CV, Lamb DR \& Nadel ER, pp. 85-118. WCB Brown and Benchmark, Dubuque, IA.

Sawka MN. (1992). Physiological consequences of hypohydration: exercise performance and thermoregulation. Med Sci Sports Exerc 24, 657-670.

Sawka MN, Wenger CB \& Pandolf KB. (1996). Thermoregulatory responses to acute exercise-heat stress and heat acclimation. In Handbook of physiology Section 4: Environmental physiology, ed. Fregly MJ \& Blatteis CM, pp. 157-186. Oxford University press, New York, NY.

Schepers RJ \& Ringkamp M. (2009). Thermoreceptors and thermosensitive afferents. Neurosci Biobehav Rev 33, 205-212.

Schwiening CJ, Mason MJ \& Thompson M. (2011). Absolute power, not sex, promotes perspiration. Exp Physiol 96, 556-558.

Shapiro Y, Pandolf KB, Avellini BA, Pimental NA \& Goldman RF. (1980a). Physiological responses of men and women to humid and dry heat. J Appl Physiol 49, 18.

Shapiro Y, Pandolf KB \& Goldman RF. (1980b). Sex differences in acclimation to a hotdry environment. Ergonomics 23, 635.

Shapiro Y, Pandolf KB, Avellini BA, Pimental NA \& Goldman RF. (1981). Heat balance and transfer in men and women exercising in hot-dry and hot-wet conditions. Ergonomics $24,375-386$.

Shapiro Y, Pandolf KB \& Goldman RF. (1982). Predicting sweat loss response to exercise, environment and clothing. Eur J Appl Physiol Occup Physiol 48, 83-96. 
Shibasaki M \& Crandall CG. (2001). Effect of local acetylcholinesterase inhibition on sweat rate in humans. J Appl Physiol 90, 757-762.

Shibasaki M, Wilson TE, Cui J \& Crandall CG. (2002). Acetylcholine released from cholinergic nerves contributes to cutaneous vasodilation during heat stress. J Appl Physiol 93, 1947-1951.

Shibasaki M, Wilson TE \& Crandall CG. (2006). Neural control and mechanisms of eccrine sweating during heat stress and exercise. J Appl Physiol 100, 1692-1701.

Stephenson LA \& Kolka MA. (1985). Menstrual cycle phase and time of day alter reference signal controlling arm blood flow and sweating. Am J Physiol 249, R186-191.

Stephenson LA \& Kolka MA. (1993). Thermoregulation in women. Exerc Sport Sci Rev 21, 231-262.

Stephenson LA \& Kolka MA. (1999). Esophageal temperature threshold for sweating decreases before ovulation in premenopausal women. J Appl Physiol 86, 22-28.

Stitt JT. (1993). Central regulation of body temperature. In Perspectives in exercise science and sports medicine Volume 6: Exercise, heat, and thermoregulation, ed. Gisofi CV, Lamb DR \& Nadel ER, pp. 1-47. WCB Brown and Benchmark, Dubuque, IA.

Stolwijk JA \& Hardy JD. (1966). Temperature regulation in man - A theoretical study. Pflügers Archiv 291, 129-162.

Szabo G. (1962). The number of eccrine sweat glands in human skin. In Advances in Biology of Skin, Volume 3, ed. Montagna W, Ellis RA \& Silver AF. Pergamon, New York.

Takamata A, Mack GW, Gillen CM, Jozsi AC \& Nadel ER. (1995). Osmoregulatory modulation of thermal sweating in humans: reflex effects of drinking. Am $J$ Physiol 268, 414-422.

Takano S, Kondo N, Shibasaki S, Aoki K, Inoue Y \& Iwata A. (1996). The influence of work loads on regional differences in sweating rates. Jpn J Physiol 46, 183-186.

Taylor NA, Caldwell JN \& Mekjavic IB. (2006). The sweating foot: Local differences in sweat secretion during exercise-induced hyperthermia. Aviat Space Environ Med 77, 1020-1027.

United States Army Center for Health Promotion and Preventive Medicine. (2003). Heat stress control and heat casualty management, technical bulletin, medical 507, pp. 1-72. Headquarters, Department of the Army and Airforce, Washington, DC.

Veicsteinas A, Ferretti G \& Rennie DW. (1982). Superficial shell insulation in resting and exercising men in cold water. J Appl Physiol 52, 1557-1564.

Webb P, Troutman SJ \& Annis JF. (1970). Automatic cooling in water cooled space suits. Aerospace Med 41, 269-277. 
Webb P. (1995). The physiology of heat regulation. Am J Physiol 268, 838-850.

Weiner JS. (1945). The regional distribution of sweating. J Physiol 104, 32-40.

Weinman KP, Slabochova Z, Bernauer EM, Morimoto T \& Sargent F. (1967). Reactions of men and women to repeated exposure to humid heat. J Appl Physiol 22, 533-538.

Welch G, Foote KM, Hansen C \& Mack GW. (2009). Nonselective NOS inhibition blunts the sweat response to exercise in a warm environment. J Appl Physiol 106, 796803.

Wenger CB. (1972). Heat of evaporation of sweat: thermodynamic considerations. J Appl Physiol 32, 456-459.

Wenger CB, Baily RB, Roberts MF \& Nadel ER. (1985). Interaction of local and reflex thermal effects in control of forearm blood flow. J Appl Physiol 58, 251-257.

Wenger CB, Stephenson LA \& Durkin MA. (1986). Effect of nerve block on response of forearm blood flow to local temperature. J Appl Physiol 61, 227-232.

Werner J. (1980). The concept of regulation for human body temperature. J Therm Biol 5, $75-82$.

Werner J. (1981). Control aspects of human temperature regulation. Automatica 17, 351362.

Werner J. (1993). Temperature regulation during exercise: an overview. In Perspectives in exercise science and sports medicine, Volume 6: Exercise, heat, and thermoregulation, ed. Gisofi CV, Lamb DR \& Nadel ER, pp. 49-84. WCB Brown and Benchmark.

White MD, Ross WD \& Mekjavic IB. (1992). Relationship between physique and rectal temperature cooling rate. Undersea Biomed Res 19, 121-130.

Wissler EH. (2008). A quantitative assesment of skin blood flow in humans. Eur J Appl Physiol 104, 145-157.

Wyndham CH, Morrison JF \& Williams CG. (1965). Heat reactions of male and female Caucasians. J Appl Pysiol 20, 357-364.

Wyss CR, Brengelmann GL, Johnson JM, Rowell LB \& Niederberger M. (1974). Control of skin blood flow, sweating, and heart rate: role of skin vs. core temperature. J Appl Physiol 36, 726-733. 
CHAPTER VI

APPENDICES 


\section{APPENDIX A}

Final published version of thesis article \#1 


\title{
Sex modulates whole-body sudomotor thermosensitivity during exercise
}

\author{
Daniel Gagnon and Glen P. Kenny \\ Human and Environmental Physiology Research Unit, School of Human Kinetics, University of Ottawa, Ottawa, Canada
}

\begin{abstract}
Non-technical summary The human body controls its temperature through coordinated physiological processes. Prior to the current study, it remained unknown if differences between males and females existed in these processes. The results from the current study show that females have a lower whole-body sweat response during exercise in the heat compared to males, which results in a greater increase in body temperature. The physiological process responsible for the lower whole-body sweat rate was a lower thermosensitivity of the response, meaning a lower increase in sweat production for a given increase in body temperature. Knowledge of sex-related differences in the physiology of temperature regulation may lead to better improvements in heat exposure guidelines for industrial, military and athletic settings.
\end{abstract}

Abstract It is unclear whether true physiological differences exist in temperature regulation between males and females during exercise, independently of differences in physical characteristics and metabolic heat production. Therefore, we examined differences in the onset threshold and thermosensitivity of whole-body sudomotor activity and cutaneous vascular conductance between males and females matched for body mass and surface area. Nine males and nine females performed $90 \mathrm{~min}$ of exercise at each of the following intensities in a warm/dry environment: $50 \%$ of maximum oxygen consumption $\left(\dot{V}_{\mathrm{O}_{2} \max }\right)$ and at a fixed rate of metabolic heat production equal to $500 \mathrm{~W}$. Evaporative heat loss (EHL, direct calorimetry) and cutaneous vascular conductance (CVC, laser-Doppler) were measured continuously. Mean body temperature was calculated from the measurements of oesophageal and mean skin temperatures. During exercise at $50 \% \dot{V}_{\mathrm{O}_{2} \max }$, a lower rate of sudomotor activity was observed in females $(385 \pm 12$ vs. $512 \pm 24 \mathrm{~W}, P<0.001)$. However, irrespective of sex, individual EHL values were strongly associated with metabolic heat production $\left(R^{2}=0.82, P<0.001\right)$. Nonetheless, a lower rate of EHL was observed in females when exercise was performed at $500 \mathrm{~W}$ of metabolic heat production $(419 \pm 7$ vs. $454 \pm 11 \mathrm{~W}$, $P=0.032$ ). Furthermore, a lower increase in EHL per increase in mean body temperature was observed in females $\left(553 \pm 77 v s .795 \pm 85 \mathrm{~W}^{\circ} \mathrm{C}^{-1}, P=0.051\right)$, with no differences in the onset threshold ( $36.77 \pm 0.06$ vs. $\left.36.61 \pm 0.11^{\circ} \mathrm{C}, P=0.242\right)$. In contrast, no differences were observed in CVC. Collectively, these findings demonstrate that females have a lower thermosensitivity of the whole-body sudomotor response compared to males during exercise in the heat performed at a fixed rate of metabolic heat production.

(Received 22 August 2011; accepted after revision 12 October 2011; first published online 17 October 2011)

Corresponding author G. P. Kenny: University of Ottawa, School of Human Kinetics, 125 University, room 367 Montpetit Hall, Ottawa, Ontario, Canada, K1N 6N5. Email: gkenny@uottawa.ca and www.hepru.ca 


\section{Introduction}

The physiological variables of temperature regulation, consisting of the body temperature at onset of effector responses (onset threshold) and the increase in effector output per unit increase in body temperature (thermosensitivity), dictate the capacity of the human body to regulate its temperature. When comparing these variables between populations, however, all other environmental (e.g. air temperature and humidity, heat production) and physical (e.g. body mass/surface area) factors must remain constant. This is particularly relevant when comparing temperature regulation between males and females, since both have unique physical characteristics which make it difficult to discern whether differences in temperature regulation are attributed to either physiological or physical/environmental variables (Nunneley, 1978; Burse, 1979; Kenney, 1985).

Most studies examining differences in temperature regulation between males and females have focused on core temperature responses (Wyndham et al. 1965; Morimoto et al. 1967; Weinman et al. 1967; Shapiro et al. 1980, 1981; McLellan, 1998). Although sex differences in core temperature might intuitively suggest differences in the physiology of temperature regulation, core temperature alone does not provide an accurate assessment of thermoregulatory function when differences in physical characteristics between sexes are not taken into account (Gagnon et al. 2009). Furthermore, studies that have examined sex differences in heat loss responses during exercise have exclusively done so during weight-bearing exercise (i.e. treadmill) at a fixed external workload (Davies, 1979; Avellini et al. 1980a,b; Moran et al. 1999), or during exercise at a fixed percentage of maximum oxygen consumption (Paolone et al. 1978; Frye \& Kamon, 1981; Horstman \& Christensen, 1982; Keatisuwan et al. 1996; Ichinose-Kuwahara et al. 2010). Although a consistent finding from these studies is a lower sweat rate in females, this observation is proportional to the variations in metabolic heat production elicited by such experimental protocols (Havenith, 2001a; Gagnon et al. 2008). Since previous studies have not fully accounted for differences in physical and/or environmental variables, differential core temperature and/or sweating responses between sexes during exercise may not necessarily indicate a true sex-related difference in temperature regulation, but may rather be attributed to simple differences in physical characteristics and rate of metabolic heat production. As such, conclusions about whether sex can modulate the physiology of temperature regulation remain limited, a matter which has recently gained interest within this field of research (Schwiening et al. 2011).

Determining whether sex can modulate the physiology of temperature regulation has important mechanistic and practical implications. Sex has traditionally not been considered an independent modulator of temperature regulation (Sawka et al. 1996). It therefore often remains unknown if and/or how changes in thermoregulatory function differ between males and females, as a function of age, chronic disease and various physiological states. Such findings could lead to sex-specific improvements in public health, particularly in the improvement of heat exposure guidelines for industrial, military and sport settings which currently do not consider sex as a potential factor affecting heat stress and strain during work in the heat (United States Army Center for Health Promotion and Preventive Medicine, 2003; American Conference of Industrial Hygienists, 2007).

Therefore, the purpose of this study was to examine whether sex can modulate the physiological variables of human temperature regulation independently of physical and environmental factors. To achieve this objective, males and females were matched for body mass and surface area, while exercise at a fixed percentage of maximum oxygen consumption was compared to a condition of fixed metabolic heat production. The physiological variables of temperature regulation consisted of the onset threshold and thermosensitivity of the evaporative heat loss and cutaneous vascular conductance responses. We hypothesised that no sex-related differences in the onset threshold and thermosensitvity of the evaporative heat loss and cutaneous vascular conductance responses would be observed during exercise at a fixed rate of metabolic heat production. A secondary objective was to contrast the results from this condition with exercise performed at a fixed percentage of maximum oxygen consumption, which we hypothesised would result in a lower evaporative heat loss response in females, proportional to a lower rate of metabolic heat production.

\section{Methods}

\section{Ethical approval}

The current experimental protocol was approved by the University of Ottawa Health Sciences and Science Research Ethics Board, in accordance with the Declaration of Helsinki. Written informed consent was obtained from all volunteers prior to their participation in the study.

\section{Participants}

An effect size of $10 \%$ and standard deviation of $5 \%$, estimated from previous publications (Gagnon et al. 2008, 2009), resulted in a minimum calculated $(\beta=0.9, \alpha=0.05)$ sample size of six participants in each group. Eighteen participants, nine males and nine females, were recruited within the University community and volunteered for the study. To eliminate 
Table 1. Participant characteristics

\begin{tabular}{|c|c|c|c|c|c|c|c|c|c|c|}
\hline ex & $\begin{array}{c}\text { Age } \\
\text { (years) }\end{array}$ & $\begin{array}{c}\text { Body mass } \\
(\mathrm{kg})\end{array}$ & $\begin{array}{l}\text { Height } \\
(\mathrm{cm})\end{array}$ & $\begin{array}{l}A_{D} \\
\left(m^{2}\right)\end{array}$ & $\begin{array}{l}\text { Fat mass } \\
\qquad(\mathrm{kg})\end{array}$ & $\begin{array}{l}\text { Lean mass } \\
(\mathrm{kg})\end{array}$ & $\begin{array}{c}\text { Bone mass } \\
(\mathrm{kg})\end{array}$ & $\begin{array}{c}\dot{V}_{\mathrm{O}_{2} \max } \\
\left(\mathrm{min}^{-1}\right)\end{array}$ & $\begin{array}{c}\dot{V}_{\mathrm{O}_{2} \max } \\
\left(\mathrm{ml} \mathrm{kg}{ }^{-1} \min ^{-1}\right)\end{array}$ & $\begin{array}{c}\dot{V}_{\mathrm{O}_{2} \max } \\
\left(\mathrm{ml} \mathrm{kg} \mathrm{LBM}^{-1} \min ^{-1}\right)\end{array}$ \\
\hline & & & & & & & & & $57.8 \pm$ & \\
\hline Emales & $27 \pm 4$ & $66.8 \pm 5.0$ & $168 \pm 5$ & $1.76 \pm 0.08$ & $17.1 \pm 6.5$ & $46.9 \pm 4.8$ & $2.7 \pm 0.3$ & $3.09 \pm 0.31$ & $46.7 \pm 6.4$ & $66.0 \pm 6.5$ \\
\hline
\end{tabular}

$A_{D}$, body surface area; $\dot{V}_{\mathrm{O}_{2} \text { max }}$, maximum oxygen consumption; LBM, lean body mass. *Significantly different from females $(P \leq 0.05)$. Values are mean \pm standard deviation.

the confounding influence of differences in physical characteristics between sexes, males and females were matched in pairs for body mass. Furthermore, to eliminate the influence of differences in hormonal status across the menstrual cycle, female participants performed each experimental session within the first and tenth day after the onset of their self-reported menses. Female participants taking oral contraceptives $(n=6)$ performed the experimental sessions during the no pill/placebo phase of oral contraceptive use. Hormonal status was confirmed by taking a venous blood sample on the day of each experimental session. None of the experimental sessions for female participants had to be withdrawn or repeated based on blood sample results. Participants were healthy, non-smoking and free of any known cardiovascular, metabolic or respiratory diseases. Participant characteristics are presented in Table 1.

\section{Experimental design}

Participants volunteered for one screening visit and two experimental sessions. During the screening visit, measurements of body height and mass, as well as maximum oxygen uptake were determined. Body height was determined using a stadiometer (Detecto, model 2391, Webb City, MO, USA), while body mass was calculated as the sum of fat tissue mass, lean tissue mass and bone mass as determined using dual-energy X-ray absorpsiometry. Body surface area was calculated from the measurements of body height and mass (DuBois \& DuBois, 1916). Maximum oxygen uptake was determined by an automated indirect calorimetry system (MOXUS system, Applied Electrochemistry, Pittsburgh, PA, USA) during a progressive incremental cycling protocol performed on an upright seated constant-load cycle ergometer (Corival, Lode B.V., Groningen, the Netherlands). The participants were asked to cycle continuously at $80 \mathrm{rpm}$, at a starting work rate of $80 \mathrm{~W}$ for $2 \mathrm{~min}$. The work rate was then increased by $20 \mathrm{~W}$ increments every minute thereafter until the subject could not maintain a pedaling cadence of at least $60 \mathrm{rpm}$ (Canadian Society for Exercise Physiology, 1986).

For each experimental session, participants reported to the laboratory between 07.00 and 09.00 , after eating a small breakfast (i.e. toast and juice), but consuming no tea or coffee that morning. The participants were also asked to drink $500 \mathrm{ml}$ of water the night prior to, as well as the morning of, each experimental session and to refrain from alcohol and exercise for $24 \mathrm{~h}$ prior to experimentation. Upon arrival at the laboratory, the participants voided their bladder and provided a urine sample before weighing themselves nude. Subsequently, the participants changed into shorts and sandals (as well as a sports bra for female participants), and sat quietly for a $30 \mathrm{~min}$ instrumentation period at an ambient room temperature of $24^{\circ} \mathrm{C}$. Following instrumentation, the participant entered the calorimeter regulated to an ambient air temperature of $35.21 \pm 0.24^{\circ} \mathrm{C}$, a specific humidity of $4.27 \pm 1.51 \mathrm{~g} \mathrm{~kg}^{-1}(\sim 12 \%$ relative humidity) and an air mass flow of $5.75 \pm 0.28 \mathrm{~kg}$ air $\mathrm{min}^{-1}$. The participant, seated in the upright position, rested for a $45 \mathrm{~min}$ habituation period. Subsequently, the participant performed $90 \mathrm{~min}$ of continuous cycling exercise at either $50 \%$ of maximum oxygen consumption, or a rate of metabolic heat production equal to $500 \mathrm{~W}$. A fixed percentage of maximum oxygen consumption (50\%) was selected since it is a widely used approach to study sex-related differences in thermoregulation during exercise. In contrast, a fixed rate of absolute heat production $(500 \mathrm{~W})$ was chosen to provide the same requirement for heat loss for males and females. At the end of the exercise period, all instrumentation was removed except for the laser-Doppler probe, and participants remained seated for a $45 \mathrm{~min}$ local heating period to determine maximum skin blood flow (see details below). At the end of the local heating period, the participants exited the calorimeter and a final nude body mass measurement was obtained.

The two experimental sessions were performed on separate days, separated by a minimum of $48 \mathrm{~h}$. For all experimentation, clothing was standardized to cotton underwear, running shorts, sandals and sports bra for female participants. Possible differences in acclimation status between males and females were not taken into account. However, since all experimentation occurred between the months of October and May, it was assumed that all participants were not heat acclimated. 


\section{Measurements}

The main thermoeffector responses during exercise in the heat consist of whole-body sudomotor activity and cutaneous vasodilatation. Therefore, the current study focused on differences between sexes in evaporative heat loss and local skin blood flow.

Whole-body sudomotor activity was estimated from measurements of evaporative heat loss using the modified Snellen direct air calorimeter (Reardon et al. 2006). In order for evaporative heat loss to be a valid measure of whole-body sudomotor activity, we ensured that the environmental conditions provided a high vapour pressure gradient between the skin surface and the surrounding air. Furthermore, we continually maintained this vapour pressure gradient by continuously providing a high air mass flow of dry air through the calorimeter. Calorimeter outflow to inflow differences in absolute humidity were collected at $8 \mathrm{~s}$ intervals throughout the trials. The real-time data were displayed and recorded on a personal computer with LabVIEW software (Version 7.0, National Instruments, TX, USA). Evaporative heat loss was subsequently calculated using the following equation:

$$
\frac{\text { Mass flow } \left._{\text {(Humidity }} \text { out }- \text { Humidity }_{\text {in }}\right) \times 2426}{60} \mathrm{~W}
$$

where mass flow is the rate of flow of air mass $(\mathrm{kg}$ air s ${ }^{-1}$ ); (Humidity out $_{\text {- Humidity }}$ ) is the calorimeter inflow-outflow difference in absolute humidity ( $\mathrm{g}$ of water $\left.(\mathrm{kg} \text { of air })^{-1}\right)$; and 2426 is the latent heat of vaporization of sweat $\left(\mathrm{J}(\mathrm{g} \text { of sweat })^{-1}\right.$ ) at $30^{\circ} \mathrm{C}$ (Wenger, 1972).

Cutaneous vasodilatation was estimated using laser-Doppler velocimetry (PeriFlux System 5000, Perimed AB, Stockholm, Sweden). Prior to the start of the experimental trial, the laser-Doppler flow probe (PR 401 Angled Probe, Perimed AB) was affixed with an adhesive ring to the upper back in a site without superficial veins that demonstrated pulsatile activity. Upper back skin blood flow responses have been shown to be similar to those observed on the forearm and chest (Ichinose et al. 2009). The probe was not moved from its location throughout the experimental trial. To determine maximum skin blood flow, a local heating period to $42^{\circ} \mathrm{C}$ for $30 \mathrm{~min}$ and then to $44^{\circ} \mathrm{C}$ for an additional $15 \mathrm{~min}$ was performed at the end of each experimental trial. Cutaneous vascular conductance was subsequently calculated as laser-Doppler velocimetry output in arbitrary perfusion units (PU) divided by mean arterial pressure and expressed as a percentage of maximum.

Indirect calorimetry was used for the concurrent measurement of metabolic energy expenditure (Nishi, 1981). Expired gas was analysed for $\mathrm{O}_{2}$ (error of $\pm 0.01 \%$ ) and $\mathrm{CO}_{2}$ (error of $\pm 0.02 \%$ ) concentrations using electrochemical gas analysers located outside of the calorimeter chamber (AMETEK model S-3A/1 and CD 3A, Applied Electrochemistry). Expired air was recycled back into the calorimeter chamber in order to account for respiratory heat exchange. Prior to each session, gas mixtures of $4 \%$ $\mathrm{CO}_{2}, 17 \% \mathrm{O}_{2}$ and balance nitrogen were used to calibrate the gas analysers and a 31 syringe was used to calibrate the turbine ventilometer (error $\pm 3 \%$, typically $<1 \%$ ).

Mean arterial pressure was measured using a Finometer (Finapres Medical Systems, Amsterdam, the Netherlands) from the beat-to-beat recording of the right middle finger arterial pressure waveform with the volume-clamp method (Penaz, 1973) and physical criteria (Wesseling et al. 1995). Prior to beginning the measurement period, a level calibration was performed and brachial artery pressure reconstruction (Gizdulich et al. 1996, 1997) was calibrated with an upper arm return-to-flow systolic pressure detection (Bos et al. 1996).

Heart rate was monitored using a Polar coded transmitter, recorded continuously and stored with a Polar Advantage interface and Polar Precision Performance software (Polar Electro, Oy, Finland).

Oesophageal and rectal temperatures were measured with general purpose thermocouple temperature probes (Mallinckrodt Medical Inc., St Louis, MO, USA). The oesophageal probe was inserted $40 \mathrm{~cm}$ past the entrance of the nostril while the participants sipped water (250-500 ml) through a straw. The rectal probe was inserted to a depth of $15 \mathrm{~cm}$ past the anal sphincter. Skin temperature was measured at 10 sites using thermocouples (Concept Engineering, Old Saybrook, CT, USA) attached to the skin with surgical tape. Mean skin temperature was subsequently calculated using a 10-point weighting of the regional proportions determined by Hardy \& DuBois (1938). Temperature data were collected using a HP Agilent data acquisition module (model 3497A) at a rate of one sample every $15 \mathrm{~s}$ and simultaneously displayed and recorded in spreadsheet format on a personal computer with LabVIEW software (Version 7.0, National Instruments, TX, USA).

Whole-body sweat production was calculated as the difference in pre- to post-measurements of body mass to the nearest $0.01 \mathrm{~kg}$ using a digital high-performance weighing terminal (model CBU150X, Mettler Toledo Inc., Mississauga, ON, Canada). Urine specific gravity was determined in duplicate using a handheld total solids refractometer (model TS400, Reichter Inc., Depew, NY, USA).

On the day of each experimental session, a venous blood sample $(10 \mathrm{ml})$ was obtained from female participants to confirm that the session occurred in the follicular/low hormone phase of the menstrual cycle. The blood samples were collected with a SST vacutainer (BD Vacutainer, Franklin Lakes, NJ, USA) for the determination of plasma 
$17 \beta$-oestradiol and progesterone. Plasma concentrations of $17 \beta$-oestradiol and progesterone were quantified using automated chemiluminescent microparticle immunoassays (ARCHITECT system; Abbott Diagnostics, Abbott Park, IL, USA) by an independent external laboratory (Gamma-Dynacare Medical Laboratories, Ottawa, ON, Canada) using appropriate monoclonal antibody-coated microparticles and acridium-labelled conjugates. The plasma concentrations representative of the follicular phase of the menstrual cycle for $17 \beta$-oestradiol and progesterone are 46-604 $\mathrm{pmoll}^{-1}$ and $0.6-4.7 \mathrm{nmoll}^{-1}$, respectively.

\section{Statistical analyses}

For all variables, minute averages were performed to carry out the statistical analyses. To examine sex-related differences in the thermal control of the evaporative heat loss and cutaneous vascular conductance responses, the visually determined linear portion of each response against mean body temperature was analysed using a simple linear regression. The onset threshold was defined as the intercept of the regression line with the evaporative heat loss and cutaneous vascular conductance values at rest, while the thermosensitivity was defined as the slope of the regression line (Cheuvront et al. 2009). To account for the relative influence of core and skin temperatures on the activation of heat loss responses (Hertzman et al. 1952; Nadel et al. 1971a,b), mean body temperature was calculated as: $0.9 \times$ oesophageal temperature $+0.1 \times$ mean skin temperature (Shibasaki et al. 2006).

All dependent variables were compared between groups (males vs. females) within each experimental condition $(50 \%$ and $500 \mathrm{~W})$. Independent samples $t$ tests were used for single comparisons between groups, while a two-way mixed model analysis of variance was used for multiple comparisons using the repeated factor of time and the non-repeated factor of group. When a significant main effect was observed, post hoc comparisons were carried out with independent samples $t$ tests. Furthermore, a simple linear correlation was performed to assess the relationship between end-exercise evaporative heat loss and rate of metabolic heat production values during exercise at a fixed percentage of maximum oxygen consumption. The level of significance for all analyses was set at an alpha level of $P \leq 0.05$, corrected for multiple comparisons using the Holm-Bonferonni approach. Analyses were performed using commercially available statistical software (SPSS 18.0 for Windows, SPSS Inc., Chicago, IL, USA). All values for sample parameters are reported as mean \pm standard deviation, while those for variables are reported as mean \pm standard error of the mean.

\section{Results}

\section{Participant characteristics}

By design, there were no differences in body mass between groups $(P=0.873)$. Furthermore, there were no differences in height between groups $(P=0.104)$, such that both sexes had a similar body surface area $(P=0.504)$. In contrast, males had a lower absolute fat mass $(P<0.001)$, as well as a greater absolute lean $(P<0.001)$ and bone $(P=0.021)$ mass compared to females. Finally, males had a higher maximum oxygen consumption both in absolute values $(P=0.001)$ and relative to body mass $(P=0.002)$. However, there were no sex differences in maximum oxygen consumption expressed as a function of lean body mass $(P=0.767)$.

\section{Exercise at a fixed percentage (50\%) of maximum oxygen consumption}

On the day of the experimental session, plasma concentrations of $17 \beta$-oestradiol and progesterone for the female participants averaged $139 \pm 28 \mathrm{pmoll}^{-1}$ and $1.2 \pm 0.2 \mathrm{nmoll}^{-1}$, respectively. Baseline urine specific gravity did not differ between groups (males: $1.015 \pm 0.002$ vs. females: $1.015 \pm 0.003, P=0.816$ ). Furthermore, there were no differences between groups in baseline oesophageal $(P=0.786$, Table 2$)$, rectal $(P=0.555$, Table 2$)$, mean skin (males: $34.72 \pm 0.11^{\circ} \mathrm{C}$ vs. females: $34.54 \pm 0.19^{\circ} \mathrm{C}, P=0.432$ ) and mean body (males: $36.68 \pm 0.08^{\circ} \mathrm{C}$ vs. females: $36.67 \pm 0.10^{\circ} \mathrm{C}$, $P=0.936)$ temperatures. Similarly, heart rate $(P=0.409)$, metabolic heat production $(P=0.328)$, whole-body evaporative heat loss $(P=0.110)$ and cutaneous vascular conductance $(P=0.469)$ did not differ between males and females prior to the beginning of exercise.

Based on the participants pre-determined absolute maximum oxygen consumption, the target oxygen consumption during exercise averaged $1917 \pm 239 \mathrm{ml} \mathrm{min}^{-1}$ for males and $1544 \pm 153 \mathrm{ml} \mathrm{min}^{-1}$ for females $(P \leq 0.001)$. Consequently, rate of metabolic heat production was significantly greater in males during exercise $(P<0.001)$, which was paralleled by a greater rate of whole-body evaporative heat loss $(P<0.001$, see Fig. $1 A$ ). However, the level of evaporative heat loss achieved during exercise significantly correlated $(P<0.001)$ with rate of metabolic heat production. In fact, differences in metabolic heat production between sexes explained more than $80 \%$ of the variance in evaporative heat loss (Fig. 2). The differences in whole-body evaporative heat loss were reflected by a greater whole-body sweat production in males $(1.69 \pm 0.06 \mathrm{~kg} v s .1 .29 \pm 0.08 \mathrm{~kg}, P=0.002)$. In contrast, there were no differences between sexes in cutaneous 
Table 2. Baseline and end-exercise oesophageal and rectal temperatures for males and females during exercise at a fixed percentage of $\dot{V}_{\mathrm{O}_{2} \max }(50 \%)$ and a fixed rate of absolute heat production (500 W)

\begin{tabular}{llcccc}
\hline Condition & Sex & Baseline $T_{\text {oes }}\left({ }^{\circ} \mathrm{C}\right)$ & End-ex $T_{\text {oes }}\left({ }^{\circ} \mathrm{C}\right)$ & Baseline $T_{\text {re }}\left({ }^{\circ} \mathrm{C}\right)$ & End-ex $T_{\text {re }}\left({ }^{\circ} \mathrm{C}\right)$ \\
\hline $50 \%$ & Males & $36.90 \pm 0.07$ & $37.81 \pm 0.08$ & $36.90 \pm 0.07$ & $38.10 \pm 0.09$ \\
& Females & $36.93 \pm 0.09$ & $37.80 \pm 0.11$ & $36.97 \pm 0.08$ & $38.19 \pm 0.07$ \\
$500 \mathrm{~W}$ & Males & $36.65 \pm 0.11$ & $37.54 \pm 0.08^{*}$ & $36.78 \pm 0.10$ & $37.89 \pm 0.07^{*}$ \\
& Females & $36.83 \pm 0.09$ & $38.13 \pm 0.19$ & $36.86 \pm 0.08$ & $38.35 \pm 0.17$ \\
\hline
\end{tabular}

End-ex, end-exercise, $T_{\text {oes, }}$ oesophageal temperature; $T_{\text {re, }}$ rectal temperature. *Significantly different from females $(P \leq 0.05)$. Values are mean \pm standard error of the mean.

vascular conductance during exercise $(P=0.221$, see Fig. $3 A$ ), as well as the maximum cutaneous vascular conductance values reached during the local heating period (males: $1.02 \pm 0.18 \mathrm{PU} \mathrm{mmHg}^{-1} v s$. females: $\left.1.23 \pm 0.25 \mathrm{PU} \mathrm{mmHg}^{-1}, P=0.500\right)$. Overall, the differences in whole-body evaporative heat loss between sexes were proportional to the differences in metabolic heat production such that no differences in both oesophageal $(P=0.953)$ and rectal $(P=0.433)$ temperatures were observed at the end of exercise (see Table 2). Furthermore, there were no significant differences in mean skin temperature throughout exercise $(P=0.117)$, which averaged $35.36 \pm 0.08^{\circ} \mathrm{C}$ and $34.96 \pm 0.16^{\circ} \mathrm{C}$ for males and females, respectively, at the end of exercise.

The mean body temperature onset threshold for evaporative heat loss (males: $36.67 \pm 0.09^{\circ} \mathrm{C} v$ s. females: $36.76 \pm 0.09^{\circ} \mathrm{C}, P=0.518$ ) and cutaneous vasodilatation (males: $36.70 \pm 0.09^{\circ} \mathrm{C}$ vs. females: $36.76 \pm 0.09^{\circ} \mathrm{C}$, $P=0.617$ ) did not differ between groups. However, the thermosensitivity of the whole-body evaporative heat loss $\left(762 \pm 56 \mathrm{~W}^{\circ} \mathrm{C}^{-1}\right.$ vs. $559 \pm 75 \mathrm{~W}^{\circ} \mathrm{C}^{-1}, P=0.049$, see Fig. $4 A$ ) and cutaneous vascular conductance responses $\left(52 \pm 5 \% \mathrm{CVC}^{\circ} \mathrm{C}^{-1}\right.$ vs. $30 \pm 4 \% \mathrm{CVC}^{\circ} \mathrm{C}^{-1}, P=0.002$, see Fig. $5 A$ ) were significantly greater in males compared to females.

\section{Exercise at a fixed rate of absolute metabolic heat production $(500 \mathrm{~W})$}

On the day of the experimental session, plasma concentrations of $17 \beta$-oestradiol and progesterone for the female participants averaged $233 \pm 66 \mathrm{pmoll}^{-1}$ and $1.1 \pm 0.3 \mathrm{nmoll}^{-1}$, respectively. Baseline urine specific gravity did not differ between groups (males: $1.020 \pm 0.003$ vs. females: $1.014 \pm 0.002, P=0.249$ ). Furthermore, there were no differences between groups in baseline oesophageal $(P=0.261$, Table 2$)$, rectal $(P=0.550$, Table 2$)$, mean skin (males: $34.83 \pm 0.13^{\circ} \mathrm{C}$ vs. females: $\left.34.83 \pm 0.10^{\circ} \mathrm{C}, P=0.962\right)$ and mean body (males: $36.45 \pm 0.12^{\circ} \mathrm{C}$ vs. females: $36.60 \pm 0.08^{\circ} \mathrm{C}$, $P=0.353)$ temperatures. Similarly, heart rate $(P=0.226)$,
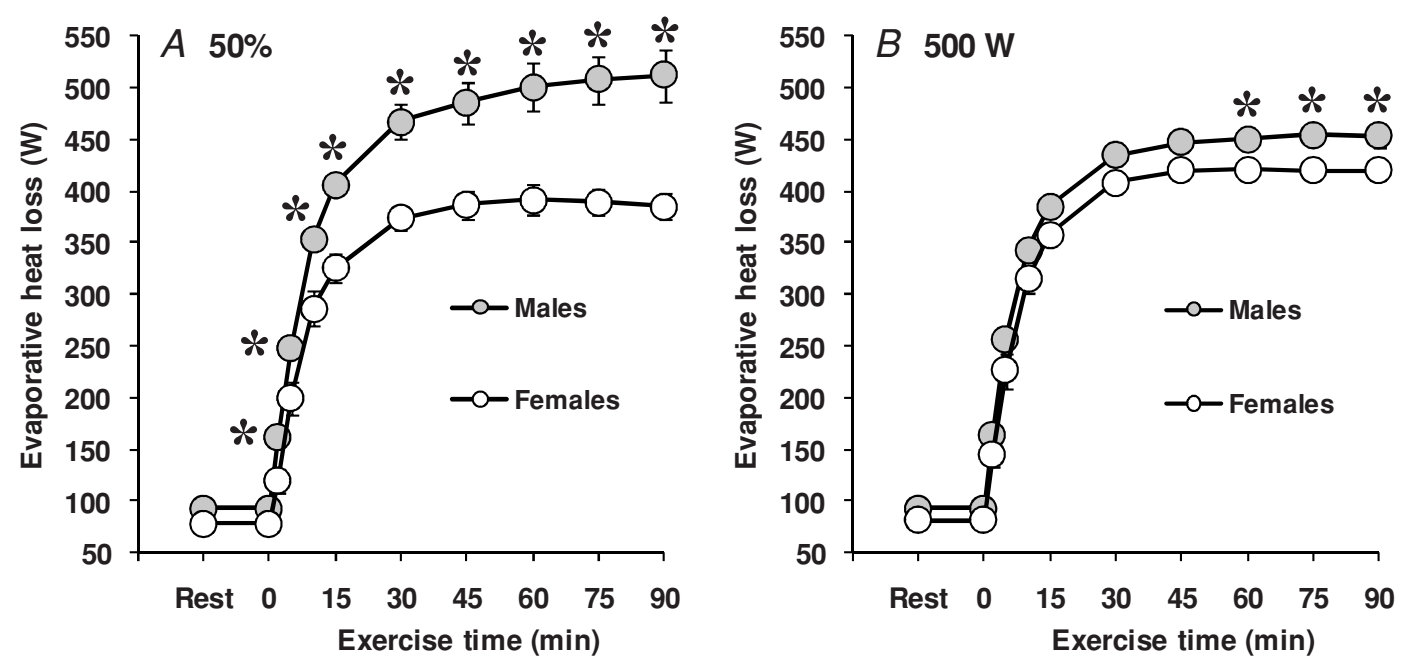

Figure 1. Sex-related differences in evaporative heat loss during exercise performed at either a fixed percentage of maximum oxygen consumption $(50 \%, A)$ or a fixed rate of metabolic heat production (500 W, B)

Values are mean \pm standard error. *Significantly different from females $(P \leq 0.05)$. 
metabolic heat production $(P=0.147)$, whole-body evaporative heat loss $(P=0.196)$ and cutaneous vascular conductance $(P=0.919)$ did not differ between males and females prior to the beginning of exercise.

By experimental design, rate of metabolic heat production during exercise did not differ between sexes (males: $508 \pm 5 \mathrm{~W}$ vs. females: $504 \pm 6 \mathrm{~W}, P=0.573$ ). Nonetheless, a greater rate of whole-body evaporative heat loss was observed in males $(P=0.028$, see Fig. $1 B)$. The greater rate of whole-body evaporative heat loss was paralleled by a greater whole-body sweat production in males $(1.63 \pm 0.07 \mathrm{~kg} v s .1 .38 \pm 0.06 \mathrm{~kg}$, $P=0.029$ ). In contrast, there were no differences in cutaneous vascular conductance during exercise $(P=0.899$, see Fig. $3 B)$, as well as the maximum cutaneous vascular conductance values reached during local heating (males: $1.24 \pm 0.34 \mathrm{PU} \mathrm{mmHg}^{-1}$ vs. females: $\left.0.97 \pm 0.20 \mathrm{PU} \mathrm{mmHg}{ }^{-1}, P=0.362\right)$. The net consequence of the lower evaporative heat loss in females was a greater end-exercise oesophageal $(P=0.019)$ and rectal $(P=0.026)$ temperature (Table 2$)$. In contrast, there were no significant differences between groups in mean skin temperature during exercise $(P=0.486)$, which averaged $35.38 \pm 0.07^{\circ} \mathrm{C}$ and $35.58 \pm 0.21^{\circ} \mathrm{C}$ for males and females, respectively, at the end of exercise.

The mean body temperature onset threshold for whole-body evaporative heat loss (males: $36.61 \pm 0.11^{\circ} \mathrm{C}$ vs. females: $\left.36.77 \pm 0.06^{\circ} \mathrm{C}, P=0.242\right)$ and cutaneous vasodilatation (males: $36.65 \pm 0.11^{\circ} \mathrm{C}$ vs. females: $36.77 \pm 0.08^{\circ} \mathrm{C}, P=0.363$ ) did not differ between groups. However, the thermosensitivity of the whole-body evaporative heat loss response was significantly greater in males compared to females $\left(795 \pm 85 \mathrm{~W}^{\circ} \mathrm{C}^{-1}\right.$ vs. $553 \pm 77 \mathrm{~W}^{\circ} \mathrm{C}^{-1}, P=0.051$, see Fig. $4 B$ ). In contrast, there were no significant differences in the thermosensitivity of the cutaneous vascular conductance response $\left(48 \pm 13 \% \mathrm{CVC}^{\circ} \mathrm{C}^{-1}\right.$ vs. $38 \pm 5 \% \mathrm{CVC}^{\circ} \mathrm{C}^{-1}, P=0.447$, see Fig. $5 B$ ).

\section{Discussion}

This is the first study to examine the independent effect of sex on the thermoeffector responses of whole-body sudomotor activity and cutaneous vasodilatation during exercise. The findings confirm previous observations that differences in sudomotor activity between males and females during exercise at a fixed percentage of maximum oxygen consumption are proportional to variations in metabolic heat production. However, contrary to our hypothesis, females demonstrate a lower whole-body sudomotor activity during exercise at a fixed rate of metabolic heat production $(500 \mathrm{~W})$. The physiological variable responsible for the lower sudomotor activity is a lower thermosensitivity of the response to changes in mean body temperature. In contrast, no differences in cutaneous vascular conductance were observed during exercise at a fixed rate of metabolic heat production. Collectively, these findings demonstrate that sex modulates the thermosensitvity of whole-body sudomotor activity during exercise, independently of differences in body mass, surface area and metabolic heat production.

Similar to previous studies which have examined sweating responses between males and females during exercise (Paolone et al. 1978; Frye \& Kamon, 1981; Horstman \& Christensen, 1982; Keatisuwan et al. 1996; Ichinose et al. 2009; Ichinose-Kuwahara et al. 2010), a lower rate of whole-body evaporative heat loss was observed in females when exercise was performed at a fixed percentage of maximum oxygen consumption. However, this response was paralleled by a lower rate of metabolic heat production (Fig. 2). These findings confirm previous observations that a lower sudomotor response in females during exercise at a fixed percentage of maximum oxygen consumption is proportional to a lower rate of metabolic heat production, and not necessarily due to physiological differences in temperature regulation (Gagnon et al. 2008). Nonetheless, the lower thermosensitivity of both the evaporative heat loss and cutaneous vascular conductance responses in females may suggest a physiological difference in the control of heat loss responses. However, greater exercise intensities (and therefore rates of metabolic heat production) are generally paralleled by a greater thermosensitivity of the sweating response (Montain et al. 1995; Kondo et al. 1998). In contrast, the thermosensitivity of the cutaneous vascular conductance response has generally been found to be unaffected by exercise intensity (Kondo et al. 2010). Yet, no

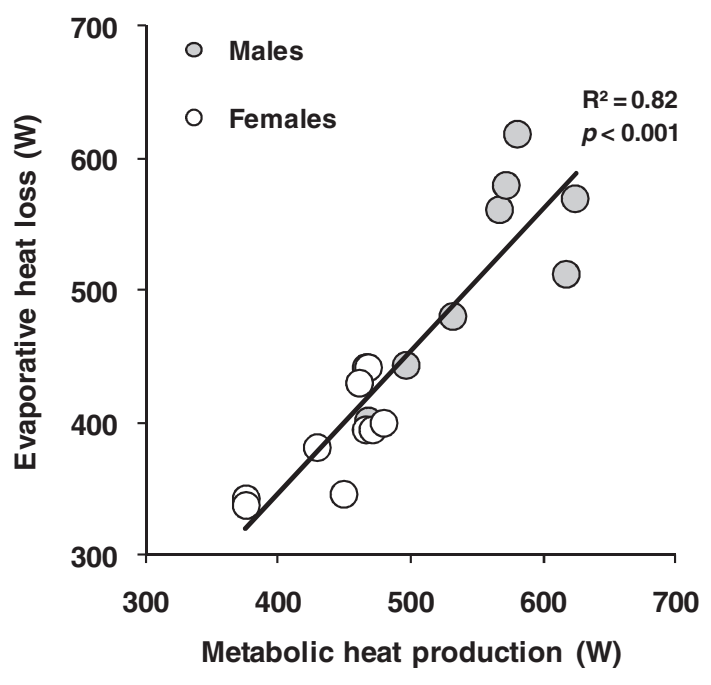

Figure 2. Relationship between evaporative heat loss and rate of metabolic heat production for males and females during exercise performed at a fixed percentage of maximum oxygen consumption 

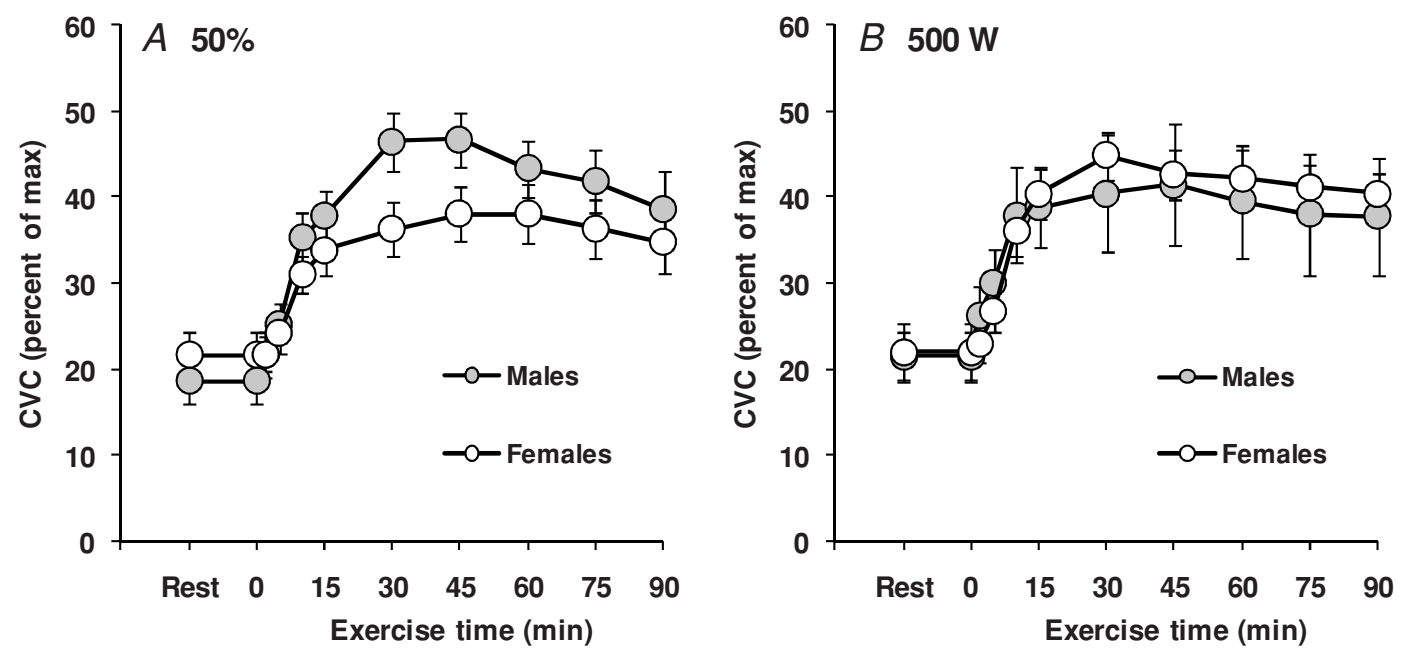

Figure 3. Sex-related differences in the cutaneous vascular response (CVC) during exercise performed at either a fixed percentage of maximum oxygen consumption $(50 \%, A)$ or a fixed rate of metabolic heat production $(500 \mathrm{~W}, B)$

Values are mean \pm standard error.

differences between males and females were observed in the onset threshold and thermosensitivity of the cutaneous vascular response when exercise was performed at a fixed rate of metabolic heat production. Together, these observations suggest that the greater thermosensitivities observed in males during exercise at a fixed percentage of maximum oxygen consumption were due to a greater rate of metabolic heat production.

In order to isolate the physiological variables of temperature regulation, consisting of the onset threshold and themosensitivity of thermoeffector responses, males and females were matched for body mass and surface area to account for the main physical characteristics which determine the individual heat stress response (Havenith et al. 1995, 1998; del Coso et al. 2011). As such, the use of a fixed absolute heat production in constant environmental conditions provided a similar requirement for heat loss in both groups. Yet, females nonetheless exhibited a lower whole-body evaporative heat loss response compared to males, due to a lower thermosensitivity of the response,

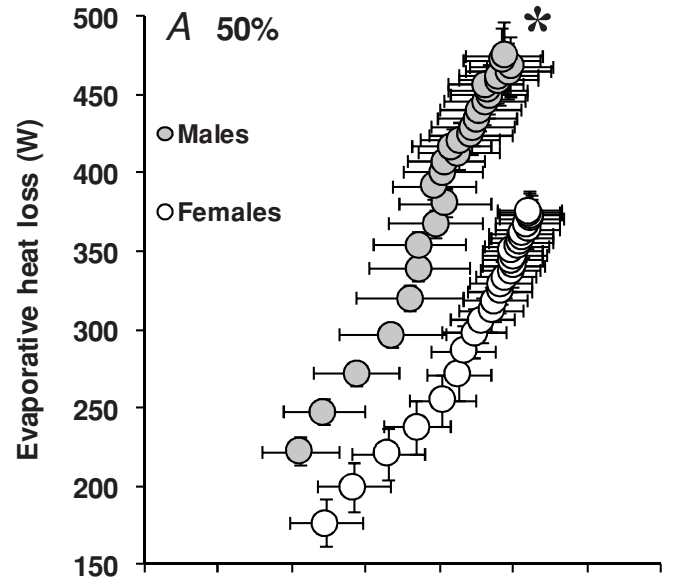

$\begin{array}{llllllll}36.3 & 36.5 & 36.7 & 36.9 & 37.1 & 37.3 & 37.5 & 37.7\end{array}$

Mean body temperature $\left({ }^{\circ} \mathrm{C}\right)$

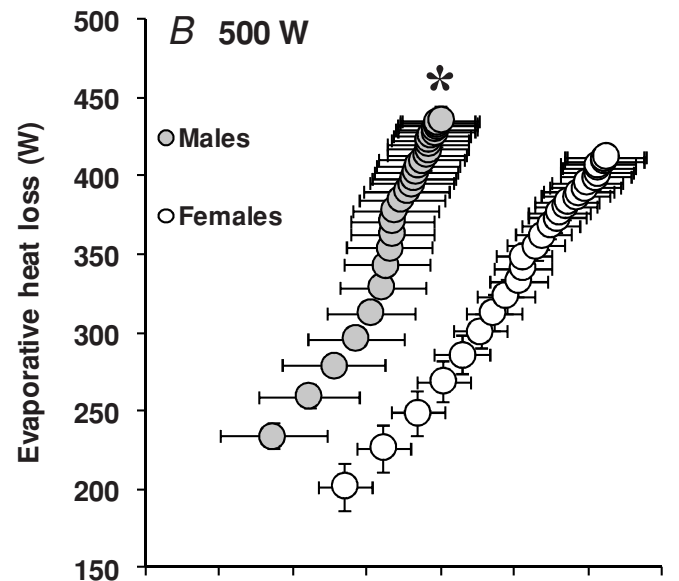

$\begin{array}{llllllll}36.3 & 36.5 & 36.7 & 36.9 & 37.1 & 37.3 & 37.5 & 37.7\end{array}$

Mean body temperature $\left({ }^{\circ} \mathrm{C}\right)$

Figure 4. Sex-related differences in the sensitivity of the evaporative heat loss response to changes in mean body temperature during exercise performed at either a fixed percentage of maximum oxygen consumption $(50 \%, A)$ or a fixed rate of metabolic heat production $(500 \mathrm{~W}, B)$

The data represent the average slopes of the linear portion of the response. Values are mean \pm standard error. *Significantly different slope from females $(P \leq 0.05)$. 
with no significant differences in the onset threshold. Consequently, these observations provide conclusive and novel evidence that sex can independently modulate whole-body sudomotor activity during exercise. A lower whole-body evaporative heat loss response for a given increase in mean body temperature suggests either: (1) altered afferent neural activity from peripheral (i.e. skin) and central (i.e. core) thermoreceptors causing a different integration of thermal information; (2) altered efferent neural activity for a given level of afferent input; and/or (3) an altered effector response (i.e. sweat production) for a given level of efferent neural activity.

Ichinose-Kuwahara et al. (2010) recently suggested that sex differences in sweat gland function improvements elicited by exercise training are intensity dependent. They reported a greater thermosensitivity of the sweating response in trained males compared to trained females. In contrast, no differences in thermosensitivity of the sweating response were observed between untrained males and untrained females. It should be noted, however, that these observations were made during exercise at fixed percentages (i.e. $35 \%, 50 \%$ and $65 \%$ ) of maximum oxygen consumption. Since males and females of various training status were compared, both sexes exercised at different external workloads (and therefore rates of metabolic heat production), which may have confounded their results (Gagnon et al. 2008; Schwiening et al. 2011). Nonetheless, their observations, combined with the results of the current study, may provide important insight into the mechanisms responsible for the lower evaporative heat loss and thermosensitivity of the response observed in females at a fixed rate of metabolic heat production.

The study by Ichinose-Kuwahara et al. (2010) suggests that sex can modulate human temperature regulation in an intensity-dependent manner, such that differences are only observed above a certain requirement for heat loss. If sex modulates the level of thermal afferent and/or efferent neural activity during exercise, it would be expected that the differences in thermosensitivity of the sweating response reported by Ichinose-Kuwahara et al. (2010) would not only be limited to trained males and females, but would also be seen between the untrained males and females. Since they only observed differences in thermosensitivity of the sweating response between the males and females who exercised at the highest external workloads (and therefore metabolic heat production), there must be a point at which the requirement for heat loss exceeds the capacity of the sweat gland to contribute to temperature regulation which, as evidenced from the current study, is lower in females compared to males. Consequently, it can be hypothesized that thermal integration and subsequent efferent neural activity is similar between sexes during exercise in the heat, with sex modulating the effector organ (i.e. sweat gland) and its response (i.e. sweat rate). This modulation may not be seen at lower rates of metabolic heat production (or external workloads), since the requirement for heat loss would not exceed the ability of the sweat gland to contribute to temperature regulation. This would explain the lack of differences in
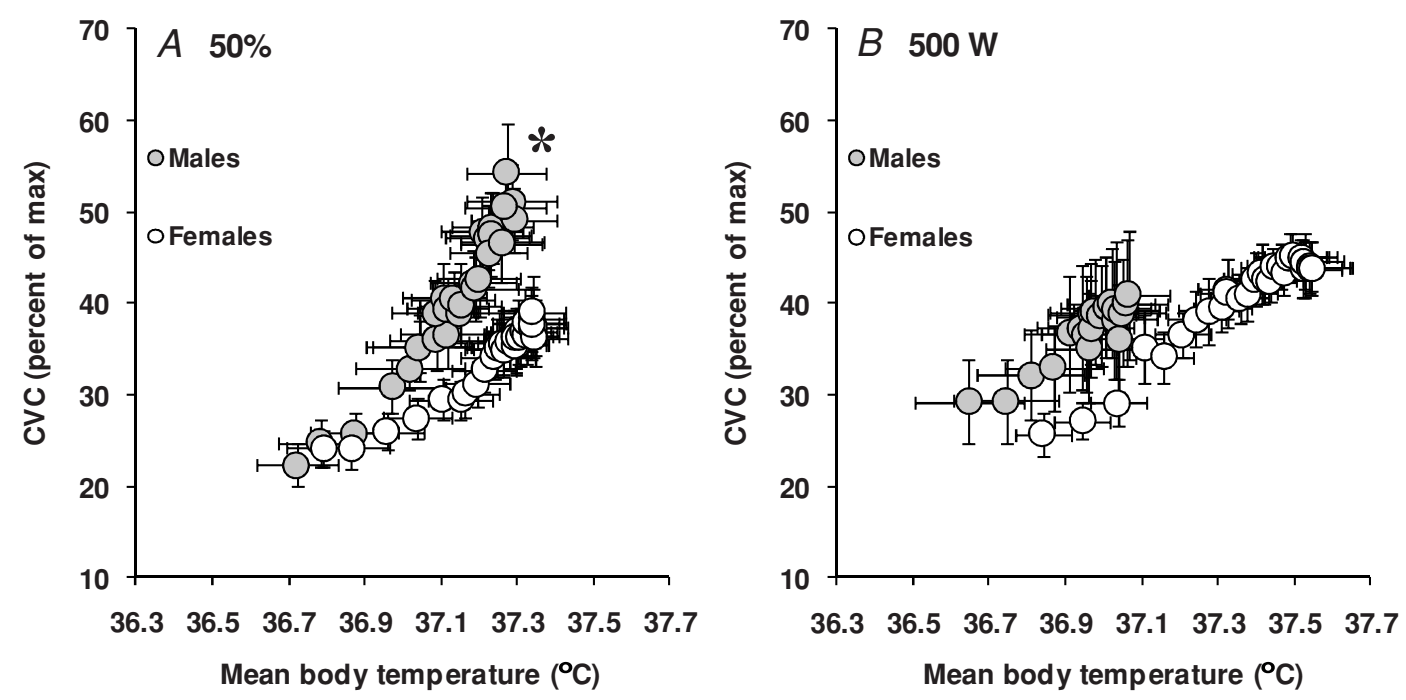

Figure 5. Sex-related differences in the sensitivity of the cutaneous vascular conductance (CVC) response to changes in mean body temperature during exercise performed at either a fixed percentage of maximum oxygen consumption $(50 \%, A)$ or a fixed rate of metabolic heat production $(500 \mathrm{~W}, B)$ The data represent the average slopes of the linear portion of the response. Values are mean \pm standard error. * Significantly different slope from females $(P \leq 0.05)$. 
sweat rate and thermosensitivity of the sweating response between untrained males and females, while a difference was observed between trained males and females in the study by Ichinose-Kuwahara et al. (2010).

In contrast, the rate of metabolic heat production chosen in the current study ( $500 \mathrm{~W}$ ) evidently exceeded the capacity of the sweat gland to contribute to temperature regulation in females, since the greater end-exercise oesophageal and rectal temperatures could only be ascribed to differences in whole-body evaporative heat loss. Furthermore, a given level of thermal afferent and/or efferent activity would only be expected to result in a lower thermosensitivity of the effector response if a maximal effector output could not offset the overall requirement for heat loss. In this situation, the combination of a lower maximal effector output and a greater increase in body temperature would result in a lower thermosensitivity of the response, as observed for evaporative heat loss in females during the $500 \mathrm{~W}$ condition of the current study. This hypothesis is further supported by previous observations of a lower sweat output per gland, despite a greater number of active sweat glands in females during passive heating (Bar-Or et al. 1968; Inoue et al. 2005), as well as a lower eccrine sweat gland response to given doses of acetylcholine (Kahn \& Rothman, 1942; Gibson \& Shelley, 1948) and pilocarpine (Madeira et al. 2010). However, since these observations were made during passive heat stress or in the absence of heat stress, future studies are needed to directly assess the specific mechanism mediating the lower whole-body evaporative heat loss response observed during exercise in the current study. Furthermore, we are unable to determine at which rate of metabolic heat production this modulation occurs since we did not compare responses between males and females at progressively increasing rates of metabolic heat production. Future studies are warranted to address this hypothesis.

While whole-body sudomotor activity represents the main thermoeffector response, particularly during exercise in the heat, increases in skin blood flow also represent an important avenue for heat exchange. In contrast to the observed differences in sudomotor activity, no sex differences in cutaneous vascular conductance were observed. To our knowledge, only Inoue et al. (2005) have specifically examined sex-related differences in skin blood flow during heat stress. Although their observations were made during passive heating, they observed similar skin blood flow responses between males and females on the forehead, chest, back and forearm. As such, the observations in the current study support these findings and extend them to exercise in the heat. However, Inoue et al. (2005) did note a greater skin blood flow response on the thigh in females. Furthermore, Hodges et al. (2010) have recently reported lower peak blood flow responses in females following a period of forearm occlusion. As such, future studies should consider examining potential sex differences in regional skin blood flow during exercise at greater combinations of exercise intensity and/or environmental temperatures.

\section{Perspectives}

The net outcome of the lower whole-body sudomotor thermosensitivity in females was shown as a greater oesophageal and rectal temperature at the end of exercise performed at a fixed rate of metabolic heat production. Prior to the current study, it was generally thought that sex differences in temperature regulation were associated with differences in physical characteristics and not with physiological differences in heat loss responses (Sawka et al. 1996; Havenith, 2001b). The findings of the current study therefore have important implications. They warrant considering sex as an independent factor in modulating human temperature regulation, particularly when examining the effects of age, chronic disease and various physiological states (e.g. dehydration, orthostatic stress, etc.). Since the majority of human temperature regulation studies focus on male participants only, or do not include enough female participants to analyse potential sex differences, it is often unknown if and/or how changes in temperature regulation differ between males and females as a function of such factors. Considering sex as a modulator of human temperature regulation could lead to improvements in public health, particularly for heat exposure guidelines which do not currently provide sex-specific exposure limits for safe work in the heat (United States Army Center for Health Promotion and Preventive Medicine, 2003; American Conference of Industrial Hygienists, 2007).

\section{Considerations}

The current study employed whole-body direct calorimetry to assess sex-related differences in sudomotor activity, the main thermoeffector during exercise in the heat. The design of the calorimeter (high air mass flow), as well as the environmental conditions employed (low specific humidity) ensure that our measurements of whole-body evaporative heat loss reflect local changes in sweat rate. In fact, the lower whole-body evaporative heat loss observed in females was paralleled by a lower whole-body sweat production. It is also interesting to note that the onset thresholds for evaporative heat loss, expressed as a change from baseline rest, were generally lower than those reported for local measurements of sweat rate, which may be due to the sensitivity of whole-body calorimetry. Nonetheless, we acknowledge that measurements of local sweat rate and/or the number of active sweat glands would provide insight into 
the specific mechanisms (number of glands vs. sweat output per gland) responsible for the lower whole-body evaporative heat loss response observed in females. It is possible that differences in absolute maximum oxygen consumption ('fitness') between males and females may explain the observed results. Several observations argue against this reasoning, however. First, the differences in absolute maximum oxygen consumption between sexes in the current study are due to differences in the amount of metabolically active tissue and not necessarily to differences in training status, since no differences were observed when maximum oxygen consumption was expressed as a function of lean body mass. Second, resting heart rates and core temperatures, a strong indication of training status, did not differ between groups. Third, recent evidence suggests that maximum oxygen consumption itself does not modulate sweat production, nor the thermosensitivity of the response (Jay et al. 2011). Finally, female participants performed the experimental trials between the first and tenth day after the onset of menses, or during the no pill/placebo period of oral contraceptive use. These time periods were primarily chosen to ensure low levels of progesterone, which has been associated with an elevated resting core temperature and parallel increases in thermoeffector onset thresholds (Stephenson \& Kolka, 1985). However, it is possible that elevations in oestrogen, which have been shown to decrease resting core temperature and onset thresholds of thermoeffector responses (Stephenson \& Kolka, 1999), may have occurred by the tenth day after the onset of menses. It is equally possible that progestin exposure may not have completely subsided during the no pill/placebo period. Nonetheless, baseline oesophageal temperature and onset thresholds of thermoeffector responses did not differ between sexes.

\section{Conclusion}

The current study examined the effect of sex on whole-body sudomotor activity and cutaneous vascular conductance during exercise in the heat. When exercise was performed at a fixed rate of absolute metabolic heat production, females demonstrated a lower evaporative heat loss, and lower thermosensitivity of the response, despite a similar requirement for heat loss compared to males. Importantly, these results were not due to differences in physical characteristics, as both sexes were matched for body mass and surface area. In contrast, no differences in cutaneous vascular conductance were observed. These results demonstrate that sex modulates whole-body sudomotor activity during exercise in the heat, independently of differences in body mass, surface area and rate of metabolic heat production.

\section{References}

American Conference of Industrial Hygienists (ACGIH) (2007). Heat Stress and Strain: TLV Physical Agents Documentation, pp. 1-36. ACGIH, Cincinnati, OH.

Avellini BA, Kamon E \& Krajewski JT (1980a). Physiological responses of physically fit men and women to acclimation to humid heat. J Appl Physiol 49, 254-261.

Avellini BA, Shapiro Y, Pandolf KB, Pimental NA \& Goldman RF (1980b). Physiological responses of men and women to prolonged dry heat exposure. Aviat Space Environ Med 51, 1081-1085.

Bar-Or O, Lundegren HM, Magnusson LI \& Buskirk ER (1968). Distribution of heat-activated sweat glands in obese and lean men and women. Hum Biol 40, 235-248.

Bos WJW, Van Goudoever J, Van Montfrans GA, Van den Meiracker AH \& Wesseling KH (1996). Reconstruction of brachial artery pressure from noninvasive finger pressure measurement. Circulation 94, 1870-1875.

Burse RL (1979). Sex differences in human thermoregulatory response to heat and cold stress. Hum Factors 21, 687-699.

Canadian Society for Exercise Physiology (1986). Determination of aerobic power, Chapter II. In Certified Fitness Appraiser Resource Manual, pp. 1-32. CSEP, Gloucester, Ontario.

Cheuvront SN, Bearden SE, Kenefick RW, Ely BR, Degroot DW, Sawka MN \& Montain SJ (2009). A simple and valid method to determine thermoregulatory sweating threshold and sensitivity. J Appl Physiol 107, 69-75.

Davies CT (1979). Thermoregulation during exercise in relation to sex and age. Eur J Appl Physiol 42, 71-79.

del Coso J, Hamouti N, Ortega JF, Fernandez-Elias VE \& Mora-Rodriguez R (2011). Relevance of individual characteristics for thermoregulation during exercise in a hot-dry environment. Eur J Appl Physiol 111, 2173-2181.

DuBois D \& DuBois EF (1916). A formula to estimate the approximate surface area if height and weight be known. Arch Intern Med 17, 863-871.

Frye AJ \& Kamon E (1981). Responses to dry heat of men and women with similar aerobic capacities. J Appl Physiol 50, 65-70.

Gagnon D, Dorman LE, Jay O, Hardcastle SG \& Kenny GP (2009). Core temperature differences between sexes during intermittent exercise: physical considerations. Eur J Appl Physiol 105, 453-461.

Gagnon D, Jay O, Lemire B \& Kenny GP (2008). Sex-related differences in evaporative heat loss: the importance of metabolic heat production. Eur J Appl Physiol 104, 821-829.

Gibson TE \& Shelley WB (1948). Sexual and racial differences in the response of sweat glands to acetylcholine and pilocarpine. J Invest Dermatol 11, 137-142.

Gizdulich P, Imholz BPM, van den Meiracker AH, Parati G \& Wesseling KH (1996). Finapres tracking of systolic pressure and baroreflex sensitivity improved by waveform filtering. J Hypertens 14, 243-250.

Gizdulich P, Prentza A \& Wesseling KH (1997). Models of brachial to finger pulse wave distortion and pressure decrement. Cardiovasc Res 33, 698-705. 
Hardy J \& DuBois E (1938). The technique of measuring radiation and convection. J Nutr 15, 461-475.

Havenith G (2001a). Human surface to mass ratio and body core temperature in exercise heat stress - a concept revisited. $J$ Therm Biol 26, 387-393.

Havenith G (2001b). Individualized model of human thermoregulation for the simulation of heat stress response. J Appl Physiol 90, 1943-1954.

Havenith G, Coenen JM, Kistemaker L \& Kenney WL (1998). Relevance of individual characteristics for human heat stress response is dependent on exercise intensity and climate type. Eur J Appl Physiol 77, 231-241.

Havenith G, Luttikholt VG \& Vrijkotte TG (1995). The relative influence of body characteristics on humid heat stress response. Eur J Appl Physiol 70, 270-279.

Hertzman AB, Randall WC, Peiss CN \& Seckendorf R (1952). Regional rates of evaporation from the skin at various environmental temperatures. J Appl Physiol 5, 153-161.

Hodges GJ, Sharp L, Clements RE, Goldspink DF, George KP \& Cable NT (2010). Influence of age, sex, and aerobic capacity on forearm and skin blood flow and vascular conductance. Eur J Appl Physiol 109, 1009-1015.

Horstman DH \& Christensen E (1982). Acclimatization to dry heat: active men vs. active women. J Appl Physiol 52, 825-831.

Ichinose-Kuwahara T, Inoue Y, Iseki Y, Hara S, Ogura Y \& Kondo N (2010). Sex differences in the effects of physical training on sweat gland responses during a graded exercise. Exp Physiol 95, 1026-1032.

Ichinose TK, Inoue Y, Hirata M, Shamsuddin AK \& Kondo N (2009). Enhanced heat loss responses induced by short-term endurance training in exercise women. Exp Physiol 94, 90-102.

Inoue Y, Tanaka Y, Omori K, Kuwahara T, Ogura Y \& Ueda H (2005). Sex- and menstrual cycle-related differences in sweating and cutaneous blood flow in response to passive heat exposure. Eur J Appl Physiol 94, 323-332.

Jay O, Bain AR, Deren TM, Sacheli M \& Cramer MN (2011). Large differences in peak oxygen uptake do not independently alter changes in core temperature and sweating during exercise. Am J Physiol Regul Integr Comp Physiol 301, R832-R444.

Kahn D \& Rothman S (1942). Sweat response to acetylcholine. J Invest Dermatol 5, 431-444.

Keatisuwan W, Ohnaka T \& Tochihara Y (1996). Physiological responses of men and women during exercise in hot environments with equivalent WBGT. Appl Hum Sci 15, 249-258.

Kenney WL (1985). A review of comparative responses of men and women to heat stress. Environ Res 37, 1-11.

Kondo N, Nishiyasu T, Inoue Y \& Koga S (2010). Non-thermal modification of heat-loss responses during exercise in humans. Eur J Appl Physiol 110, 447-458.

Kondo N, Takano S, Aoki K, Shibasaki M, Tominaga H \& Inoue Y (1998). Regional differences in the effect of exercise intensity on thermoregulatory sweating and cutaneous vasodilation. Acta Physiol Scand 164, 71-78.

McLellan TM (1998). Sex-related differences in thermoregulatory responses while wearing protective clothing. Eur J Appl Physiol 78, 28-37.
Madeira LG, da Fonseca MA, Fonseca IA, de Oliveira KP, Passos RL, Machado-Moreira CA \& Rodrigues LO (2010). Sex-related differences in sweat gland cholinergic sensitivity exist irrespective of differences in aerobic capacity. Eur J Appl Physiol 109, 93-100.

Montain SJ, Latzka WA \& Sawka MN (1995). Control of thermoregulatory sweating is altered by hydration level and exercise intensity. J Appl Physiol 79, 1434-1439.

Moran DS, Shapiro Y, Laor A, Izraeli S \& Pandolf KB (1999). Can gender differences during exercise-heat stress be assessed by the physiological strain index? Am J Physiol Regul Physiol 276, R1798-R1804.

Morimoto T, Slabochova Z, Naman RK \& Sargent F (1967). Sex differences in physiological reactions to thermal stress. J Appl Physiol 22, 526-532.

Nadel ER, Bullard RW \& Stolwijk JA (1971a). Importance of skin temperature in the regulation of sweating. J Appl Physiol 31, 80-87.

Nadel ER, Mitchell JW, Saltin B \& Stolwijk JA (1971b). Peripheral modifications to the central drive for sweating. J Appl Physiol 31, 828-833.

Nishi Y (1981). Measurement of thermal balance in man. In Bioengineering, Thermal Physiology and Comfort, ed. Cena K \& Clark J, pp. 29-39. Elsevier, New York, NY.

Nunneley SA (1978). Physiological responses of women to thermal stress: a review. Med Sci Sports Exerc 10, 250-255.

Paolone AM, Wells CL \& Kelly GT (1978). Sexual variations in thermoregulation during heat stress. Aviat Space Environ Med 49, 715-719.

Penaz J (1973). Photoelectric measurement of blood pressure, volume and flow in the finger. Digest of the 10th International Conference on Medical and Biological Engineering. Dresden, p. 104.

Reardon FD, Leppik KE, Wegmann R, Webb P, Ducharme MB \& Kenny GP (2006). The Snellen human calorimeter revisited, re-engineered and upgraded: design and performance characteristics. Med Biol Eng Comput 44, 721-728.

Sawka MN, Wenger CB \& Pandolf KB (1996).

Thermoregulatory responses to acute exercise-heat stress and heat acclimation. In Handbook of Physiology, Section 4, Environmental Physiology, ed. Fregly MJ \& Blatteis CM, pp. 157-186. Oxford University Press, New York, NY.

Schwiening CJ, Mason MJ \& Thompson M (2011). Absolute power, not sex, promotes perspiration. Exp Physiol 96, 556-558.

Shapiro Y, Pandolf KB, Avellini BA, Pimental NA \& Goldman RF (1981). Heat balance and transfer in men and women exercising in hot-dry and hot-wet conditions. Ergonomics 24, 375-386.

Shapiro Y, Pandolf KB \& Goldman RF (1980). Sex differences in acclimation to a hot-dry environment. Ergonomics 23, 635-642.

Shibasaki M, Wilson TE \& Crandall CG (2006). Neural control and mechanisms of eccrine sweating during heat stress and exercise. J Appl Physiol 100, 1692-1701.

Stephenson LA \& Kolka MA (1985). Menstrual cycle phase and time of day alter reference signal controlling arm blood flow and sweating. Am J Physiol Regul Physiol 249, R186-R191. 
Stephenson LA \& Kolka MA (1999). Esophageal temperature threshold for sweating decreases before ovulation in premenopausal women. J Appl Physiol 86, 22-28.

United States Army Center for Health Promotion and Preventive Medicine (2003). Heat Stress Control and Heat Casualty Management, Technical Bulletin, Medical 507, pp. 1-72. Headquarters, Department of the Army and Airforce, Washington, DC.

Weinman KP, Slabochova Z, Bernauer EM, Morimoto T \& Sargent F (1967). Reactions of men and women to repeated exposure to humid heat. J Appl Physiol 22, 533-538.

Wenger CB (1972). Heat of evaporation of sweat: thermodynamic considerations. J Appl Physiol 32, 456-459.

Wesseling KH, de Wit B, van der Hoeven GMA, van Goudoever J \& Settels JJ (1995). Physiocal, calibrating finger vascular physiology for Finapres. Homeostasis 36, 67-82.

Wyndham CH, Morrison JF \& Williams CG (1965). Heat reactions of male and female Caucasians. J Appl Pysiol 20, 357-364.

\section{Author contributions}

All authors contributed to the conception and design of the experiments, to the collection, analysis and interpretation of data, as well as to the drafting and critical revising of the manuscript. All authors have approved the final version of the manuscript. All experiments were performed at the University of Ottawa.

\section{Acknowledgements}

The current study was performed by D.G., in partial fulfillment for the degree of Doctor of Philosophy from the University of Ottawa. D.G. is supported by an Alexander Graham Bell Canadian Graduate Scholarship from the Natural Sciences and Engineering Research Council. The current work was supported by the Natural Sciences and Engineering Research Council (RGPIN-298159-2004 and RGPIN-298159-2009) and Leaders Opportunity Fund from the Canada Foundation for Innovation (22529). Dr Kenny is supported by a University of Ottawa Research Chair in Environmental Physiology. The authors wish to thank Dr Ollie Jay and Dr Craig Crandall for providing critical input into the development of this work, as well as all the participants who volunteered for the present study. 


\section{APPENDIX B}

Final published version of thesis article \#2 


\title{
Sex differences in thermoeffector responses during exercise at fixed requirements for heat loss
}

\author{
Daniel Gagnon and Glen P. Kenny \\ Human and Environmental Physiology Research Unit, School of Human Kinetics, University of Ottawa, Ottawa, Canada
}

Submitted 23 May 2012; accepted in final form 9 July 2012

Gagnon D, Kenny GP. Sex differences in thermoeffector responses during exercise at fixed requirements for heat loss. $J$ Appl Physiol 113: 746-757, 2012. First published July 12, 2012; doi:10.1152/japplphysiol.00637.2012.-To assess potential mechanisms responsible for the lower sudomotor thermosensitivity in women during exercise, we examined sex differences in sudomotor function and skin blood flow (SkBF) during exercise performed at progressive increases in the requirement for heat loss. Eight men and eight women cycled at rates of metabolic heat production of 200, 250, and $300 \mathrm{~W} / \mathrm{m}^{2}$ of body surface area, with each rate being performed sequentially for $30 \mathrm{~min}$. The protocol was performed in a direct calorimeter to measure evaporative heat loss (EHL) and in a thermal chamber to measure local sweat rate (LSR) (ventilated capsule), SkBF (laser-Doppler), sweat gland activation (modified iodine-paper technique), and sweat gland output (SGO) on the back, chest, and forearm. Despite a similar requirement for heat loss between the sexes, significantly lower increases in EHL and LSR were observed in women $(P \leq 0.001)$. Sex differences in EHL and LSR were not consistently observed during the first and second exercise periods, whereas EHL $\left(348 \pm 13\right.$ vs. $\left.307 \pm 9 \mathrm{~W} / \mathrm{m}^{2}\right)$ and LSR on the back (1.61 \pm 0.07 vs. $\left.1.20 \pm 0.09 \mathrm{mg} \cdot \mathrm{min}^{-1} \cdot \mathrm{cm}^{-2}\right)$, chest $(1.33 \pm 0.06$ vs. $1.08 \pm 0.09$ $\left.\mathrm{mg} \cdot \mathrm{min}^{-1} \cdot \mathrm{cm}^{-2}\right)$, and forearm $(1.53 \pm 0.07 \mathrm{vs} .1 .20 \pm 0.06$ $\mathrm{mg} \cdot \mathrm{min}^{-1} \cdot \mathrm{cm}^{-2}$, men vs. women) became significantly greater in men during the last exercise period $(P<0.05)$. At each site, differences in LSR were solely due to a greater SGO in men, as opposed to differences in sweat gland activation. In contrast, no sex differences in SkBF were observed throughout the exercise period. The present study demonstrates that sex differences in sudomotor function are only evidenced beyond a certain requirement for heat loss, solely through differences in SGO. In contrast, the lower EHL and LSR in women are not paralleled by a lower SkBF response.

skin blood flow; sweat; temperature regulation; thermoregulation

DURING EXERCISE, INCREASES in core and mean skin temperatures provide afferent neural information initiating (i.e., onset threshold) sweat production and increases in skin blood flow, with their output increasing proportionally (i.e., thermosensitivity) to the rise in core and mean skin temperatures $(20,51)$. Together, the onset threshold and thermosensitivity represent the physiological mechanisms of temperature regulation. Recently, we observed a lower thermosensitivity of whole body evaporative heat loss in women during exercise, with no differences in the onset threshold (16). In contrast, no sex differences were observed in skin vascular conductance (16). Importantly, the lower sudomotor thermosensitivity in women was independent of differences in physical characteristics and rate of metabolic heat production, suggesting that true physiological differences exist between the sexes.

\footnotetext{
Address for reprint requests and other correspondence: G. P. Kenny, Univ of Ottawa, School of Human Kinetics, 125 Univ., Rm. 367 Montpetit Hall, Ottawa, Ontario, Canada K1N 6N5 (e-mail: gkenny@uottawa.ca).
}

A lower thermosensitivity of whole body evaporative heat loss could be related to either a central (neural activity) and/or peripheral (effector response) modulation of temperature regulation. The onset threshold of thermoeffector responses has typically been used to represent central modifications of temperature regulation, whereas the thermosensitivity is thought to represent a peripheral modulation (36). Additionally, it is generally accepted that any factor that exhibits a central modulation of temperature regulation must shift the onset threshold of both local sweat production and skin blood flow (18). For example, factors, such as sex hormones (47), hyperosmolality (41), and heat acclimation (1), consistently shift the onset threshold of both heat loss responses, with inconsistent (acclimation) or no changes (sex hormones, osmolality) in thermosensitivity. Finally, if sex modulates the level of thermal afferent and/or efferent neural activity, sex differences in thermoeffector responses should be evident at any combination of exercise intensity and environmental conditions (i.e., requirement for heat loss).

In contrast, a peripheral modulation of sudomotor function would be expected to result in sex differences in the thermosensitivity of the response, without any differences in the onset threshold for sweating and skin blood flow. Furthermore, the lower sweat rate in women would be associated with a lower sweat gland output (39), and differences in local sweat rate and/or evaporative heat loss would only be evidenced above a certain requirement for heat loss. Although a number of studies have examined sex differences in sweat rate during exercise, insight into potential physiological differences between men and women are limited due to employed experimental protocols $(15,42)$ and a lack of considering confounding physical differences (13). Nonetheless, recent observations suggest that sex-related differences in local sweat rate may only be observed above a certain exercise intensity (25), suggesting that sex differences in sudomotor function are not evidenced at all requirements for heat loss. To our knowledge, however, no study has specifically examined whether sex differences in sudomotor function and/or skin blood flow are only evidenced above a certain requirement for heat loss during exercise. Such information would provide valuable physiological insight to determine whether the lower sudomotor thermosensitivity observed in women during exercise is associated with a central and/or peripheral modulation of temperature regulation.

The present study, therefore, examined sex differences in the onset threshold and thermosensitivity of sudomotor function (local and whole body) and skin blood flow during exercise performed at increasing requirements for heat loss. To determine if sex differences in sudomotor function are only evidenced above a certain requirement for heat loss, the experimental paradigm included one continuous exercise bout divided into three consecutive periods, performed at increasing 
levels of metabolic heat production. We hypothesized that sex differences in sudomotor function would only be evidenced at the highest requirement for heat loss. Furthermore, we hypothesized that these differences would be paralleled by a lower thermosensitivity of the response, without any differences in the onset threshold. In contrast, we hypothesized that no sex differences in skin blood flow would be observed, in terms of both the onset threshold and thermosensitivity.

\section{METHODS}

\section{Ethical Approval}

The present experimental protocol was approved by the University of Ottawa Health Sciences and Science Research Ethics Board. Written, informed consent was obtained from all volunteers before their participation in the study.

\section{Participants}

Expected sex differences in end-exercise whole body evaporative heat loss (16) and local sweat rate (25) were used to calculate $(\beta=$ $0.8, \alpha=0.05)$ a minimum sample size of six participants in each group, assuming an effect of $20 \%$ and standard deviation of $12 \%$. Sixteen participants, eight men and eight women, were recruited within the university community and volunteered for the study. To minimize the influence of differences in hormonal status across the menstrual cycle, female participants performed each experimental session within the 1st and 10th day after the onset of their selfreported menses. Three female participants were taking oral contraceptives: one used Aviane (pill 1: $0.1 \mathrm{mg}$ levonorgestrel/ $/ 0.020 \mathrm{mg}$ ethinyl estradiol, pill 2: placebo), another used Tri-Cyclen (pill 1: $0.180 \mathrm{mg}$ norgestimate $/ 0.025 \mathrm{mg}$ ethinyl estradiol, pill 2: $0.215 \mathrm{mg}$ norgestimate/ $0.025 \mathrm{mg}$ ethinyl estradiol, pill 3: $0.250 \mathrm{mg}$ norgestimate/0.025 mg ethinyl estradiol, pill 4: placebo), and the other used Triquilar (pill 1: $50 \mu \mathrm{g}$ levonorgestrel/30 $\mu \mathrm{g}$ ethinyl estradiol, pill 2: $75 \mu \mathrm{g}$ levonorgestrel/40 $\mu \mathrm{g}$ ethinyl estradiol, pill 3: $125 \mu \mathrm{g}$ levonorgestrel/30 $\mu \mathrm{g}$ ethinyl estradiol, pill 4: placebo). These three female participants performed the experimental sessions during the no pill/ placebo phase of oral contraceptive use. Hormonal status was confirmed by taking a venous blood sample on the day of each experimental session. None of the experimental sessions for female participants had to be withdrawn or repeated based on blood sample results. Participants were healthy, nonsmoking, and free of any known cardiovascular, metabolic, and respiratory diseases. Participant characteristics are presented in Table 1.

\section{Experimental Design}

All participants volunteered for one preliminary and two experimental sessions. During the preliminary session, training history, body height, mass, and density, as well as maximum oxygen uptake, were determined. Training history was assessed by having the participants quantify their physical activity levels using the quantitative (3 mo) and 7-day physical activity recall questionnaires proposed by Kohl et al. (30). Body height was determined using a stadiometer (Detecto, model 2391, Webb City, MO), whereas body mass was measured using a digital high-performance weighing terminal (model CBU150X,
Mettler Toledo, Mississauga, ON, Canada). Body surface area was subsequently calculated from the measurements of body height and mass (9). Body density was measured using the hydrostatic weighing technique and used to calculate body fat percentage (46). Maximum oxygen uptake was determined by indirect calorimetry (MOXUS system, Applied Electrochemistry, Pittsburgh, PA) during a progressive incremental exercise protocol (5) performed on an upright, seated, constant-load cycle ergometer (Corival, Lode BV, Groningen, the Netherlands).

For each experimental session, participants reported to the laboratory between 700 and 900 . The participants were asked to drink 500 $\mathrm{ml}$ of water the night before, as well as the morning of, each experimental session and to refrain from alcohol, caffeine, and exercise $24 \mathrm{~h}$ before experimentation. On arrival at the laboratory, the participants provided a urine sample, weighed themselves nude, and changed into shorts, sandals, as well as a sports bra for female participants. They subsequently sat upright for a 60-min instrumentation period at an ambient room temperature of $24^{\circ} \mathrm{C}$. Following instrumentation, participants entered a thermal chamber for one of the experimental sessions, while they entered a whole body calorimeter for the other session. The order in which the sessions were performed was balanced both within and between sexes. The thermal chamber was regulated to an ambient air temperature of $40.1 \pm 0.2^{\circ} \mathrm{C}$ and a relative humidity of $24 \pm 2 \%(\sim 11.31 \mathrm{~g} / \mathrm{kg}$ specific humidity), and a fan placed in front of the participant provided an airflow of $1.04 \pm$ $0.20 \mathrm{~m} / \mathrm{s}$. The calorimeter was regulated to an ambient air temperature of $40.08 \pm 0.15^{\circ} \mathrm{C}$, a specific humidity of $5.47 \pm 2.82 \mathrm{~g} / \mathrm{kg}(\sim 12 \%$ relative humidity), and an air mass flow of $7.74 \pm 0.25 \mathrm{~kg}$ air $/ \mathrm{min}$. In both cases, participants rested for a 30-min baseline period in the upright seated posture. Subsequently, they performed $90 \mathrm{~min}$ of continuous upright seated cycling exercise. The exercise period was performed at fixed rates of metabolic heat production equal to 200, 250 , and $300 \mathrm{~W} / \mathrm{m}^{2}$, with each level being $30 \mathrm{~min}$ in duration. The participants did not stop exercising between each exercise period. At the end of exercise during the experimental session performed in the thermal chamber, all instrumentation was removed, except for the laser-Doppler flow probes, and the participants remained seated for a 45-min local heating period to determine maximum skin blood flow (see details below). A final nude body weight measurement was obtained at the end of the experimental session.

Body mass, by influencing rate of metabolic heat production, and body surface area, by affecting heat exchange, are the main physical characteristics that can influence local and whole body sweat rate during exercise (22). As such, we employed fixed rates of metabolic heat production during non-weight-bearing exercise (i.e., cycling) to negate any influence of differences in body mass, while we adjusted the rate of metabolic heat production per unit of surface area to negate any differences in the surface area available for heat exchange. Previous studies have shown that the level of local and whole body sweat rate achieved during exercise is determined by the ratio of the required evaporation for heat balance $\left(\mathrm{E}_{\mathrm{req}}\right)$ and the maximum evaporation possible $\left(\mathrm{E}_{\max }\right)$ in a given environment $(2,43)$. Since men and women performed the exercise bout in the same environmental conditions (producing the same $\mathrm{E}_{\max }$ ), the use of fixed rates of metabolic heat production expressed per unit of body surface area (producing the same $\mathrm{E}_{\text {req }}$ ) ensured that the $\mathrm{E}_{\text {req }}-$ to- $\mathrm{E}_{\max }$ ratio, and

Table 1. Participant characteristics

\begin{tabular}{|c|c|c|c|c|c|c|c|c|c|}
\hline \multirow[b]{2}{*}{ Sex } & \multirow[b]{2}{*}{ Age, yr } & \multirow[b]{2}{*}{ Body Mass, kg } & \multirow[b]{2}{*}{ Height, cm } & \multirow[b]{2}{*}{$A_{\mathrm{D}}, \mathrm{m}^{2}$} & \multirow[b]{2}{*}{ Fat Mass, kg } & \multirow[b]{2}{*}{ FFM, kg } & \multicolumn{3}{|c|}{$\dot{\mathrm{V}}_{2 \max }$} \\
\hline & & & & & & & $1 / \min$ & $\mathrm{ml} \cdot \mathrm{kg}^{-1} \cdot \min ^{-1}$ & $\mathrm{ml} \cdot \mathrm{kg} \mathrm{FFM}{ }^{-1} \cdot \min ^{-1}$ \\
\hline Men & $27 \pm 6$ & $73.9 \pm 13.5^{*}$ & $174 \pm 10^{*}$ & $1.88 \pm 0.22 *$ & $11.0 \pm 5.4$ & $62.9 \pm 10.4^{*}$ & $3.78 \pm 0.70 *$ & $51.4 \pm 6.8^{*}$ & $60.2 \pm 7.8$ \\
\hline Women & $28 \pm 5$ & $60.7 \pm 3.7$ & $166 \pm 5$ & $1.67 \pm 0.07$ & $13.0 \pm 2.7$ & $47.6 \pm 3.3$ & $2.68 \pm 0.36$ & $44.1 \pm 4.5$ & $56.1 \pm 3.9$ \\
\hline
\end{tabular}

Values are mean $\pm \mathrm{SD}$. $A_{\mathrm{D}}$, body surface area; $\dot{\mathrm{V}}_{2 \mathrm{max}}$, maximum oxygen consumption; FFM, fat free mass. $*$ Significantly different from women $(P \leq 0.05)$. 
therefore the requirement for heat loss (12), was similar between sexes. As such, any observed differences in either local sweat rate or whole body evaporative heat loss could be ascribed to physiological (rather than physical) differences between sexes.

In addition to the two experimental sessions, 10 of the participants (5 men and 5 women) returned to the laboratory for a third experimental visit to address possible sex differences in changes in plasma volume and osmolality. For this experimental visit, the participants first rested for a minimum of $30 \mathrm{~min}$ in the upright seated posture, after which baseline blood samples were drawn. The participants were then transferred to the thermal chamber, where they exercised at the same external workloads and environmental conditions as during the experimental session performed in the chamber, while blood samples were taken at the end of each exercise period.

Experimental sessions were performed on separate days, separated by a minimum of $48 \mathrm{~h}$. For all experimentation, clothing was standardized to cotton underwear, running shorts, and sandals (as well as a sports bra for female participants). Possible differences in acclimatization status between men and women were not taken into account. However, since all experimentation occurred between the months of February and June, it was assumed that all participants were not heat acclimatized.

\section{Measurements}

Local sweat rate on the left upper back, chest, and forearm was measured from $3.8-\mathrm{cm}^{2}$ plastic capsules attached to the skin with adhesive rings and topical skin glue (Collodion HV, Mavidon Medical Products, Lake Worth, FL). Anhydrous compressed air was passed through each capsule at a rate of $11 / \mathrm{min}$. Water content of the effluent air was measured using high-precision dew point mirrors (model 473, RH Systems, Albuquerque, NM). Local sweat rate was calculated using the difference in water content between effluent and influent air, multiplied by the flow rate and normalized for the skin surface area under the capsule.

The number of active sweat glands was measured in an area adjacent to each local sweat rate site (to avoid removing the sweat capsule) at 30, 60, and $90 \mathrm{~min}$ of exercise using the modified iodine-paper technique with computer-assisted analysis (14). The number of glands determined by computer analysis was divided by the surface area of the paper to give a value of active sweat glands per square centimeter. The sweat output per gland was calculated by dividing the sweat rate at the corresponding measurement period by the number of active sweat glands.

Local skin blood flow was estimated using laser-Doppler velocimetry (PeriFlux System 5000, Perimed AB, Stockholm, Sweden). Before the start of the experimental trial, laser-Doppler flow probes (integrating probe 413, Perimed AB, Stockholm, Sweden) were affixed with an adhesive ring to the left upper back, chest, and forearm in a site adjacent to the sweat capsules that demonstrated pulsatile activity. The probes were not moved from their location throughout the experimental trial. To determine maximum skin blood flow, a local heating period to $42^{\circ} \mathrm{C}$ for $30 \mathrm{~min}$ and then to $44^{\circ} \mathrm{C}$ for an additional 15 min was performed at the end of the experimental trial.

Blood flow to the right forearm was measured using venous occlusion plethysmography (model AI6, D.E. Hokanson, Bellevue, WA). Cuffs were placed around the wrist and upper arm, and a mercury-in-rubber strain gauge was placed around the widest part of the forearm. Measurements were performed for 2-min periods at the 10th and 20th min of each exercise period. The right forearm was supported at heart level by placing custom supports at the elbow and hand, such that the forearm did not touch anything. Before $(5 \mathrm{sec})$ and throughout the measurement periods, the wrist cuff was inflated to a pressure of $250 \mathrm{mmHg}$ to occlude the circulation of blood to the hand, while the cuff around the upper arm inflated $(50 \mathrm{mmHg})$ and deflated in cycles of $15 \mathrm{~s}$. This procedure yielded eight measurements per time period, which were averaged to give one forearm blood flow value per time point (in $\mathrm{ml} \cdot 100 \mathrm{ml}$ tissue ${ }^{-1} \cdot \mathrm{min}^{-1}$ ).

Systolic and diastolic blood pressures were determined by manual auscultation of the brachial artery at the 5th, 15th, and 25th minute of each exercise period, as well as during the local heating period to determine maximum skin vascular conductance. All auscultations were performed by the same experienced investigator. Mean arterial pressure was subsequently calculated as diastolic blood pressure plus one-third of pulse pressure. Skin vascular conductance was calculated as laser-Doppler velocimetry output in arbitrary perfusion units divided by mean arterial pressure and expressed as a percentage of maximum. Forearm vascular conductance (in $\mathrm{ml} \cdot 100 \mathrm{ml}$ tissue ${ }^{-1} \cdot \mathrm{min}^{-1} \cdot \mathrm{mmHg}^{-1}$ ) was calculated by dividing forearm blood flow by mean arterial pressure.

Esophageal temperature was measured with a general purpose thermocouple temperature probe (Mallinckrodt Medical, St. Louis, MO). The probe was inserted $40 \mathrm{~cm}$ past the entrance of the nostril, while the participants sipped water (100-300 ml) through a straw. Skin temperature was measured at 10 sites using thermocouples (Concept Engineering, Old Saybrook, CT) attached to the skin with surgical tape. Mean skin temperature was subsequently calculated using a 10-point weighting of the regional proportions determined by Hardy and DuBois (21). Temperature data were collected using a HP Agilent data acquisition module (model 3497A) at a rate of one sample every $15 \mathrm{~s}$ and simultaneously displayed and recorded in spreadsheet format on a personal computer with LabVIEW software (version 7.0, National Instruments).

The modified Snellen direct air calorimeter (38) was employed to measure whole body evaporative heat loss. In order for evaporative heat loss to be a valid measure of whole body sweat production, we ensured that the environmental conditions provided a high-vapor pressure gradient between the skin surface and the surrounding air. Furthermore, we continually maintained this vapor pressure gradient by providing a high mass flow of dry air through the calorimeter. Inflow and outflow values of absolute humidity were collected at 8-s intervals throughout the trials. The real time data were displayed and recorded on a personal computer with LabVIEW software (version 7.0, National Instruments). Evaporative heat loss was subsequently calculated using the calorimeter outflow-inflow difference in absolute humidity, multiplied by the air mass flow and latent heat vaporization of sweat at $30^{\circ} \mathrm{C}(50)$.

Indirect calorimetry was used for the measurement of metabolic energy expenditure (37). Expired gas was analyzed for oxygen (error of $\pm 0.01 \%$ ) and carbon dioxide (error of $\pm 0.02 \%$ ) concentrations using electrochemical gas analyzers (AMETEK model S-3A/1 and CD 3A, Applied Electrochemistry, Pittsburgh, PA). For the calorimeter session, the gas analyzers were located outside of the calorimeter, and expired air was recycled back into the calorimeter to account for respiratory heat exchange. Before each session, gas mixtures of known concentrations were used to calibrate the gas analyzers and a 3-liter syringe was used to calibrate the turbine ventilometer.

Urine-specific gravity was determined in duplicate using a handheld total solids refractometer (model TS400, Reichter, Depew, NY).

On the day of each experimental session, a venous blood sample $(10 \mathrm{ml})$ was obtained from female participants to confirm that the session occurred in the follicular/low-hormone phase of the menstrual cycle. The blood samples were collected with a SST vacutainer (BD Vacutainer, Franklin Lakes, NJ) for the determination of plasma $17 \beta$-estradiol and progesterone. Plasma concentrations of $17 \beta$-estradiol and progesterone were quantified by an independent external laboratory (Gamma-Dynacare Medical Laboratories, Ottawa, ON, Canada), with plasma concentrations representative of the follicular phase of the menstrual cycle of 46-604 pmol/l and 0.6-4.7 nmol/1, respectively.

For the additional experimental visit, blood samples were drawn without stasis after a minimum of 30-min baseline rest in the upright seated posture, as well as at 30,60, and 90 min of exercise through an indwelling plastic catheter in a superficial vein. At each time point, 
one sample $(\sim 5 \mathrm{ml})$ was drawn and transferred into a K2 EDTA vacutainer (BD Vacutainer) to determine hematocrit and hemoglobin, while two additional samples $(\sim 10 \mathrm{ml})$ were drawn and transferred into SST vacutainers (BD Vacutainer) for the measurement of plasma osmolality. Hematocrit and hemoglobin concentrations were determined using the Coulter method (Coulter $\mathrm{A}^{\mathrm{c}} \cdot \mathrm{T}$ diff 2 analyzer, Beckman Coulter, Miami, FL) and used to estimate changes in plasma volume (8). To determine plasma osmolality, both samples were immediately centrifuged at normal room temperature, and osmolality was determined in duplicate by freezing point depression (Osmometer, Advanced Instruments).

\section{Data Analysis}

For all variables, minute averages were performed to carry out the statistical analyses. To account for the relative influence of core and mean skin temperatures on the activation of sweat production $(24,35$, $36)$ and increases in skin blood flow $(53,54)$, mean body temperature was calculated as follows: $0.9 \times$ esophageal temperature $+0.1 \times$ mean skin temperature (45). The onset threshold and thermosensitivity of local sweat rate and whole body evaporative heat loss during each exercise period were determined using the linear portion of each response plotted against mean body temperature and analyzed using segmented regression analysis (6). Since skin blood flow did not increase with each exercise period (see RESULTS section), the onset threshold was determined during the first exercise period only, by plotting skin blood flow (as a percentage of maximum) over time and determining visually the point at which it increased over three consecutive measurements. The corresponding mean body temperature at that time point was taken as the onset threshold $(32,49)$. The thermosensitivity was determined as the slope of the relationship between skin vascular conductance and mean body temperature, plotted using the values at baseline, as well as at the end of each exercise period.

\section{Statistical Analysis}

All dependent variables were compared between groups (men and women) within each experimental condition (chamber and calorimeter). Independent samples $T$-tests were used for single comparisons between groups, while a two-way mixed-model analysis of variance was used for multiple comparisons using the repeated factor of time and the nonrepeated factor of group. When a significant main effect was observed, post hoc comparisons were carried out with the HolmBonferroni approach. The level of significance for all analyses was set at an $\alpha$-level of $P \leq 0.05$. Statistical analyses were performed using commercially available statistical software (SPSS 19.0 for Windows, SPSS, Chicago, IL). Segmented regression analysis was performed using GraphPad Prism 5.0 (GraphPad Software, La Jolla, CA). Participant characteristics, training history, and exercise intensities are presented as means $\pm \mathrm{SD}$, while all other variables are reported as mean $\pm 95 \%$ confidence intervals.

\section{RESULTS}

\section{Participant Characteristics}

There were no differences in age between groups $(P=$ $0.607)$. However, men had a significantly greater height $(P=$ $0.040)$ and body mass $(P=0.018)$. The differences in body mass were due to differences in fat free mass $(P \leq 0.001)$, as fat mass did not significantly differ between groups $(P=$ 0.363). Furthermore, men had a greater maximum oxygen consumption, both in absolute values $(P=0.001)$ and relative to body mass $(P=0.025)$. However, there were no significant differences between groups in maximum oxygen consumption when expressed as a function of fat free mass $(P=0.204)$.

\section{Training History}

During the 3 mo before their participation in the study, men and women reported engaging in physical activities long enough to work up a sweat, on average $6 \pm 3$ (range: $3-10)$ and $7 \pm 2$ (range: $5-12$ ) times/wk, respectively $(P=0.433)$. On average, men exercised $11 \pm 8$ (range: $2-25) \mathrm{h} / \mathrm{wk}$, while women exercised $11 \pm 6$ (range: $2-22) \mathrm{h} / \mathrm{wk}(P=0.972)$. During the 7 days before their participation in the study, men and women reported performing vigorous physical activity for $4 \pm 3$ (range: $0-8$ ) and $5 \pm 2$ (range: $1-8$ ) h, respectively $(P=0.744)$. Men and women also reported performing moderate physical activity for $4 \pm 3$ (range: $0-9$ ) and $4 \pm 4$ (range: $0-13)$ h, respectively $(P=0.933)$.

\section{Experimental Session 1: Whole Body Evaporative Heat Loss}

On the day of the experimental session, plasma concentrations of $17 \beta$-estradiol and progesterone for the female participants averaged $406 \pm 139 \mathrm{pmol} / \mathrm{l}$ and $1.6 \pm 0.1 \mathrm{nmol} / \mathrm{l}$, respectively. Urine-specific gravity did not differ between groups (men: $1.016 \pm 0.009$ vs. women: $1.011 \pm 0.008, P=$ 0.244 ). By design, rate of metabolic heat production did not differ between groups during the first (men: $200 \pm 3$ vs. women: $\left.200 \pm 7 \mathrm{~W} / \mathrm{m}^{2}, P=0.856\right)$, second $(247 \pm 2$ vs. $\left.248 \pm 5 \mathrm{~W} / \mathrm{m}^{2}, P=0.646\right)$, and third $(302 \pm 3$ vs. $300 \pm 4$ $\mathrm{W} / \mathrm{m}^{2}, P=0.412$ ) exercise periods. The external workloads associated with these rates of metabolic heat production did not differ between groups (men: $71 \pm 9,96 \pm 13,116 \pm 15 \mathrm{~W}$ vs. women: $67 \pm 6,92 \pm 9,109 \pm 11 \mathrm{~W}$, respectively, $P=$ 0.321 ), but represented a lower percentage of maximum oxygen consumption in men $(36 \pm 5,45 \pm 6,55 \pm 7 \%$ vs. $45 \pm$ $6,57 \pm 5,68 \pm 5 \%$, respectively; $P \leq 0.001)$.

Despite exercising at similar requirements for heat loss, changes over time in whole body evaporative heat loss significantly differed between groups $(P=0.002$, Fig. $1 A)$. Although evaporative heat loss was similar at the end of the first $(P=0.418)$ and second $(P=0.394)$ exercise periods, it became greater in men at the end of the third exercise period $\left(348 \pm 26\right.$ vs. $305 \pm 17 \mathrm{~W} / \mathrm{m}^{2}$, men vs. women, $\left.P=0.015\right)$. When examined in relation to the requirement for heat loss (Fig. 1A), evaporative heat loss reached a similar percentage of the $\mathrm{E}_{\text {req }}$ needed for heat balance in men and women during the first $(P=0.480)$ and second $(P=0.402)$ exercise periods. However, during the third exercise period, evaporative heat loss reached $84 \pm 5 \%$ of $E_{\text {req }}$ in women, whereas it represented $94 \pm 5 \%$ in men $(P=0.024)$. These differences were primarily due to a "leveling off" of evaporative heat loss in women, such that it did not significantly change over time during the last 10 min of the exercise period $(P>0.1)$, whereas evaporative heat loss significantly increased with time until the 26th min of exercise in men $(P<0.05)$. The onset threshold for evaporative heat loss did not differ between men and women at the start of each exercise period (all $P>0.1$, Table 2). The thermosensitivity of evaporative heat loss did not differ between the sexes during the first two exercise periods (both $P>$ $0.1)$, but was greater in men during the last exercise period $(P=0.007$, Table 3 and Fig. $1 B)$.

At the end of the 30-min baseline period, esophageal temperature averaged $36.69 \pm 0.12^{\circ} \mathrm{C}$ in men and $37.03 \pm 0.18^{\circ} \mathrm{C}$ in women $(P \leq 0.01)$. During the exercise period, changes over time in esophageal temperature significantly differed between 


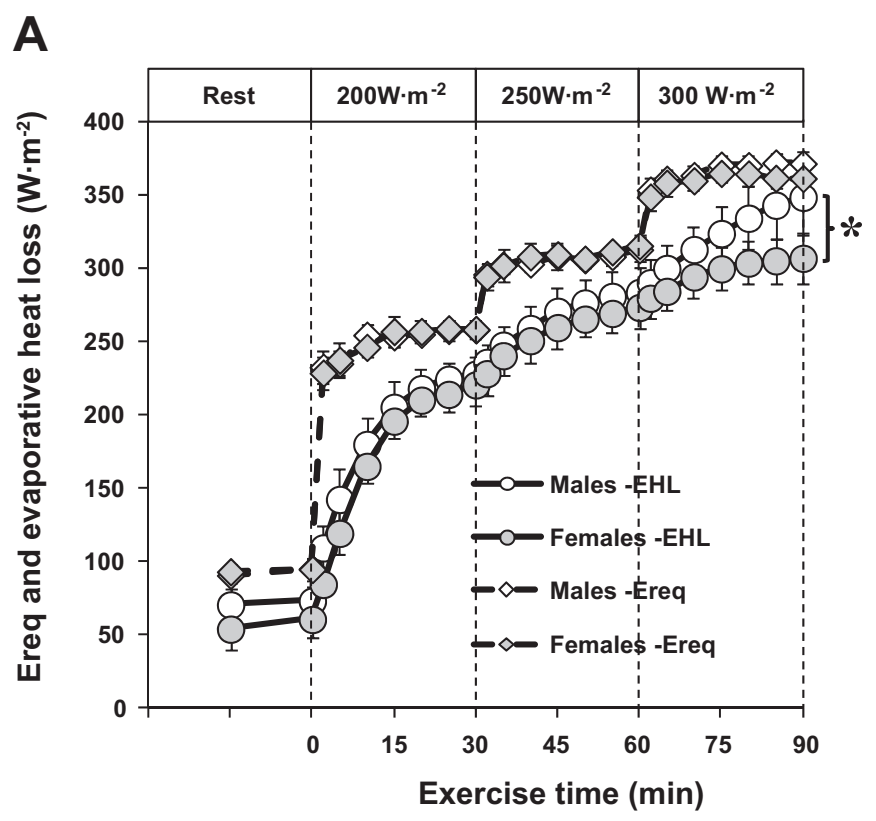

B

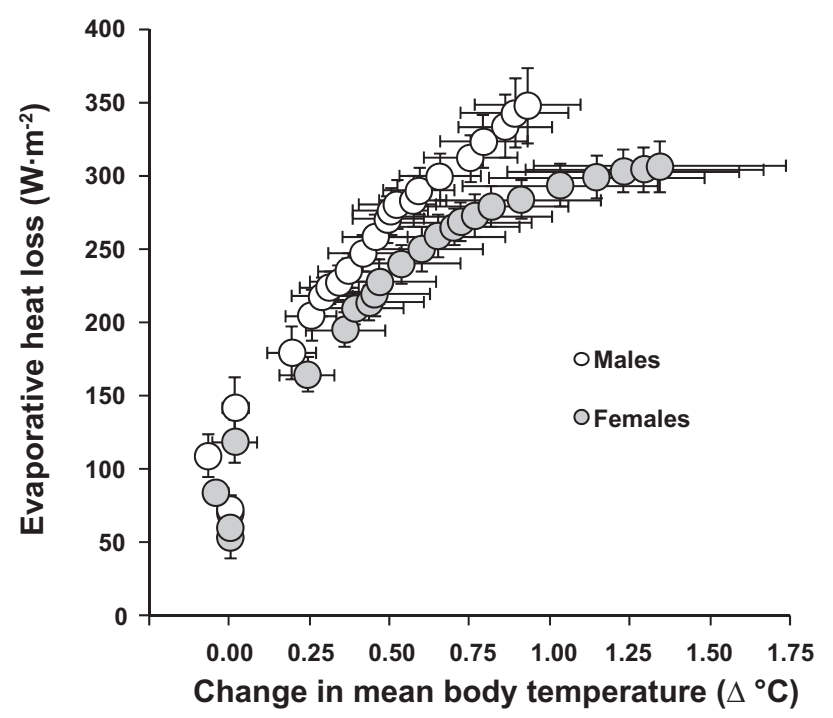

Fig. 1. Sex differences in evaporative heat loss (EHL) relative to the required evaporation for heat balance $\left(\mathrm{E}_{\mathrm{req}} ; A\right)$, as well as in EHL as a function of changes in mean body temperature $(B)$ during exercise performed at increasing rates of metabolic heat production $\left(200,250,300 \mathrm{~W} / \mathrm{m}^{2}\right)$. Dashed lines represent the beginning of each exercise period. Values are means $\pm 95 \%$ confidence intervals. *Significantly different EHL between men and women $(P<0.05) . \Delta$, Change.

the sexes (time $\times$ sex interaction, $P=0.010$ ). Although the change in esophageal temperature during the first $(0.36 \pm 0.09$ vs. $\left.0.52 \pm 0.18^{\circ} \mathrm{C}, P=0.145\right)$ and second $(0.24 \pm 0.04$ vs. $0.33 \pm 0.13^{\circ} \mathrm{C}$, men vs. women, $P=0.215$ ) exercise periods did not significantly differ between the sexes, it was significantly greater in women $\left(0.61 \pm 0.16^{\circ} \mathrm{C}\right)$ compared with men $\left(0.37 \pm 0.07^{\circ} \mathrm{C}, P=0.018\right)$ during the last exercise period. In contrast, no sex differences in mean skin temperature were observed throughout the exercise period $(P=0.490)$, averaging $35.52 \pm 0.26,35.60 \pm 0.26$, and $35.82 \pm 0.29^{\circ} \mathrm{C}$ for men and $35.83 \pm 0.26,35.94 \pm 0.39$, and $36.24 \pm 0.58^{\circ} \mathrm{C}$ for women at the end of the first, second, and third exercise period, respectively. Furthermore, no sex differences in heart rate were observed at the end of the first ( $108 \pm 7$ vs. $113 \pm 7$ beats/min, $P=0.351)$, second $(125 \pm 11$ vs. $135 \pm 10$ beats $/ \mathrm{min}, P=$ $0.212)$, and third $(143 \pm 12$ vs. $153 \pm 10$ beats/min, men vs. women, $P=0.251$ ) exercise period. Overall, the change in body weight was significantly greater in men during the exercise period $(1.70 \pm 0.12$ vs. $1.45 \pm 0.10 \mathrm{~kg}$ in women, $P=$ $0.008)$. However, it represented a similar percent change in both groups $(-2.32 \pm 0.20$ vs. $-2.38 \pm 0.14 \%$, men vs. women, $P=0.596)$.

\section{Experimental Session 2: Local Heat Loss Responses}

On the day of the experimental session, plasma concentrations of $17 \beta$-estradiol and progesterone for the female participants averaged $225 \pm 138 \mathrm{pmol} / \mathrm{l}(P=0.205 \mathrm{vs}$. calorimeter session $)$ and $1.7 \pm 0.5 \mathrm{nmol} / \mathrm{l}(P=0.520 \mathrm{vs}$. calorimeter session), respectively. Urine specific gravity did not differ between groups (men: $1.018 \pm 0.010$ vs. women: $1.009 \pm$ $0.008, P=0.061)$. By design, rate of metabolic heat production did not differ between groups during the first (men: $197 \pm$ 16 vs. women: $\left.204 \pm 3 \mathrm{~W} / \mathrm{m}^{2}, P=0.246\right)$, second $(252 \pm 2$ vs. $\left.250 \pm 3 \mathrm{~W} / \mathrm{m}^{2}, P=0.076\right)$, and third (303 \pm 2 vs. $305 \pm$ $\left.6 \mathrm{~W} / \mathrm{m}^{2}, P=0.412\right)$ exercise periods. The external workloads associated with these rates of metabolic heat production did not differ between groups (men: $68 \pm 7,86 \pm 10$, and $105 \pm 16$ $\mathrm{W}$ vs. women: $60 \pm 9,81 \pm 12$, and $93 \pm 13 \mathrm{~W}, P=0.140$ ), but represented a lower percentage of maximum oxygen consumption in men $(37 \pm 5,46 \pm 7$, and $55 \pm 7 \%$ vs. $46 \pm 4$, $58 \pm 4$, and $69 \pm 5 \%, P \leq 0.001)$.

Local sweat rate. Despite exercise being performed at fixed requirements for heat loss, changes in local sweat rate on the back $(P<0.001)$, chest $(P \leq 0.001)$, and forearm $(P<0.001)$ significantly differed over time between sexes. Upper back sweat rate (Fig. 2A) was similar at the end of the first exercise period $(P=0.483)$, but became greater in men at the end of the second $(P=0.012)$, and third $(P=0.004)$ exercise periods. Similarly, chest sweat rate (Fig. $3 A$ ) did not differ between groups at the end of the first $(P=0.802)$ and second $(P=$ $0.382)$ exercise periods, but was greater in men at the end of the last $(P=0.044)$ exercise period. In contrast, forearm sweat rate (Fig. 4A) was significantly greater in men at the end of each exercise period $(P \leq 0.05)$. The onset threshold for local sweat rate at all sites (Table 2), as well as at the onset of each exercise period, did not differ between men and women $(P>$ $0.1)$. There were no sex differences in the thermosensitivity of local sweat rate at all sites during the first exercise period $(P>$ 0.1 , Table 3). During the second exercise period, no differences in thermosensitivity were observed between the sexes on the chest and forearm $(P>0.1)$, while it was greater in men on the upper back $(P=0.014)$. In contrast, the thermosensitivity at all sites was significantly greater in men during the last exercise period ( $P \leq 0.01$, Table 3 ). The mean of all three local sweat rate measurements against the change in mean body temperature is presented in Fig. 5A. The change in body weight was significantly greater in men during the exercise period $(2.02 \pm$ 0.15 vs. $1.59 \pm 0.09 \mathrm{~kg}$ in women, $P \leq 0.001)$. However, it represented a similar percent change in both groups $(-2.78 \pm$ 0.25 vs. $-2.62 \pm 0.13 \%$, men vs. women, $P=0.323)$. 
Table 2. Onset threshold of thermoeffector responses

\begin{tabular}{|c|c|c|c|c|c|c|}
\hline & \multicolumn{2}{|c|}{$200 \mathrm{~W} / \mathrm{m}^{2}$} & \multicolumn{2}{|c|}{$250 \mathrm{~W} / \mathrm{m}^{2}$} & \multicolumn{2}{|c|}{$300 \mathrm{~W} / \mathrm{m}^{2}$} \\
\hline & Men & Women & Men & Women & Men & Women \\
\hline \multicolumn{7}{|c|}{ Sudomotor activity, $\Delta^{\circ} \mathrm{C}$} \\
\hline Whole body & $0.01 \pm 0.01$ & $0.01 \pm 0.01$ & $0.02 \pm 0.02$ & $0.02 \pm 0.02$ & $0.04 \pm 0.02$ & $0.02 \pm 0.02$ \\
\hline Back & $0.02 \pm 0.02$ & $0.02 \pm 0.01$ & $0.02 \pm 0.01$ & $0.01 \pm 0.01$ & $0.06 \pm 0.06$ & $0.02 \pm 0.01$ \\
\hline Chest & $0.02 \pm 0.02$ & $0.01 \pm 0.00$ & $0.02 \pm 0.01$ & $0.01 \pm 0.01$ & $0.02 \pm 0.01$ & $0.01 \pm 0.01$ \\
\hline Forearm & $0.03 \pm 0.02$ & $0.02 \pm 0.02$ & $0.02 \pm 0.01$ & $0.01 \pm 0.01$ & $0.02 \pm 0.01$ & $0.03 \pm 0.02$ \\
\hline \multicolumn{7}{|c|}{ Skin blood flow, $\Delta^{\circ} \mathrm{C}$} \\
\hline Back & $0.06 \pm 0.02$ & $0.07 \pm 0.02$ & $\mathrm{n} / \mathrm{a}$ & $\mathrm{n} / \mathrm{a}$ & $\mathrm{n} / \mathrm{a}$ & $\mathrm{n} / \mathrm{a}$ \\
\hline Chest & $0.04 \pm 0.02$ & $0.07 \pm 0.02$ & $\mathrm{n} / \mathrm{a}$ & $\mathrm{n} / \mathrm{a}$ & $\mathrm{n} / \mathrm{a}$ & $\mathrm{n} / \mathrm{a}$ \\
\hline Forearm & $0.06 \pm 0.01$ & $0.08 \pm 0.02$ & $\mathrm{n} / \mathrm{a}$ & $\mathrm{n} / \mathrm{a}$ & $\mathrm{n} / \mathrm{a}$ & $\mathrm{n} / \mathrm{a}$ \\
\hline
\end{tabular}

Values are means $\pm 95 \%$ confidence intervals. Whole body sudomotor activity was measured by direct calorimetry. n/a, Not applicable as the onset threshold for increases in skin blood flow was only measured at the beginning of the first exercise period. $\Delta$, Change.

Sweat gland activation. The number of active sweat glands (Table 4) on the upper back was significantly greater in women compared with men at the end of each exercise period $(P<$ 0.001). As such, the greater upper back sweat rate in men was entirely due to a greater sweat gland output $(P<0.001)$. Similarly, changes over time in the number of active sweat glands on the chest significantly differed between men and women $(P=0.018)$. Although the number of active sweat glands did not differ at the end of the first $(P=0.871)$ and second $(P=0.770)$ exercise periods, it became greater in women at the end of the third exercise period $(P=0.021)$. A similar pattern was observed for sweat gland output on the chest $(P<0.001)$, such that it did not differ between sexes at the end of the first $(P=0.480)$ and second $(P=0.153)$ exercise periods, but became greater in men at the end of the third exercise period $(P \leq 0.001)$. In contrast, the number of active sweat glands on the forearm did not differ between the sexes throughout exercise $(P=0.456)$. Consequently, the greater forearm sweat rate observed in men was entirely due to a greater sweat output per gland $(P \leq 0.001$, Table 4$)$.

Local skin blood flow. Skin blood flow at each site increased significantly from baseline rest during exercise $(P<0.001)$. Although skin blood flow values at the upper back significantly increased from the first to third exercise period $(P \leq 0.05)$, those at the chest and forearm did not $(P>0.05)$. No significant differences were observed between the sexes in skin blood flow at the back $(P=0.195)$, chest $(P=0.705)$, and forearm $(P=$ 0.212). Similarly, no differences were observed in the onset threshold for increases in skin blood flow at each site $(P>0.1$, Table 2).

Local skin vascular conductance. Mean arterial pressure significantly increased from baseline values during exercise $(P<0.001)$, with no significant changes from the first to the third exercise period $(P=0.363)$. Mean arterial pressure was significantly lower in women at baseline rest $(80 \pm 2$ vs. $86 \pm$ $3 \mathrm{mmHg}$ in men, $P=0.006)$, and remained lower at the end of the first $(83 \pm 2$ vs. $90 \pm 5 \mathrm{mmHg}, P=0.014)$, second $(83 \pm$ 2 vs. $91 \pm 5 \mathrm{mmHg}, P=0.026)$, and third $(84 \pm 3$ vs. $91 \pm$ $5 \mathrm{mmHg}$, women vs. men, $P=0.038)$ exercise periods. Nonetheless, skin vascular conductance at the back $(P=$ 0.199 , Fig. $2 B)$, chest $(P=0.643$, Fig. $3 B)$, and forearm $(P=$ 0.221 , Fig. $4 B$ ) did not differ between the sexes. There were also no sex differences in the thermosensitivity of skin vascular conductance $(P>0.1$, Table 3$)$. The mean of all three local skin vascular conductance measurements against the change in mean body temperature is presented in Fig. $5 B$.

Whole limb forearm blood flow and vascular conductance. Forearm blood flow and vascular conductance increased from baseline values during exercise $(P<0.001)$, with no significant changes from the first to the third exercise period $(P>0.1)$. Forearm blood flow $(P=0.721)$ and vascular conductance $(P=$ 0.278 ) did not differ between the sexes throughout exercise. Forearm

Table 3. Thermosensitivity of thermoeffector responses

\begin{tabular}{|c|c|c|c|c|c|c|}
\hline & \multicolumn{2}{|c|}{$200 \mathrm{~W} / \mathrm{m}^{2}$} & \multicolumn{2}{|c|}{$250 \mathrm{~W} / \mathrm{m}^{2}$} & \multicolumn{2}{|c|}{$300 \mathrm{~W} / \mathrm{m}^{2}$} \\
\hline & Men & Women & Men & Women & Men & Women \\
\hline \multicolumn{7}{|c|}{ Sudomotor activity } \\
\hline
\end{tabular}

Values are means $\pm 95 \%$ confidence intervals. Whole body sudomotor activity was measured by direct calorimetry. n/a, Not applicable as the thermosensitivity of skin vascular conductance was not measured at each exercise period. *Significantly different from men $(P \leq 0.05)$. 
A

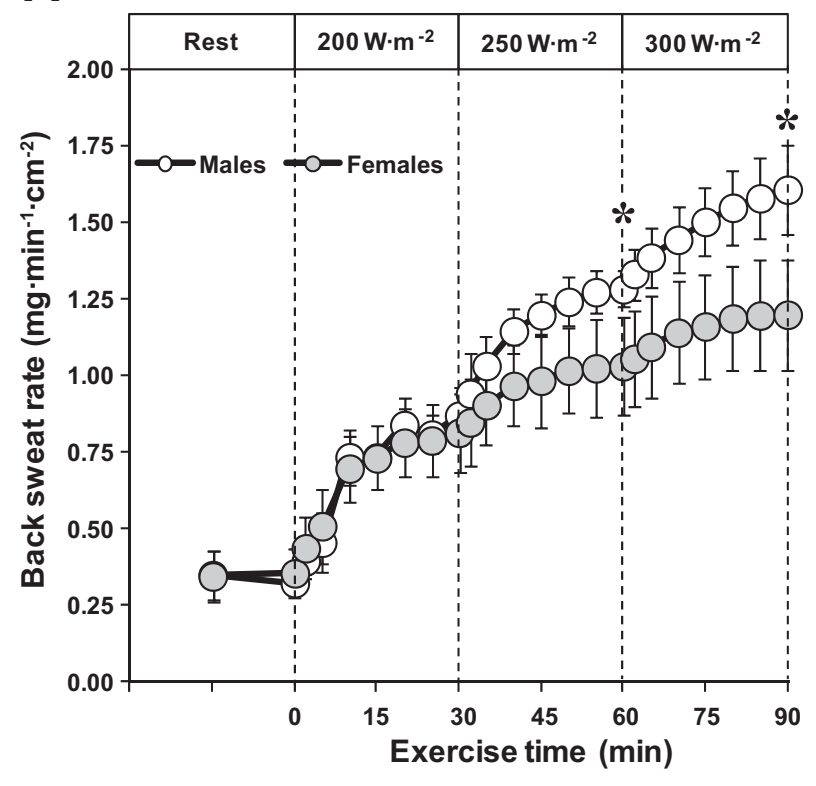

B

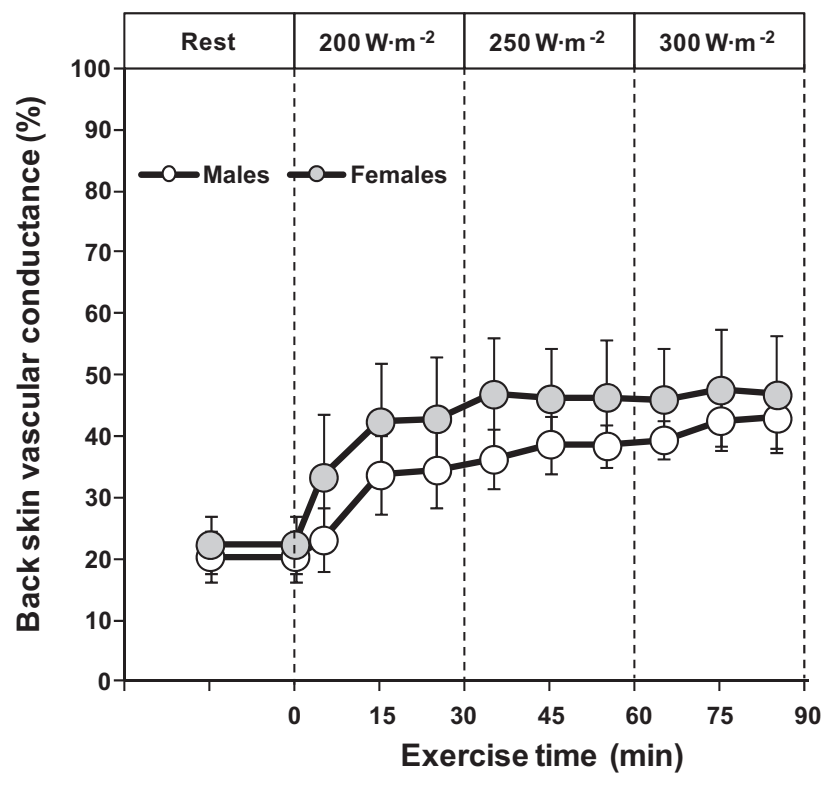

Fig. 2. Sex differences in upper back sweat rate $(A)$ and skin vascular conductance presented as a percentage of maximum $(B)$ during exercise performed at increasing rates of metabolic heat production $(200,250,300$ $\mathrm{W} / \mathrm{m}^{2}$ ). Dashed lines represent the beginning of each exercise period. Values are means $\pm 95 \%$ confidence intervals. *Significantly different sweat rate between men and women $(P<0.05)$.

vascular conductance averaged $0.05 \pm 0.01,0.09 \pm 0.03,0.09 \pm$ 0.02 , and $0.09 \pm 0.01 \mathrm{ml} \cdot 100 \mathrm{ml}$ tissue ${ }^{-1} \cdot \mathrm{min}^{-1} \cdot \mathrm{mmHg}^{-1}$ in men vs. $0.06 \pm 0.01,0.10 \pm 0.01,0.10 \pm 0.01$, and $0.10 \pm 0.02$ $\mathrm{ml} \cdot 100 \mathrm{ml}$ tissue ${ }^{-1} \cdot \mathrm{min}^{-1} \cdot \mathrm{mmHg}^{-1}$ in women during baseline rest, and the first, second, and third exercise period, respectively. Furthermore, the thermosensitivity of forearm vascular conductance $(P=0.651$, Table 3$)$ did not differ between groups.

Esophageal and mean skin temperatures and heart rate. At the end of the 30-min baseline period, esophageal temperature averaged $36.97 \pm 0.17^{\circ} \mathrm{C}$ in men and $37.42 \pm 0.07^{\circ} \mathrm{C}$ in women $(P \leq$
0.01). The change in esophageal temperature during the first $\left(0.28 \pm 0.15\right.$ vs. $\left.0.43 \pm 0.13^{\circ} \mathrm{C}, P=0.184\right)$ and second $(0.32 \pm$ $0.07^{\circ} \mathrm{C}$ vs. $0.37 \pm 0.13^{\circ} \mathrm{C}$, men vs. women, $P=0.500$ ) exercise periods did not significantly differ between the sexes. However, it was significantly greater in women $\left(0.72 \pm 0.16^{\circ} \mathrm{C}\right)$ compared with men $\left(0.53 \pm 0.09^{\circ} \mathrm{C}, P=0.052\right)$ during the last exercise period. Mean skin temperature was statistically greater in women at the end of the first $\left(36.80 \pm 0.15\right.$ vs. $36.33 \pm 0.12^{\circ} \mathrm{C}$, $P \leq 0.001)$, second ( $36.97 \pm 0.27$ vs. $\left.36.46 \pm 0.18^{\circ} \mathrm{C}, P=0.008\right)$,

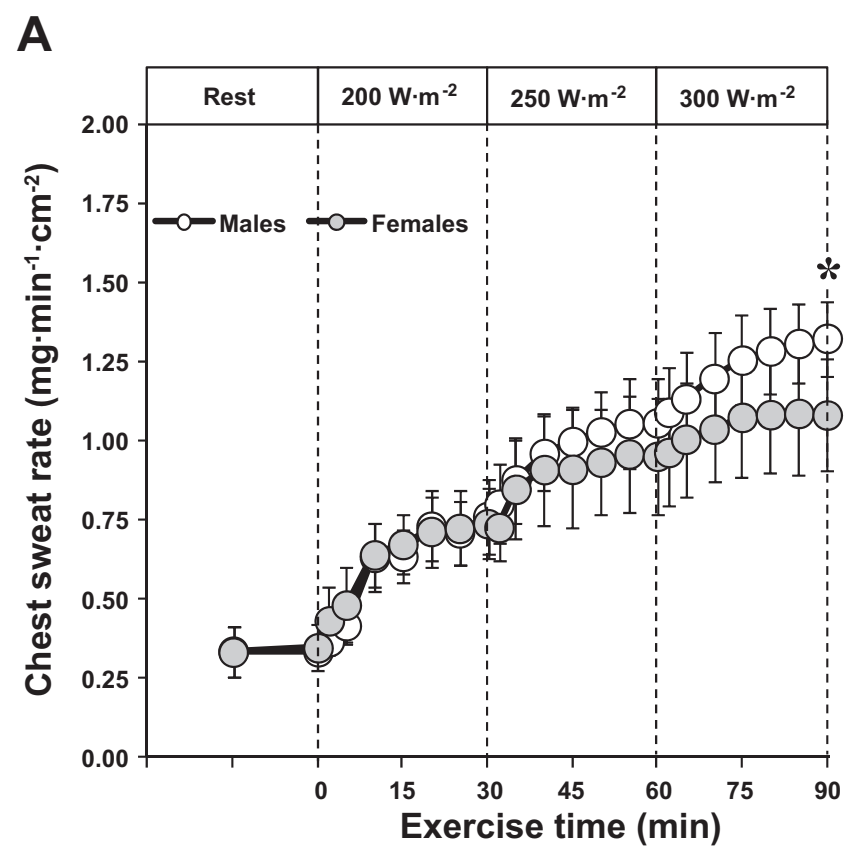

B

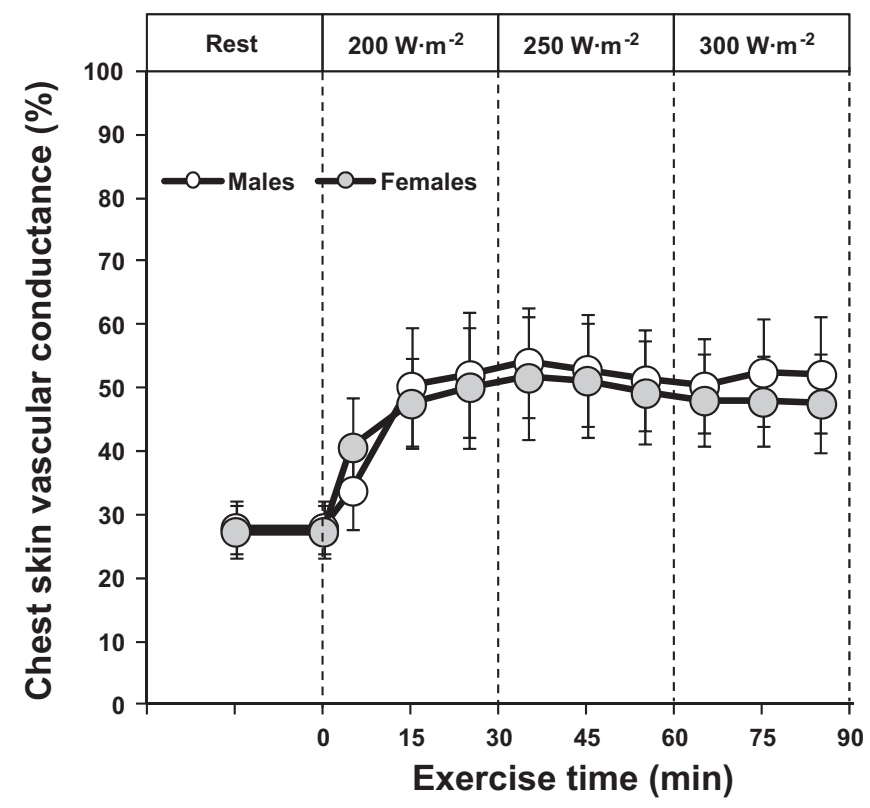

Fig. 3. Sex differences in chest sweat rate $(A)$ and skin vascular conductance presented as a percentage of maximum $(B)$ during exercise performed at increasing rates of metabolic heat production $\left(200,250,300 \mathrm{~W} / \mathrm{m}^{2}\right)$. Dashed lines represent the beginning of each exercise period. Values are means $\pm 95 \%$ confidence intervals. *Significantly different sweat rate between men and women $(P<0.05)$. 
A

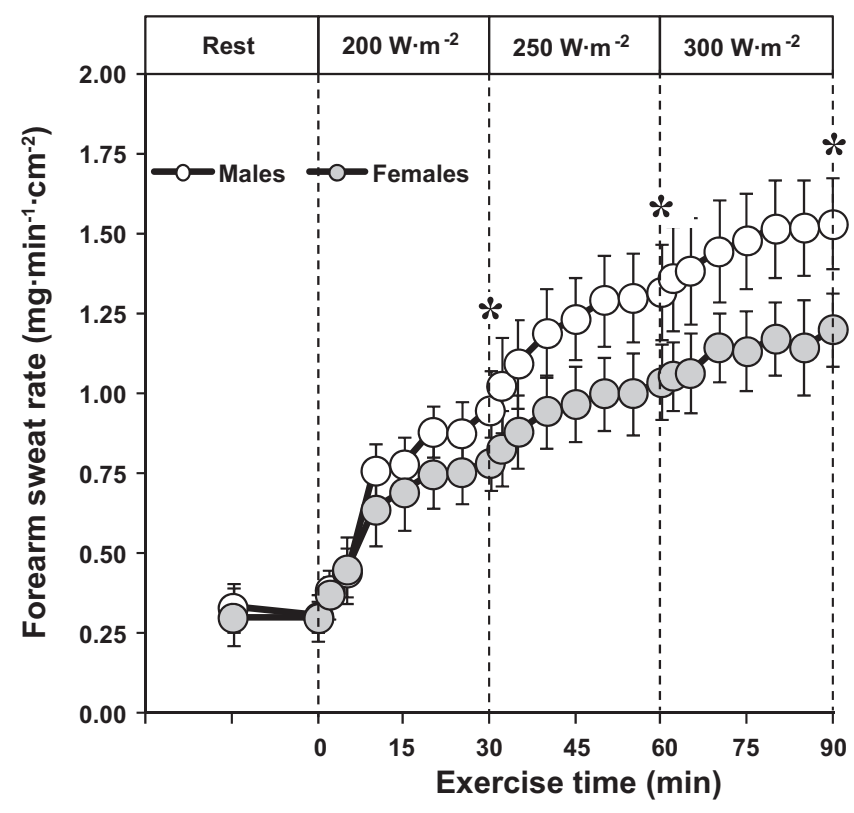

B

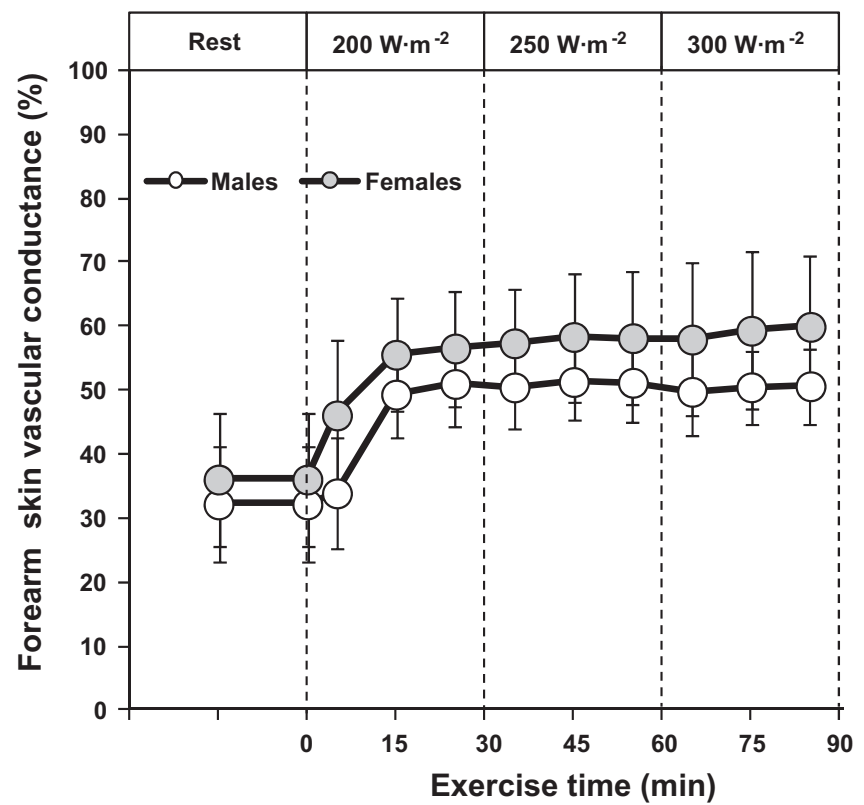

Fig. 4. Sex differences in forearm sweat rate $(A)$ and skin vascular conductance presented as a percentage of maximum $(B)$ during exercise performed at increasing rates of metabolic heat production $\left(200,250,300 \mathrm{~W} / \mathrm{m}^{2}\right)$. Dashed lines represent the beginning of each exercise period. Values are means $\pm 95 \%$ confidence intervals. *Significantly different sweat rate between men and women $(P<0.05)$

and third $\left(37.30 \pm 0.24\right.$ vs. $36.83 \pm 0.23^{\circ} \mathrm{C}$, women vs. men, $P=$ $0.015)$ exercise period. In contrast, no sex differences in heart rate were observed at the end of the first $(103 \pm 6$ vs. $114 \pm 9$ beats $/ \mathrm{min}, P=0.063)$, second $(123 \pm 9$ vs. $134 \pm 12$ beats $/ \mathrm{min}$, $P=0.136)$, and third (146 \pm 8 vs. $151 \pm 13$ beats/min, men vs. women, $P=0.546)$ exercise periods.

\section{Changes in Plasma Volume and Osmolality}

Decreases in plasma volume became greater with each exercise period $(P \leq 0.001)$, with no significant differences between sexes $(P=0.767)$. Changes from baseline in plasma volume averaged $-2.5 \pm 4.3,-5.7 \pm 3.9$, and $-10.4 \pm 4.2 \%$ for men and $0.1 \pm 3.7,-7.0 \pm 4.0$, and $-9.2 \pm 2.6 \%$ for women at the end of the first, second, and third exercise period, respectively. Baseline values of plasma osmolality did not significantly differ between sexes (men: $295 \pm 1 \mathrm{mosmol} /$ $\mathrm{kgH}_{2} \mathrm{O}$ vs. women: $296 \pm 3$ mosmol $\left./ \mathrm{kgH}_{2} \mathrm{O}, P=0.659\right)$. Plasma osmolality levels significantly increased with each exercise period $(P \leq 0.001)$. However, there were no significant differences in plasma osmolality between the sexes at the end of each exercise period $(P=0.805)$, averaging $297 \pm 2$, $300 \pm 2$, and $302 \pm 2 \mathrm{mosmol} / \mathrm{kgH}_{2} \mathrm{O}$ for men and $297 \pm 3$,
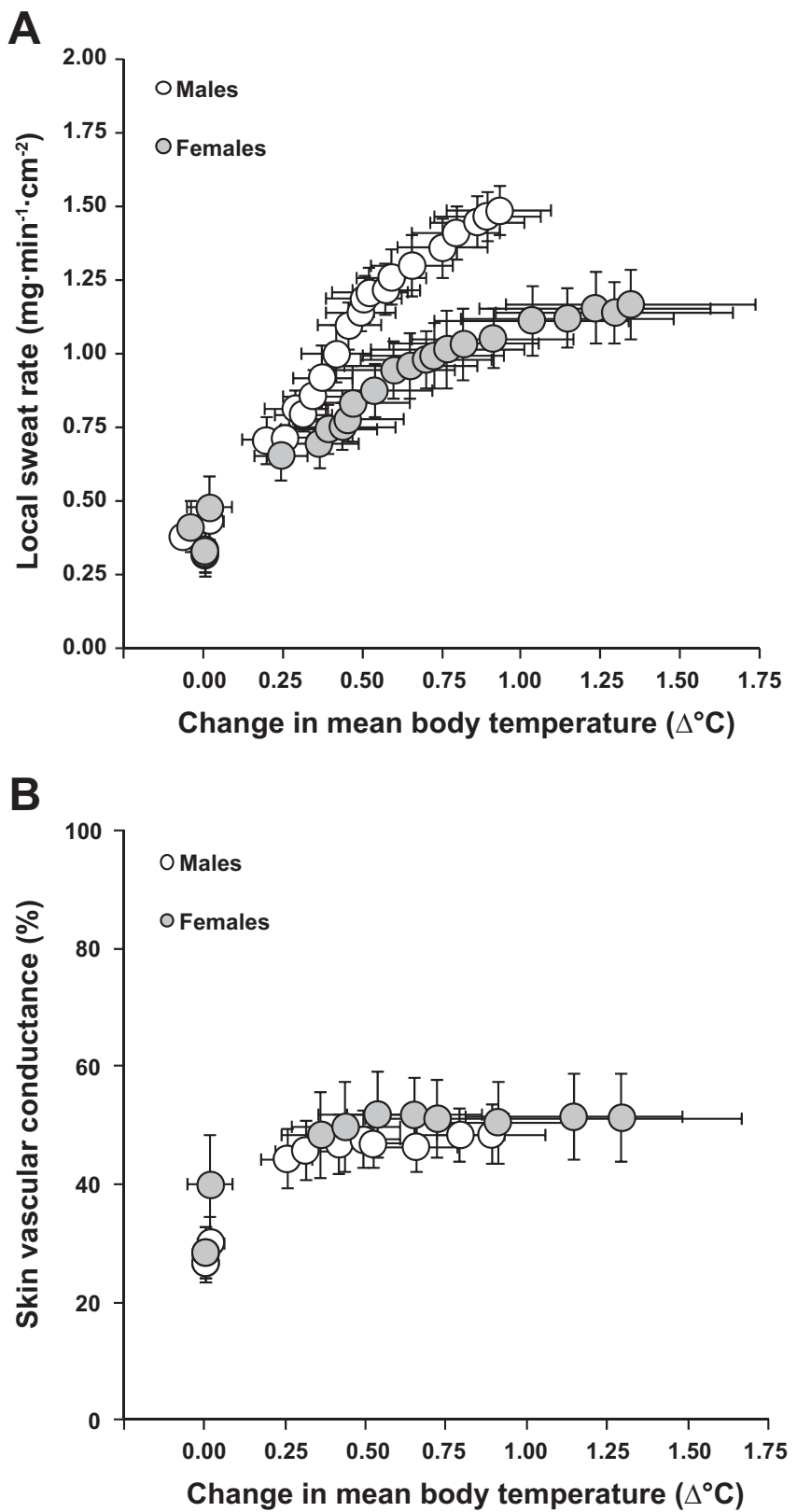

Fig. 5. Graphical representation of local sweat rate $(A)$ and skin vascular conductance $(B)$ as a function of changes in mean body temperature in men and women during exercise performed at increasing rates of metabolic heat production. The values represent the mean of three measurement sites (back, chest, forearm). Values are means $\pm 95 \%$ confidence intervals. 
Table 4. Sex differences in the number of active sweat glands and the sweat output per gland during exercise performed at increasing rates of metabolic heat production

\begin{tabular}{|c|c|c|c|c|c|c|c|}
\hline \multirow[b]{2}{*}{ Heat Production, $\mathrm{W} / \mathrm{m}^{2}$} & \multirow[b]{2}{*}{ Sex } & \multicolumn{2}{|c|}{ Back } & \multicolumn{2}{|c|}{ Chest } & \multicolumn{2}{|c|}{ Forearm } \\
\hline & & $\begin{array}{l}\text { No. Active Glands } \\
\text { per } \mathrm{cm}^{2}\end{array}$ & SGO, $\mu \mathrm{g} /$ gland & $\begin{array}{l}\text { No. Active Glands } \\
\text { per } \mathrm{cm}^{2}\end{array}$ & SGO, $\mu \mathrm{g} / \mathrm{gland}$ & $\begin{array}{l}\text { No. Active Glands } \\
\text { per } \mathrm{cm}^{2}\end{array}$ & SGO, $\mu \mathrm{g} / \mathrm{gland}$ \\
\hline \multirow[t]{2}{*}{ a200 } & Men & $56 \pm 8$ & $15.97 \pm 1.79$ & $57 \pm 6$ & $13.56 \pm 2.76$ & $92 \pm 12$ & $10.09 \pm 1.53$ \\
\hline & Women & $82 \pm 13^{*}$ & $9.95 \pm 1.06^{*}$ & $56 \pm 8$ & $12.22 \pm 2.20$ & $106 \pm 27$ & $7.46 \pm 1.54 *$ \\
\hline \multirow[t]{2}{*}{250} & Men & $58 \pm 6$ & $22.30 \pm 1.83$ & $64 \pm 9$ & $16.87 \pm 3.34$ & $112 \pm 12$ & $11.89 \pm 1.64$ \\
\hline & Women & $92 \pm 9^{*}$ & $11.23 \pm 1.38 *$ & $66 \pm 7$ & $13.60 \pm 2.38$ & $119 \pm 18$ & $8.61 \pm 1.06^{*}$ \\
\hline \multirow[t]{2}{*}{300} & Men & $58 \pm 8$ & $28.01 \pm 3.28$ & $59 \pm 7$ & $22.71 \pm 3.28$ & $101 \pm 7$ & $15.30 \pm 2.00$ \\
\hline & Women & $93 \pm 6^{*}$ & $13.04 \pm 1.91 *$ & $73 \pm 8 *$ & $13.82 \pm 1.69 *$ & $123 \pm 23$ & $9.83 \pm 1.65^{*}$ \\
\hline
\end{tabular}

Values are means $\pm 95 \%$ confidence intervals. SGO, sweat gland output. * Significantly different from men $(P \leq 0.05)$.

$300 \pm 2$, and $303 \pm 3 \mathrm{mosmol} / \mathrm{kgH}_{2} \mathrm{O}$ for women at the end of the first, second, and third exercise period, respectively.

\section{DISCUSSION}

The present study examined sex differences in sudomotor function (local and whole body) and skin blood flow during exercise performed at increasing requirements for heat loss. The main findings demonstrate that women exhibit a lower whole body evaporative heat loss and local sweat rate that is only evidenced beyond a certain requirement for heat loss. These differences are paralleled by a lower thermosensitivity of both responses, without any differences in the onset threshold. The lower local sweat rate in women is attributed to a lower sweat output per gland, as opposed to differences in the number of active sweat glands. In contrast, no sex differences in skin blood flow, as well as in the onset threshold and thermosensitivity of the skin blood flow response, were observed at all requirements for heat loss.

Although a number of studies have examined differences in sweat rate between men and women during exercise, the majority employed experimental protocols that resulted in men exercising at greater rates of metabolic heat production compared with women, making it difficult to determine if sex differences in sweat rate were truly due to physiological differences in temperature regulation, or simply associated with differences in metabolic heat production (15). An important consideration of the present study is the use of fixed rates of metabolic heat production expressed per unit of body surface area, which, combined with fixed environmental conditions, resulted in the same $\mathrm{E}_{\text {req }}$ for both sexes during exercise. This experimental approach is essential to ascribe the observed differences in local sweat rate and whole body evaporative heat loss to physiological sex differences (rather than physical), as previous studies have shown that the level of local and whole body sweat rate achieved during exercise is determined by the ratio of $E_{\text {req }}$ and the $E_{\max }$ possible in a given environment $(2,43)$.

To differentiate between a central and peripheral modulation of sudomotor function, the present study examined the onset threshold and thermosensitivity of local sweat rate and whole body evaporative heat loss during progressive increases in the requirement for heat loss. In theory, differences in neural activity between men and women would expect to yield differences in sweat production, as well as in the onset threshold of the response, at all requirements for heat loss. For example, central adaptations associated with acclimation, sex hormones, and hyperosmolality consistently result in a shift in the onset threshold of both sweating and skin blood flow, with little to no change in thermosensitivity $(1,47)$. Furthermore, these shifts are apparent whether the requirement for heat loss is high, such as during exercise, or whether it is relatively low, such as during passive heat stress $(4,10,48)$. In the present study, the onset threshold of both local sweat rate and whole body evaporative heat loss, as well as for increases in skin blood flow, did not differ between the sexes. Furthermore, sex differences in sudomotor thermosensitivity were not observed at lower exercise intensities, only becoming evident at the greatest requirement for heat loss employed. It should be noted that the greater local sweat rate on the back and forearm observed in men during the first and second exercise bouts is likely the result of regional differences in sweat rate between the sexes (23), as whole body evaporative heat loss did not differ at these two requirements for heat loss.

Measurements of sweat gland activation have also been used to determine whether differences in sweat rate between conditions and/or populations are mediated centrally or peripherally. While sweat gland activation must result from thermoefferent neural activity, the sweat output per gland reflects the peripheral properties of the sweat gland itself (39). As such, differences in central sudomotor function between the sexes would be expected to result in varying levels of sweat gland activation. In the present study, sweat gland activation was greater in women compared with men. These results are consistent with previous observations during passive heat stress $(3,26,29)$ and exercise $(11,25,34)$. Consequently, the observed sex differences in local sweat rate were solely the result of a lower sweat gland output in women. The sweat gland's maximal capacity to produce sweat has been used as an indicator of peripheral modulation (40). Interestingly, we observed a clear leveling off in women of whole body evaporative heat loss at the highest requirement for heat loss, whereas it continued to increase in men. This observation is particularly evident when examining evaporative heat loss in relation to $\mathrm{E}_{\text {req }}$ (see Fig. 1A). During the first two exercise periods, evaporative heat loss accounted for a similar proportion of the evaporation needed for heat balance in men and women. However, the lack of increase in evaporative heat loss during the last $10 \mathrm{~min}$ of the third exercise period in women resulted in evaporative heat loss values that accounted for a significantly lower proportion of $E_{\text {req. }}$. In contrast, the greater and continued increase in whole body evaporative heat loss in men maintained evaporative heat loss values that accounted for $>90 \%$ of the required value for heat balance. Although a true test of concept would require an additional rise in the requirement for heat loss combined with 
a total absence of increases in evaporative heat loss, these observations provide evidence of a lower maximal evaporative capacity, and therefore maximal sweat production, in women.

In contrast to sudomotor function, sex-related differences in skin blood flow during heat stress have been less examined. Inoue et al. (26) did not observe any sex differences in back, chest, and forearm skin blood flow during passive heating of the lower limbs, while Kolka et al. (31) reported a similar onset threshold and thermosensitivity of forearm skin blood flow between sexes during exercise in a warm $\left(30^{\circ} \mathrm{C}\right)$ environment. It should be noted, however, that Inoue et al. (26) did report a greater thermosensitivity of skin blood flow on the thigh in women, which led them to speculate that women may rely to a greater extent on increases in skin blood flow compared with men for effective heat dissipation. In contrast, our results do not support a greater reliance on skin blood flow in women for heat loss during exercise in the heat, as we did not observe any differences in both local and whole limb skin blood flow at all requirements for heat loss. Furthermore, recent evidence suggests that skin blood flow can independently modulate the thermosensitivity of local sweat rate, without affecting the onset threshold of the response (52). As such, the similar local and whole limb skin blood flow between men and women in the present study rule out the possibility that the lower thermosensitivity of local sweat rate in women is associated with differences in skin blood flow.

\section{Perspectives}

The observed sex differences in sudomotor thermosensitivity, which only occurred at the highest requirement for heat loss, combined with the lack of sex differences in the onset threshold of the response, as well as in skin blood flow as a whole, are consistent with a peripheral modulation of sudomotor function in women. This is particularly evident when considering that parallel shifts in the onset threshold of both thermoeffector responses are typical of a central modulation of temperature regulation (18). A peripheral modulation of sudomotor function during exercise in women could be mediated through sex differences in either the cholinergic sensitivity of the sweat gland $(17,28,33)$, the physical properties (e.g., size) of the sweat gland (40), the concentration of cholinergic agonists released in the sudomotor junction, and/or the concentration of acetylcholinesterase present within the sudomotor junction (44). Further research is, therefore, needed to determine which of these factors is specifically responsible in mediating the lower sudomotor thermosensitivity in women during exercise.

\section{Considerations}

It may be argued that the observed differences in sudomotor function are related to differences in the percentage of maximum oxygen consumption elicited by fixed rates of metabolic heat production. However, this would disregard recent findings, which demonstrate that differences in relative exercise intensity and maximum oxygen consumption between independent groups do not modulate local sweat production when exercise is performed at a fixed requirement for heat loss (7, 27). It is also noteworthy that relative exercise intensity differed between men and women during each exercise period, yet consistent differences in local sweat rate and whole body evaporative heat loss were only observed during the last exercise period. Moreover, both sexes in the present study had a similar training history, suggesting that the lower absolute maximum oxygen consumption in women is likely attributed to a lower fat free mass, as opposed to differences in training status. In contrast to local sweat rate $(7,27)$, increases in skin blood flow during exercise are determined not only by the requirement for heat loss, but also by the competition created by the metabolic requirement of the active musculature (19). In the present study, the similar skin blood flow response in women occurred despite a relatively greater demand for blood flow to the active musculature, particularly at the highest requirement for heat loss. It is unknown whether similar results would have been observed if exercise had been performed at fixed percentages of maximum oxygen consumption. Future studies are required to determine the impact of using fixed requirements for heat loss compared with fixed percentages of maximum oxygen consumption on the skin blood flow response. Finally, it should also be considered that we did not observe any sex differences in changes in plasma volume and osmolality throughout the experimental protocol in a subset of participants. It is, therefore, unlikely that the present results can be attributed to possible differences in either of these variables. However, it is possible that, although changes in plasma volume were similar between men and women, absolute plasma volume would have started at a lower level in women, thus reducing to lower absolute values. Future studies are needed to examine this possibility.

\section{Conclusion}

The present study examined sex differences in sudomotor function (local and whole body) and skin blood flow during exercise in the heat performed at increasing requirements for heat loss. Consistent sex differences in local sweat rate and whole body evaporative heat loss were only evidenced at the highest requirement for heat loss employed. A lower local sweat rate and whole body evaporative heat loss was observed in women, which was paralleled by a lower thermosensitivity of each response without any differences in the onset threshold. Furthermore, the lower local sweat rate in women was solely the result of a lower sweat gland output, as opposed to differences in sweat gland activation. We also observed a leveling off of whole body evaporative heat loss at the highest requirement for heat loss in women, which suggests a lower maximal evaporative capacity. In contrast, no sex differences in both the onset threshold and thermosensitivity of skin blood flow were observed throughout the experimental protocol. Taken together, these results provide evidence that sex differences in sudomotor function during exercise are mediated peripherally.

\section{ACKNOWLEDGMENTS}

The current study was performed by D. Gagnon in partial fulfillment for the degree of Doctor of Philosophy from the University of Ottawa. The authors acknowledge the contributions of Drs. Ollie Jay and Craig Crandall, who provided critical input into the development of this work. The authors thank all of the members of the Human and Environmental Physiology Research Unit who assisted with data collection, as well as all of the participants who volunteered for the present study. 


\section{GRANTS}

D. Gagnon is supported by an Alexander Graham Bell Canadian Graduate Scholarship from the National Sciences and Engineering Research Council (NSERC). The current work was supported by the NSERC (RGPIN-298159 2009) and Leaders Opportunity Fund from the Canada Foundation for Innovation (22529). G. P. Kenny is supported by a University of Ottawa Research Chair in Environmental Physiology.

\section{DISCLOSURES}

No conflicts of interest, financial or otherwise, are declared by the author(s).

\section{AUTHOR CONTRIBUTIONS}

Author contributions: D.G. and G.P.K. conception and design of research; D.G. performed experiments; D.G. analyzed data; D.G. and G.P.K. interpreted results of experiments; D.G. prepared figures; D.G. drafted manuscript; D.G. and G.P.K. edited and revised manuscript; D.G. and G.P.K. approved final version of manuscript.

\section{REFERENCES}

1. Armstrong CG, Kenney WL. Effects of age and acclimation on responses to passive heat exposure. J Appl Physiol 75: 2162-2167, 1993.

2. Bain AR, Deren TM, Jay O. Describing individual variation in local sweating during exercise in a temperate environment. Eur J Appl Physiol 111: 1599-1607, 2011.

3. Bar-Or O, Lundegren HM, Magnusson LI, Buskirk ER. Distribution of heat-activated sweat glands in obese and lean men and women. Hum Biol 40: 235-248, 1968.

4. Bittel J, Henane R. Comparison of thermal exchanges in men and women under neutral and hot conditions. J Physiol 250: 475-489, 1975.

5. Canadian Society for Exercise Physiology. Determination of aerobic power. In: Certified Fitness Appraiser Resource Manual. Gloucester, Ontario, Canada: CSEP, 1986, chapt. II, p. 1-32.

6. Cheuvront SN, Bearden SE, Kenefick RW, Ely BR, Degroot DW, Sawka MN, Montain SJ. A simple and valid method to determine thermoregulatory sweating threshold and sensitivity. J Appl Physiol 107: 69-75, 2009.

7. Cramer MN, Bain AR, Jay O. Local sweating on the forehead, but not forearm, is influenced by aerobic fitness independently of heat balance requirements during exercise. Exp Physiol 97: 572-582, 2012.

8. Dill DB, Costill DL. Calculation of percentage changes in volumes of blood, plasma, and red cells in dehydration. J Appl Physiol 37: 247-248, 1974.

9. DuBois D, DuBois EF. A formula to estimate the approximate surface area if height and weight be known. Arch Intern Med 17: 863-871, 1916.

10. Fox RH, Goldsmith R, Kidd DJ, Lewis HE. Blood flow and other thermoregulatory changes with acclimatization to heat. J Physiol 166: $548-562,1963$.

11. Frye AJ, Kamon E. Sweating efficiency in acclimated men and women exercising in humid and dry heat. J Appl Physiol 54: 972-977, 1983.

12. Gagge AP, Gonzales RR. Mechanisms of heat exchange In: Handbook of Physiology. Environmental Physiology. Bethesda, MD: Am. Physiol. Soc., 1996 sect. 4, vol. I, chapt. 4, p. 45-84.

13. Gagnon D, Dorman LE, Jay O, Hardcastle SG, Kenny GP. Core temperature differences between sexes during intermittent exercise: physical considerations. Eur J Appl Physiol 105: 453-461, 2009.

14. Gagnon D, Ganio MS, Lucas RA, Pearson J, Crandall CG, Kenny GP. Modified iodine-paper technique for the standardized determination of sweat gland activation. J Appl Physiol 112: 1419-1425, 2012.

15. Gagnon D, Jay O, Lemire B, Kenny GP. Sex-related differences in evaporative heat loss: the importance of metabolic heat production. Eur $J$ Appl Physiol 104: 821-829, 2008.

16. Gagnon D, Kenny GP. Sex modulates whole-body sudomotor thermosensitivity during exercise. J Physiol 589: 6205-6217, 2011.

17. Gibson TE, Shelley WB. Sexual and racial differences in the response of sweat glands to acetylcholine and pilocarpine. J Invest Dermatol 11: 137-142, 1948.

18. Gisolfi CV, Wenger CB. Temperature regulation during exercise: old concepts, new ideas. Exerc Sport Sci Rev 12: 339-372, 1984.

19. González-Alonso J, Crandall CG, Johnson JM. The cardiovascular challenge of exercising in the heat. J Physiol 586: 45-53, 2008.

20. Hammel HT. Regulation of internal body temperature. Апnи Rev Physiol 30: 641-710, 1968.
21. Hardy J, DuBois E. The technique of measuring radiation and convection. J Nutr 15: 461-475, 1938.

22. Havenith G, Coenen JM, Kistemaker L, Kenney WL. Relevance of individual characteristics for human heat stress response is dependent on exercise intensity and climate type. Eur J Appl Physiol 77: 231-241, 1998.

23. Havenith G, Fogarty A, Bartlett R, Smith CJ, Ventenat V. Male and female upper body sweat distribution during running measured with technical absorbents. Eur J Appl Physiol 104: 245-255, 2008.

24. Hertzman AB, Randall WC, Peiss CN, Seckendorf R. Regional rates of evaporation from the skin at various environmental temperatures. $J$ Appl Physiol 5: 153-161, 1952.

25. Ichinose-Kuwahara T, Inoue Y, Iseki Y, Hara S, Ogura Y, Kondo N. Sex differences in the effects of physical training on sweat gland responses during a graded exercise. Exp Physiol 95: 1026-1032, 2010.

26. Inoue Y, Tanaka Y, Omori K, Kuwahara T, Ogura Y, Ueda H. Sexand menstrual cycle-related differences in sweating and cutaneous blood flow in response to passive heat exposure. Eur J Appl Physiol 94: 323-332, 2005.

27. Jay O, Bain AR, Deren TM, Sacheli M, Cramer MN. Large differences in peak oxygen uptake do not independently alter changes in core temperature and sweating during exercise. Am J Physiol Regul Integr Comp Physiol 301: R832-R841, 2011.

28. Kahn D, Rothman S. Sweat response to acetylcholine. J Invest Dermatol 5: 431-444, 1942.

29. Knip AS. Measurement and regional distribution of functioning eccrine sweat glands in male and female Caucasians. Hum Biol 41: 380-387, 1969.

30. Kohl HW, Blair SN, Paffenbarger RS, Macera CA, Kronenfeld JJ. A mail survey of physical activity habits as related to measured physical fitness. Am J Epidemiol 127: 1228-1239, 1988

31. Kolka MA, Stephenson LA, Rock PB, Gonzalez RR. Local sweating and cutaneous blood flow during exercise in hypobaric environments. $J$ Appl Physiol 62: 2224-2229, 1987.

32. Mack GW, Cordero D, Peters J. Baroreceptor modulation of active cutaneous vasodilation during dynamic exercise in humans. J Appl Physiol 90: 1464-1473, 2001.

33. Madeira LG, da Fonseca MA, Fonseca IA, de Oliveira KP, Passos RL, Machado-Moreira CA, Rodrigues LO. Sex-related differences in sweat gland cholinergic sensitivity exist irrespective of differences in aerobic capacity. Eur J Appl Physiol 109: 93-100, 2010.

34. Morimoto T, Slabochova Z, Naman RK, Sargent F. Sex differences in physiological reactions to thermal stress. J Appl Physiol 22: 526-532, 1967.

35. Nadel ER, Bullard RW, Stolwijk JA. Importance of skin temperature in the regulation of sweating. J Appl Physiol 31: 80-87, 1971.

36. Nadel ER, Mitchell JW, Saltin B, Stolwijk JA. Peripheral modifications to the central drive for sweating. J Appl Physiol 31: 828-833, 1971.

37. Nishi Y. Measurement of thermal balance in man. In: Bioengineering, Thermal Physiology and Comfort, edited by Cena K and Clark J. New York: Elsevier, 1981, p. 29-39.

38. Reardon FD, Leppik KE, Wegmann R, Webb P, Ducharme MB, Kenny GP. The Snellen human calorimeter revisited, re-engineered and upgraded: design and performance characteristics. Med Biol Eng Comput 44: 721-728, 2006.

39. Sato K, Dobson RL. Regional and individual variations in the function of the human eccrine sweat gland. J Invest Dermatol 54: 443-449, 1970.

40. Sato K, Sato F. Individual variations in structure and function of human eccrine sweat gland. Am J Physiol Regul Integr Comp Physiol 245: R203-R208, 1983.

41. Sawka MN. Physiological consequences of hypohydration: exercise performance and thermoregulation. Med Sci Sports Exerc 24: 657-670, 1992.

42. Schwiening CJ, Mason MJ, Thompson M. Absolute power, not sex, promotes perspiration. Exp Physiol 96: 556-558, 2011.

43. Shapiro Y, Pandolf KB, Goldman RF. Predicting sweat loss response to exercise, environment and clothing. Eur J Appl Physiol Occup Physiol 48: 83-96, 1982.

44. Shibasaki M, Crandall CG. Effect of local acetylcholinesterase inhibition on sweat rate in humans. J Appl Physiol 90: 757-762, 2001.

45. Shibasaki M, Wilson TE, Crandall CG. Neural control and mechanisms of eccrine sweating during heat stress and exercise. J Appl Physiol 100: 1692-1701, 2006.

46. Siri WE. Gross composition of the body. In: Advances in Biological and Medical Physics, edited by Lawrence JH and Tobias CA. New York: Academic, 1956, p. 239-280. 
47. Stephenson LA, Kolka MA. Thermoregulation in women. Exerc Sport Sci Rev 21: 231-262, 1993.

48. Takamata A, Mack GW, Gillen CM, Jozsi AC, Nadel ER. Osmoregulatory modulation of thermal sweating in humans: reflex effects of drinking. Am J Physiol Regul Integr Comp Physiol 268: R414-R422, 1995.

49. Takamata A, Nagashima K, Nose H, Morimoto T. Role of plasma osmolality in the delayed onset of thermal cutaneous vasodilation during exercise in humans. Am J Physiol Regul Integr Comp Physiol 275: R286-R290, 1998.

50. Wenger CB. Heat of evaporation of sweat: thermodynamic considerations. J Appl Physiol 32: 456-459, 1972.
51. Werner J. Control aspects of human temperature regulation. Automatica (Oxf) 17: 351-362, 1981.

52. Wingo JE, Low DA, Keller DM, Brothers RM, Shibasaki M, Crandall CG. Skin blood flow and local temperature independently modify sweat rate during passive heat stress in humans. J Appl Physiol 109: 1301-1306, 2010.

53. Wissler EH. A quantitative assessment of skin blood flow in humans. Eur J Appl Physiol 104: 145-157, 2008.

54. Wyss CR, Brengelmann GL, Johnson JM, Rowell LB, Niederberger M. Control of skin blood flow, sweating, and heart rate: role of skin vs. core temperature. J Appl Physiol 36: 726-733, 1974.

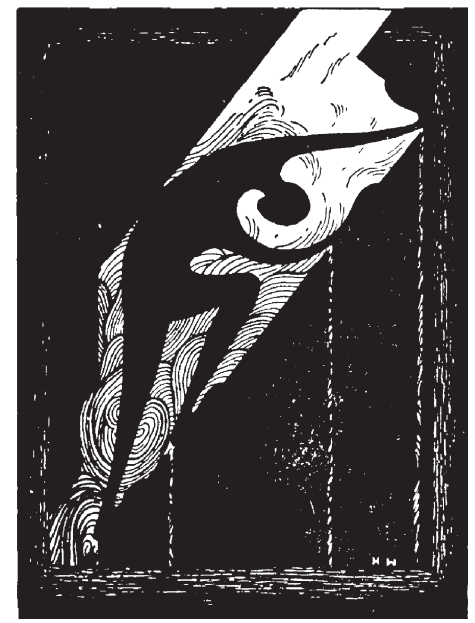




\section{APPENDIX C}

Additional results from thesis study \#1 

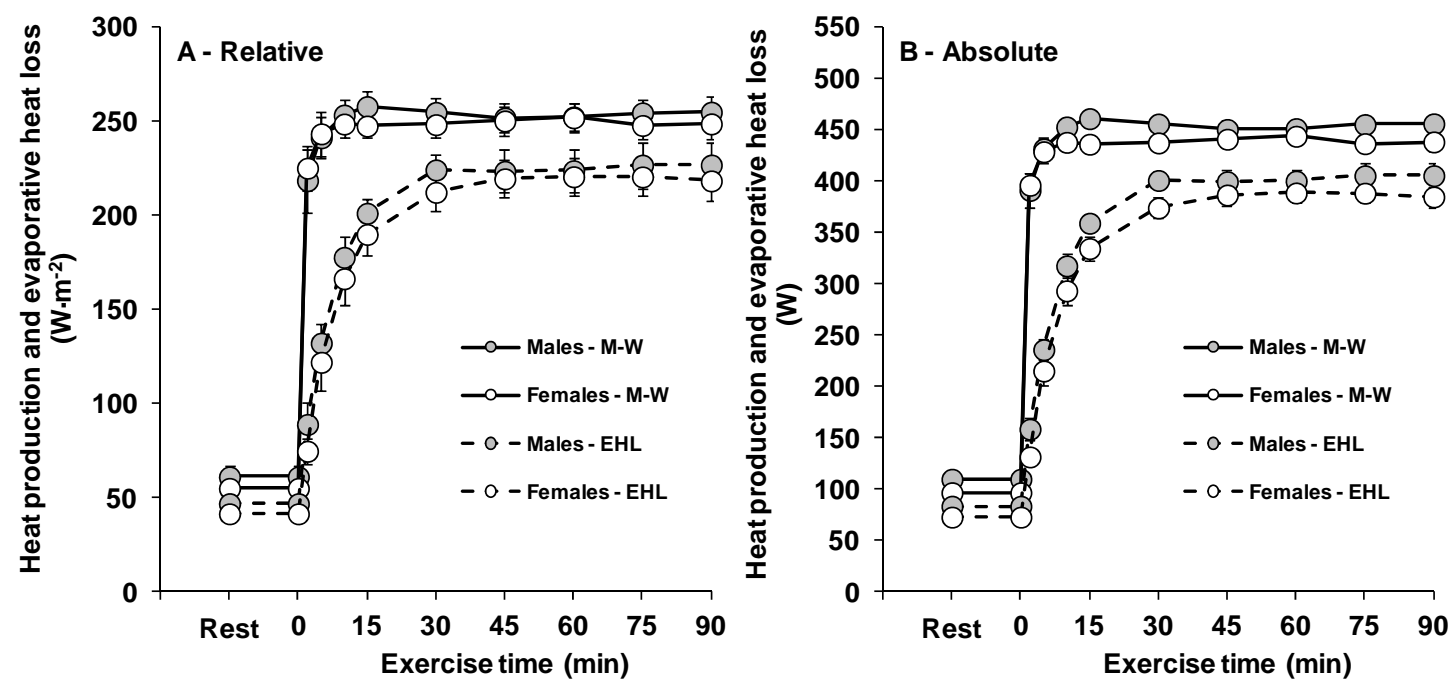

Appendix C Figure. Rate of metabolic heat production (M-W) and evaporative heat loss (EHL) in males and females during exercise performed at a fixed rate of metabolic production of $250 \mathrm{~W} \cdot \mathrm{m}^{-2}$. Panel A (relative) presents the data expressed relative to body surface area, while panel B (absolute) presents the same data in absolute values. Values are mean \pm standard error.

Appendix C Table. Mean body temperature onset threshold and thermosensitivity of the evaporative heat loss response for males and females during exercise at a fixed rate of heat production relative to body surface area $\left(250 \mathrm{~W} \cdot \mathrm{m}^{2}\right)$.

\begin{tabular}{ccc}
\hline & Males & Females \\
& 36.52 & 36.66 \\
Baseline & \pm 0.08 & \pm 0.05 \\
$\left({ }^{\circ} \mathrm{C}\right)$ & 36.63 & 36.81 \\
& \pm 0.10 & \pm 0.06 \\
Onset threshold & 826 & 678 \\
$\left({ }^{\circ} \mathrm{C}\right)$ & \pm 111 & \pm 91 \\
Sensitivity & 0.96 & 0.95 \\
$\left(\mathrm{~W}^{\circ} \mathrm{C}^{-1}\right)$ & \pm 0.02 & \pm 0.02 \\
$\mathrm{R}^{2}$ &
\end{tabular}

$\mathrm{R}^{2}$, correlation coefficient of the evaporative heat loss to mean body temperature relationship. Values are mean \pm standard error. 


\section{APPENDIX D}

Published version of article examining the reliability of the modified iodine-paper technique 


\title{
Modified iodine-paper technique for the standardized determination of sweat
}

\section{gland activation}

\author{
Daniel Gagnon, ${ }^{1}$ Matthew S. Ganio, ${ }^{2,3,4}$ Rebekah A. I. Lucas, ${ }^{2,3}$ James Pearson, ${ }^{2,3}$ Craig G. Crandall, \\ and Glen P. Kenny ${ }^{1}$ \\ ${ }^{1}$ Human and Environmental Physiology Research Unit, School of Human Kinetics, University of Ottawa, Ottawa, Canada; \\ ${ }^{2}$ Institute for Exercise and Environmental Medicine, Texas Health Presbyterian Hospital; ${ }^{3}$ University of Texas Southwestern \\ Medical Center, Dallas, Texas; and; ${ }^{4}$ Department of Health, Human Performance, and Recreation, University of Arkansas, \\ Fayetteville, Arkansas
}

Submitted 6 December 2011; accepted in final form 7 February 2012

Gagnon D, Ganio MS, Lucas RAI, Pearson J, Crandall CG, Kenny GP. Modified iodine-paper technique for the standardized determination of sweat gland activation. J Appl Physiol 112: 1419-1425, 2012. First published February 9, 2012; doi:10.1152/japplphysiol.01508.2011.— Quantifying sweat gland activation provides important information when explaining differences in sweat rate between populations and physiological conditions. However, no standard technique has been proposed to measure sweat gland activation, while the reliability of sweat gland activation measurements is unknown. We examined the interrater and internal reliability of the modified-iodine paper technique, as well as compared computer-aided analysis to manual counts of sweat gland activation. Iodine-impregnated paper was pressed against the skin of 35 participants in whom sweating was elicited by exercise in the heat or infusion of methylcholine. The number of active glands was subsequently determined by computer-aided analysis. In total, 382 measurements were used to evaluate: 1) agreement between computer analysis and manual counts; 2) the interrater reliability of computer analysis between independent investigators; and 3) the internal reliability of sweat gland activation measurements between duplicate samples. The number of glands identified with computer analysis did not differ from manual counts $(68 \pm 29$ vs. $72 \pm 24$ glands $\left./ \mathrm{cm}^{2} ; P=0.27\right)$. These measures were highly correlated $(r=0.77)$ with a mean bias \pm limits of agreement of $-4 \pm 38$ glands $/ \mathrm{cm}^{2}$. When comparing computer analysis measures between investigators, values were highly correlated $(r=0.95 ; P<0.001)$ and the mean bias \pm limits of agreement was $4 \pm 18$ glands $/ \mathrm{cm}^{2}$. Finally, duplicate measures of sweat gland activation were highly correlated $(r=0.88 ; P<0.001)$ with a mean bias \pm limits of agreement of $3 \pm 29$ glands $/ \mathrm{cm}^{2}$. These results favor the use of the modified-iodine paper technique with computer-aided analysis as a standard technique to reliably evaluate the number of active sweat glands.

heat-activated sweat glands; heat loss; sweat rate; sweat output; thermoregulation

SWEAT PRODUCTION FROM ECCRINE glands is arguably the most important effector mechanism involved in human temperature regulation during heat stress. It is therefore not surprising that normal sweat rate responses have been thoroughly characterized at rest and during exercise $(25,27,30,40)$, with many investigations examining how sweat production differs between populations $(3,20,22,33,41)$, as well as with various physiological $(23,28,38)$ and disease (24) states. Furthermore, recent work has established a valid method to assess the

\footnotetext{
Address for reprint requests and other correspondence: G. P. Kenny, Univ. of Ottawa, School of Human Kinetics, 125 Univ., Rm. 367 Montpetit Hall, Ottawa, Ontario, Canada K1N 6N5 (e-mail: gkenny@uottawa.ca).
}

physiological control of sweating (9), as well as examine its normal biological variation (19).

Sweat is produced by $2-4$ million eccrine sweat glands dispersed over the nonglabrous skin regions of the human body $(34,35)$. As such, total sweat production is determined by both the number of activated glands, as well as the output per individual gland $(7,25)$. Assessments of sweat gland activation have been used clinically to evaluate the extent of neurological damage caused by various disease states (13), as well as experimentally to evaluate sweat gland function in relation to exercise intensity (26), exercise training $(8,12)$, age $(2$, $14-17,21,39)$, obesity $(5)$, and sex $(5,11,18,29)$. Importantly, the number of active sweat glands has also been used to determine whether differences in sweat rate between populations/conditions are mediated via central or peripheral mechanisms $(36,37)$.

To date, experimental assessments of sweat gland function have been achieved through a variety of techniques, including the starch-iodine technique $(12,15-18,25,26,29,39)$, the modified iodine-paper technique $(5,8,11,36,37)$, and the macrophotographic technique $(2,21)$. Briefly, the starch-iodine technique consists of painting the skin surface with iodine and subsequently applying starch paper. The modified iodine-paper technique consists of applying iodine-impregnated paper onto the surface of unpainted skin. In both cases, the active sweat glands produce identifiable blue dots on the starch/iodineimpregnated paper. In contrast, the macrophotographic technique consists of painting the skin with Vaseline to promote beading of sweat while a series of pictures are taken from the measurement area. Common to all techniques is that the number of active sweat glands is subsequently counted manually, the count typically performed by the same experienced investigator.

Given the valuable information provided by measurements of sweat gland activation, it is surprising that no standard technique has been advocated to experimentally determine the number of active sweat glands. Considering that multiple laboratories utilize various techniques to achieve a common objective, the use of a standard technique would provide measurement consistency and allow direct comparisons between laboratories. Furthermore, interrater reliability of measuring the number of active sweat glands has not been examined. Since determining the number of active sweat glands within a collected sample is most often achieved though manual counts, it is unknown whether the number of active sweat glands determined by one investigator can reliably be interpreted by other external laboratories. With these issues in 
mind, we sought to evaluate the modified iodine-paper technique, in combination with a free, publicly available computer program (ImageJ), to count the number of active sweat glands. Specifically, we investigated 1 ) the agreement between computer-assisted and manual counts of active sweat glands; and 2) whether computer-assisted analysis is reliable between investigators from independent laboratories. Furthermore, we were interested in using the modified iodine-technique to determine the internal reliability of duplicate active sweat gland measurements. We hypothesized that the modified iodine-paper technique with computer-assisted analysis would provide a standardized and reliable means of determining the number of active sweat glands.

\section{METHODS}

\section{Ethical Approval}

The experimental protocol was approved by the University of Ottawa Health Sciences and Science Research Ethics Board, as well as the Institutional Review Boards of the University of Texas Southwestern Medical Center and Texas Health Presbyterian Hospital Dallas. Written informed consent was obtained from all volunteers before their participation in the study.

\section{Subjects}

The subjects consisted of 35 volunteers (13 females). All subjects were healthy, nonsmoking, and free of any known cardiovascular, metabolic, and respiratory diseases. The subjects had a mean \pm SD age of $34 \pm 11 \mathrm{yr}$, body height of $172 \pm 11 \mathrm{~cm}$, and body mass of $78.1 \pm 16.9 \mathrm{~kg}$.

\section{Experimental Design}

Study 1. Subjects were part of a larger study examining sex-related differences in temperature regulation. Upon arrival at the laboratory, the subject changed into shorts and sandals (as well as a sports bra for female subjects) and sat quietly for a 60 -min instrumentation period at an ambient room temperature of $\sim 24^{\circ} \mathrm{C}$. Following instrumentation, the subject was transferred to an environmental chamber regulated to an ambient air temperature of $40^{\circ} \mathrm{C}$ and a relative humidity of $20 \%$. A fan was placed in front of the subject to provide an airflow of $\sim 1 \mathrm{ml} / \mathrm{s}$. The subject, seated in the upright position, rested for a 30-min baseline period. Subsequently, the subject performed in succession three 30-min exercise periods at fixed rates of metabolic heat production equal to 200,250 , and $300 \mathrm{~W} / \mathrm{m}^{2}$. The number of active sweat glands on the upper back, chest, and forearm was determined in duplicate at 30, 60, and $90 \mathrm{~min}$ of exercise using the technique described below. The measurements for the back were performed on the upper trapezius muscle, $\sim 5 \mathrm{~cm}$ medial from the acromion; for the chest on the pectoralis major muscle, $\sim 5 \mathrm{~cm}$ below the clavicle; and for the forearm on the dorsal side, at the greatest circumference determined visually.

Study 2. Subjects were part of a larger study investigating the effect of heat acclimation on skin-grafted individuals compared with controls. Two intradermal microdialysis probes, consisting of two reinforced sections of polyimide tubing connected by a 1-cm dialysis membrane (Bio-analytical Systems, West Lafayette, IN), were inserted into healthy, noninjured skin by advancing a 25 -gauge needle 15-20 $\mathrm{mm}$ through the dermal layer, followed by threading the microdialysis probe through the lumen of the needle and withdrawing the needle. Microdialysis probes were perfused with lactated Ringer solution (Baxter, Deerfield, IL) at a rate of $2 \mu \mathrm{l} / \mathrm{min}$ via a perfusion pump (Harvard Apparatus, Holliston, MA) while hyperemia associated with insertion trauma subsided (a minimum of $90 \mathrm{~min}$ ). At each site, dose-response curves for sweating were assessed upon adminis- tration of increasing doses of methylcholine $\left(1 \times 10^{-7} \mathrm{M}\right.$ to $1 \mathrm{M}$ at 10 -fold increments). Each dose was administered for $5 \mathrm{~min}$ at a perfusion rate of $2 \mu \mathrm{l} / \mathrm{min}$. The highest dose (i.e., $1 \mathrm{M}$ ) was continually administered until a maximum plateau in sweating occurred ( $\sim 20-30 \mathrm{~min})$ after which the ventilated capsule used to measure sweat rate was removed and sweat gland activation was determined in duplicate using the technique described below. This experimental protocol was performed before and following 7 days of heat acclimation.

\section{Measurement of Sweat Gland Activation}

For both studies, the number of active sweat glands was determined using the modified iodine-paper technique originally proposed and validated by Randall $(31,32)$ and subsequently modified by Davis et al. (10). Four to five days before an experimental session, pieces of $100 \%$ cotton paper (32 lb; Southworth, Agawam, MA) were cut to a predetermined size $\left(9 \mathrm{~cm}^{2}\right.$ in study $1 ; 2.83 \mathrm{~cm}^{2}$ in study 2$)$ and placed in a sealed container containing iodine in solid form (Sigma-Aldrich, St. Louis, MO). Each piece of cotton paper was supported to avoid direct contact with the iodine. After $\sim 48 \mathrm{~h}$, the pieces of paper became saturated with iodine (as indicated by their dark brown color) and were subsequently transferred to a sealed bag for use during the experimental protocol. To ensure a uniform application on the skin surface, double-sided tape was used to affix the cotton paper to a flat hard plastic surface. Before the application of the cotton paper the skin was blotted dry, following which the cotton paper was firmly pressed against the skin surface for a period of $\sim 5 \mathrm{~s}$. With the use of this technique, sweat excreted from the active sweat glands forms easily identifiable blue dots on the iodine-impregnated paper when it is placed in contact with the skin surface. After the paper was removed from the skin, it was immediately scanned at high resolution (600 dots/in.) using a commercially available scanner for subsequent analysis using the ImageJ image processing and analysis program (1).

Image processing and analysis. Image J is a public domain Java image processing and analysis program that can be downloaded for free (http://rsbweb.nih.gov/ij/index.html, last accessed November 20 2011) on any operating system. ImageJ is particularly useful for determining the number of active sweat glands, as it can easily identify the number of individual particles from a scanned image. The reader is referred to the APPENDIX for step-by-step instructions on how to analyze sweat gland activation samples. It is important to note that the analysis requires the investigator to define a lower and upper size limit for the pixel area, which is the minimum/maximum size allowable for a dot to be considered in the count. In the current study, the investigators were allowed to choose the limits they deemed appropriate to ensure that all sweat glands were included within the count. Once the analysis performed, the software generates a count of the particles present in the image, which is the number of active glands for that sample (see Fig. 1). The number of glands is then divided by the surface area of the paper to give a value of active sweat glands per square centimeter.

\section{Data Analyses}

The following terms were used to describe comparisons made in the current study: 1) agreement: variability in sweat gland activation measurements between computer-assisted analysis and manual counts; 2) interrater reliability: the variability in sweat gland activation counts as determined by computer-assisted analysis between independent investigators; and 3) internal reliability: the variability of duplicate sweat gland activation measurements (determined using computer-assisted analysis).

A wide range of sweat gland activation measures were obtained by combining data from study 1 and study 2 and analyzed as one data set to answer the following questions: 1 ) is there good agreement between computer software and manual analyses when determining the number of active sweat glands?; and 2) is computer-assisted analysis 
A

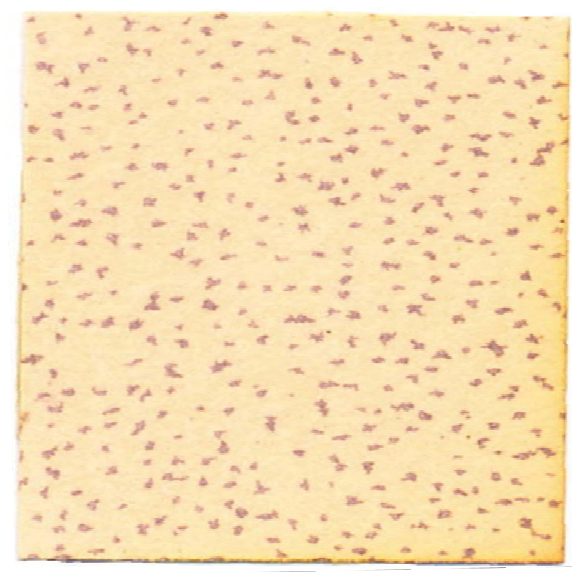

B

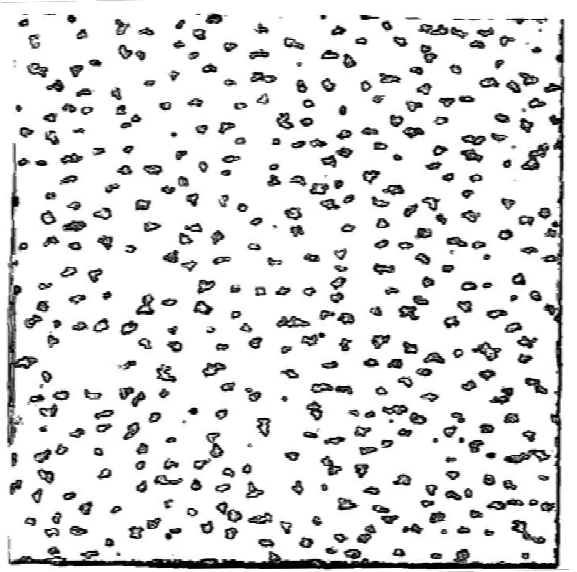

C

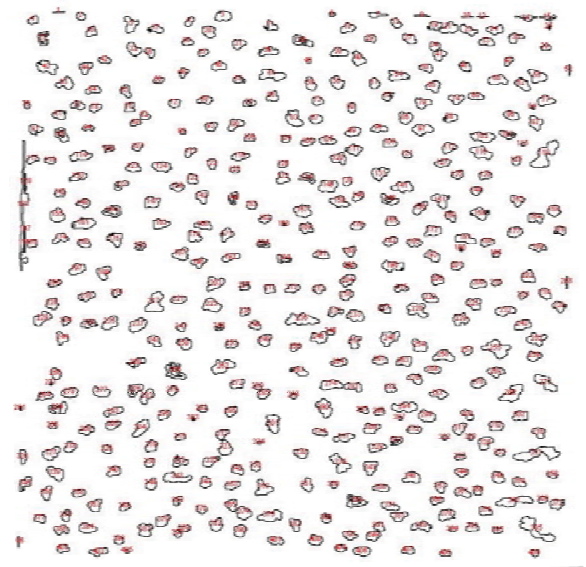

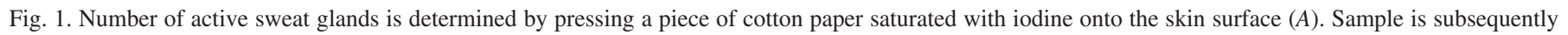

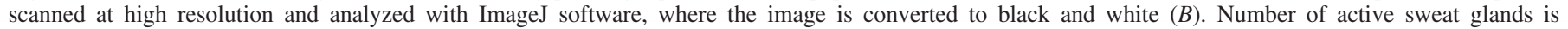
subsequently counted, with each individual count being outlined by the software $(C)$.

reliable between two independent investigators (i.e., interrater reliability)? Furthermore, we examined the internal reliability of the modified iodine-paper technique by analyzing duplicate sweat gland activation measurements obtained from the same subject at the same site via computer-assisted analysis. To address the agreement between computer analysis and manual counts (question 1), 50 random samples from each study (100 total) were chosen by investigator 1 and presented to investigator 2, who analyzed each image through computer analysis and manually. Manual counts were performed by printing an enlarged version of the scanned image of the sample, and each gland was manually circled with a pen. To address interrater reliability of computer analysis between two independent investigators (question 2), all images from both data sets were independently analyzed by each investigator. Similarly, to determine the internal reliability of the modified iodine-paper technique, duplicate measurements obtained from a given subject at a given time point were analyzed independently by each investigator using computer-assisted analysis. For all analyses, the investigators were blinded to the experimental condition, time point, and location at which the image was obtained.

\section{Statistical Analyses}

Based on the recommendations by Atkinson and Nevill (4), we used a range of statistical methods to assess the modified-iodine paper technique with computer-assisted analysis. For each question, differences between analysis techniques (computer-assisted vs. manual) as well as between investigators (investigator 1 vs. investigator 2) were compared with independent sample $t$-tests, Bland-Altman plots, Pearson-Product moment correlations, and coefficients of variation. Bland-Altman plots were constructed by calculating mean bias and limits of agreement (6). The difference between measures (i.e., counts), with a $95 \%$ probability, will lie within the respective limits of agreement of these plots. Limits of agreement were calculated by multiplying the standard deviation of the mean difference between analysis technique/investigators by two (4). Furthermore, we included qualitative limits of magnitude based on the largest differences in sweat gland activation between populations reported in the literature $(5,14)$ (limit 1: +50 glands $/ \mathrm{cm}^{2}$ and limit 2: -25 glands $/ \mathrm{cm}^{2}$ ). Because the total number of activated sweat glands varied between subjects and between studies, the coefficient of variation was calculated to provide an index of relative differences independent of total glands present. The coefficient of variation was calculated for each comparative count and then averaged together to provide an overall coefficient of variation for each research question. The smallest change worth detecting with the current method was calculated using the formula: $1.96 \times \sqrt{2} \times \mathrm{SE}$, where SE stands for standard error of measurement, which itself was calculated using the formula: $\mathrm{SD} \times$ $\sqrt{1-\mathrm{ICC}}$ where SD stands for standard deviation and ICC for intraclass correlation coefficient of duplicate measurements. SigmaPlot 12.0 and Microsoft Excel 2010 were used for all analyses. Alpha was set at 0.05 for all statistical tests. Data are reported as means \pm SD.

\section{RESULTS}

\section{Descriptive Statistics}

There was a wide range of sweat gland activation within the images analyzed. The number of glands activated pharmacologically averaged 59 glands $/ \mathrm{cm}^{2}$, with a SD of 17 glands $/ \mathrm{cm}^{2}$. The minimum number of glands activated pharmacologically was 22 glands $/ \mathrm{cm}^{2}$, while the maximum was 99 glands $/ \mathrm{cm}^{2}$. During exercise in the heat, average sweat gland activation was 81 glands $/ \mathrm{cm}^{2}$, with a SD of 30 glands $/ \mathrm{cm}^{2}$. The minimum number of glands activated during exercise was 35 glands $/ \mathrm{cm}^{2}$, with the maximum observed being 187 glands $/ \mathrm{cm}^{2}$. As such, the images analyzed provided a good range of sweat gland activation values with which to assess the modified iodinepaper technique with computer-assisted analysis.

\section{Is There Good Agreement Between Computer and Manual Analysis?}

One-hundred samples were included in the analysis. The number of glands identified with computer-aided analysis $\left(68 \pm 29\right.$ glands $\left./ \mathrm{cm}^{2}\right)$ did not significantly differ from manual counts $\left(72 \pm 24\right.$ glands $\left./ \mathrm{cm}^{2} ; P=0.27\right)$. The coefficient of variation between manual and computer-assisted counts was $16 \pm 15 \%$. The two methods were highly correlated $(r=$ $0.77 ; P<0.001)$ and the mean bias \pm limits of agreement (computer - manual) was $-4 \pm 38$ glands $/ \mathrm{cm}^{2}$, with $86 \%$ (86 out of 100) of individual differences falling within the qualitative limits of magnitude (Fig. 2A). 

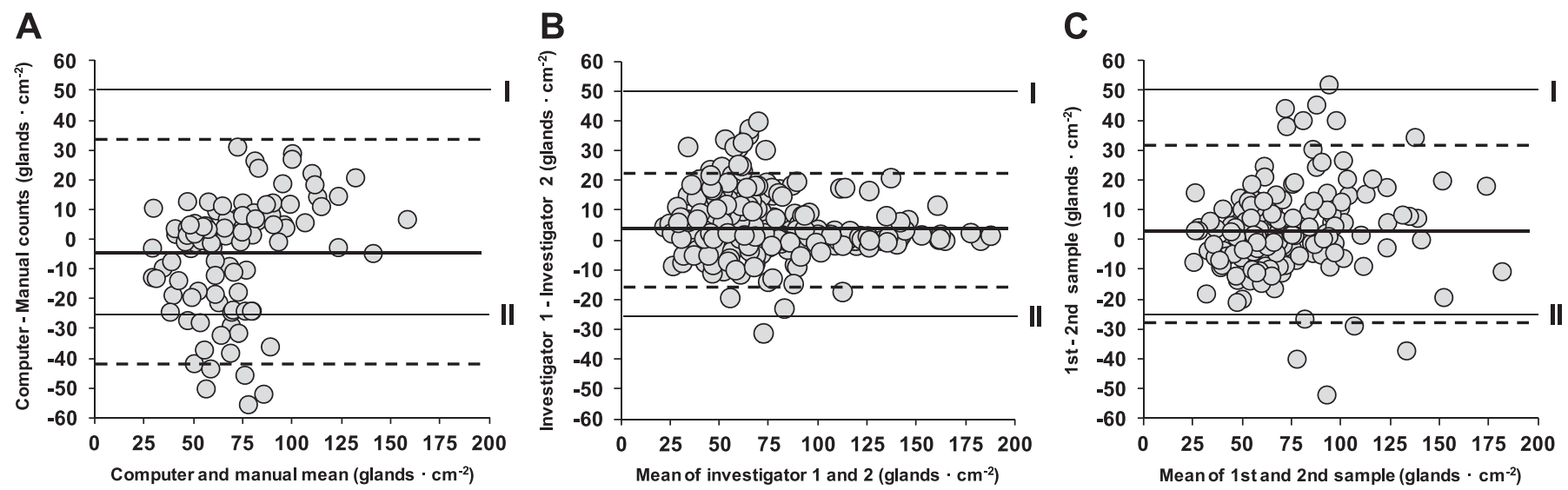

Fig. 2. Bland-Altman plot of intermethod (computer vs. manual analysis; $A$ ), interinvestigator (investigator 1 vs. 2; $B$ ), and internal (sample 1 vs. $2 ; C$ ) differences in the number of active sweat glands. Circles represent an individual count of active sweat glands $(A: n=100 ; B: n=382 ; C: n=167)$. In $A-C$, the bold solid line represents the mean bias, while the dashed lines represent the limits of agreement. Roman numerals represent the largest range of reported differences in sweat gland activation.

\section{Is Computer-Assisted Analysis Reliable Between Two Independent Investigators?}

Three-hundred eighty-two samples were included in the analysis. With the use of computer-assisted analysis, the number of glands identified by investigator $1\left(74 \pm 28\right.$ glands $\left./ \mathrm{cm}^{2}\right)$ did not differ significantly from investigator $2(70 \pm 30$ glands $\left./ \mathrm{cm}^{2} ; P=0.07\right)$. The coefficient of variation between the two investigators was $7 \pm 10 \%$. Counts from both laboratories were highly correlated $(r=0.95 ; P<0.001)$, and the mean bias \pm limits of agreement (analyzer 1 - analyzer 2 ) was $4 \pm 18$ glands $/ \mathrm{cm}^{2}$, with $99 \%$ of individual differences (381 out of 382) falling within the qualitative limits of magnitude (Fig. 2B).

\section{What Is the Internal Reliability of the Modified Iodine-Paper Technique?}

One-hundred sixty-seven sequential samples were included in the analysis. When duplicate measures were analyzed using computer-assisted analysis, the number of glands in the first sample $\left(73 \pm 31\right.$ glands $\left./ \mathrm{cm}^{2}\right)$ did not significantly differ from the second sample $\left(71 \pm 29\right.$ glands $\left./ \mathrm{cm}^{2} ; P=0.37\right)$. The coefficient of variation between samples was $11 \pm 10 \%$. Sweat gland counts from duplicate samples were highly correlated $(\mathrm{r}=0.88 ; P<0.001)$, and the mean bias \pm limits of agreement (sample 1 - sample 2) was $3 \pm 29$ glands $/ \mathrm{cm}^{2}$, with $96 \%$ (161 out of 167) of individual differences falling within the qualitative limits of magnitude (Fig. 2C). The smallest detectable change calculated from duplicate measurements was 30 glands $/ \mathrm{cm}^{2}$.

\section{DISCUSSION}

The current study examined the agreement between computerassisted analysis and manual counts of sweat gland activation, the interrater reliability of computer-assisted analysis, as well as the internal reliability of the modified iodine-paper technique. The results demonstrate that computer-assisted counts of active sweat glands show good agreement compared with manual analysis. Further, the number of active sweat glands determined using computer-assisted analysis shows little variability between independent investigators (interrater), as well as between duplicate measurements (internal). Combined with its ease of use, we propose that the modified iodine-paper technique with computer-assisted analysis provides a simple and reliable determination of the number of active sweat glands.

Before the current study, no standard technique to measure sweat gland activation had been advocated. This has led to the use of a variety of techniques, making comparisons difficult and possibly limiting interpretations between different laboratories. Furthermore, no study has specifically examined whether determining the number of active sweat glands is reliable between independent investigators. In the current study, we chose to examine the reliability of the modified iodine-paper technique, with computer-assisted analysis, due in large part to its ease of use and minimal time required for analysis. By examining the reliability of this technique, we were interested in determining whether it could be used as a standard technique to determine the number of active sweat glands.

\section{Is There Good Agreement Between Computer and Manual Analysis?}

Computer-determined counts of active sweat glands closely agreed with those obtained by manual count. This was evidenced by a strong correlation and small coefficient of variation between the two methods. Further, the bias and limits of agreement were relatively small between the two methods and fell within the upper and lower ranges of reported differences in the literature (see Fig. 2A). Although the modified-iodine paper technique has previously been validated $(31,32)$ and used in a number of publications $(5,8,11,36,37)$, the use of computer-assisted analysis has never been compared with manual counts. It is therefore interesting to compare the counts obtained in the current study with those reported in the literature. The number of active sweat glands measured using the current modified iodine-paper technique provided similar values to those reported in previous studies where manual counts were performed. Specifically, the reported number of active sweat glands during exercise range from $\sim 80$ glands $/ \mathrm{cm}^{2}$ during low $\left(35 \% \dot{\mathrm{V}}_{2}\right.$ max $)$ to $\sim 120$ glands $/ \mathrm{cm}^{2}$ during moderate $\left(65 \% \dot{\mathrm{V}}_{2}\right.$ max $)$ intensity exercise in normal ambient conditions $\left(25-30^{\circ} \mathrm{C}, 40-50 \%\right.$ relative humidity) and up to over 150 
glands $/ \mathrm{cm}^{2}$ during moderate intensity exercise in a hot $(35-$ $49^{\circ} \mathrm{C}, 30-80 \%$ relative humidity) environment $(12,25,26$, 29). Similarly, the number of active sweat glands during pharmacologically induced sweating range from $\sim 60$ to 120 glands $/ \mathrm{cm}^{2}(10,16)$. These values resemble the number of active sweat glands measured in the current data set during exercise in the heat $\left(81 \pm 30\right.$; range of 35-137 glands $\left./ \mathrm{cm}^{2}\right)$ and pharmacological stimulation $(59 \pm 12$; range of 22-99 glands $/ \mathrm{cm}^{2}$ ).

\section{Is Computer-Assisted Analysis Reliable Between Two Independent Investigators?}

The use of computer-assisted analysis adds a layer of objectivity to the determination of the number of active sweat glands for a given sample. When manually counting the number of sweat glands, the investigator must subjectively determine dots that actually constitute a single sweat gland vs. those that may have converged due to a high output from multiple glands. In contrast, the use of computer software allows the user to define a lower and upper size limit for the pixel area, which is the minimum/maximum size allowable for a dot to be considered in the count. It is important to note that using a fixed pixel range has the potential to reduce all subjectivity associated with the determination of what constitutes a gland or not when analyzing multiple samples. However, this approach assumes that the sweat glands from all collected samples will be of the same size. This may very well occur when measurements are taken from a given anatomical location during a repeated measures design experiment (e.g., pre- to postacclimation on the forearm). In the current study, however, the use of a fixed pixel range limit was deemed inappropriate as the anatomical locations (e.g., back vs. forearm) and populations (males vs. females) from which the samples were obtained resulted in different gland sizes on the collected samples. Consequently, the investigators freely adjusted the upper and lower pixel size limits based on a subjective interpretation of what should be considered a sweat gland or not. However, adjusting the upper and lower size limits does add subjectivity to the computeraided analysis, which led us to examine interrater reliability. Even though the investigators were allowed to determine the pixel area limits, and therefore the size of dots that would be considered a gland or not, there was little interrater variability for individual counts. There was a very high correlation between analyzers $(r=0.95)$, and the mean bias between investigators was only 4 glands $/ \mathrm{cm}^{2}$, with all but one individual difference falling inside the limits of magnitude (see Fig. $2 B$ ). These results favor the use of computer-assisted analysis as a standard procedure to determine the number of active sweat glands between independent laboratories.

\section{What Is the Internal Reliability of The Modified Iodine-Paper Technique?}

The results from the current study suggest there is some variability between duplicate measurements, although with no evident systematic bias between the first and second measurements (Fig. 2C). It is important to note that the variability in the number of active sweat glands over duplicate measurements was due to variability in the modified iodine-paper technique itself, as the counts were performed by computer-assisted analysis. To our knowledge, no study has specifically exam- ined the internal reliability of determining the number of active sweat glands, regardless of the method employed. However, Buono and Sjoholm (8) did report a 5\% coefficient of intrasubject variation when using the modified-iodine paper technique combined with manual analysis. In contrast, we report an intrasubject coefficient of variation of $11 \pm 10 \%$. Furthermore, the smallest difference worth detecting calculated from duplicate measurements was 30 glands $/ \mathrm{cm}^{2}$, suggesting that differences in sweat gland activation of less than $\sim 30$ glands $/ \mathrm{cm}^{2}$ using the current method may not be worth considering (i.e., differences within the error of the measurement). Together, these values provide a basis to determine whether observed differences in sweat gland activation should be interpreted as meaningful when using the evaluated techniques. It is interesting to note that the calculated smallest detectable change is consistent with previous studies $(5,8,14,18,26)$ reporting significant differences in sweat gland activation between various populations and/or experimental conditions. Duplicate measures were also highly correlated $(r=0.88 ; P<0.001)$ and the mean bias \pm limits of agreement (sample 1 - sample 2) was $3 \pm 29$ glands $/ \mathrm{cm}^{2}$, with the vast majority of individual differences falling within the limits of magnitude (Fig. 2C). These data indicate that the modified-iodine paper technique with computer-assisted analysis is sensitive enough to detect typical changes in sweat gland activation.

\section{Perspectives}

The use of standard measurement techniques and analytical tools is important to ensure consistency and allow for more direct comparisons between independent laboratories. In the current study, we used the modified iodine-paper technique due to its ease of use and minimal need of equipment. It also allows for a rapid determination of the number of active sweat glands and thus multiple measurements at a given time period, as opposed to relying on a single sample. While we did not compare the current method with those of previous studies (e.g., starch-iodine and macrophotographic), the results of the current study provide a strong basis for advocating the use of the modified-iodine paper technique combined with computer-assisted analysis for the standard determination of sweat gland activation. First, computer-assisted counts of the number of active sweat glands show good agreement with those obtained manually. The advantages of computer-assisted analysis are that it provides a more objective count of the number of active sweat glands, and the analysis of a sample is done within minutes, as opposed to longer periods of time required for manual analysis. Second, computer-assisted analysis is reliable between two investigators from independent laboratories. This ensures that the counts obtained in one laboratory can be reliably replicated in another, making comparisons between different laboratories more direct and meaningful. Third, the measurement technique itself shows little variability between duplicate measures, resulting in relatively low values of measurement noise and of smallest detectable difference. As such, small differences in sweat gland activation between populations and/or experimental conditions can be identified. 


\section{Conclusion}

The current study examined the modified iodine-paper technique with computer-assisted analysis for the simple and reliable determination of sweat gland activation. Computer-assisted counts of active glands showed good agreement compared with commonly used manual counts. Furthermore, computer-assisted determination of active sweat glands showed little interrater variability. Finally, we examined the internal reliability of duplicate measurements of sweat gland activation, which fell within the range of previously reported differences. Based on the observed results, we propose that the modified-iodine paper technique with computer-assisted analysis be employed as a standard measurement of sweat gland activation.

\section{APPENDIX}

\section{Using ImageJ to Count the Number of Active Sweat Glands}

Step 1) to analyze a sample, determine the edges of the scanned image using the "Find edges" option (Process toolbar-Find edges).

Step 2) next, set the image type to 8-bit grayscale (Image toolbarType-8-bit) before converting the image to a binary (black and white) image (Process toolbar-Binary-Make binary). Once this step is complete, the dots produced by the active glands are displayed in black, with the background being white.

Step 3) to perform a count of the number of active glands, select the "Analyze particles" (Analyze toolbar-Analyze particles) and first define a lower and upper size limit for the pixel area, which is the minimum/maximum size allowable for a dot to be considered in the count. Before running the analysis, ensure that the following options are chosen: display results, clear results, exclude on edges, record starts. Also, ensure that the "Outlines" option is selected under the "Show" menu to visually examine which particles have been included by the software during the analysis.

Step 4) once the analysis performed, the software generates a count of the particles present in the image, which is the number of active glands for that sample. It also provides an image in which each individual count included in the analysis has been circled in red. If the number of particles included in the analysis is inadequate, return to step 3 and adjust the lower and upper size limit of the pixel area accordingly.

Step 5) the number of particles is divided by the surface area of the paper to give a value of active sweat glands per square centimeter.

\section{ACKNOWLEDGMENTS}

We thank Brendan Swift, Kimberly Hubing, and Jena Langlois for assistance during data collection.

\section{GRANTS}

The current work was supported by the Natural Sciences and Engineering Research Council (RGPIN-298159-2009), Leaders Opportunity Fund from the Canada Foundation for Innovation (22529), and National Institute of General Medical Sciences Grant GM-068865. G. P. Kenny is supported by a University of Ottawa Research Chair in Environmental Physiology.

\section{DISCLOSURES}

No conflicts of interest, financial or otherwise, are declared by the author(s).

\section{AUTHOR CONTRIBUTIONS}

Author contributions: D.G., M.S.G., R.A.L., J.P., C.G.C., and G.P.K. conception and design of research; D.G., M.S.G., R.A.L., and J.P. performed experiments; D.G. and M.S.G. analyzed data; D.G., M.S.G., R.A.L., J.P., C.G.C., and G.P.K. interpreted results of experiments; D.G. and M.S.G. prepared figures; D.G. and M.S.G. drafted manuscript; D.G., M.S.G., R.A.L.,
J.P., C.G.C., and G.P.K. edited and revised manuscript; D.G., M.S.G., R.A.L., J.P., C.G.C., and G.P.K. approved final version of manuscript.

\section{REFERENCES}

1. Abramoff MD, Magalhaes PJ, Ram SJ. Image processing with ImageJ. Biophot Intl 11: 36-42, 2004

2. Anderson RK, Kenney WL. Effect of age on heat-activated sweat gland density and flow during exercise in dry heat. J Appl Physiol 63: 10891094, 1987.

3. Armstrong LE, Maresh CM. Effects of training, environment, and host factors on the sweating response to exercise. Int J Sports Med 19: 103-105, 1998 .

4. Atkinson G, Nevill AM. Statistical methods for assessing measurement error (reliability) in variables relevant to sports medicine. Sports Med 26: 217-238, 1998.

5. Bar-Or O, Lundegren HM, Magnusson LI, Buskirk ER. Distribution of heat-activated sweat glands in obese and lean men and women. Hum Biol 40: 235-248, 1968.

6. Bland JM, Altman DG. Statistical methods for assessing agreement between two methods of clinical measurement. Lancet 8: 307-310, 1986.

7. Buono MJ, Connolly KP. Increases in sweat rate during exercise: gland recruitment versus output per gland. J Therm Biol 17: 267-270, 1992.

8. Buono MJ, Sjoholm NT. Effect of physical training on peripheral sweat production. J Appl Physiol 65: 811-814, 1988.

9. Cheuvront SN, Bearden SE, Kenefick RW, Ely BR, Degroot DW, Sawka MN, Montain SJ. A simple and valid method to determine thermoregulatory sweating threshold and sensitivity. J Appl Physiol 107: 69-75, 2009.

10. Davis SL, Wilson TE, Vener JM, Crandall CG, Petajan JH, White AT. Pilocarpine-induced sweat gland function in individuals with multiple sclerosis. J Appl Physiol 98: 1740-1744, 2005.

11. Frye AJ, Kamon E. Sweating efficiency in acclimated men and women exercising in humid and dry heat. J Appl Physiol 54: 972-977, 1983.

12. Ichinose-Kuwahara T, Inoue Y, Iseki Y, Hara S, Ogura Y, Kondo N. Sex differences in the effects of physical training on sweat gland responses during a graded exercise. Exp Physiol 95: 1026-1032, 2010.

13. Illigens BM, Gibbons $\mathbf{C H}$. Sweat testing to evaluate autonomic function Clin Auton Res 19: 79-87, 2009.

14. Inbar O, Morris N, Epstein Y, Gass G. Comparison of thermoregulatory responses to exercise in dry heat among prepubertal boys, young adults and older males. Exp Physiol 89: 691-700, 2004

15. Inoue Y. Longitudinal effects of age on heat-activated sweat gland density and output in healthy active older men. Eur J Appl Physiol Occup Physiol 74: 72-77, 1996.

16. Inoue Y, Havenith G, Kenney WL, Loomis JL, Buskirk ER. Exerciseand methylcholine-induced sweating responses in older and younger men: effect of heat acclimation and aerobic fitness. Int J Biometeorol 42 : 210-216, 1999.

17. Inoue Y, Shibasaki M. Regional differences in age-related decrements of the cutaneous vascular and sweating responses to passive heating. Eur $J$ Appl Physiol Occup Physiol 74: 78-84, 1996.

18. Inoue Y, Tanaka Y, Omori K, Kuwahara T, Ogura Y, Ueda H. Sexand menstrual cycle-related differences in sweating and cutaneous blood flow in response to passive heat exposure. Eur J Appl Physiol 94: 323-332, 2005 .

19. Kenefick RW, Cheuvront SN, Elliott LD, Ely BR, Sawka MN. Biological and analytical variation of the human sweating response: implications for study design and analysis. Am J Physiol Regul Integr Comp Physiol 302: R252-R258, 2012.

20. Kenney WL. A review of comparative responses of men and women to heat stress. Environ Res 37: 1-11, 1985.

21. Kenney WL, Fowler SR. Methylcholine-activated eccrine sweat gland density and output as a function of age. J Appl Physiol 65: 1082-1086, 1988.

22. Kenney WL, Munce TA. Invited review: aging and human temperature regulation. J Appl Physiol 95: 2598-2603, 2003.

23. Kenny GP, Journeay WS. Human thermoregulation: separating therma and nonthermal effects on heat loss. Front Biosci 1: 259-290, 2010.

24. Kenny GP, Yardley J, Brown C, Sigal RJ, Jay O. Heat stress in older individuals and patients with common chronic diseases. CMAJ 182: 1053-1060, 2010.

25. Kondo N, Shibasaki M, Aoki K, Koga S, Inoue Y, Crandall CG. Function of human eccrine sweat glands during dynamic exercise and passive heat stress. J Appl Physiol 95: 1877-1881, 2001. 
26. Kondo N, Takano S, Aoki K, Shibasaki M, Tominaga H, Inoue Y. Regional differences in the effect of exercise intensity on thermoregulatory sweating and cutaneous vasodilation. Acta Physiol Scand 164: 71-78, 1998.

27. Kuno Y. Human Perspiration. Springfield, IL: Charles C. Thomas, 1956.

28. Mekjavic IB, Eiken O. Contribution of thermal and nonthermal factors to the regulation of body temperature in humans. J Appl Physiol 100: 2065-2072, 2006.

29. Morimoto T, Slabochova Z, Naman RK, Sargent F. Sex differences in physiological reactions to thermal stress. J Appl Physiol 22: 526-532, 1967.

30. Nielsen B, Nielsen M. On the regulation of sweat secretion in exercise. Acta Physiol Scand 64: 314-322, 1965.

31. Randall WC. Quantitation and regional distribution of sweat glands in man. J Clin Invest 25: 761-767, 1946.

32. Randall WC. Sweat gland activity and changing patterns of sweat secretion on the skin surface. Am J Physiol 147: 391-398, 1946.

33. Rowland T. Thermoregulation during exercise in the heat in children: old concepts revisited. J Appl Physiol 105: 718-724, 2008.

34. Sato K. The mechanisms of eccrine sweat production. In: Perspectives in Exercise Science and Sports Medicine Volume 6: Exercise, Heat, and
Thermoregulation, edited by Gisofi CV, Lamb DR, Nadel ER. Dubuque, IA: WCB Brown and Benchmark, 1993, p. 85-118.

35. Sato K. The physiology, phramacology and biochemistry of the eccrine sweat gland. Rev Physiol Biochem Phramacol 79: 52-131, 1977.

36. Sato K, Dobson RL. Regional and individual variations in the function of the human eccrine sweat gland. J Invest Dermatol 54: 443-449, 1970.

37. Sato K, Sato F. Individual variations in structure and function of human eccrine sweat gland. Am J Physiol Regul Integr Comp Physiol 245: R203-R208, 1983.

38. Sawka MN, Latzka WA, Matott RP, Montain SJ. Hydration effects on temperature regulation. Int J Sports Med 19: S108-110, 1998.

39. Shibasaki M, Inoue Y, Kondo N, Iwata A. Thermoregulatory responses of prepubertal boys and young men during moderate exercise. Eur J Appl Physiol Occup Physiol 75: 212-218, 1997.

40. Shibasaki M, Wilson TE, Crandall CG. Neural control and mechanisms of eccrine sweating during heat stress and exercise. J Appl Physiol 100 1692-1701, 2006.

41. Taylor NA. Eccrine sweat glands. Adaptations to physical training and heat acclimation. Sports Med 3: 387-397, 1986.

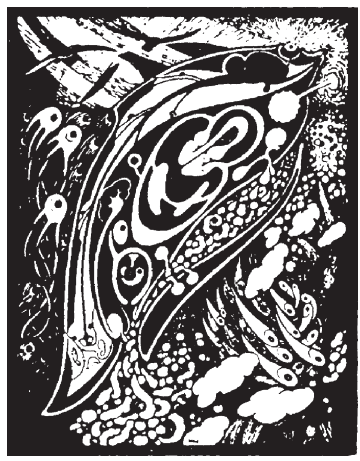




\section{APPENDIX E}

Final version of topical review article submitted to the Journal of Physiology 


\section{Does sex have an independent effect on thermoeffector responses during exercise in the heat?}

Final version of article submitted to the Journal of Physiology (JPHYSIOL/2012/240739)

Daniel Gagnon and Glen P. Kenny

Human and Environmental Physiology Research Unit, School of Human Kinetics, University of Ottawa, Ottawa, Canada

Running title: Sex-differences in temperature regulation.

Key words: Heat loss, Sweat, Skin blood flow, Temperature regulation, Thermoregulation.

Total word count: 4,475

Table of contents category: Integrative - Invited topical review 


\section{KEY POINTS}

1. Because male and females generally differ in terms of physical characteristics, it remained unknown whether males and females differ in the physiological properties of human temperature regulation during exercise in the heat.

2. Recent findings demonstrate that the sweating response to exercise in the heat differs in females compared to males, irrespective of differences in physical characteristics and rate of metabolic heat production.

3. Specifically, females sweat less compared to males when exercise is performed in hot environments that allow full evaporation of the sweat produced. However, this lower sweating response is only observed above a certain combination of metabolic heat production and environmental parameters.

4. The physiological parameter associated with the lower sweating response in females is a lower thermosensitivity of the response, meaning a lower increase in sweat production for a given change in body temperature.

5. The recent findings suggest that the lower sweating response in females is due to sexdifferences in the sweat gland itself. 


\section{ABSTRACT}

Although a number of studies have examined potential differences in temperature regulation between males and females during heat stress, conclusions have remained limited as to whether reported differences are due to confounding physical characteristics or to actual differences in the physiological variables of temperature regulation. Recent observations suggest that sex-differences in temperature regulation, particularly in sudomotor activity, go beyond those associated with physical characteristics. Females have recently been shown to have a lower sudomotor activity, as well as a lower thermosensitivity of the response compared to males during exercise performed at a fixed rate of metabolic heat production. Furthermore, sex-differences in local and whole-body sudomotor activity are only evident above a certain combination of environmental conditions and rate of metabolic heat production. In contrast, both the onset threshold and thermosensitivity of cutaneous vasodilation are similar between males and females. In theory, differences in the thermosensitivity of sudomotor activity could be related to either a central (neural activity/integration) and/or peripheral (effector organ) modulation of temperature regulation in females. Based on recent findings, sex-differences in sudomotor activity appear to be mediated peripherally, albeit a central modulation has yet to be conclusively ruled out. The current review provides a brief, yet comprehensive review of the current state of knowledge pertaining to sex-differences in temperature regulation during exercise in the heat. 


\section{Introduction}

A consistent growth in publications investigating sex-differences in temperature regulation during heat stress began during the 1960s. These studies aimed to determine if males and females could tolerate prolonged exercise in the heat to a similar extent preand post-acclimatisation, and led to the contradictory notions that females thermoregulate both less (pre-acclimatisation) and more (post-acclimatisation) effectively than males. These findings were summarised in three review articles, all of which raised the possibility that reported sex-differences in temperature regulation could have been due to confounding differences in physical characteristics and/or fitness between sexes (Nunneley, 1978; Burse, 1979; Kenney, 1985). A number of subsequent studies therefore attempted to control for either or both of these variables. Overall, these later studies led to the general consensus that sex-differences in temperature regulation can be explained by differences in physical characteristics and aerobic fitness (Sawka et al., 1996; Havenith, 2001b). Recent studies (Gagnon \& Kenny, 2011, 2012) which have attempted to isolate the effect of sex per se, however, suggest that true physiological differences in temperature regulation may exist between males and females, particularly in maximal sweating as observed during exercise performed in environments that allow its full evaporation.

The purpose of the current review is to summarise these recent findings and to provide a brief, yet exhaustive review of the current knowledge pertaining to sexdifferences in local and whole-body heat loss responses. To do so, the current review will first provide a brief overview of the physiological and physical variables governing temperature regulation during exercise in the heat. This will serve to provide a background against which to assess potential physiological sex-differences in sweating and/or skin blood flow. 


\section{Physiology of temperature regulation}

The neural control of body temperature is achieved through thermoreceptors which detect changes in body temperature both centrally within the central nervous system (Hammel et al., 1960), as well as peripherally in the skin (Pierau, 1996) and core (Stitt, 1993). The peripheral thermoreceptors are responsible for transmitting thermoafferent information to the central nervous system, particularly in the region of the preoptic anterior hypothalamus where most of thermal integration is thought to occur (Boulant, 1996). Integration of thermal information ultimately results in the central nervous system sending thermoefferent signals, via the autonomic nervous system, to the appropriate effector organs which control and alter rates of heat exchange within the body and from the body to the environment (Werner, 1980; Werner, 1981). The relation between neural integration and effector output is best described by a mean body temperature onset threshold beyond which effector responses increase proportionally to the change in core/skin temperatures (Figure 1). During exercise in the heat, cutaneous vasodilation and increased sudomotor activity serve to dissipate heat from the body for the proper regulation of body temperature (Hardy, 1961). Since both responses are affected by core and skin temperatures (Fusco et al., 1961; Nadel et al., 1971a; Wenger et al., 1985), the change in effector response is often analysed as a function of the change in mean body temperature (Gisolfi \& Wenger, 1984), calculated using a weighted summation of core and mean skin temperatures (i.e. $\mathrm{X} \cdot$ core $+[1-\mathrm{X}] \cdot$ mean skin). It should be noted that the influence of core temperature is heavily weighted ( 0.8 to 0.9 ) during heat stress, such that it represents the main variable driving the relationship between mean body temperature and thermoeffector output. Therefore, studies have also analysed changes in the onset threshold and thermosensitivity of thermoeffector responses as a function of changes in core temperature only, while examining the 
influence that skin temperature may have upon this relationship (Nadel et al., 1971a; Nadel et al., 1971b). When mean body temperature is used as the independent variable, the onset threshold is determined as the mean body temperature at which a sustained increase in thermoeffector output occurs, while the rate at which the thermoeffector output changes as a function of the increase in mean body temperature is known as the thermosensitivity (Hammel, 1968; Cheuvront et al., 2009). Since the interpretation of thermoefferent activity, namely skin sympathetic nerve activity, is problematic between individuals or over separate days (Young et al., 2009), the onset threshold and the thermosensitivity of thermoeffector responses currently represent the only viable means by which the physiology of human temperature regulation can be evaluated (Figure 1). Although both variables can represent a central and/or peripheral modulation of temperature regulation (Hammel, 1968), it has been suggested that a parallel shift in the onset threshold of all effector responses must occur to be representative of a central modulation (Gisolfi \& Wenger, 1984). As such, changes in the thermosensitivity of an effector response, without parallel changes in the onset threshold, likely imply a peripheral modulation. In fact, changes in onset threshold have traditionally been used as an indicator of central modulation of temperature regulation, while the thermosensitivity has been used to describe peripheral adaptations in effector responses (Nadel et al., 1971b; Nadel et al., 1974).

\section{Temperature regulation and exercise in the heat}

At the onset of dynamic exercise, there is an instant and rapid elevation in the rate of metabolic heat production with a time constant of $\sim 5$ minutes (Kenny et al., 2008). The increased heat production at the onset of exercise is not immediately matched by an increase in whole-body heat loss (Webb, 1995). Mean body temperature therefore rises 
beyond onset threshold values, activating the heat loss responses of cutaneous vasodilation and sweating (Benzinger, 1969; Werner, 1993; Sawka et al., 1996). Together, both serve to increase whole-body heat loss (Figure 2), with a time constant of $\sim 10$ minutes (Webb et al., 1970; Kenny et al., 2008). While the onset threshold at which heat loss responses are activated and the rate at which they increase (thermosensitivity) depend upon changes in mean body temperature, the level of whole-body heat loss achieved during exercise in the heat depends upon the required evaporation for heat balance $\left(E_{\text {req }}\right)$, which is the sum of metabolic heat production and dry heat exchange. Since evaporation of sweat represents the main component of total heat loss during exercise, particularly in the heat, the level of sudomotor activity achieved is therefore driven by the evaporation needed to achieve heat balance (Figure 2). When the maximal evaporation possible within a given environment $\left(E_{\max }\right)$ does not limit an individual's ability to achieve heat balance (i.e. compensable; $E_{\max } \geq E_{\text {req }}$ ), the level of sudomotor activity achieved during exercise is driven by the required evaporation for heat balance (Jay et al., 2011; Cramer et al., 2012). However, when the combination of environmental conditions and metabolic heat production exceed the individual's maximum evaporative capacity, therefore creating an uncompensable heat stress scenario (i.e. $E_{\mathrm{sk}} \max <E_{\text {req }}$ ), the level of sudomotor activity will be driven by the individual's maximum sweating rate (Figure 2). It should be noted, however, that these scenarios assume that all of the sweat produced by the body is evaporated (i.e. 100\% efficiency). In reality, sweating efficiency decreases as the required evaporation for heat balance approaches the maximum evaporative capacity of the individual within a given environment (Candas et al., 1979). Consequently, the level of sudomotor activity achieved is more precisely related with the ratio of required evaporation for heat balance and the individual's maximum evaporative capacity in that environment (Shapiro et al., 1982; Bain et al., 2011). 


\section{Physical factors influencing sex-related differences in temperature regulation}

The main physical characteristics influencing temperature regulation during exercise in the heat are body mass and surface area (Anderson, 1999; Havenith, 2001b). Briefly, body mass represents the heat storage capacity of the body, such that individuals with a greater body mass typically have smaller increases in core temperature during heat stress (Havenith et al., 1995; Havenith et al., 1998). In contrast, the amount of body surface area exposed to the external environment determines the rate of heat exchange between the skin and the ambient air, such that a high body surface area is generally associated with a lower core temperature during heat stress (Havenith \& van Middendorp, 1990; Havenith et al., 1995; Havenith et al., 1998).

The possible impact sex-differences in physical characteristics may have upon temperature regulation was put forward by Burse (1979). As a population, females are smaller and have less body surface area compared to males which makes it difficult to differentiate whether a different core temperature and/or heat loss response is attributed to either simple differences in physical characteristics; in the physiological variables of temperature regulation; or a combination of the two. Studies which examine sexdifferences in temperature regulation during exercise in the heat have generally failed to consider sex-differences in physical characteristics when examining both sexes as a whole. In some studies (Shapiro et al., 1980b; McLellan, 1998), the potential impact of such differences was investigated by comparing subgroups of males and females with similar physical characteristics. In either case, most studies have relied upon core temperature as an indicator of thermoregulatory function, the majority of which report greater end-exercise core temperatures in females. Although sex-differences in core temperature might intuitively suggest differences in the physiology of temperature regulation (e.g. altered sweating response), we have shown that females can exhibit 
greater core, skin and active muscle temperatures despite a similar whole-body heat loss response compared to males (Gagnon et al., 2009). Therefore, core temperature alone cannot be reliably used to gain insight into potential physiological differences in temperature regulation when males and females are not matched for select physical characteristics.

Another important physical characteristic to consider when comparing heat loss responses between sexes during exercise is maximum oxygen consumption $\left(\mathrm{VO}_{2} \max \right)$. In the studies performed during the 1960s, greater heart rates in females led to the suggestion that physical fitness should be considered when comparing males and females during exercise in the heat (Drinkwater et al., 1976; Drinkwater et al., 1977). To account for potential differences in physical fitness, subsequent studies either compared males and females during treadmill exercise at a fixed external workload (Davies, 1979; Avellini et al., 1980a; Avellini et al., 1980b; Shapiro et al., 1980a; McLellan, 1998; Moran et al., 1999), or during exercise performed at a given percentage of $\mathrm{VO}_{2} \max$ (Paolone et al., 1978; Frye \& Kamon, 1981; Horstman \& Christensen, 1982; Keatisuwan et al., 1996; Ichinose-Kuwahara et al., 2010). In some cases, an attempt was made to compare males and females with similar aerobic capacities expressed relative to body weight (Avellini et al., 1980a; Frye \& Kamon, 1981; Moran et al., 1999; IchinoseKuwahara et al., 2010). In general, it was found that physically active females had similar cardiovascular responses and heat tolerance times despite lower sweat rates compared to males when treadmill exercise was performed at a given external workload. On the other hand, when both sexes exercised at the same percentage of $\mathrm{VO}_{2} \max$, it was generally found that females had lower end-exercise core temperatures despite having lower sweat rates. However, both exercise protocols contain inherent methodological issues due to the fact that males and females were not matched for body mass. 
Metabolic energy expenditure is proportional to body mass during weight bearing exercise such as treadmill walking (Austin \& Lansing, 1986). Consequently, treadmill walking at a fixed external workload elicits a lower rate of metabolic heat production in females due to their lower body mass (Havenith, 2001a). This results in a lower required evaporation for heat balance $\left(E_{\text {req }}\right)$ which itself can explain the lower sweat rates observed. Similarly, exercise at a given percentage of $\mathrm{VO}_{2}$ max also elicits a lower rate of metabolic heat production in females. This occurs both when females have a lower absolute $\mathrm{VO}_{2} \max \left(\right.$ in $\mathrm{L} \cdot \mathrm{min}^{-1}$ ) as well as when both sexes are matched for relative $\mathrm{VO}_{2}$ max (either per unit of body mass or of fat free mass) if females have a lower body mass (see calculation example in Appendix). While this problem has been recognised previously (Kenney, 1985; Bar-Or, 1998), and again more recently (Schwiening et al., 2011), this protocol was employed in most studies because it was thought that exercise at a given rate of metabolic heat production would cause undue physiological strain to females since they would be working at a greater percentage of $\mathrm{VO}_{2}$ max (Bar-Or, 1998). Nonetheless, when males and females exercise at the same percentage of $\mathrm{VO}_{2}$ max, the lower rate of metabolic heat production in females results in a lower rate of whole-body sudomotor activity (Gagnon et al., 2008; Gagnon \& Kenny, 2011). Since whole-body sudomotor activity is determined by local sweat production, it follows that a lower rate of metabolic heat production will elicit a lower sweat rate in females (Figure 3). As such, protocols based either on treadmill exercise performed at a fixed external workload or on exercise performed at a given percentage of $\mathrm{VO}_{2}$ max result in a lower required evaporation for heat balance in females when males and females are not matched for body mass. This limitation explains the lower sweat rates in females reported in many studies, and conclusions therefore remained limited as to whether sex actually modulates the physiological variables of temperature regulation during exercise in the heat. 


\section{Physiological sex-related differences in temperature regulation}

The majority of studies which have examined physiological differences in temperature regulation in females have generally focused on those related to the female menstrual cycle. The rise in plasma concentrations of progesterone and estrogen during the luteal phase of the menstrual cycle shifts resting body temperature by $\sim 0.3-0.5^{\circ} \mathrm{C}$ relative to the follicular phase (Stephenson \& Kolka, 1993). In parallel, the core temperature onset thresholds for cutaneous vasodilation (Stephenson \& Kolka, 1985; Kolka \& Stephenson, 1997) and sweating (Stephenson \& Kolka, 1985) are similarly shifted to core temperatures which are $\sim 0.3-0.5^{\circ} \mathrm{C}$ greater relative to the follicular phase. In contrast, the thermosensitivity of each response is generally unchanged. This upward shift in temperature regulation is similarly affected in females taking oral contraceptives by the synthetic progesterone and estrogen contained in combination contraceptives (Charkoudian \& Johnson, 1997). For more specific differences in temperature regulation across the menstrual cycle, the reader is referred to excellent reviews on this topic (Stephenson \& Kolka, 1993; Marsh \& Jenkins, 2002; Charkoudian \& Joyner, 2004). However, these findings emphasise the need to examine females in the follicular phase (days 1-10) of the menstrual cycle, or during the no pill/placebo phase of oral contraceptive use, when trying to isolate a true sex-related difference in temperature regulation (i.e. between males and females).

In contrast to the influence of sex hormones, very few experiments have examined a possible influence of sex per se on the onset threshold and thermosensitivity of sweating and cutaneous vasodilation. Recently, we sought to determine whether such differences were apparent during exercise in the heat (Gagnon \& Kenny, 2011). Males and females, matched for body mass $(\sim 66-67 \mathrm{~kg})$ and surface area $\left(\sim 1.76-1.79 \mathrm{~m}^{2}\right)$, performed $90 \mathrm{~min}$ of exercise in a warm $\left(35^{\circ} \mathrm{C}\right)$ and dry $(12 \%$ relative humidity $)$ 
environment at either $50 \%$ of $\mathrm{VO}_{2}$ max or at a fixed rate of metabolic heat production of $500 \mathrm{~W}$. Females were tested in the follicular phase (days 1-10) of the menstrual cycle or during the no pill/placebo period if using oral contraceptives. As expected, rate of metabolic heat production was significantly greater in males throughout exercise performed at $50 \%$ of $\mathrm{VO}_{2}$ max, which was paralleled by a greater rate of whole-body sudomotor activity, as well as a greater thermosensitivity of the whole-body sudomotor and cutaneous vascular responses. Importantly, more than $80 \%$ of the variance in wholebody sudomotor activity between sexes was explained by differences in rate of metabolic heat production. Furthermore, previous studies have shown that the thermosensitivity of both sudomotor activity and cutaneous vascular conductance increases at greater rates of metabolic heat production (Montain et al., 1995; Kondo et al., 1998). Therefore, the lower rate of whole-body sudomotor activity in females during this condition, as well as the lower thermosensitivity of the response, was mainly attributed to the lower rate of metabolic heat production associated with the experimental protocol. However, when exercise was performed at a fixed rate of metabolic heat production, whole-body sudomotor activity and the thermosensitivity of the response were nonetheless lower in females. In contrast, no sex-differences in the onset threshold for whole-body sudomotor activity, as well as in cutaneous vascular conductance as a whole, were observed during exercise performed at a fixed rate of metabolic heat production. These observations suggest a sex-difference in sudomotor activity that is not associated with differences in physical characteristics and rate of metabolic heat production.

In terms of physiological control, a lower thermosensitivity in females of the whole-body sudomotor response could be due to: 1) altered thermoafferent information from peripheral thermoreceptors; 2) altered neural integration of thermoafferent activity, 3) altered thermoefferent neural activity, 4) an altered thermoeffector response for a given 
level of thermoefferent activity, or 5) a combination of these possibilities. In theory, if sex modulates sudomotor activity centrally though differences in neural activity and/or integration, sex-differences in sweat rate might be expected to be observed at any combination of ambient conditions and rate of metabolic heat production. In contrast to this possibility, a study by Ichinose-Kuwahara et al., (2010) suggests that sex-differences in sweat gland function improvements elicited by exercise training are intensitydependent. Although they used an exercise protocol in which fixed percentages of $\mathrm{VO}_{2}$ max were employed, they only report a greater thermosensitivity of the local sweating response in trained males compared to trained females. In contrast, no differences were observed between untrained males and untrained females. Despite the discussed limitations associated with the experimental protocol (Gagnon et al., 2008; Schwiening et al., 2011), the fact that differences in local sudomotor thermosensitivity were only observed between the males and females which exercised at the greatest external workloads (and therefore rates of metabolic heat production), led us to believe that the threshold at which the requirement for heat loss exceeds the capacity of the sweat gland to contribute to temperature regulation might be lower in females.

We therefore examined sex-differences in local and whole-body sudomotor activity during exercise performed at progressive increments in the requirement for heat loss. Males and females performed three successive 30 min periods of cycling exercise at fixed rates of metabolic heat production equal to 200,250 , and $300 \mathrm{~W} \cdot \mathrm{m}^{-2}$ of body surface area. The ambient temperature $\left(40^{\circ} \mathrm{C}\right)$ and relative humidity $(10-20 \%)$ were fixed which, combined with fixed rates of metabolic heat production, elicited the same requirement for heat loss in males and females. Once again, females were tested in the follicular phase (days 1-10) of the menstrual cycle or during the no pill/placebo phase of oral contraceptive use. We observed that whole-body sudomotor activity did not 
significantly differ between males and females during the first two exercise periods, becoming greater in males during the last exercise period. Similarly, consistent sexdifferences in local sudomotor activity were only evidenced at the highest requirement for heat loss employed (Gagnon \& Kenny, 2012). Furthermore, the thermosensitivity of whole-body and local sudomotor activity was generally similar between males and females at the lower requirements for heat loss, only becoming greater in males at the highest requirement for heat loss. In contrast, no sex-differences were observed in the onset thresholds for sudomotor activity (local and whole-body), as well as in local and whole-limb cutaneous vasodilation at all requirements for heat loss. These observations emphasise that sex-differences in sudomotor activity are only evidenced above a certain combination of environmental conditions and rate of metabolic heat production. Taken together, the observed differences in sudomotor thermosensitivity and lack of differences in the onset threshold, combined with the lack of differences in cutaneous blood flow as a whole, are inconsistent with a central modulation of sudomotor activity in females, and point toward a peripheral modulation of the thermoeffector organ.

A peripheral modulation of the thermoeffector organ could stem from differences in the physical properties of the sweat gland itself (e.g. size), the sensitivity of the sweat gland to a given concentration of neurotransmitters released from sudomotor nerve terminals, and/or in the breakdown of acetylcholine within the sudomotor junction. The lower local sweat rates observed in females at the highest requirement for heat loss were solely due to differences in sweat gland output, as sweat gland recruitment was generally greater in females (Gagnon \& Kenny, 2012). These findings are consistent with previous studies during passive heating (Bar-Or et al., 1969; Knip, 1969; Inoue et al., 2005), and exercise (Morimoto et al., 1967; Frye \& Kamon, 1983; Ichinose-Kuwahara et al., 2010). Furthermore, we observed a clear leveling off of sudomotor activity in females at the 
highest requirement for heat loss (Gagnon \& Kenny, 2012), which provides evidence for a lower maximal sweating capacity. Since variations in sweat gland output (Sato \& Dobson, 1970) and the maximal capacity of the gland to produce sweat (Sato \& Sato, 1983) have been used to evaluate differences in the physical properties of the sweat gland, these findings hint towards the possibility of sex-differences in the physical properties of the sweat gland itself. Furthermore, studies have shown a lower sweat response in females to locally administered acetylcholine (Kahn \& Rothman, 1942; Gibson \& Shelley, 1948) and pilocarpine (Madeira et al., 2010), which points towards a sex-difference in the cholinergic sensitivity of the sweat gland. Taken together, these findings support the hypothesis that sex-differences in sudomotor activity are mediated peripherally through differences in the thermoeffector organ, rather than centrally though potential differences in neural activity.

\section{Future directions}

The recent findings summarised in this review article (Figure 4) are limited to the follicular phase of the menstrual cycle/low hormone period of oral contraceptive use. Furthermore, comparisons were performed in environments which permit full evaporation of the sweat produced. It is important to recognise, however, that these delimitations were specifically chosen to investigate the influence of sex per se on thermoeffector responses, particularly in examining differences in maximal sweating capacity between males and females (Gagnon \& Kenny, 2012). Nonetheless, we acknowledge that future work is needed to determine whether these recent findings will hold true as a function of changes in hormonal status and in a variety of environmental conditions.

In terms of hormonal status, the sex-differences in sweat rate highlighted in the current review article would not be expected to differ across the female menstrual cycle. 
As discussed previously, the main change in thermoregulatory function that occurs over the course of the female menstrual cycle is a shift in resting body temperature, with a parallel shift in the onset threshold for sweating and cutaneous vasodilation (Stephenson \& Kolka, 1985; Kolka \& Stephenson, 1997). In contrast, however, the thermosensitivity of each response is generally not affected. Since we consistently did not observe any sexdifferences in the onset threshold for sweating (local and whole-body), but observed a lower thermosensitivity of the response in females during the follicular phase of the menstrual cycle/low hormone period of oral contraceptive use (Gagnon \& Kenny, 2011, 2012), we would expect similar observations if females in the luteal phase of the menstrual cycle/high hormone phase of oral contraceptive use were compared to males. It is important to note that the absolute onset temperature threshold would be expected to be greater in females during the luteal phase of the menstrual cycle/high hormone phase of oral contraceptive use, but this would simply result from a higher resting core temperature. If the change in core temperature were examined as the onset threshold, there is no evidence to suggest that it would significantly differ from males.

An important avenue of future research is to examine whether the observed sexdifferences in sweat rate hold true in a variety of environmental conditions, particularly those which do not permit full evaporation of the sweat produced. A greater sweat rate in males at high requirements for heat loss may not be evidenced in hot and humid environments, as the skin surface would become saturated at sweat rates which do not approach maximum due to the relatively low vapour pressure gradient. In these scenarios, it is therefore possible that males and females may exhibit a similar sweat rate, as it would be limited in males by the low vapor pressure gradient between the skin surface and the environment, as opposed to being limited in females by potential peripheral differences in sweating. A few studies have investigated sex-related differences as a 
function of environmental conditions, generally reporting lower sweat rates in females whether the environment was considered dry or humid (Morimoto et al., 1967; Shapiro et al., 1980a; Keatisuwan et al., 1996). However, the conclusions from these studies are equally confounded by the aforementioned limitations based on differences in physical characteristics and particularly in rate of metabolic heat production between males and females. Examining sex-differences in sweat rate at a given requirement for heat loss in relation to whether the environment is dry or humid is therefore an important avenue of future research.

While recent findings provide a strong case for a peripheral modulation of sudomotor activity in females, studies are required to directly evaluate a possible central modulation. Recent advances in the use of skin sympathetic nerve activity to evaluate the cutaneous vascular response to heat stress (Kamijo et al., 2011) may hold promise in evaluating possible sex-differences in skin sympathetic nerve activity. Regardless of a possible central modulation, the specific mechanisms responsible for the peripheral modulation of sweating in females also need to be further examined. Although previous studies have demonstrated a lower cholinergic sensitivity of the sweat gland in females, it is unclear whether this response is mediated through differences in receptor sensitivity or through differences in acetylcholinesterase activity. Studies are also needed to determine whether differences in the physical properties of the sweat gland are indeed apparent. Finally, temperature regulation is intricately linked to the cardiovascular system, particularly during exercise in the heat (González-Alonso et al., 2008). Future studies should therefore consider examining whether the lower sudomotor activity in females has any implications on the cardiovascular response during exercise in the heat. 


\section{Summary}

Until recently, conclusions remained limited as to whether or not true physiological differences in human temperature regulation exist between males and females or if previously observed differences were solely due to confounding differences in physical characteristics and rate of metabolic heat production. Recent observations clearly establish sex-differences in sudomotor activity during exercise, independently of differences in physical characteristics and rate of metabolic heat production. The findings imply a lower maximal sweat rate in females during exercise, which can only be evidenced at a requirement for heat loss that exceeds the maximal capacity of the sweat gland in females, within an environment that ensures full evaporation of the sweat produced. Furthermore, current evidence points towards a peripheral modulation of sudomotor activity in females, although a central modulation has yet to be conclusively ruled out. In contrast, the cutaneous vascular response to exercise in the heat does not appear to differ between sexes. These recent findings provide a rationale for future studies to consider sex as an independent modulator of human temperature regulation during exercise in the heat. 


\section{REFERENCES}

Anderson GS. (1999). Human morphology and temperature regulation. Int J Biometeorol 43, 99-109.

Austin DM \& Lansing MW. (1986). Body size and heat tolerance: a computer simulation. Hum Biol 58, 153-169.

Avellini BA, Kamon E \& Krajewski JT. (1980a). Physiological responses of physically fit men and women to acclimation to humid heat. J Appl Physiol 49, 254-261.

Avellini BA, Shapiro Y, Pandolf KB, Pimental NA \& Goldman RF. (1980b). Physiological responses of men and women to prolonged dry heat exposure. Aviat Space Environ Med 51, 1081-1085.

Bain AR, Deren TM \& Jay O. (2011). Describing individual variation in local sweating during exercise in a temperate environment. Eur J Appl Physiol 111, 1599-1607.

Bar-Or O. (1998). Effects of age and gender on sweating pattern during exercise. Int $J$ Sports Med 19 Suppl 2, S106-107.

Bar-Or O, Lundegren HM \& Buskirk ER. (1969). Heat tolerance of exercising obese and lean women. J Appl Physiol 26, 403-409.

Benzinger TH. (1969). Heat regulation: homeostasis of central temperature in man. Physiol Rev 49, 671-759.

Boulant JA. (1996). Hypothalamic neurons regulating body temperature. In Handbook of physiology Section 4: Environmental physiology, ed. Fregly M \& Blatteis C, pp. 105-126. Oxford University press, New York, NY.

Burse RL. (1979). Sex differences in human thermoregulatory response to heat and cold stress. Hum Factors 21, 687-699.

Candas V, Libert JP \& Vogt JJ. (1979). Human skin wettedness and evaporative efficiency of sweating. J Appl Physiol 46, 522-528.

Charkoudian N \& Johnson JM. (1997). Modification of active cutaneous vasodilation by oral contraceptive hormones. J Appl Physiol 83, 2012-2018.

Charkoudian N \& Joyner MJ. (2004). Physiologic considerations for exercise performance in women. Clin Chest Med 25, 247-255.

Cheuvront SN, Bearden SE, Kenefick RW, Ely BR, Degroot DW, Sawka MN \& Montain SJ. (2009). A simple and valid method to determine thermoregulatory sweating threshold and sensitivity. J Appl Physiol 107, 69-75.

Cramer MN, Bain AR \& Jay O. (2012). Local sweating on the forehead, but not forearm, is influenced by aerobic fitness independently of heat balance requirements during exercise. Exp Physiol 97, 572-582. 
Davies CT. (1979). Thermoregulation during exercise in relation to sex and age. Eur $J$ Appl Physiol 42, 71-79.

Drinkwater BL, Denton JE, Kupprat IC, Talag TS \& Horvath SM. (1976). Aerobic power as a factor in women's response to work in hot environments. J Appl Physiol 41, 815-821.

Drinkwater BL, Kupprat IC, Denton JE \& Horvath SM. (1977). Heat tolerance of female distance runners. Ann NY Acad Sci 301, 777-792.

Frye AJ \& Kamon E. (1981). Responses to dry heat of men and women with similar aerobic capacities. J Appl Physiol 50, 65-70.

Frye AJ \& Kamon E. (1983). Sweating efficiency in acclimated men and women exercising in humid and dry heat. J Appl Physiol 54, 972-977.

Fusco MM, Hardy JD \& Hammel HT. (1961). Interaction of central and peripheral factors in physiological temperature regulation. Am J Physiol 200, 572-580.

Gagnon D, Dorman LE, Jay O, Hardcastle SG \& Kenny GP. (2009). Core temperature differences between sexes during intermittent exercise: physical considerations. Eur J Appl Physiol 105, 453-461.

Gagnon D, Jay O, Lemire B \& Kenny GP. (2008). Sex-related differences in evaporative heat loss: the importance of metabolic heat production. Eur J Appl Physiol 104, 821-829.

Gagnon D \& Kenny GP. (2011). Sex modulates whole-body sudomotor thermosensitivity during exercise. $J$ Physiol 589, 6205-6217.

Gagnon D \& Kenny GP. (2012). Sex-differences in thermoeffector responses during exercise at fixed requirements for heat loss. J Appl Physiol 113, 746-757.

Gibson TE \& Shelley WB. (1948). Sexual and racial differences in the response of sweat glands to acetylcholine and pilocarpine. J Invest Dermatol 11, 137-142.

Gisolfi CV \& Wenger CB. (1984). Temperature regulation during exercise: old concepts, new ideas. Exerc Sport Sci Rev 12, 339-372.

González-Alonso J, Crandall CG \& Johnson JM. (2008). The cardiovascular challenge of exercising in the heat. $J$ Physiol 586, 45-53.

Hammel HT. (1968). Regulation of internal body temperature. Ann Rev Physiol 30, 641710.

Hammel HT, Hardy JD \& Fusco MM. (1960). Thermoregulatory responses to hypothalamic cooling in unanesthetized dogs. Am J Physiol 198, 481-486.

Hardy JD. (1961). Physiology of temperature regulation. Physiol Rev 41, 521-606. 
Havenith G. (2001a). Human surface to mass ratio and body core temperature in exercise heat stress - a concept revisited. J Therm Biol 26, 387-393.

Havenith G. (2001b). Individualized model of human thermoregulation for the simulation of heat stress response. J Appl Physiol 90, 1943-1954.

Havenith G, Coenen JM, Kistemaker L \& Kenney WL. (1998). Relevance of individual characteristics for human heat stress response is dependent on exercise intensity and climate type. Eur J Appl Physiol 77, 231-241.

Havenith G, Luttikholt VG \& Vrijkotte TG. (1995). The relative influence of body characteristics on humid heat stress response. Eur J Appl Physiol 70, 270-279.

Havenith G \& van Middendorp H. (1990). The relative influence of physical fitness, acclimatization state, anthropometric measures and gender on individual reactions to heat stress. Eur J Appl Physiol 61, 419-427.

Horstman DH \& Christensen E. (1982). Acclimatization to dry heat: active men vs. active women. J Appl Physiol 52, 825-831.

Ichinose-Kuwahara T, Inoue Y, Iseki Y, Hara S, Ogura Y \& Kondo N. (2010). Sex differences in the effects of physical training on sweat gland responses during a graded exercise. Exp Physiol 95, 1026-1032.

Inoue Y, Tanaka Y, Omori K, Kuwahara T, Ogura Y \& Ueda H. (2005). Sex- and menstrual cycle-related differences in sweating and cutaneous blood flow in response to passive heat exposure. Eur J Appl Physiol 94, 323-332.

Jay O, Bain AR, Deren TM, Sacheli M \& Cramer MN. (2011). Large differences in peak oxygen uptake do not independently alter changes in core temperature and sweating during exercise. Am J Physiol Regul Integr Comp Physiol 301, 832-841.

Kahn D \& Rothman S. (1942). Sweat response to acetylcholine. J Invest Dermatol 5, 431-444.

Kamijo Y, Okada Y, Ikegawa S, Okazaki K, Goto M \& Nose H. (2011). Skin sympathetic nerve activity component synchronizing with cardiac cycle is involved in hypovolaemic suppression of cutaneous vasodilatation in hyperthermia. J Physiol 589, 6231-6242.

Keatisuwan W, Ohnaka T \& Tochihara Y. (1996). Physiological responses of men and women during exercise in hot environments with equivalent WBGT. Appl Hum Sci 15, 249-258.

Kenney WL. (1985). A review of comparative responses of men and women to heat stress. Environ Res 37, 1-11. 
Kenny GP, Webb P, Ducharme MB, Reardon FD \& Jay O. (2008). Calorimetric measurement of postexercise net heat loss and residual body heat storage. Med Sci Sports Exerc 40, 1629-1636.

Knip AS. (1969). Measurement and regional distribution of functioning eccrine sweat glands in male and female Caucasians. Hum Biol 41, 380-387.

Kolka MA \& Stephenson LA. (1997). Effect of luteal phase elevation in core temperature on forearm blood flow during exercise. J Appl Physiol 82, 1079-1083.

Kondo N, Takano S, Aoki K, Shibasaki M, Tominaga H \& Inoue Y. (1998). Regional differences in the effect of exercise intensity on thermoregulatory sweating and cutaneous vasodilation. Acta Physiol Scand 164, 71-78.

Madeira LG, da Fonseca MA, Fonseca IA, de Oliveira KP, Passos RL, Machado-Moreira CA \& Rodrigues LO. (2010). Sex-related differences in sweat gland cholinergic sensitivity exist irrespective of differences in aerobic capacity. Eur J Appl Physiol 109, 93-100.

Marsh SA \& Jenkins DG. (2002). Physiological responses to the menstrual cycle: implications for the development of heat illness in female athletes. Sports Med 32, 601-614.

McLellan TM. (1998). Sex-related differences in thermoregulatory responses while wearing protective clothing. Eur J Appl Physiol 78, 28-37.

Montain SJ, Latzka WA \& Sawka MN. (1995). Control of thermoregulatory sweating is altered by hydration level and exercise intensity. J Appl Physiol 79, 1434-1439.

Moran DS, Shapiro Y, Laor A, Izraeli S \& Pandolf KB. (1999). Can gender differences during exercise-heat stress be assessed by the physiological strain index? Am $J$ Physiol 276, 1798-1804.

Morimoto T, Slabochova Z, Naman RK \& Sargent F. (1967). Sex differences in physiological reactions to thermal stress. J Appl Physiol 22, 526-532.

Nadel ER, Bullard RW \& Stolwijk JA. (1971a). Importance of skin temperature in the regulation of sweating. J Appl Physiol 31, 80-87.

Nadel ER, Mitchell JW, Saltin B \& Stolwijk JA. (1971b). Peripheral modifications to the central drive for sweating. J Appl Physiol 31, 828-833.

Nadel ER, Pandolf KB, Roberts MF \& Stolwijk JA. (1974). Mechanisms of thermal acclimation to exercise and heat. $J$ Appl Physiol 37, 515-520.

Nunneley SA. (1978). Physiological responses of women to thermal stress: a review. Med Sci Sports Exerc 10, 250-255.

Paolone AM, Wells CL \& Kelly GT. (1978). Sexual variations in thermoregulation during heat stress. Aviat Space Environ Med 49, 715-719. 
Pierau F. (1996). Peripheral thermosensors. In Handbook of physiology Section 4: Environmental physiology, ed. Fregly M \& Blatteis C, pp. 85-104. Oxford University press, New York, NY.

Sato K \& Dobson RL. (1970). Regional and individual variations in the function of the human eccrine sweat gland. J Invest Dermatol 54, 443-449.

Sato K \& Sato F. (1983). Individual variations in structure and function of human eccrine sweat gland. Am J Physiol 245, 203-208.

Sawka MN, Wenger CB \& Pandolf KB. (1996). Thermoregulatory responses to acute exercise-heat stress and heat acclimation. In Handbook of physiology Section 4: Environmental physiology, ed. Fregly MJ \& Blatteis CM, pp. 157-186. Oxford University press, New York, NY.

Schwiening CJ, Mason MJ \& Thompson M. (2011). Absolute power, not sex, promotes perspiration. Exp Physiol 96, 556-558.

Shapiro Y, Pandolf KB, Avellini BA, Pimental NA \& Goldman RF. (1980a). Physiological responses of men and women to humid and dry heat. $J$ Appl Physiol 49, $1-8$.

Shapiro Y, Pandolf KB \& Goldman RF. (1980b). Sex differences in acclimation to a hotdry environment. Ergonomics 23, 635.

Shapiro Y, Pandolf KB \& Goldman RF. (1982). Predicting sweat loss response to exercise, environment and clothing. Eur J Appl Physiol Occup Physiol 48, 83-96.

Stephenson LA \& Kolka MA. (1985). Menstrual cycle phase and time of day alter reference signal controlling arm blood flow and sweating. Am J Physiol 249, R186-191.

Stephenson LA \& Kolka MA. (1993). Thermoregulation in women. Exerc Sport Sci Rev 21, 231-262.

Stitt JT. (1993). Central regulation of body temperature. In Perspectives in exercise science and sports medicine Volume 6: Exercise, heat , and thermoregulation, ed. Gisofi CV, Lamb DR \& Nadel ER, pp. 1-47. WCB Brown and Benchmark, Dubuque, IA.

Webb P. (1995). The physiology of heat regulation. Am J Physiol 268, 838-850.

Webb P, Troutman SJ \& Annis JF. (1970). Automatic cooling in water cooled space suits. Aerospace Med 41, 269-277.

Wenger CB, Baily RB, Roberts MF \& Nadel ER. (1985). Interaction of local and reflex thermal effects in control of forearm blood flow. J Appl Physiol 58, 251-257. 
Werner J. (1980). The concept of regulation for human body temperature. J Therm Biol 5, $75-82$

Werner J. (1981). Control aspects of human temperature regulation. Automatica 17, 351362.

Werner J. (1993). Temperature regulation during exercise: an overview. In Perspectives in exercise science and sports medicine, Volume 6: Exercise, heat , and thermoregulation, ed. Gisofi CV, Lamb DR \& Nadel ER, pp. 49-84. WCB Brown and Benchmark.

Young CN, Keller DM, Crandall CG \& Fadel PJ. (2009). Comparing resting skin sympathetic nerve activity between groups: caution needed. J Appl Physiol 106, 1751-1752. 


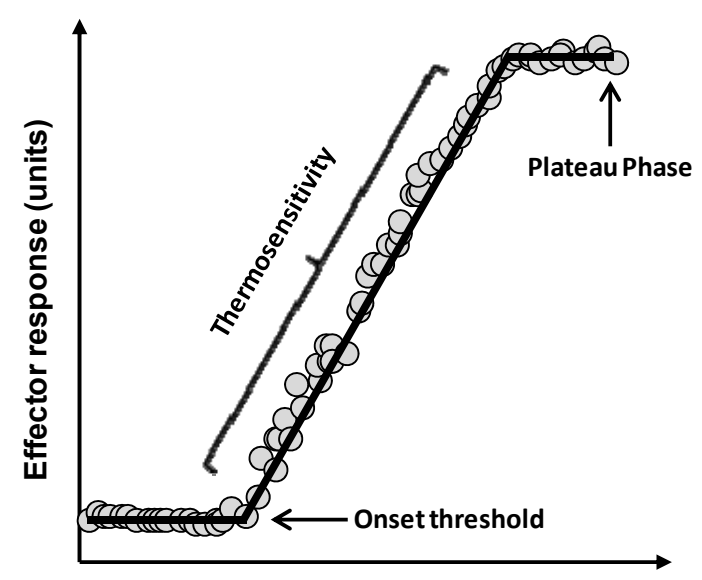

Change in mean body temperature $\left(\Delta^{\circ} \mathrm{C}\right)$

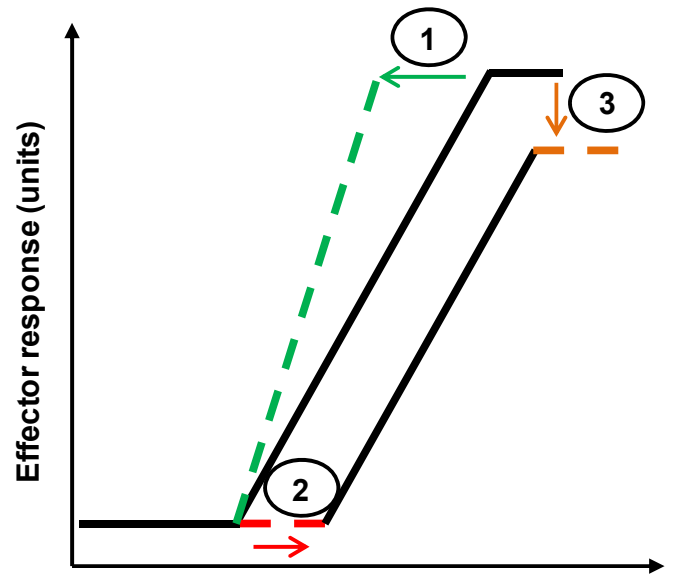

Change in mean body temperature $\left(\Delta^{\circ} \mathrm{C}\right)$

Figure 1. Schematic representation of the thermoeffector output-to-mean body temperature relationship during heat stress. Left panel: An increase in mean body temperature occurs before the effector response is activated at a given onset threshold. The effector output subsequently increases proportionally to the increase in mean body temperature, the linear portion of which represents the thermosensitivity of the response. Once the effector response reaches maximal values, a flattening of the line is observed, whereby no further increase in effector output occurs despite increasing mean body temperature. It should be noted that this relationship has been demonstrated using local, whole-body, and whole-limb measurements of thermoeffector responses. Right panel: Examples of how the parameters of the thermoeffector output-to-mean body temperature relationship can change: 1) The thermosensitivity of the response is increased, such that a greater change in effector output occurs for a given change in mean body temperature. 2) The onset threshold of the response is shifted to the right, such that a greater change in mean body temperature is required to initiate the activation of effector output. 3) The plateau phase of the effector output is reduced, such that lower maximal values are attained for a given change in mean body temperature. 

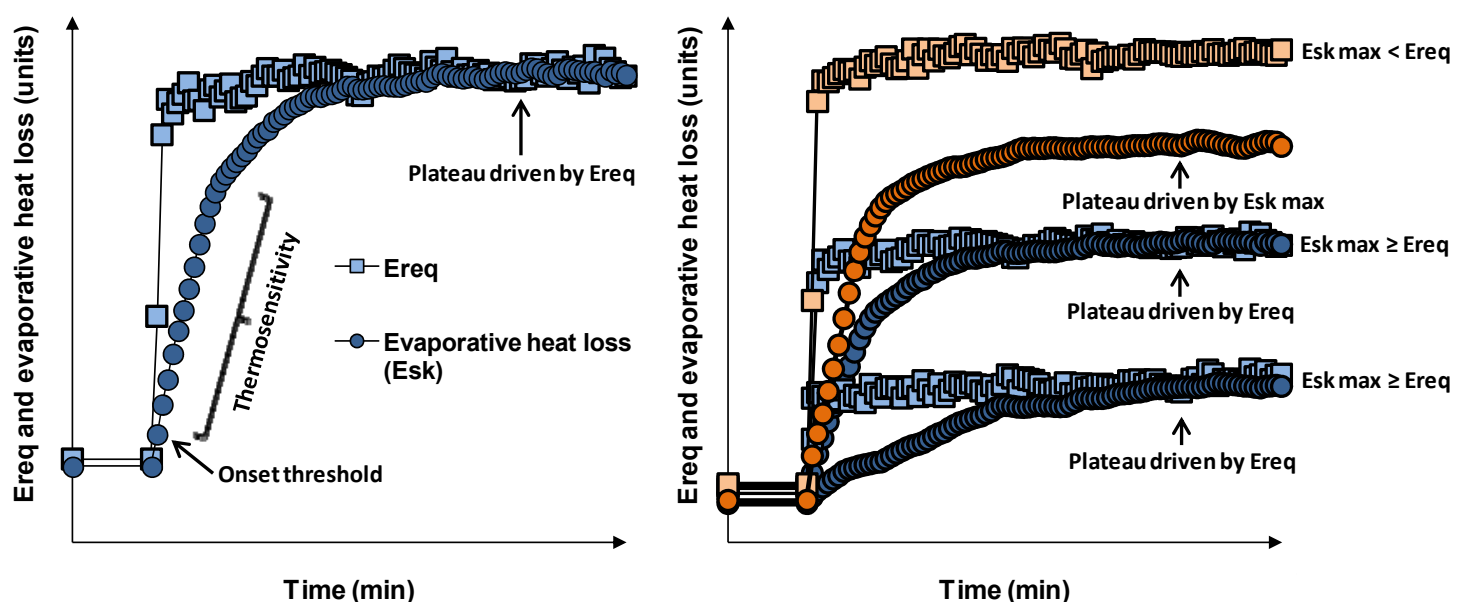

Figure 2. Schematic illustration of the relationship between the required evaporation for heat balance $\left(E_{\text {req }}\right)$ and evaporative heat loss $\left(E_{\mathrm{sk}}\right)$ during exercise. Left panel: The initial increase in evaporative heat loss during exercise is dictated by the onset threshold for sweating, with the subsequent linear increase in evaporative heat loss a function of the change in mean body temperature (thermosensitivity). However, the level of evaporative heat loss attained during exercise is determined by the required evaporation for heat balance $\left(E_{\text {req }}\right)$. Right panel: When the required evaporation for heat balance does not exceed the individual's maximal evaporative (sweating) capacity $\left(E_{\text {sk }} \max \geq E_{\text {req }}\right)$, the level of evaporative heat loss attained during exercise is determined by the required evaporation for heat balance (blue colour). However, when the required evaporation for heat balance exceeds the individual's maximum evaporative capacity $\left(E_{\mathrm{sk}} \max <E_{\mathrm{req}}\right)$, the level of evaporative heat loss attained during exercise is determined by the individual's maximal evaporative ( $E_{\mathrm{sk}} \max$ ) capacity (orange colour). 

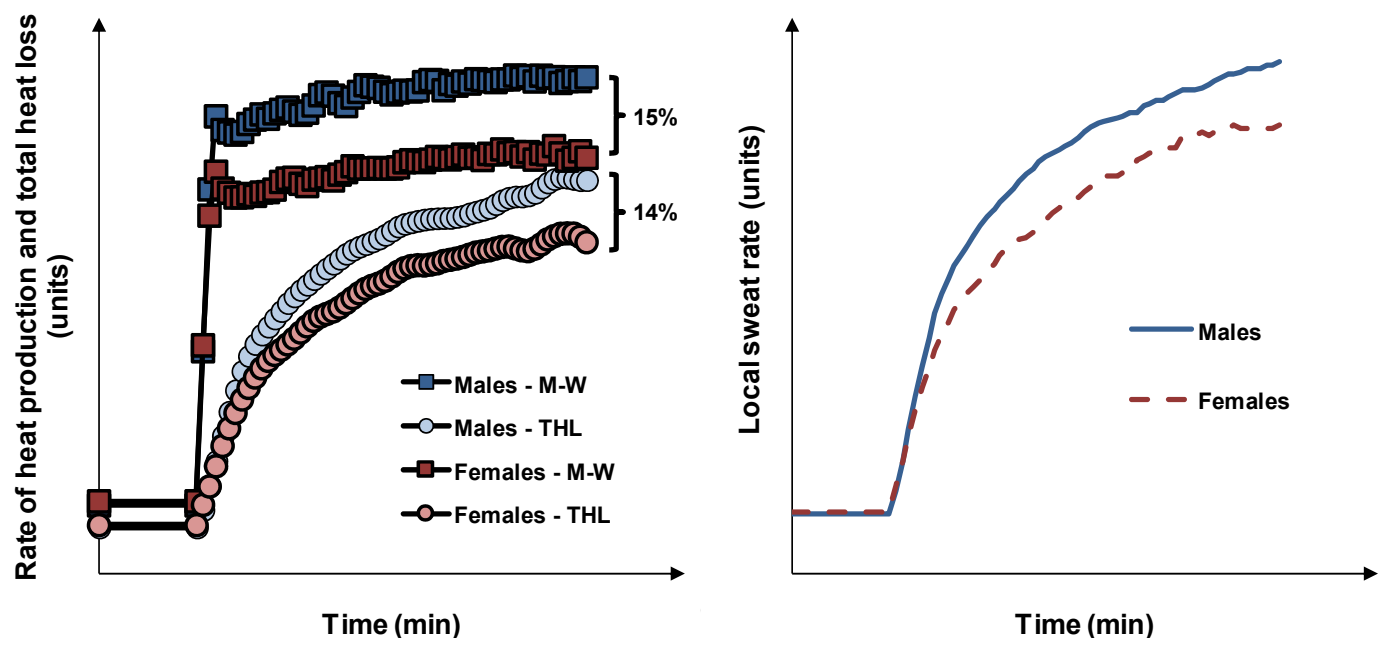

Figure 3. Schematic illustration of the relationship between sex-differences in metabolic heat production (M-W) and total whole-body heat loss (THL). Left panel: Exercise performed at a fixed percentage of maximum oxygen consumption results in a rate of metabolic heat production (squares) that is $\sim 15 \%$ greater in males compared to females. Consequently, rate of whole-body heat loss is proportionately greater in males, such that the differences in whole-body heat loss between sexes are of the same order $(\sim 14 \%)$ as those for rate of metabolic heat production. Right panel: The greater rate of whole-body heat loss is reflected by a greater rate of local sweat production in males compared to females. In this situation, the greater rate of local sweat production can be attributed to the differences in rate of metabolic heat production elicited by employing an experimental protocol in which exercise is performed at a given percentage of maximum oxygen consumption. The left panel is re-drawn with kind permission of Springer Science+Business Media from Gagnon et al. Eur J Appl Physiol 104, 821-829, 2008. 


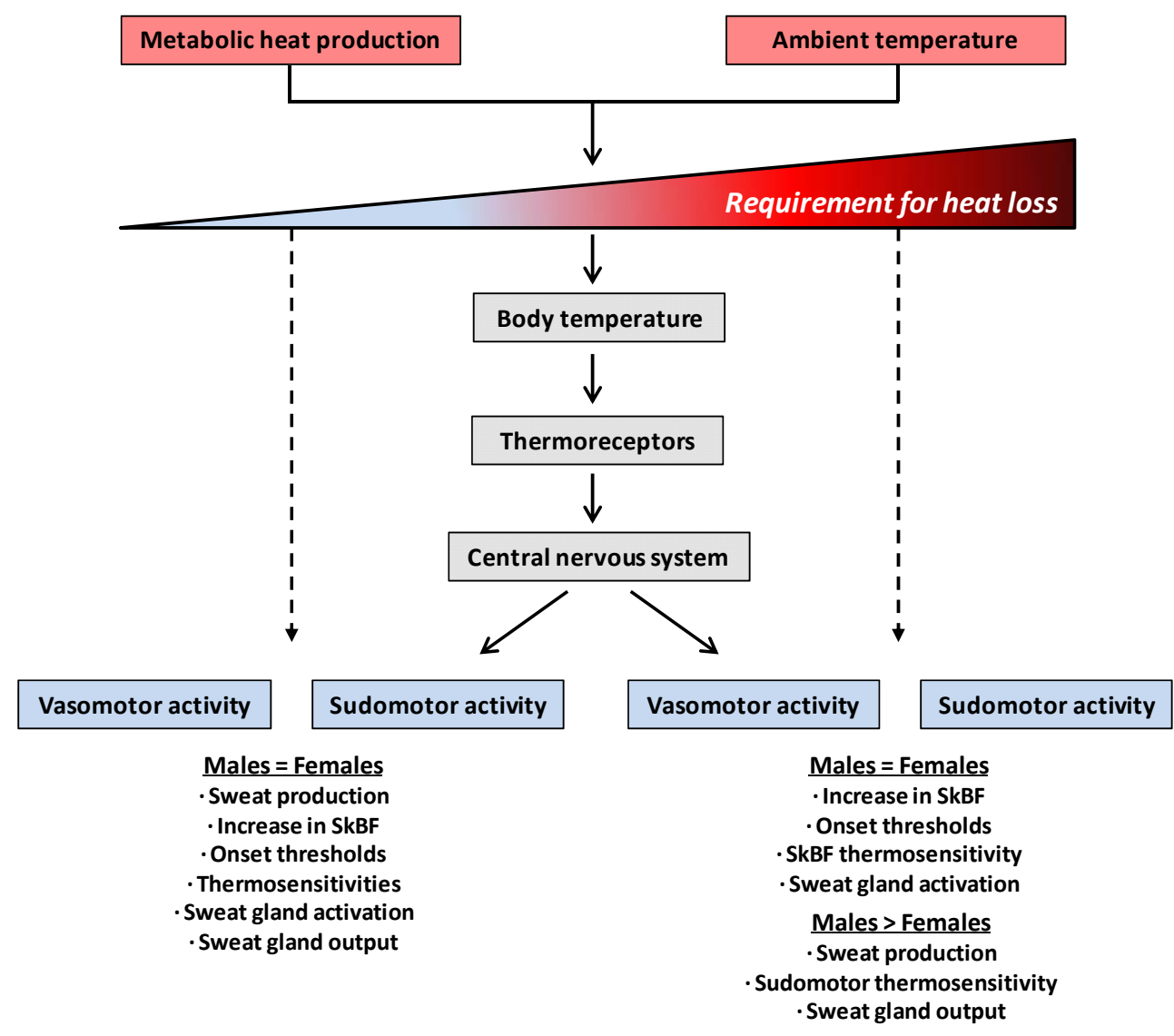

Figure 4. Schematic summary of sex-differences in temperature regulation as a function of the requirement for heat loss during exercise in the heat. The sum of metabolic heat production and dry heat exchange from the ambient temperature form the requirement for heat loss and drive increases in body (core and skin) temperatures. Increases in body temperature are sensed by thermoreceptors (central and peripheral) which transmit thermoafferent information to the central nervous system where thermal integration occurs. The central nervous system sends thermoefferent signals to the effector organs (cutaneous blood vessels and sweat glands) to initiate vasomotor and sudomotor activity. At low requirements for heat loss (left dashed arrow) no sex-differences are evidenced for increases in skin blood flow (SkBF) and sweat production, as well as in the physiological variables (onset threshold, thermosensitivity, sweat gland activation, sweat gland output) of vasomotor and sudomotor activity. At high requirements for heat loss (right dashed arrow), there are also no sex-differences in SkBF, onset thresholds for both vasomotor and sudomotor activity, SkBF thermosensitivity, and sweat gland activation. In contrast, a greater sweat production, sudomotor thermosensitivity and sweat gland output is observed in males. The precise requirement for heat loss at which sex-differences in sudomotor activity are evidenced remains to be determined. 


\section{ACKNOWLEDGEMENTS}

D.G. is supported by an Alexander Graham Bell Canadian Graduate Scholarship from the Natural Sciences and Engineering Research Council. Work presented in this review was supported by the Natural Sciences and Engineering Research Council (RGPIN-2981592009) and Leaders Opportunity Fund from the Canada Foundation for Innovation (22529). G.P.K. is supported by a University of Ottawa Research Chair in Environmental Physiology. The authors acknowledge the contribution of Dr. Ollie Jay and Dr. Craig Crandall who provided critical input into the development of this work. 
APPENDIX: Example calculation of sex-differences in metabolic heat production during exercise at a fixed percentage of maximum oxygen consumption

If a male and female perform exercise at $50 \%$ of their same relative $\mathrm{VO}_{2 \max }$ of $50 \mathrm{ml} \cdot \mathrm{kg}^{-}$ ${ }^{1} \cdot \mathrm{min}^{-1}$, exercise oxygen consumption would equal $25 \mathrm{ml} \cdot \mathrm{kg}^{-1} \cdot \mathrm{min}^{-1}$ in both cases. Assuming that the male weighs $70 \mathrm{~kg}$ and the female $60 \mathrm{~kg}$, absolute oxygen consumption will equal $1750 \mathrm{ml} \cdot \mathrm{min}^{-1}$ for the male and $1500 \mathrm{ml} \cdot \mathrm{min}^{-1}$ for the female. Assuming a respiratory exchange ratio of 0.85 and the same external workload, the 250 $\mathrm{ml} \cdot \mathrm{min}^{-1}$ difference between sexes will result in a rate of metabolic heat production that is $\sim 80$ to $85 \mathrm{~W}$ greater in the male. Such a difference in rate of metabolic heat production has been shown to result in proportional differences in whole-body heat loss (Gagnon et al., 2008). 


\begin{abstract}
APPENDIX F
Ethics approval notices for thesis research projects
\end{abstract}




\section{Université d'Ottawa University of Ottawa \\ Service de subventions de recherche et déontologie Research Grants and Ethics Services}

\section{Ethics Approval Notice}

\section{Health Sciences and Science REB}

Principal Investigator / Supervisor / Co-investigator(s) / Student(s)

$\begin{array}{llll}\text { First Name } & \text { Last Name } & \text { Affiliation } & \text { Role } \\ \text { Glen } & \text { Kenny } & \text { Health Sciences/Human Kinetics } & \text { Principal Investigator } \\ \text { Daniel } & \text { Gagnon } & \text { Health Sciences/Human Kinetics } & \text { Co-investigator }\end{array}$

File Number: H08-09-04

Type of Project: Professor

Title: Sex-related Differences in Whole-body Heat loss

Approval Date (mm/dd/yyyy)

$09 / 17 / 2009$

(Ia: Approval, Ib: Approval for initial stage only)

\section{Expiry Date (mm/dd/yyyy) Approval Type}

$09 / 16 / 2010$
Ia

Special Conditions / Comments:

$\mathrm{N} / \mathrm{A}_{\mathrm{H}}$ 


\section{Université d'Ottawa University of Ottawa \\ Service de subventions de recherche et déontologie Research Grants and Ethics Services}

\section{Ethics Approval Notice \\ Health Sciences and Science REB}

\begin{tabular}{llll}
\multicolumn{2}{l}{ Principal Investigator / Supervisor / Co-investigator(s)/Student(s) } \\
First Name & $\underline{\text { Last Nane }}$ & $\underline{\text { Affiliation }}$ & \\
Glen & Kenny & Health Sciences/Human Kinetics & $\underline{\text { Sole }}$ \\
Daniel & Gagnon & Health Sciences/Human Kinetics & Student Researcher
\end{tabular}

File Number: H03-10-04

Type of Project: PhD Thesis

Title: Sex-related Differences in Eccrine Sweat Gland Function

Approval Date (mm/dd/yyyy)

$05 / 28 / 2010$

(Ia: Approval, Ib: Approval for initial stage only)

Special Conditions / Comments:

$\mathrm{N} / \mathrm{A}$

\section{Expiry Date (mm/dd/yyy) Approval Type}

$05 / 27 / 2011$

Ia 


\section{Université d'Ottawa University of Ottawa Bureau d'éthique et d'intégrité de la recherche Office of Research Ethics and Integrity}

\section{Ethics Approval Notice}

\section{Health Sciences and Science REB}

Principal Investigator / Supervisor / Co-investigator(s) / Student(s)

$\begin{array}{llll}\text { First Name } & \text { Last Name } & \text { Affiliation } & \text { Role } \\ \text { Glen } & \text { Kenny } & \text { Health Sciences / Human Kinetics } & \text { Supervisor } \\ \text { Daniel } & \text { Gagnon } & \text { Health Sciences / Human Kinetics } & \text { Student Researcher } \\ \text { Matthew } & \text { Coutsos } & \text { Health Sciences / Human Kinetics } & \text { Research Assistant } \\ \text { Jill } & \text { Stapleton } & \text { Health Sciences / Human Kinetics } & \text { Research Assistant }\end{array}$

File Number: H03-11-02

Type of Project: PhD Thesis

Title: $\quad$ Sex-related Differences in the Physiological Control of Heat Loss Responses

Approval Date (mm/dd/yyyy)

06/15/2011

\section{Expiry Date (mm/dd/yyyy)}

$06 / 14 / 2012$
Approval Type

Ia

(Ia: Full Approval)

Special Conditions / Comments:

N/A 